Sandra Regina de Moraes

\title{
SÍNTESE E CARACTERIZAÇÃO DA MISTURA DE POLIANILINA EM DIFERENTES MATRIZES POLIMÉRICAS PARA PROTEÇÃO CONTRA A CORROSÃO DE LIGAS METÁLICAS.
}

Tese apresentada ao Instituto de Química de São Carlos, da Universidade de São Paulo para obtenção do título de Doutor em Ciências (Físico-Química).

Orientador: Prof. Dr. Artur de Jesus Motheo

São Carlos

2005 


\section{Dedicatória}

Aos meus pais, irmãos e a Deus

por estarem sempre ao meu lado,

na alegria ou na tristeza, na luz ou nas trevas. 


\section{DESEJO}

Desejo primeiro que você ame e amando, também seja amado E se não for, seja breve esquecer e esquecendo não guarde magoas.

Desejo também, que tenha amigos

Que mesmo maus e inconseqüentes sejam corajosos e fiéis

E que pelo menos num deles, você possa confiar sem duvidar

E porque a vida é assim, Desejo que tenha inimigos, nem muitos nem poucos E que entre eles haja pelo menos um, que seja justo, para que você não se sinta demasiadamente seguro.

Desejo ainda que você seja tolerante, não com os que amam pouco, porque isso é fácil,

Mas com os que amam muito, irremediavelmente

E fazendo bom uso dessa tolerância, você sirva de exemplo para os outros.

Desejo que você sendo jovem, não amadureça depressa demais

E sendo maduro não insista em rejuvenescer

E que sendo velho, não se dedique ao desespero

Porque cada idade tem o seu prazer, e a sua dor

E é preciso deixar, que eles escorram por entre nós

Desejo também que você plante uma semente por mais minúscula que seja E acompanhe o seu crescimento para que você saiba de quantas muitas vidas é feita uma árvore.

Desejo por fim, que você sendo um homem tenha uma boa mulher

E sendo uma mulher, tenha um bom homem

E que se amem hoje, amanhã e no dia seguinte

E quando estiverem exaustos e sorridentes ainda haja amor para recomeçar

E se tudo isso acontecer não tenho mais nada a Desejar.

Vitor Hugo 


\section{Agradecimentos}

$\Pi$ Ao Prof. Dr. Artur de Jesus Motheo pela orientação, compreensão e amizade.

П Ao Instituto de Química de São Carlos/USP pela oportunidade e suporte para minha progressão acadêmica.

П A todos os profissionais do IQSC-USP que contribuíram para a realização deste trabalho.

$\Pi$ Aos amigos do Grupo de eletroquímica Interfacial (Geqi): Laerte, Marcos, Douglas, Rodrigo, Eveline, Geoff, Marciana, Fábio, Fabiana, Álvaro, Douglas Machado, Thaís e Karen pelas valiosas discussões, sugestões e amizade.

$\Pi$ Aos velhos e novos amigos cuja distância e a proximidade pode ser sempre resumida em palavras de apoio e carinho.

П Ao Gavin por fazer parte de minha história.

$\Pi$ A CAPES pela bolsa de estudo.

$\Pi$ Aos meus pais, irmãos e a Deus.

П A todos que direta ou indiretamente contribuíram de algum modo para a realização desta tese. 


\section{Sumário}

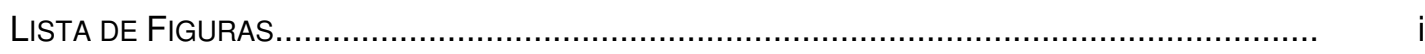

LISTA DE TABELAS....................................................................................... viii

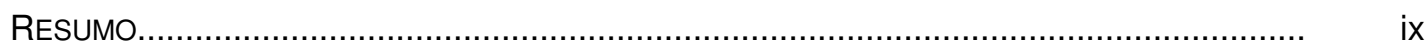

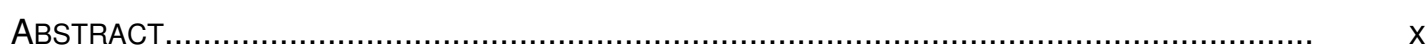

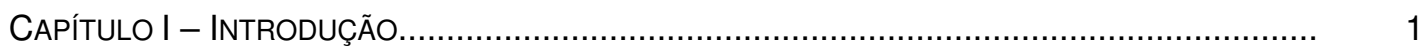

1.1. Preâmbulo.................................................................................................

1.2. Polímeros condutores..................................................................................... 3

1.3. Polianilina.................................................................................................. 5

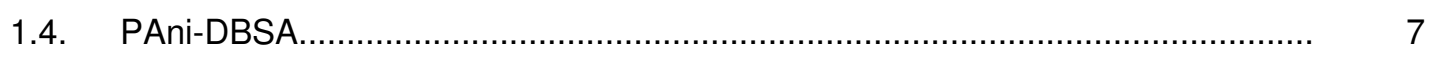

1.5. Blendas e compósitos de PAni............................................................... 10

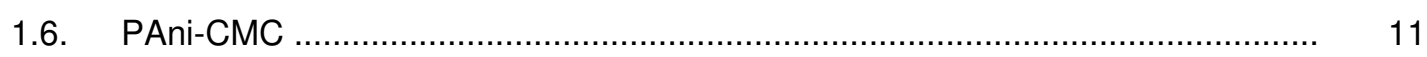

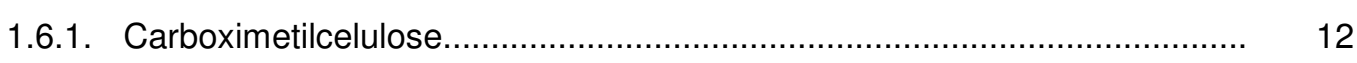

1.6.2. Parâmetros característicos de carboximeticelulose.................................... 13

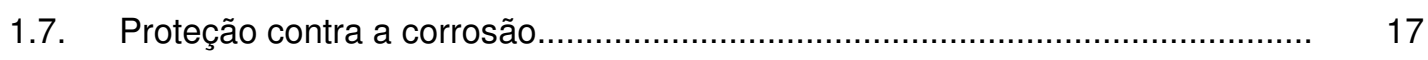

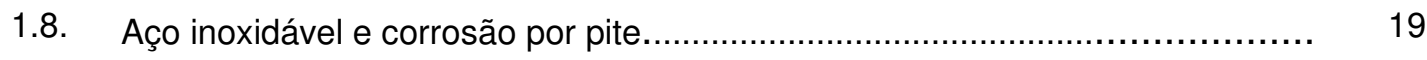

1.8.1. Formação de pites............................................................................ 20

1.9. Blendas de PAni-DBSA contra a corrosão............................................ 25

1.10 PAni-CMC contra a corrosão................................................................. 27

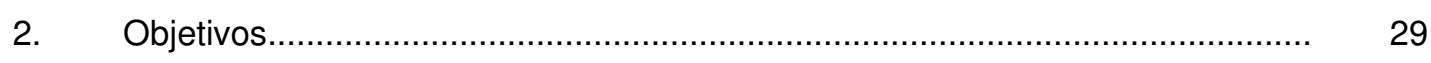

CAPÍTULO II - EXPERIMENTAL................................................................................ 30

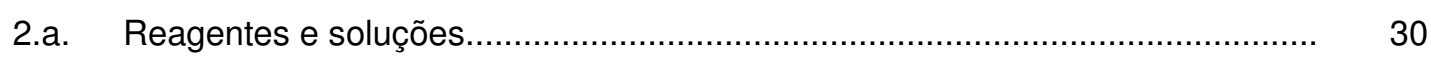

2.b. Célula eletroquímica e eletrodos................................................................ 31

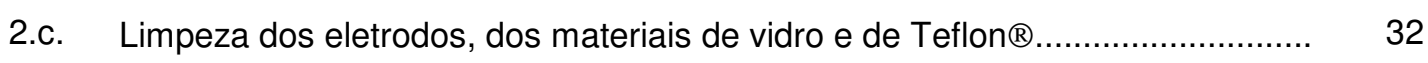

2.1. Procedimento da síntese eletroquímica.......................................................... 33 
2.1.1. Eletropolimerização sobre eletrodo de platina.......................................... 33

2.1.2. Eletropolimerização sobre eletrodo de aço inoxidável.............................. 33

2.1.3. Voltametria cíclica.............................................................................. 33

2.2. Procedimento da síntese química............................................................... 35

2.2.1. Procedimento da síntese química........................................................ 35

2.2.2. Técnica de perfil de potencial.............................................................. 35

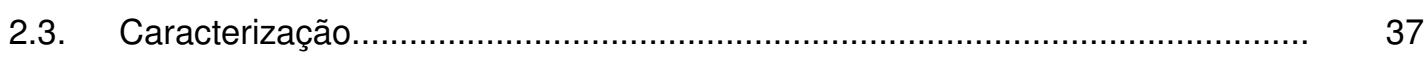

2.3.1. Caracterização voltamétrica............................................................. 37

2.3.2. Estimativa da espessura dos filmes poliméricos...................................... 37

2.3.3. Espectroscopia na região do ultravioleta, do visível e do infravermelho próximo (UV-Vis-NIR) ............................................................... 38

2.3.4. Espectroscopia na região do infravermelho ......................................... 39

2.3.5. Medidas de condutividade.................................................................. 40

2.3.6. Microscopia eletrônica de varredura (MEV)........................................... 40

2.3.7. Espectroscopia por energia Dispersiva de raio-x (EDX).......................... 41

2.3.8. Análise Térmica (TG) ................................................................... 42

2.4. Ensaios de corrosão............................................................................. 44

2.4.1. Potencial de circuito aberto..................................................................... 44

2.4.2. Polarização potenciodinâmica.............................................................. 44

Capítulo III - Síntese e CARActerizaÇÃo de PANI-CMC EletropolimeRIZADA.............. 47

3.1. Estudos preliminares sobre a eletropolimerização de PAni-CMC.......................... 48

3.1.1. Eletropolimerização de PAni-CMC sobre aço inoxidável.......................... 48

3.1.2. Efeito da concentração de monômero................................................... 50

3.1.3. Eletropolimerização de PAni-CMC sobre platina...................................... 53

3.1.4. Efeito da concentração de CMC............................................................. 54

3.2. Caracterização de PAni-CMC ............................................................................. 56

3.2.1. Caracterização voltamétrica.................................................................. 56

3.2.2. Espectroscopia no UV-VIS-NIR ............................................................ 58

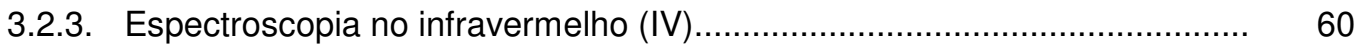


3.2.4. Condutividade

3.2.5. Microscopia eletrônica de varredura (MEV) e EDX...................................... 64

3.3 A proposta de interação entre a PAni e a CMC................................................... 68

CAPÍTULO IV - SínTESE QuíMICA E CARACTERIZAÇÃO DE PANI-CMC................................ 69

4.1. Polimerização química de PAni-CMC .............................................................. 70

4.2. Caracterização de PAni-CMC química............................................................... 75

4.2.1. Espectroscopia no UV-VIS-NIR ...................................................... 75

4.2.2. Espectroscopia no infravermelho (IV)...................................................

4.2.3. Condutividade.............................................................................. 78

4.2.4. Microscopia eletrônica de varredura (MEV).............................................. 79

4.2.5. Análise terrmogravimétrica (TG) ....................................................... 81

CAPÍtULO V - SíntESE E CARACTERIZAÇÃO de PANI-DBSA ELETROPOLIMERIZADA............. 85

5.1. Estudos preliminares sobre a eletropolimerização de PAni-DBSA ...................... 86

5.1.1. Comportamento do DBSA em meio aquoso............................................... 86

5.1.2. Comportamento eletroquímico em presença de DBSA............................. 88

5.1.2.1. Eletrodo de aço inoxidável (AISI-304) ................................................. 88

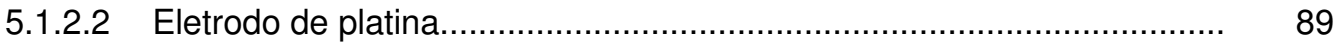

5.1.3. A estabilidade da solução de DBSA em presença de anilina...................... 90

5.2. Eletropolimerização de PAni-DBSA sobre platina e aço inoxidável..................... 91

5.2.1. Efeito da concentração de monômero......................................................... 94

5.2.2. Efeito da concentração de DBSA ........................................................... 99

5.2.3. Algumas considerações cinéticas da eletropolimerização de PAni-DBSA.. 101

5.3. Caracterização................................................................................. 102

5.3.1. Caracterização voltamétrica.................................................................. 103

5.3.2. Espectroscopia no UV-VIS-NIR.......................................................... 104

5.3.3. Espectroscopia no infravermelho (IV).................................................. 106

5.3.4 Microscopia eletrônica de varredura (MEV)............................................... 109

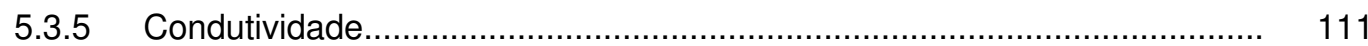


CAPÍTULO VI - ENSAIOS DE CORROSÃO.

6.1. Ensaios de corrosão de PAni-CMC .................................................................... 113

6.1.1. Comparação de PAni-CMC e PAni...................................................... 116

6.2. Ensaios de corrosão de PAni-DBSA................................................................. 122

6.2.1. Estimativa da espessura dos filmes..................................................... 122

6.2.2. Potencial de circuito aberto ....................................................... 126

Capítulo VII - Conclusões e Perspectivas de Trabalhos Futuros.......................... 130

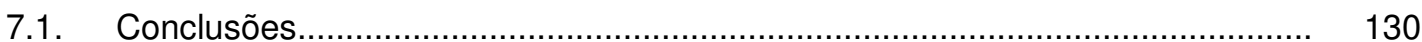

7.2. Perspectivas de Trabalhos Futuros........................................................... 134

Referências Bibliográficas....................................................................................... 135 


\section{Lista de Figuras}

$\begin{array}{ll}\text { Figura 1. Estrutura geral da polianilina na forma base. } & 05\end{array}$

Figura 2. Processo de dopagem da PAni com ácido protônico. 06

$\begin{array}{ll}\text { Figura 3. Estrutura da carboximetilcelulose. } & 12\end{array}$

Figura 4. Exemplificação da distribuição do substituintes (R) (a) ao longo da 15 cadeia polimérica e $(b)$ dentro da unidade monomérica $(C M C$ com $D S=1)$.

Figura 5. Principais formas de corrosão.

Figura 6. Os íons metálicos dissolvidos através de uma parte do filme não desenvolvida (a) são capturados para formar um filme (a') resultante das ligações em ponte com o grupo $\mathrm{OH}$. Os íons cloreto substituem as moléculas de água (b) prevenindo a reação em ponte (b'), resultando na quebra do filme.

Figura 7. Ilustração esquemática do mecanismo de crescimento de pites.

Figura 8. Esquema da (a) célula eletroquímica; do (b) contra-eletrodo de platina e dos eletrodos de trabalho de (b) platina e (c) aço inoxidável utilizados nos experimentos.

Figura 9. (a) Variação do potencial com o tempo e (b) curva resultante da corrente por potencial em um experimento de voltametria cíclica..

Figura 10. Esquema geral do sistema de polimerização química.

Figura 11. Conversão da leucoesmeraldina (LE), a forma reduzida de PAni, para 38 a esmeraldina (EM), a forma oxidada de PAni.

Figura 12. Curva termogravimétrica de um processo em um estágio [115].

Figura 13. Curva de polarização potenciodinâmica padrão para um material metálico que sofre uma dissolução ativo-passiva, indicando as diferentes regiões que formam a curva de polarização e os parâmetros eletroquímicos de interesse [121].

Figura 14. Voltamogramas cíclicos obtidos a partir de solução $\mathrm{H}_{3} \mathrm{PO}_{4} 1,0 \mathrm{~mol} \mathrm{~L}^{-1}$ contendo $0,1 \%$ de CMC (a) anilina $0,1 \mathrm{~mol} \mathrm{~L}^{-1} \mathrm{e}$ (b) sem anilina. $50 \mathrm{mV} \mathrm{s}^{-1}$. 
Figura 15. Valores da densidade de corrente do pico A dos voltamogramas de 50 crescimento dos filmes eletropolimerizados sobre AISI-304 obtidos a partir de solução $\mathrm{H}_{3} \mathrm{PO}_{4} 1,0 \mathrm{~mol} \mathrm{~L}^{-1}$ em função da concentração de anilina. (O) sem CMC e (ם) contendo $0,1 \% \mathrm{CMC}$.

Figura 16. Dependência da corrente do primeiro pico anódico com o número de ciclos em várias concentrações de anilina a $50 \mathrm{mV} \mathrm{s}^{-1}$. (๑) 0,10; $(\Delta) 0,15$; $(\square)$ 0,$20 ;(\nabla) 0,25$ e $(\diamond) 0,30 \mathrm{~mol} \mathrm{~L}^{-1}$.

Figura 17. Velocidade de formação $\left.\left((\bullet) \mathrm{v}_{1},(\Delta) \mathrm{v}_{2},(\square) \mathrm{v}_{3}, \nabla \mathrm{v}_{4},(\bullet) \mathrm{v}_{5}\right)\right)$ em vários valores de corrente de pico anódico em diferentes concentrações anilina em $\mathrm{H}_{3} \mathrm{PO}_{4} 1,0 \mathrm{~mol} \mathrm{~L}^{-1}$ e CMC 0,1\%.

Figura 18. Dependência da corrente do primeiro pico anódico com o número de 53 ciclos em várias concentrações de anilina sobre Pt, a $50 \mathrm{mV} \mathrm{s}^{-1}$. (O) PAni e (ם) PAni-CMC.

Figura 19. Velocidade de formação $\left.\left((\bullet) \mathrm{v}_{1},(\Delta) \mathrm{v}_{2},(\square) \mathrm{v}_{3}, \nabla \mathrm{v}_{4},(\bullet) \mathrm{v}_{5}\right)\right)$ de PAni53 CMC sobre $\mathrm{Pt}$ em diferentes concentrações anilina em $\mathrm{H}_{3} \mathrm{PO}_{4}$ 1,0 M e CMC $0,1 \%$.

Figura 20. Voltamogramas cíclicos $\left(20^{\circ}\right.$ ciclo) de PAni-CMC obtidos sobre aço 55 inoxidável a partir de solução de $\mathrm{H}_{3} \mathrm{PO}_{4} \quad 1,0 \mathrm{~mol} \mathrm{~L}^{-1}$ contendo $0,2 \mathrm{~mol} \mathrm{~L}^{-1}$ de anilina: (a) sem CMC e com (b) 0,1\%, (c) 0,3\%, (d) $1 \%$ de CMC a $50 \mathrm{mV} \mathrm{s}^{-1}$.

Figura 21. Voltamogramas Cíclicos $\left(5^{\circ}\right.$ ciclo) dos polímeros eletropolimerizados 57 sobre Pt por 60 ciclos de potenciais, a partir de uma solução de $\mathrm{H}_{3} \mathrm{PO}_{4} 1 \mathrm{~mol} \mathrm{~L}^{-1} \mathrm{e}$ $0,2 \mathrm{~mol} \mathrm{~L}^{-1}$ de anilina (a) PAni (sem CMC) e PAni-CMC com (b) $0,1 \%$ e (c) $1,0 \%$ de $\mathrm{CMC}$, em $\mathrm{H}_{2} \mathrm{SO}_{4} 0,5 \mathrm{~mol} \mathrm{~L}^{-1}$, a $50 \mathrm{mV} \mathrm{s}^{-1}$.

Figura 22. Espectro no UV-Vis-NIR dos polímeros eletropolimerizados sobre (I) Pt e (II) AISI-304 de (a) PAni; PAni-CMC (b) 0,1\%; (c) 0,3\%; (d) 0,6\% e (e) $1 \%$ CMC. Polímeros desdopados.

Figura 23. Espectro no UV-Vis-NIR de eletropolimerizado sobre (I) Pt e (II) AISI304 de (a) PAni e PAni-CMC (b) $0,1 \%$; (c) $0,3 \%$; (d) $0,6 \%$ e (e) $1 \%$ CMC. Polímeros dopados.

Figura 24. Espectro no infravermelho de (a) CMC, PAni-CMC (b) $0,1 \%$, (c) $1 \%$ 61 CMC e (d) PAni, dopados. Polímeros eletropolimerizado sobre (I) Pt e (II) AISI304. 
Figura 25. Espectro no infravermelho de (a) CMC, PAni-CMC (b) $0,1 \%$, (c) $1 \%$ 61 CMC e (d) PAni desdopados. Polímeros eletropolimerizado sobre (I) Pt e (II) AISI304.

Figura 26. Condutividade dos polímeros eletropolimerizados sobre AISI-304, na forma dopada, em função da concentração de CMC.

Figura 27. Micrografias dos polímeros eletropolimerizados sobre AISI-304 a partir 65 de $\mathrm{H}_{3} \mathrm{PO}_{4} 1 \mathrm{~mol} \mathrm{~L}^{-1}$ e 0,2 $\mathrm{mol} \mathrm{L}^{-1}$ de anilina, (a) PAni e em presença de CMC: (b) 0,1\%; (c) 0,3\%; (d) 0,6\% e (e) 1\%. Ampliações: 1000 vezes (a direita) e 15.000 vezes (a esquerda).

Figura 28. Espectros de EDX dos polímeros eletrodepositados sobre AISI-304 a partir de $\mathrm{H}_{3} \mathrm{PO}_{4} 1 \mathrm{~mol} \mathrm{~L}^{-1}$ e $0,2 \mathrm{~mol} \mathrm{~L}^{-1}$ de anilina, (a) PAni e PAni-CMC: (b) 0,1\%; (c) $0,3 \%$; (c) $0,6 \%$ e (d) $1 \%$.

Figura 29. Dependência do conteúdo de $P$ nos polímeros eletrodepositados 67 sobre AISI-304 a partir de $\mathrm{H}_{3} \mathrm{PO}_{4} 1 \mathrm{~mol} \mathrm{~L}^{-1}$ e $0,2 \mathrm{~mol} \mathrm{~L}^{-1}$ de anilina em presença de diferentes concentrações de $\mathrm{CMC}$.

Figura 30. Curvas potenciométricas dos polímeros obtidos a partir de solução de 70 $\mathrm{H}_{3} \mathrm{PO}_{4} 1 \mathrm{~mol} \mathrm{~L}^{-1}$ contendo $0,2 \mathrm{~mol} \mathrm{~L}^{-1}$ anilina e $\mathrm{CMC}$ nas concentrações de: (a) $0,1 \%$ e (b) $1 \%$.

Figura 31. Curvas calorimétricas dos polímeros obtidos a partir de solução de 71 $\mathrm{H}_{3} \mathrm{PO}_{4} 1 \mathrm{~mol} \mathrm{~L}^{-1}$ contendo $0,2 \mathrm{~mol} \mathrm{~L}^{-1}$ anilina e CMC nas concentrações de: (a) $0,1 \%$ e (b) $1 \%$.

Figura 32. Máxima temperatura de síntese de PAni-CMC e o inverso do máximo 73 do tempo ( $\left.1 / \mathrm{t}_{\text {máx }}\right)$ para obter essa temperatura (equivalente a velocidade global do sistema) quando diferentes concentrações de CMC foram utilizadas.

Figura 33. Esquema de formação de precipitados de PAni-CMC e dipersão de PAni-CMC (PAni, esfera rachurada) obtida a partir da agregação de sobrecamda superficial de CMC. Cátions (-) e ânions (0) em dispersão no meio. (I e II) concentrações de CMC $<0,6 \%$ e (III e IV) concentrações de CMC maior que $0,6 \%$.

Figura 34. Espectro no UV-Vis-NIR dos polímeros quimicamente sintetizados: (a) PAni e PAni-CMC (b) 0,1; (c) 0,3 e (d) 0,6 \% de CMC. Polímeros (A) desdopados e (B) dopados.

Figura 35. Espectro no infravermelho de (a) PAni e da blendas PAni-CMC obtidas a partir de $\mathrm{H}_{3} \mathrm{PO}_{4} 1 \mathrm{~mol} \mathrm{~L}^{-1}$ contendo $0,2 \mathrm{~mol} \mathrm{~L}^{-1}$ anilina e $\mathrm{CMC}$ na concentração de (b) 0,1 ; (c) 0,3 e (d) $0,6 \%$. Na forma dopado. 
Figura 36. Espectro no infravermelho de (a) PAni e da blendas PAni-CMC obtidas 77 a partir de $\mathrm{H}_{3} \mathrm{PO}_{4} 1 \mathrm{~mol} \mathrm{~L}^{-1}$ contendo $0,2 \mathrm{~mol} \mathrm{~L}^{-1}$ anilina e $\mathrm{CMC}$ na concentração de (b) 0,1 ; (c) 0,3 e (d) $0,6 \%$. Na forma desdopado.

Figura 37. Condutividade elétrica de PAni e PAni-CMC como uma função das diferentes concentrações de CMC.

Figura 38. Micrografias das partículas dos polímeros dopados (a) precipitados de 80 PAni e blendas de PAni-CMC preparadas a partir de (b) $0,1 \%$; (c) $0,3 \%$ e (d) $0,6 \%$ de CMC; (e) filme obtido a partir da dispersão de PAni-CMC 1\%.

Figura 39. Curvas termogravimétricas para (a) CMC; (b) PAni; (c) blendas PAni82 CMC obtidas a partir de CMC: $(-)$ 0,1\%; (....) 0,3\% e (----) 0,6\% de CMC.

Figura 40. Curvas termogravimétricas para $(-)$ CMC comercia e $(-)$ PAni; Blendas de PAni-CMC obtidas a partir de $(-)$ 0,1\%; (-) 0,3\% e (-) 0,6\% CMC.

Figura 41. Dependência da condutância do DBSA em meio aquoso, a $25^{\circ} \mathrm{C}$. 86

Figura 42. Voltamograma cíclico do AISI-304 em DBSA 0,05 mol L-1 . Curva (a) 88 0,6 a 0,9 V; (b) $-0,6$ a $1,0 \mathrm{~V}$; (c) $-0,6$ a $1,1 \mathrm{~V}$; (d) $-0,6$ a $1,2 \mathrm{~V}$; (e) $-0,6$ a $1,3 \mathrm{~V}$; (f) $-0,6$ a $1,4 \mathrm{~V}$; (g) $-0,6$ a $1,5 \mathrm{~V}$; (h) $-0,6$ a $1,6 \mathrm{~V}$; a $50 \mathrm{mV} \mathrm{s}^{-1}$. Um ciclo de potencial de varredura.

Figura 43. Voltamograma cíclico da Pt em presença de DBSA $0,05 \mathrm{~mol} \mathrm{~L}^{-1}$. Curva (a) $-0,2$ a 0,8 V; (b) $-0,2$ a 1,2 V; a $50 \mathrm{mV} \mathrm{s}^{-1}$. Um ciclo de potencial de varredura.

Figura 44. Dependência do $\mathrm{pH}$ de uma solução de DBSA $0,05 \mathrm{~mol} \mathrm{~L}^{-1} \mathrm{com}$ a 91 adição de diferentes concentrações de anilina.

Figura 45. Voltamogramas de crescimento de PAni-DBSA sobre aço inoxidável a 92 partir de uma solução de DBSA $0,05 \mathrm{~mol} \mathrm{~L}^{-1}$ contendo anilina $0,01 \mathrm{~mol} \mathrm{~L}^{-1}$, a 50 $\mathrm{mV} \mathrm{s}^{-1}$. (a) $1^{\circ}$ ciclo; (b) $2-30^{\circ}$, (c) $31-60^{\circ}$ e (d) $61-90^{\circ}$ ciclos.

Figura 46. Voltamogramas de crescimento de PAni-DBSA sobre platina a partir 93 de uma solução de DBSA $0,05 \mathrm{~mol} \mathrm{~L}^{-1}$ contendo anilina $0,01 \mathrm{~mol} \mathrm{~L}^{-1}$, a $50 \mathrm{mV} \mathrm{s}^{-1}$. (a) 30 ciclos, (b) 60 ciclos e (d) 90 ciclos.

Figura 47. Voltamogramas cíclicos de crescimento de PAni-DBSA sobre AISI-304 94 partir de uma solução de DBSA $0,05 \mathrm{~mol} \mathrm{~L}^{-1}$ contendo anilina $0,015 \mathrm{~mol} \mathrm{~L}^{-1}$. Número de ciclos: (a) $1^{\circ}$ ciclo; (b) $2-30^{\circ}$, (c) $31-60^{\circ}$ e (d) $61-90^{\circ}$ ciclos. $\mathrm{v}=50 \mathrm{mV} \mathrm{s}^{-1}$.

Figura 48. Voltamogramas de crescimento de PAni-DBSA sobre AISI-304 a partir de uma solução de DBSA $0,05 \mathrm{~mol} \mathrm{~L}^{-1}$ contendo anilina $0,020 \mathrm{~mol} \mathrm{~L}^{-1}$. Número de ciclos: (a) $1^{\circ}$ ciclo; (b) $2-30^{\circ}$, (c) $31-60^{\circ}$ e (d) $61-90^{\circ}$ ciclos. $v=50 \mathrm{mV} \mathrm{s}^{-1}$. 
Figura 49. Voltamogramas de crescimento de PAni-DBSA sobre AISI-304 a partir 95 de uma solução de DBSA $0,05 \mathrm{~mol} \mathrm{~L}^{-1}$ contendo anilina $0,025 \mathrm{~mol} \mathrm{~L}^{-1}$. (a) $1^{\circ}$ ciclo; (b) 2-30 , (c) $31-60^{\circ}$ e (d) $61-90^{\circ}$ ciclos. $v=50 \mathrm{mV} \mathrm{s}^{-1}$.

Figura 50. Voltamogramas de crescimento de PAni-DBSA sobre AISI-304 a partir 96 de uma solução de DBSA $0,05 \mathrm{~mol} \mathrm{~L}^{-1}$ contendo anilina $0,030 \mathrm{~mol} \mathrm{~L}^{-1}$. Número de ciclos: (a) $1^{\circ}$ ciclo; (b) $2-30^{\circ}$, (c) $31-60^{\circ}$ e (d) $61-90^{\circ}$ ciclos. $v=50 \mathrm{mV} \mathrm{s}^{-1}$.

Figura 51. Voltamogramas de crescimento de PAni-DBSA sobre Pt a partir de 97 uma solução de DBSA $0,05 \mathrm{~mol} \mathrm{~L}^{-1}$ contendo anilina (a) 0,015 ; (b) 0,020 ; (c) 0,025; (d) 0,030 mol L-1. Número de ciclos: (I) 30; (II) 60 e (III) 90 ciclos. $\mathrm{V}=50 \mathrm{mV} \mathrm{s}^{-1}$.

Figura 52. Valores de densidade de corrente do primeiro pico anódico $\left(\mathrm{j}_{A}\right)$ em 98 relação ao número de ciclos. PAni eletropolimerizada em solução de DBSA 0,05 mol L $\mathrm{L}^{-1}$ contendo diferentes concentrações de anilina $(\boldsymbol{\square})$ 0,010; $(O)$ 0,015; (A) 0,020; ( $\mathbf{\nabla})$ 0,025; ( ) 0,030 mol L-1; sobre (a) Pt e (b) AISI-304.

Figura 53. Dependência da carga anódica referente ao primeiro pico de oxidação 100 de PAni-DBSA sobre (a) Pt e (b) AISI-304, em diferentes concentrações de DBSA

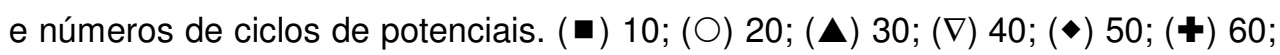
(x) 70; (*) 80 e (- ) 90 ciclos.

Figura 54. Carga anódica do pico $A, Q_{P A}$, versus o número de ciclos $(N)$ durante a 101

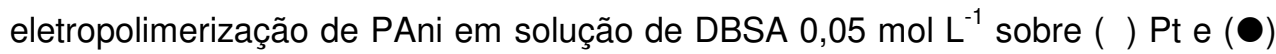
AISI-304.

Figura 55. Resposta eletroquímica em solução de (a) $\mathrm{H}_{2} \mathrm{SO}_{4} \quad 0,5 \mathrm{~mol} \mathrm{~L}^{-1}$ e (b) 104 DBSA $0,05 \mathrm{~mol} \mathrm{~L}^{-1}$ de PAni-DBSA eletropolimerizada sobre (...) Pt e (一) AISI304. $\mathrm{v}=50 \mathrm{mV} \mathrm{s}^{-1}$. Filmes eletropolimerizados em (I) 30 ciclos e (II) 60 ciclos.

Figura 56. Espectros de UV-VIS-NIR de PAni DBSA eletropolimerizada sobre 106 (-) Pt e (---) AISI-304 a partir de uma solução de DBSA 0,05 mol L-1 contendo $0,015 \mathrm{~mol} \mathrm{~L}^{-1}$ de anilina. (a) desdopado e (b) dopado.

Figura 57. Espectro no infravermelho de (a) DBSA (comercial) e PAni-DBSA 108 dopada, eletropolimerizada sobre (b) Pt e (c) AISI-304 a partir de uma solução aquosa de DBSA 0,05 $\mathrm{mol} \mathrm{L}^{-1}$ contendo $0,015 \mathrm{~mol} \mathrm{~L}^{-1}$ de anilina.

Figura 58. Espectro no infravermelho de (a) DBSA (comercial) e de PAni-DBSA 108 desdopada, eletropolimerizada sobre (b) Pt e (c) AISI-304 a partir de uma solução aquosa de DBSA 0,05 mol L-1 contendo 0,015 $\mathrm{mol} \mathrm{L}^{-1}$ de anilina.

Figura 59. Micrografias de PAni-DBSA eletropolimerizada sobre Pt : (a) (50) e (b) 110 90 ciclos; sobre AISI-304: (c) 51 ciclo e (d) 91 ciclos. 
Figura 60. Curvas potenciodinâmicas em solução aquosa de $\mathrm{NaCl} 3 \%$, aerada a 113 $25{ }^{\circ} \mathrm{C}$ do AISI-304 (a) sem recobrimento e recoberto com PAni-CMC dopada (b) $0,1 \%$; (c) $0,3 \%$; (d) $0,6 \%$ e (e) $1 \%$ de CMC.

Figura 61. Curvas potenciodinâmicas em solução aquosa de $\mathrm{NaCl} 3 \%$, aerada a 115 $25^{\circ} \mathrm{C}$ do AISI-304 (a) sem recobrimento e recoberto com PAni-CMC desdopada (b) $0,1 \%$; (c) $0,3 \%$; (d) $0,6 \%$ e (e) $1 \%$ de CMC.

Figura 62. Dependência do potencial de corrosão $\left(\Delta \mathrm{E}_{\text {corr }}\right)$ do AISI-304 recoberto com PAni-CMC em relação a concentração de CMC. PAni-CMC na forma ( $\square$ ) dopada e $(\bullet)$ desdopada.

Figura 63. Curvas potenciodinâmicas em solução aquosa de $\mathrm{NaCl} 3 \%$, aerada a $25^{\circ} \mathrm{C}$ do AISI-304 (a) sem recobrimento e recoberto com (b) PAni dopada e PAniCMC dopada (c) $0,1 \%$; (d) $1 \%$ CMC.

Figura 64. Curvas potenciodinâmicas em solução aquosa de $\mathrm{NaCl} 3 \%$, aerada a $25{ }^{\circ} \mathrm{C}$ do AISI-304 (a) sem recobrimento e recoberto com (b) PAni e PAni-CMC (c) $0,1 \%$; (d) $1 \%$ desdopada.

Figura 65. Micrografias do AISI-304 recoberto com diferentes filmes dos polímeros na forma dopada, antes e após corrosão e espectros de EDX após os ensaios corrosivos.

Figura 66. Variação dos teores de fósforo $(\mathrm{P})$ e cloro $(\mathrm{Cl})$ nos filmes eletropolimerizados sobre AISI-304 em presença de diferentes concentrações de CMC. (a) antes e (b) após os ensaios de corrosão.

Figura 67. Curvas potenciodinâmicas em solução de $\mathrm{NaCl} 3 \%$ do AISI-304 (a) 123 sem recobrimento e recoberto com filmes de PAni/BSA de diferentes espessuras: (b) 0,07 (c) 0,25 (d) 0,26 e (e) $0,48 \mu \mathrm{m}$.

Figura 68. Dependência do potencial de corrosão do AIS-304 recoberto com PAni-DBSA em função da espessura dos filmes, polarização potenciodinâmica em $\mathrm{NaCl} 3 \%$.

Figura 69. Curvas potenciodinâmicas em solução de $\mathrm{NaCl} 3 \%$ do AISI-304 (a) 126 sem recobrimento e recoberto com filmes de PAni/DBSA (espessura 0,25 $\mu \mathrm{m}$ ) na forma (b) dopada e (c) desdopada.

Figura 70. Potencial de circuito aberto do AISI-304 (a) sem recobrimento; e (b) 127 recoberto com PAni-DBSA de espessura $0,25 \mu \mathrm{m}$ em solução de $\mathrm{NaCl} 3 \%$.. 
Figura 71. Micrografias do AISI-304 recoberto com PAni-DBSA dopada (a) antes 128 da corrosão e (b) após a corrosão; (c) PAni-DBSA desdopada após a corrosão; (d) PAni-DBSA dopada imersa por 30 dias em solução de $\mathrm{NaCl} 3 \%$. Eletrodo de AISI-304 (e) após polimento mecânico; (f) sem filme PAni-DBSA dopado após corrosão; (g) sem filme de PAni-DBSA desdopada após corrosão; (h) sem filme de PAni-DBSA dopado quando imerso 30 dias em solução de $\mathrm{NaCl} 3 \%$. 


\section{Lista de Tabelas}

Tabela 1. Parâmetros eletroquímicos extraídos de diferentes estudos sobre a 26 proteção contra a corrosão de blendas de PAni-DBSA

Tabela 2. Composição nominal e a obtida por análise de EDX do aço inoxidável AISI-304

Tabela 3. Valores dos teores dos elementos, obtidos por EDX, dos filmes de PAni e PAni-CMC eletropolimerizados sobre AISI-304

Tabela 4. A velocidade de crescimento de PAni-DBSA $\left(\Delta Q_{P A} / \Delta N\right)$ sobre 102 eletrodos de platina e de aço inoxidável

Tabela 5. Valores de carga anódica e potenciais de pico do primeiro processo 104 redox de PAni-DBSA, obtidos da resposta eletroquímica dos filmes em $\mathrm{H}_{2} \mathrm{SO}_{4} 0,5$ mol L $\mathrm{L}^{-1}$ e DBSA $0,05 \mathrm{~mol} \mathrm{~L}^{-1}$

Tabela 6. Potencial de corrosão, densidade de corrente de corrosão, potencial de pite e variação entre o potencial de pite e o potencial de corrosão do AISI-304 sem e com recobrimento de PAni-CMC. \% CMC $(\mathrm{m} / \mathrm{v})$

Tabela 7. Carga anódica, $Q_{a}$ e espessura calculada dos filmes de PAni-DBSA sobre AISI-304

Tabela 8. Principais parâmetros eletroquímicos obtidos das curvas 124 potenciodinâmicas do AISI-304 sem recobrimento e recoberto com filmes PAniDBSA de diferentes espessura em $\mathrm{NaCl}$ 


\begin{abstract}
Resumo
Neste trabalho foram polimerizadas blendas e compósitos de polianilina (PAni), utilizando métodos químico e eletroquímico, sobre eletrodos de platina ( $\mathrm{Pt}$ ) e aço inoxidável (AISI-304), em diferentes meios aquosos. As blendas e compósitos de PAni foram preparados a partir de solução aquosa de $\mathrm{H}_{3} \mathrm{PO}_{4}$, contendo anilina e diferentes concentrações de carboximetilcelulose sódica $(\mathrm{CMC})$ ou ácido dodecilbenzenosulfônico (DBSA). Para a formação dos filmes poliméricos, sobre ambos os substratos metálicos, a técnica de voltametria cíclica foi utilizada, tendo sido investigada a influência das concentrações de CMC e de DBSA nas características do processo de polimerização bem como, no material resultante. Por outro lado, na polimerização química, realizada a $20^{\circ} \mathrm{C}$ e na presença de $\left(\left(\mathrm{NH}_{4}\right)_{2} \mathrm{~S}_{2} \mathrm{O}_{8}\right)$, curvas potenciométricas e calorimétricas foram obtidas para auxiliar na caracterização das sínteses. Os materiais poliméricos foram caracterizados com o uso das técnicas de voltametria cíclica (resposta eletroquímica), espectroscopia de UV-Vis-NIR, espectroscopia de infravermelho, de medidas de condutividade por quatro pontos, microscopia eletrônica de varredura, espectroscopia dispersiva de energia de raios-x (EDX) e termogravimetria (TG). A partir dos resultados obtidos, foram observadas diferenças decorrentes da concentração de CMC, com influência tanto na velocidade de polimerização, quanto nas propriedades físicas e químicas de PAni-CMC. As interações entre PAni e CMC ocorrem por ligações de hidrogênio sendo a estrutura dos filmes PAni-CMC fortemente depende da concentração de CMC. Há significativas diferenças, tanto no processo de eletropolimerização de PAni-DBSA sobre Pt e AISI-304, quanto nas propriedades físicas e químicas dos polímeros. Estruturalmente, os filmes de PAniDBSA eletropolimerizados sobre AISI-304 são mais porosos e apresentam maior eletroatividade, conseqüência da pré-camada de óxido formada durante a eletropolimerização. Mediante os ensaios de corrosão, foi verificado que os filmes de PAni-CMC aplicados sobre AISI-304 apresentam variação na composição após os ensaios de corrosão, enquanto que a proteção fornecida pelos filmes de PAni-DBSA depende da espessura dos mesmos. Ambos os filmes protegem efetivamente superfícies de aço inoxidável AISI-304 contra a corrosão e são alternativas extremamente viáveis quando comparados aos materiais convencionalmente utilizados.
\end{abstract}




\begin{abstract}
In this work, polyaniline (PAni) blends and composites were obtained on platinum (Pt) and stainless steel (AISI-304) substrates. The effects of chemical and electrochemical syntheses were studied in different aqueous media. PAni blends and composites were prepared from aniline monomer-containing solutions of $\mathrm{H}_{3} \mathrm{PO}$, that contained different concentrations of sodium carboxymethylcellulose (CMC) or dodecylbenzene sulphonic acid (DBSA). For the formation of polymeric films on Pt and steel AISI-304 electrodes, cyclic voltammetry was the technique employed and the effect of monomer, CMC and DBSA concentration on both the process characteristics and the resultant material were investigated. Chemical polymerization was performed at $20^{\circ} \mathrm{C}$, in the presence of an oxidizing agent $\left[\left(\mathrm{NH}_{4}\right)_{2} \mathrm{~S}_{2} \mathrm{O}_{8}\right]$ and potentiometric and calorimetric curves were obtained, which permitted the characterization of the synthesis. The resultant polymeric materials were characterized by their electrochemical response, ultraviolet (UV-VIS) and infrared (IR) spectroscopies, conductivity measurements, scanning electronic microscopy (SEM), film composition analysis by energy dispersive ray- $x$ spectroscopy (EDS) and thermogravimetric analysis (TG). From the polymer characterization, the results demonstrate the differences between the PAni polymers due to CMC concentration used in the polymerization, which influences both the polymerization rate and the physical and chemical properties of the PAni-CMC composite. The interaction between PAni and CMC occurs by hydrogen bonding, and the structure of the PAni-CMC film depends strongly on the CMC concentration. There are significant differences between the electropolymerization process of PAni-DBSA films on Pt and that on steel AISI-304, resulting in different the physical and chemical properties of the respective polymers. Structurally, the PAni-DBSA films electropolymerized on steel AISI-304 are more porous and present greater electroactivity due to an oxide layer formed during the electropolymerization. From corrosion assays, which involved performing open circuit potential and potentiodynamic curves in $\mathrm{NaCl}$, the viability of application of PAni-CMC and PAni-DBSA films electropolymerized on steel AISI-304 electrodes was analyzed. For the PAni-CMC films on steel AISI-304 a significant change in the film composition occurred after the corrosion assays. On the other hand the corrosion protection of steel AISI-304 covered with PAni-DBSA is dependent on the film thickness. The electrochemical parameters extracted from the potentiodynamic curves demonstrate that both films protect stainless steel against corrosion. Furthermore, the corrosion studies show that PAni-CMC and PAniDBSA films are viable alternatives to the conventionally used corrosion protection films.
\end{abstract}




\section{Capítulo I}

\section{Introdução}

\subsection{Preâmbulo}

Antigamente, acreditava-se que os polímeros orgânicos eram excelentes isolantes e, assim promoviam significativas vantagens para muitas aplicações sobre os materiais condutores elétricos. No mundo moderno, compostos orgânicos e condutividade elétrica estão totalmente associados desde 1977, quando um polímero orgânico eletricamente condutor foi descoberto [1]. Durante os últimos 20 anos, uma variedade de diferentes polímeros condutores tem sido desenvolvida. O sucesso desses materiais poliméricos está evidenciado pelas diversas áreas de interesse, como: química sintética, eletroquímica, física do estado sólido, ciências do material, ciências de polímero, engenharia eletrônica e elétrica [2].

Dentre os polímeros condutores, a polianilina (PAni) emergiu como o material de escolha para diversos estudos e inúmeras aplicações. O interesse neste polímero condutor e seus derivados, origina-se do fato de que a PAni pode existir em diferentes estados de oxidação e ser dopado por uma variedade de diferentes dopantes, seja por processos não redox, ou por oxidação química parcial, ou oxidação eletroquímica. Essas propriedades, combinadas a facilidade de síntese, processamento, satisfatória estabilidade ambiental e um custo relativamente baixo dos reagentes, sugerem a esse material um potencial de aplicabilidade tecnológica significativo.

Entretanto, a grande desvantagem dos polímeros condutores está em sua baixa solubilidade em inúmeros solventes (incluindo a água) e processamento térmico. Em busca de soluções para tais problemas, ácidos protônicos funcionalizados por exemplo (ácido dodecilbenzenosulfônico e canforsulfônico), blendas e compósitos de polímeros condutores 
foram preparados. Por volta de 1984, blendas de PAni foram produzidas por métodos eletroquímicos e, a partir de então, diferentes métodos de síntese e inúmeros polímeros (isolantes) sintéticos ou naturais foram misturados a polímeros condutores, resultando em patentes e artigos científicos sobre materiais poliméricos condutores com novas propriedades.

Blendas poliméricas são misturas homogêneas ou heterogêneas de dois polímeros quimicamente diferentes. Essas blendas, são usualmente preparadas por mistura mecânica de diferentes polímeros em fusão, solução, ou pela polimerização de um monômero na presença de um outro polímero. Já os denominados compósitos poliméricos, consistem de matrizes poliméricas contínuas e materiais preenchedores embebidos nesta matriz. Freqüentemente, esses materiais preenchedores, denominados cargas, podem ser mineral, vidro, metal ou polímero e, quanto ao formato, podem ser esféricos, placas, fibras, etc. Na grande maioria, as blendas e os compósitos são preparados por razões econômicas e muitos, usualmente apresentam maior resistência ao impacto do que seus componentes individuais [3,4].

A seleção de materiais poliméricos que possibilite a preparação das blendas e compósitos de PAni em presença de um polímero (natural ou sintético) é de suma importância, devido a união das propriedades dos diferentes materiais e conseqüente expansão da aplicabilidade.

A carboximetilcelulose $(\mathrm{CMC})$ é o segundo, em escala de produção, dos derivados de celulose. Esta substância é obtida pela reação alcalina da celulose com ácido monocloroácetico ou monocloroacetato de sódio em um processo heterogêneo, isopropanol/água. O produto comercial, a carboximetilcelulose sódica é um polietrólito fraco com pKa $=3,0 \pm 0,2$, com muita aplicação industrial em diversas áreas (por ex., alimentos e farmacêuticas) e, mais recentemente, tem sido utilizada em tintas a base de água [5,6]. Muitos polieletrólitos solúveis em água, como a CMC, apresentam propriedades favoráveis a formação de filmes a partir de soluções aquosas, combinadas com boa adesão dos filmes sobre superfícies sólidas. Nas preparações dessas coberturas, os polieletrólitos podem atuar isoladamente ou como estabilizador da suspensão de sólidos, por exemplo, em coberturas nas quais um pigmento tenha que ser fixado sobre uma superfície.

O ácido dodecilbenzenosulfônico (DBSA) é uma mistura de polímeros solúveis, nos quais os grupos hidrofóbicos são grupos alquílicos de cadeia longa (> C10). Sua estrutura é 
constituída pela presença de um grupo polar e outro apolar. O DBSA atua como ácido protônico funcionalizado, que simultaneamente dopa e induz processabilidade ao polímero de PAni. Assim, quando a síntese da PAni se realiza em presença de surfactantes aniônicos, como o DBSA, esses são incorporados às cadeias poliméricas do polímero, podendo agir como um contra-íon; suas longas cadeias alquílicas podem afastar as cadeias poliméricas da PAni uma das outras, facilitando a difusão de solventes orgânicos, aumentando assim, a solubilidade e proporcionando ordenação dessas cadeias poliméricas [2].

A aplicabilidade dos polímeros condutores como revestimento contra a corrosão metálica teve seu marco em 1985, quando a PAni eletropolimerizada sobre aço inoxidável ferrítico protegeu a superfície contra a corrosão, em um meio ácido. Em continuidade, diversas investigações sobre a utilização da PAni contra a corrosão foram realizadas visando a compreensão do mecanismo de proteção do metal, o melhor estado de oxidação da PAni, o pH do meio agressivo (neutro ou ácido). Contudo, ainda hoje existem controvérsias sobre a proteção contra a corrosão metálica pelos polímeros condutores, mas há um consenso de que PAni tem um bom desempenho como revestimento contra a corrosão. Além disto, entre os polímeros condutores, a PAni é o único dos polímeros condutores comercialmente disponível que vem sendo empregada em forma de tintas para aplicação sobre superfícies metálicas.

O propósito do presente trabalho foi o de continuidade na pesquisa de polímeros condutores visando a aplicação em revestimentos protetores contra a corrosão. A execução deste trabalho, além de resultar em um amadurecimento pessoal, propiciou um material novo para consulta, o qual aborda novos materiais que combinam diferentes polímeros (PAni, CMC e DBSA), com propriedades diferentes e de relevância à comunidade científica e acadêmica. Neste trabalho, constam descrições sobre os métodos de síntese, caracterização e sobre a aplicabilidade dos materiais poliméricos, como revestimento contra a corrosão metálica. Ou seja, este trabalho trata de novos materiais, que podem vir a ser, para gerações futuras, alternativos aos de hoje utilizados.

\subsection{Polímeros condutores}

O termo polímero intrinsecamente condutor (PIC), também conhecido como "metal sintético", refere-se a uma grande classe de polímeros orgânicos que possuem, não somente 
as propriedades mecânicas e processabilidade dos polímeros convencionais, mas também propriedades elétrica, eletrônica e magnética inerentes aos metais, ausentes nos polímeros convencionais [7]. Essas propriedades são intrínsecas do material dopado, sendo completamente diferente daquelas originadas das misturas físicas de um polímero não condutor com um material condutor, tal como, metal ou carbono em pó. Nos PICs a condutividade é devida a deslocalização dos elétrons das ligações $\pi$ sobre a estrutura polimérica, exibindo as propriedades eletrônicas, tais como transições ópticas de baixa energia, baixos potenciais de ionização e elevada afinidade eletrônica [8].

A deslocalização dos elétrons é uma conseqüência da presença de duplas ligações conjugadas na estrutura polimérica. Para tornar esses polímeros eletricamente condutores é necessário introduzir transportadores móveis de carga em suas duplas ligações. Isto pode ser realizado por reações de oxidação e redução, denominadas de "dopagem". O conceito de dopagem distingue os polímeros condutores de todos os outros tipos de polímeros. Essas cargas permanecem deslocalizadas, sendo neutralizadas pela incorporação de contra-íons (ânions ou cátions) denominados dopantes. Os polímeros condutores podem se apresentar em três estados: não condutor (descarregado), oxidado, no qual os elétrons podem ser removidos da estrutura, e reduzido (o menos comum), no qual os elétrons são adicionados a estrutura. Os processos de dopagem são usualmente reversíveis e a condutividade pode variar entre a de materiais isolantes $\left(<10^{-10} \mathrm{~S} \mathrm{~cm}^{-1}\right)$ e de metais $\left(10^{5} \mathrm{~S} \mathrm{~cm}^{-1}\right)$ [9].

Dentre os diversos polímeros condutores, os mais comuns, exemplos típicos de polímeros conjugados são polipirrol, politiofeno, polianilina e seus derivados [10].

Para a síntese dos polímeros condutores, os métodos químicos e eletroquímicos são freqüentemente utilizados, produzindo polímeros em forma de filme fino, ou espesso, ou em forma de partículas sólidas (pó), nas formas dopada ou não-dopada. Quanto a aplicação tecnológica, esses materiais têm sido empregados nas mais diversas áreas: baterias, eletrocatálise, sensores, proteção contra a corrosão, janelas eletrocrômicas, etc. [1,8-10].

Um dos polímeros condutores mais investigados, a polianilina (PAni) tem várias vantagens sobre os demais, ressaltando a facilidade de polimerização química e eletroquímica, a facilidade de dopagem e desdopagem por tratamento com soluções aquosas ácida e base e a elevada resistência à degradação ambiental [11]. 


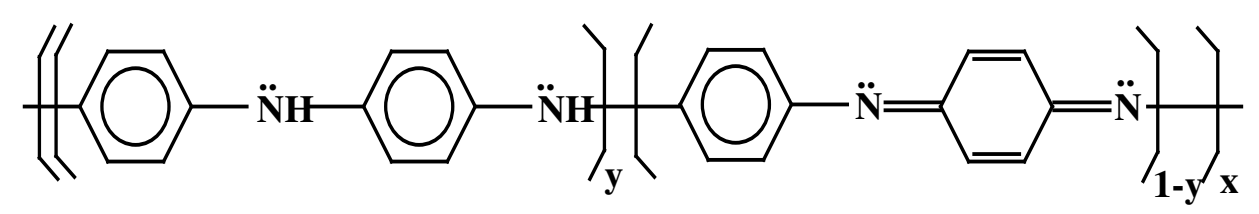

Figura 1. Estrutura geral da polianilina na forma base.

\subsection{Polianilina}

PAni foi primeiramente relatada na literatura científica por Letheby, em 1862, e obviamente, naquele tempo, a natureza da PAni como polímero condutor não foi compreendida. Este polímero, que foi chamado de "aniline black" era muito usado, nas indústrias têxteis e de impressão, como corante. No século passado, durante a década de 60 , a PAni tornou-se um polímero de interesse científico devido a suas propriedades elétricas incomuns e, a partir disso, extensivamente estudada [12,13].

O termo polianilina, comumente empregado hoje, refere-se a uma família de polímeros consistindo de 1000 ou mais unidades repetitivas de p-fenilenoimina, existindo em vários estados de oxidação e com diferentes valores de condutividade elétrica [12].

A composição química geral da PAni é mostrada na Figura 1, sendo que y corresponde à fração de unidades repetitivas reduzidas (grupos aminas) e (1-y) a fração de unidades repetitivas oxidadas (grupos iminas).

Em princípio, y pode variar continuamente de zero a um, mas quando y assumir o valor 1, o polímero estará completamente reduzido (chamado de leucoesmeraldina) e, assumindo o valor de 0 , o polímero estará completamente oxidado, sendo denominado de pernigranilina. Quando y assume o valor 0,5 tem-se a PAni conhecida como base esmeraldina, representada na Fig.1. O polímero então, constituirá de quantidades iguais de unidades reduzidas (grupos aminas) e unidades oxidadas (grupos iminas). Em presença de doadores de prótons, geralmente ácidos protônicos, conforme Fig 2, a protonação da forma base se promove, preferencialmente nos grupamentos iminas (os grupos mais básicos), e ocorre a inserção do ânion na estrutura (para manter a neutralidade de carga), originando a forma mais condutora da PAni, o sal esmeraldina. Desta forma, diz-se que a PAni está em seu estado dopado e o ânion, o contra-íon ou dopante. 


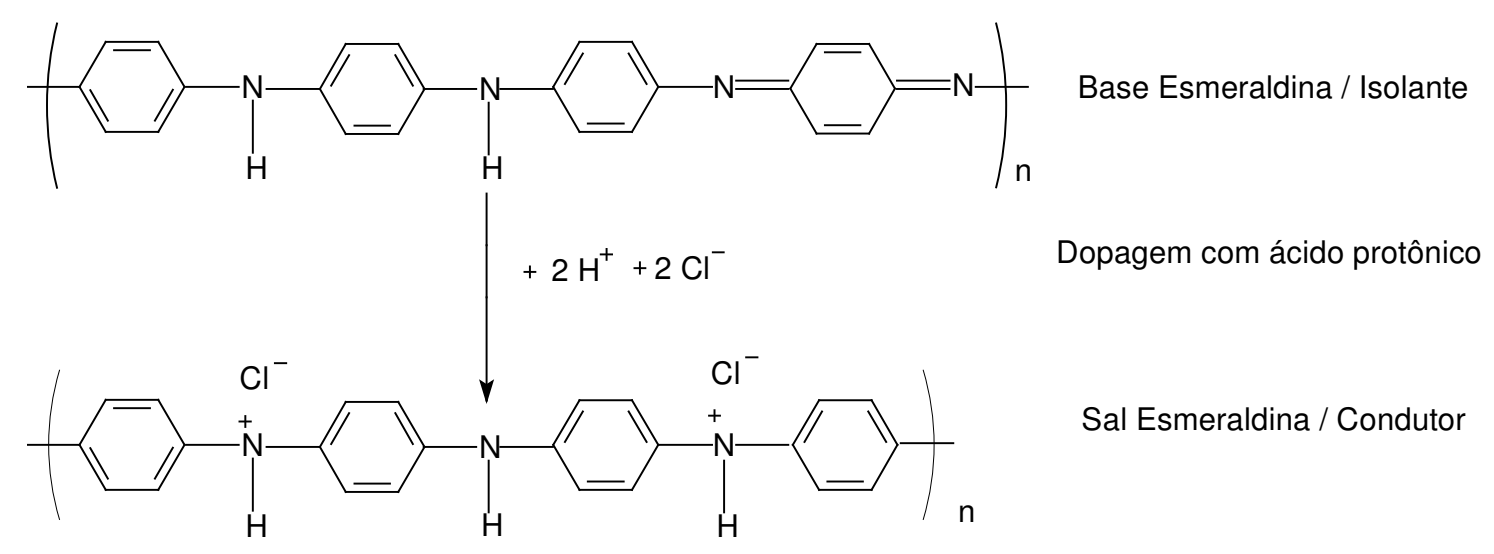

Figura 2. Processo de dopagem da PAni com ácido protônico.

O monômero pode ser quimicamente polimerizado usando persulfato de amônio, $\left(\mathrm{NH}_{4}\right)_{2} \mathrm{~S}_{2} \mathrm{O}_{8}$ como agente oxidante, em solução aquosa de ácido clorídrico para originar PAni [13,14], a qual pode ser preparada por eletropolimerização [15].

A PAni é normalmente preparada na forma de sal esmeraldina a partir das técnicas de polimerização, química e eletroquímica e, por tratamento com base, a forma base esmeraldina pode ser obtida. O processo de dopagem usado para aumentar e diminuir a condutividade elétrica da PAni é por protonação (dopagem) e desprotonação (desdopagem), respectivamente (Fig. 2) [12,13].

Tradicionalmente, a PAni é um material difícil de sofrer processamento. Entretanto, uma forma de PAni mais processável tem sido preparada por modificação da estrutura polimérica, mediante a introdução de vários grupos funcionais, tais como: alcoxi, amino, alquil, aril e grupos sulfonil [16]. O uso de novos aditivos (ácidos), tais como o ácido canforsulfônico (CSA) ou ácido dodecilbenzenosulfônico (DBSA) é uma medida alternativa para aumentar a solubilidade da PAni [17].

A PAni tem estado na categoria dos polímeros de difícil manuseio, por sua baixa solubilidade em solventes convencionais, os aceitáveis nas indústrias e, também, por não poder ser submetida a tratamentos térmicos. Esses inconvenientes podem ser contornados empregando ácidos protônicos funcionalizados, durante a síntese ou no processo de dopagem do polímero, que são intercalados dentro da matriz polimérica e atuam como agentes dopantes e/ou plastificantes [17]. 
Em um polímero, as propriedades como fusibilidade e solubilidade estão relacionadas as ramificações laterais da cadeia polimérica. Essas ramificações podem dificultar a aproximação entre as cadeias e diminuir a interação entre as mesmas, causando prejuízos ás propriedades mecânicas do polímero. A formação de retículos devido as ligações cruzadas existentes impede o deslizamento de uma cadeia sobre a outra, aumentando a resistência mecânica, mas torna o polímero insolúvel e infusível. Assim, as substâncias adicionadas ao polímero, que interferem na forma de sua cadeia, originando propriedades semelhantes entre a forma reticulada e a ramificada, são denominadas de plastificantes. No caso de uma cadeia ramificada, se este efeito é causado pela própria ramificação da cadeia, é dito que a ramificação funciona como um plastificante interno do polímero $[18,19]$.

Um ácido protônico funcionalizado é geralmente representado por $\mathrm{H}^{+}\left(M^{-}-R\right)$, em que $\left(M^{-}-R\right)$ é um contra-íon aniônico, contendo um grupo funcional R. Este grupo funcional é especificamente selecionado para ser compatível com líquidos orgânicos não polares ou fracamente polares. Assim, as cadeias carbônicas do ácido podem funcionar também como plastificantes, afastando as cadeias do polímero e facilitando o tratamento a quente da PAni. Dentre os ácidos protônicos funcionalizados, o ácido dodecilbenzenosulfônico (DBSA) destacase por produzir PAni com valores de condutividade maiores que outros ácidos funcionalizados. Além disso, seu uso tem proporcionado obter PAni solúvel em uma grande quantidade de solventes (xileno, m-cresol, clorofórmio, ácido fórmico, dimetilsulfóxido, etc.). Como conseqüência, também tem proporcionando a obtenção de misturas miscíveis de PAni em uma variedade de polímeros isolantes convencionais, tais como resina epoxi [20] silicatos [21], poliuretano [22] e etileno-proprileno-dieno [23].

\subsection{PAni-DBSA}

Dos inúmeros estudos sobre PAni-DBSA descritos em literatura, na grande maioria, o método de polimerização empregado é por via química. Dentre os diferentes métodos químicos utilizados, o mais freqüente tem sido a polimerização por emulsão em uma etapa $[24,25]$. Neste caso, o complexo de PAni-DBSA produzido exibe elevada massa molar, alta condutividade e alta solubilidade em solventes orgânicos, no estado condutor. Outros métodos de preparação da PAni-DBSA que têm sido empregados são a polimerização de anilina em micelas [26,27], 
suspensão [28] e dispersão [29]. No entanto, esses métodos são fortemente dependentes das condições de síntese, tais como concentrações dos reagentes, temperatura de síntese, entre outros parâmetros e, podem resultar PAni-DBSA em dispersões e não precipitados de PAniDBSA (pó).

Han et al. [25] sintetizaram e caracterizaram nanopartículas de PAni a partir de dispersões aquosas de solução micelar de DBSA, o qual atuou como dopante e surfactante. A cinética de polimerização e as condições ótimas de polimerização foram determinadas por espectroscopia nas regiões do ultravioleta e do visível. Os autores concluíram que o aumento de DBSA no meio reacional tem forte influência sobre a velocidade de polimerização e, a velocidade de polimerização aumenta devido a diminuição do pH e ao aumento na formação de micelas. Dentre as conclusões, os autores relataram que a ótima razão de monômero e oxidante para a reação de polimerização é 0,5 e, entre o monômero e DBSA, a razão é praticamente unitária. Também, concluíram que o excesso de DBSA diminui o nível de dopagem da PAni devido á uma competição entre as moléculas de DBSA que não reagiram. Estas moléculas que não reagiram podem interferir no processo de dopagem e na movimentação das micelas para a polimerização de anilina. Uma outra observação foi que a condutividade elétrica varia com a razão de DBSA e monômero, alcançado um máximo valor de $24 \mathrm{~S} \mathrm{~cm}^{-1}$ para o material particulado.

Apesar de haver inúmeros estudos sobre a polimerização química, pouco tem sido conhecido sobre a utilização de métodos eletroquímicos para a polimerização de PAni-DBSA, bem como as propriedades química ou física dos filmes de PAni-DBSA eletropolimerizados.

Choi et al. [24] investigaram algumas das propriedades eletroquímicas de filmes de PAniDBSA quimicamente obtida. Esses filmes demonstram importante potencial de uso em baterias secundária como eletrodo. De fato, a PAni-DBSA pode ter várias vantagens como eletrodo devido primeiro, a facilidade de formação de filmes sobre substratos metálicos, como $\mathrm{Fe}, \mathrm{Ni}$ e $\mathrm{Pt}$, na forma eletricamente condutora e segundo, a uma melhoria na atividade eletroquímica da reação redox com PAni, pois o DBSA inserido dentro da matriz polimérica pode promover uma rápida movimentação de cátions pequenos para o interior do filme.

Moulton et al. [30] estudaram a síntese química de PAni-DBSA pelo método de polimerização micelar e, também relatam que, quando uma solução de DBSA 0,65 mol L'-1 
contendo anilina $0,13 \times 10^{-3} \mathrm{~mol} \mathrm{~L}^{-1}$ é utilizada na polimerização eletroquímica por voltametria cíclica sobre carbono vítreo, o perfil voltamétrico de crescimento não se mostra similar aquele característico da PAni e nem da nanodispersão de PAni-DBSA obtida quimicamente. Moulton et al. [30] não se preocuparam em otimizar as condições para a eletropolimerização de PAniDBSA e sim, verificar a influência de uma concentração residual de anilina $\left(0,13 \times 10^{-3} \mathrm{~mol} \mathrm{~L}^{-1}\right)$, que permaneceu sem reagir, a partir de um filme nas formado sobre o substrato (carbono vítreo) da nanodispersão de PAni-DBSA.

Kuramoto et al. [28] afirmam que a aceleração no crescimento de PAni sobre platina, na presença de polivinilsulfonato ou dodecilbenzenosulfonato de sódio (SDS), deve-se a elevada concentração local de monômero de anilina no meio reacional, que é favorecida pelo estado micelar que se forma durante a polimerização.

Recentemente, Prissanaroon et al. [31] em um estudo sobre a interface polímero/metal, eletropolimerizaram pirrol a partir de uma solução de DBSA $0,05 \mathrm{~mol} \mathrm{~L}^{-1}$ contendo $0,05 \mathrm{~mol} \mathrm{~L}^{-1}$ de pirrol sobre os eletrodos de aço inoxidável e de cobre. Uma relevante observação dos autores foi que as camadas interfaciais são constituídas de $\mathrm{Fe}_{2} \mathrm{O}_{3}$ e $\mathrm{CuO}$ para o aço e cobre, respectivamente. Segundo os autores, essas camadas de óxidos são formadas devido à dissolução dos eletrodos durante a eletropolimerização, além de uma outra camada fina de DBSA na região de interface entre o polímero e o substrato. Neste estudo, há vários pontos de interesse a serem considerados: (i) a razão monômero e DBSA utilizada é de 1:1; (ii) os autores não mencionam sobre nenhum problema durante a eletropolimerização, tais como formações de emulsão, de complexo pirrol-DBSA e fase no meio reacional; (iii) a constatação da formação das camadas interfaciais de $\mathrm{Fe}_{2} \mathrm{O}_{3}$ e de DBSA para o substrato de aço por diferentes técnicas.

Com base no descrito, uma investigação sobre a síntese eletroquímica de PAni-DBSA é de suma importância: em vista de algumas desvantagens em se obter PAni-DBSA via química; pelas inúmeras possibilidades de aplicação dos filmes eletrodepositados, além da inexistência de um estudo sistemático sobre a eletropolimerização e sobre as propriedades inibidoras da corrosão por filmes de PAni-DBSA. 


\subsection{Blendas e compósitos de PAni}

Os problemas característicos de processamento térmico e solubilidade da PAni têm sido solucionados pelo uso de ácidos protônicos funcionalizados como dopantes, ou pela preparação de compósitos ou blendas com os polímeros convencionais (naturais ou sintéticos). Misturas de polímero em solução e o processamento térmico com diferentes polímeros termoplásticos, como o cloreto de polivinila (PVC) e poliuretana (PU), têm originado blendas, as quais têm sido desenvolvidas com sucesso e aplicadas como dissipadores eletrostáticos (ESD) e blindagem de isolamento eletromagnético (EMI). Blendas de PAni processadas termicamente estão se tornando preferenciais do ponto de vista industrial, devido á sua facilidade de manuseio e baixo custo, comparadas a outros processos. Normalmente, o objetivo é preparar blendas de PAni com baixo limite de percolação, as quais podem ser obtidas pelo método de processamento térmico [32,33].

Algumas tecnologias de preparação de blendas de PAni como material de isolamento podem também ser usadas para preparar coberturas de PAni para proteção contra a corrosão, dando a devida atenção a adesão e uniformidade das coberturas. Vários tipos de blendas, dependendo da matriz polimérica (polímero isolante), têm sido sintetizada pelos métodos químico e eletroquímico. Anand et al. [34] realizaram uma revisão sobre as blendas de PAni até o ano de 1998. Dentre as diferentes sínteses químicas mencionadas, as relacionadas a seguir foram utilizadas neste trabalho:

1) polimerização química in situ na qual a anilina e a matriz hospedeira são misturadas e o oxidante é adicionado.

2) processabilidade induzida pelo contra-íon, pelo uso de ácidos protônicos funcionalizados para dopar, bem como, resultar polianilina solúvel em solventes orgânicos em sua forma condutora.

A preparação da mistura de PAni em um polímero convencional, por via eletroquímica, pode consistir na polimerização da anilina, pelos métodos potenciostático, galvanostático e potenciodinâmico (voltametria cíclica) de diferentes maneiras: primeiro sobre um substrato previamente recoberto com o polímero isolante $[2,34]$. Neste caso, o substrato metálico é revestido pelo polímero isolante, formando uma matriz polimérica porosa, antes de ser colocado na solução eletrolítica com o monômero. Segundo, o substrato não é previamente 
revestido e a PAni é eletropolimerizada a partir da mistura do monômero no polímero isolante sobre o eletrodo. Durante a polimerização, ânions entram na estrutura polimérica a partir da solução para manter a neutralidade de carga da estrutura. Em ambos os casos, o eletrodo previamente revestido ou não, o processo de eletropolimerização origina um material compósito. Isto porque, o polímero condutor que interage com a matriz polimérica isolante comporta-se como carga dentro desta matriz e, quando o polímero condutor dopado é reduzido as interações entre os dois polímeros não podem ser destruídas [2,34].

A eletropolimerização da PAni tem sido realizada utilizando diversas matrizes poliméricas, tais como policarbonato (PC) [35], poliestireno sulfonado [36], Nafion [36], polimetilmetacrilato (PMMA) [37], borracha nitrílica [38], acetato de celulose [39], poliacrilonitrila [40] e poliuretana (PU) em soluções aquosas de acetonitrila e elilenoglicol [41]. Enquanto, quimicamente as matrizes poliméricas utilizadas são: poli(N-vinilpirrolidona) [42,43], poli(metil vinil eter), poli(ácido estirenosulfônico), poli(óxido de etileno), poli(vinil álcool) [44,45], metilcelulose [44,46], etil(hidroxietil) celulose [46] e hidroxipropilcelulose (HPC) [47].

Como conseqüência da melhoria nas propriedades elétricas e mecânicas demonstradas pelas blendas e compósitos de PAni, diversas aplicações têm sido sugeridas, tais como: membranas de separação de gás, filmes resistores, materiais de blindagem (EMI), sistema de filtração [48], coberturas antiestáticas [49], sensores [48] e revestimentos contra a corrosão metálica [50].

\subsection{PAni-CMC}

Os éteres de celulose, especificamente metilcelulose $[44,46]$ e etil(hidroxietil) celulose [46] têm sido utilizados na preparação química de dispersão de PAni em meio alcoólico. A facilidade no uso de derivados celulósico como a hidroxipropilcelulose (HPC) está no fato de se poder utilizar um meio aquoso [47]. Algumas vezes, o uso de polímeros solúveis em água tem originado partículas de PAni em dispersão. A morfologia dessas partículas então pode variar, no caso de dispersões, em esférica, grão de arroz ou agulha, devido á variação de polidispersividade no tamanho. Chattopadhyay et al. [46] relatam que a morfologia das partículas de PAni sintetizadas em presença de metilcelulose pode ser controlada por diferentes fatores, dentre eles, pela composição da mistura de etanol-água (o solvente), pela (i) 


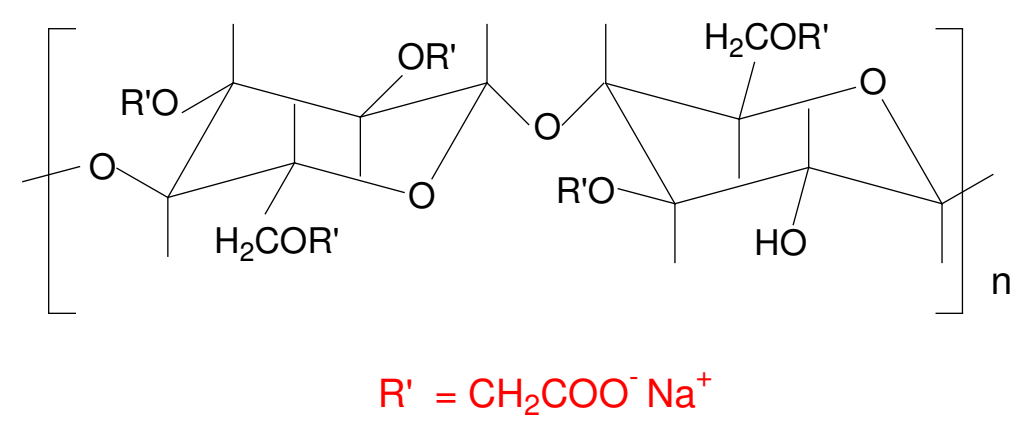

Figura 3. Estrutura da carboximetilcelulose.

variação da eficiência de adsorção da meticelulose sobre a partícula e pela (ii) velocidade de polimerização.

Comparativamente a síntese eletroquímica, a síntese química é relativamente simples, barata e maior quantidade de material polimérico é obtido, porém com menor grau de pureza devido a impossibilidade de controle das reações paralelas. Relativamente rápido, os métodos eletroquímicos, apresentam várias vantagens, proporcionando um maior controle sobre a síntese, o material polimérico é obtido diretamente em forma de filme sobre o substrato de interesse, em menor quantidade, mas de maior pureza. Em alguns casos, as propriedades dos filmes (p. ex.: elétricas, morfológicas) podem ser modificadas simplesmente, variando as condições de eletrossíntese. Além do mais, a síntese eletroquímica é considerada limpa e, um sistema eletrólito - matriz polimérica pode ser apropriado para a penetração de espécies iônicas (monômero e eletrólito) na matriz polimérica. Contudo, no geral, há uma grande preferência pela via química.

\subsubsection{Carboximetilcelulose}

A carboximetilcelulose ou CMC é a segunda na escala de produção dos derivados de celulose, sendo sua produção anual cerca de 280 toneladas [5,6]. A CMC cuja fórmula química é descrita pela Figura 3 é obtida a partir de uma reação alcalina da celulose com ácido monocloroacético ou monocloroacetato de sódio em um processo heterogêneo, em meio reacional isopropanol/água. 
Um rendimento entre $60-70 \%$ pode ser atingido tendo como principal produto lateral o glicolato de sódio e dependendo do uso e propriedade requerida a CMC pode ser ainda purificada.

A carboximetilcelulose sódica ( $\mathrm{NaCMC}$ ) comercial, usualmente, tem um grau de substituição (DS), definido como o número de grupos de hidroxila substituídos por unidade de anidroglucose, entre 0,5 e 1,0 com os grupos carboxílicos fixados em todas as três posições. A solubilidade em água ( $\mathrm{pH}$ neutro) é observada para $\mathrm{NaCMC}$ quando o valor de DS está entre 0,4 e 0,6 .

Os derivados éteres de celulose, incluindo a CMC são importantes por apresentarem propriedades que os qualificam como espessantes, emulsificantes, aglutinantes e termoplásticos. Estas características os tornam adequados para aplicações em diversas áreas industriais como as de tintas, papel, alimentos, farmacêuticas, cosméticos, cerâmicas, têxteis, entre outras [51-54].

O uso de $\mathrm{CMC}$ em tintas tem gerado grande interesse na indústria de tintas com base aquosa. A partir da combinação da CMC de grau refinado com outros derivados de celulose não-iônicos, tais como a hidroxietil celulose, uma viscosidade média pode ser obtida. Todavia, a CMC de grau bruto também tem sido utilizada na produção de tintas de baixo custo em particular na Itália e na França [6].

Usualmente a CMC e a hidroximetilcelulose, em tintas látex são empregadas como controladores de viscosidade (agentes tixotrópicos), permintindo que a tinta tenha um "encorpamento" durante o tempo de estocagem e, quando utilizada, seja facilmente homogeneizada após rápida agitação. Esses agentes controladores de viscosidade fazem com que os pigmentos e cargas da tinta não sedimentem [55]. 


\subsubsection{Parâmetros característicos de carboximeticelulose}

Os principais parâmetros da CMC são o grau de polimerização, a viscosidade e o grau de substituição. Dentre este parâmetros, maior ênfase é dado ao grau de substituição, visto que, é um parâmetro que rege os substitituintes estrututrais na molécula de CMC e foi utilizado como base na proposta de interação da PAni com a CMC.

O grau de substituição (DS) representa o número médio de hidroxilas por unidade de $\beta$ D-glicopiranose que são substituídas por grupos carboximetila. As hidroxilas localizadas nos carbonos C2, C3 e C6 das unidades de $\beta$-D-glicopiranose que compõem a celulose podem ser substittuídas por grupos carboximetila. Assim, o grau máximo de substituição que pode ser atingido é igual á 3 .

A freqüência de substituição em cada hidroxila é uma função de sua reatividade intrínseca, mas também, da estrutura supramolecular da celulose e da realização da reação em meio homogêneo ou heterogêneo $[52,53,56]$. Estudos de espectroscopia de ressonância magnética nuclear (RMN) indicam que a distribuição dos substituintes é da ordem dos carbonos C2>C6 >>C3 [52,53,56,57].

A distribuição dos substituintes não é uniforme, razão pela qual, numa mesma molécula podem existir unidades monoméricas e regiões com diferentes graus de substituição. A distribuição dos substituintes, e portanto, de cargas ao longo da cadeia, pode corresponder a uma de muitas combinações possíveis, aliada à distribuição de massa molecular; e para um dado DS, um fator determinante das propriedades dos polímeros. Deste ponto de vista, produtos idênticos, no que diz respeito aos respectivos valores de DS, podem apresentar propriedades diferentes. Portanto, a distribuição de substituintes é um parâmetro de difícil controle $[53,56]$. Como pode ser observado na Figura 4, a distribuição de substituintes envolve a presença e posições dos substituintes ao longo da cadeia polimérica e também dentro de cada unidade monomérica.

A distribuição dos substituintes ao longo da cadeia influencia as propriedades química e física, tais como solubilidade, estabilidade na presença de eletrólitos e aditivos em função da temperatura, estabilidade quanto a degradação, etc. $[53,56]$. As posições de substituintes em cada unidade monomérica podem influenciar a solubilidade e estabilidade e propriedades de suas soluções $[52,53,56]$. Devido ás possibilidades de distribuição dos substituintes ao longo 


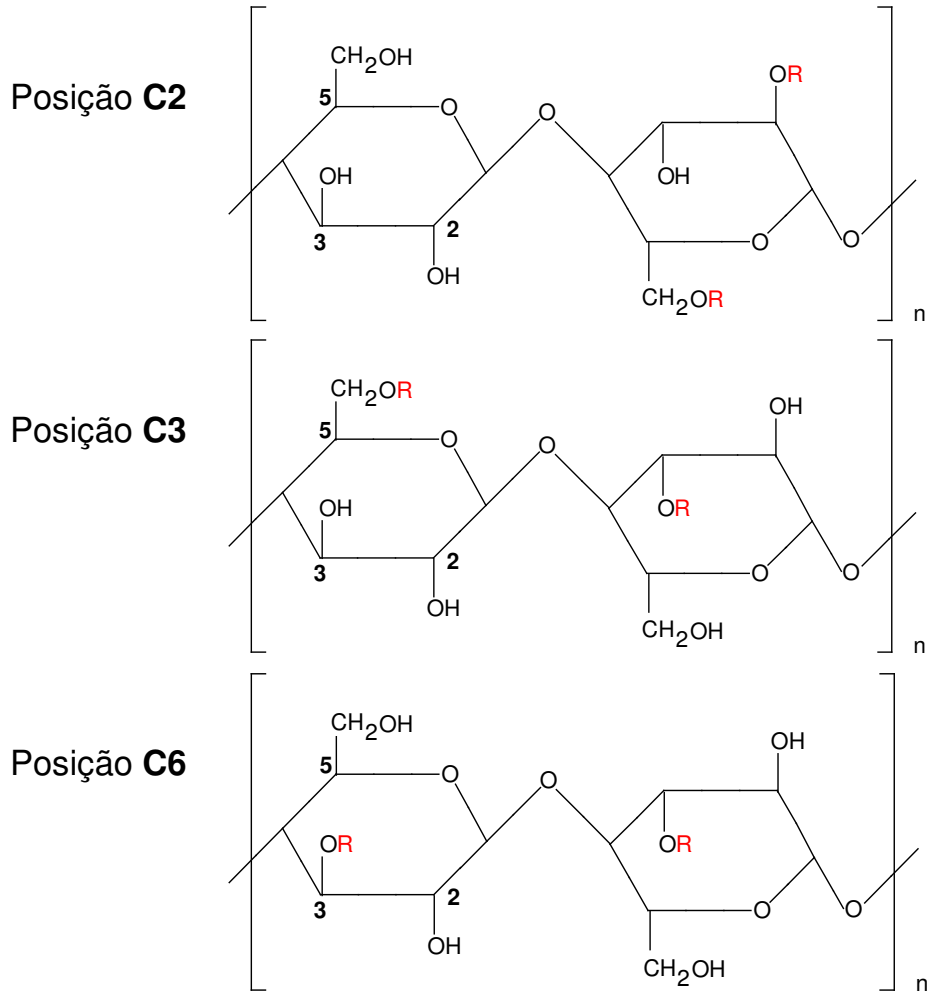

(a)
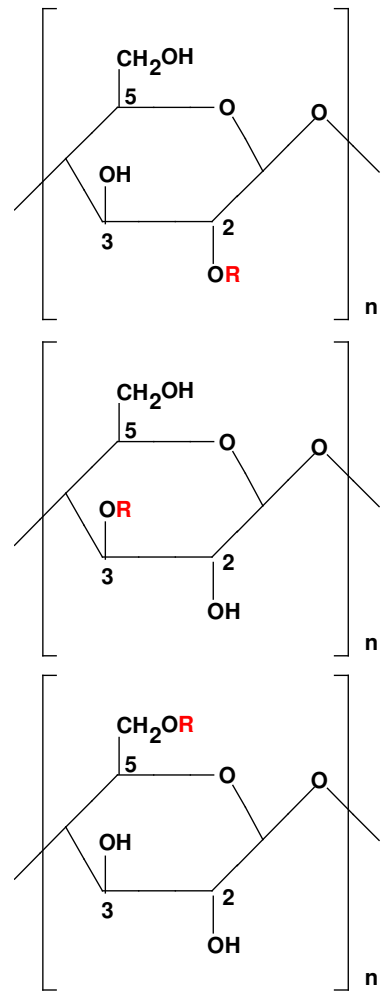

(b)

Figura 4. Exemplificação da distribuição do substituintes (R) (a) ao longo da cadeia polimérica e (b) dentro da unidade monomérica (CMC com DS = 1).

da cadeia de CMC e para minimizar a complexidade estrutural da mistura PAni-CMC, para a proposta de interação entre a CMC e a PAni, baseada nos resultados deste trabalho, foi considerando que: (i) o grau de substituição da CMC empregada é unitário; e (ii) a interação somente ocorre no carbono C2, o qual é o mais reativo, conforme observado pela Figura 4.

O uso de CMC como matriz polimérica hospedeira na preparação de blendas ou compósitos tem sido reportado em diversos estudos com polipirrol [58-60] e PAni $[61,62]$. No caso de misturas com PAni, a CMC é incorporada pela polimerização química e eletroquímica do monômero ou por dopagem em solução aquosa, com melhorias nas características química ou física do polímero.

Otero et al. [58] investigaram a eletropolimerização de pirrol em presença de CMC em soluções aquosa de $\mathrm{LiClO}_{4}$ sobre Pt utilizando os métodos galvanostático e potenciostático. Os autores estudaram diferentes parâmetros de síntese (concentração de monômero e de CMC) e realizaram um estudo cinético, do qual determinaram a ordem de reação em relação a concentração de monômero e CMC. Dentre as conclusões, os autores relatam que baixa 
produtividade de corrente ou eficiência de carga armazenada, durante a polimerização, e sugerem que há uma variação no mecanismo de reação. A presença de reações paralelas cuja influencia aumenta durante o tempo de polimerização, produz uma diminuição no crescimento do filme compósito e uma degradação parcial do polímero, a qual pode ser deduzida a partir de uma rápida diminuição na razão das cargas de oxidação e de polimerização.

Em um outro estudo, Otero et al. [59] utilizaram soluções aquosa de $\mathrm{LiClO}_{4}$ contendo CMC e monômero em concentrações da ordem de $10^{-2} \mathrm{~mol} \mathrm{~L}^{-1}$. A influência dessas concentrações, em diferentes condições de síntese (temperatura, potencial e densidade de corrente), foram investigadas e, devido ás baixas concentrações de reagentes utilizadas, foram obtidos filmes finos de compósitos de PPy-CMC. Os autores relatam que baixas concentrações de monômero podem promover a formação de filmes passivos sobre a superfície do eletrodo devido á ocorrência de uma adsorção preferencial de CMC sobre a superfície metálica. A partir de concentrações de monômeros maiores que $10^{-2} \mathrm{~mol} \mathrm{~L}^{-1}$ o rápido processo de polimerizaçãooxidação impede o processo de adsorção-passivação. Em continuidade, também relatam que o processo de adsorção de CMC sobre eletrodos de platina, ou sobre o filme já crescido, somente será competitivo com o crescimento de polipirrol em baixas velocidades de polimerização, a partir de concentrações de pirrol de $0,1 \mathrm{~mol} \mathrm{~L}^{-1}$. Em altas concentrações de pirrol (maiores que $0,1 \mathrm{~mol} \mathrm{~L}^{-1}$ ) a polimerização prossegue como o esperado e, quanto mais elevada a concentração de CMC, mais rápido se torna o processo de polimerização.

Banerjee [61] realizou a síntese química de PAni a $2^{\circ} \mathrm{C}$, em presença de $2,5 \mathrm{~g} \mathrm{CMC}$ (como estabilizador), $\mathrm{HCl} 1,2 \mathrm{~mol} \mathrm{~L}^{-1}$ e persulfato de amônio (o oxidante) em dois meios, aquoso e etanol/água. Posteriormente, misturou a PAni-CMC no copolímero SBA (copolímero de estireno e n-butil acrilato). Segundo o autor, a polimerização por dispersão, usando CMC como estabilizador estérico em água, somente resulta em precipitados macroscópicos de partículas de PAni quando a quantidade de CMC é menor que 1\% (em peso). Para quantidades de CMC maiores que 5\%, dispersões estáveis são obtidas, pois nestes casos, as elevadas concentrações de CMC em solução mpedem a sedimentação das partículas de PAni. O autor também avalia a influência da concentração de monômero e caracteriza os materiais poliméricos obtidos por diferentes técnicas (IV, MEV, microscopia eletrônica de transmissão e medidas de condutividade). Contudo, o autor visa a obtenção de uma dispersão de PAni em 
meio alcoólico (50\% de etanol) em presença de CMC e SBA. Mas, para PAni-CMC descreve que a incorporação de CMC nas partículas coloídais aumenta com a diminuição da concentração de anilina e, consequentemente com a concentração de oxidante, considerando a razão de monômero e oxidante sendo unitária. De forma geral, é concluído que condutividade da blenda PAni-CMC, diminui com a porcentagem de CMC (o polímero não condutor) e por análise no infravermelho da blenda constatado a incorporação de CMC.

No estudo de Banerjee descrito anteriormente são propostos dois meios para obtenção de blendas de PAni-CMC e esses modos de preparação promovem PAni-CMC na forma de precipitado ou dispersão. Contudo não investiga sistematicamente os parâmetros de síntese (meio aquoso, temperatura, concentração de regentes entre outros). Parâmetros como esses são de extrema relevância quando se visa uma aplicabilidade as blendas de PAni-CMC, isto tanto na forma de precipitado ou dispersão, principalmente como um componente de tinta de base aquosa.

Em um outro estudo, Banerjee [61] preparou filmes de PAni-CMC sobre polietileno, a partir de soluções aquosas de CMC contendo diferentes concentrações de $\mathrm{K}_{2} \mathrm{Cr}_{2} \mathrm{O}_{7}$ (o agente oxidante), anilina $0,1 \mathrm{~mol} \mathrm{~L}^{-1}$ e $\mathrm{HCl} 1,2 \mathrm{~mol} \mathrm{~L}^{-1}$. Os filmes compósitos de PAni-CMC foram preparados pela polimerização oxidativa da anilina no interior da matriz polimérica (polietileno), a qual foi embebida com a solução de oxidante. O autor investiga a interação entre a mistura dos polímeros que tende á influenciar a condutividade e as propriedades físicas dos filmes resultante.

\subsection{Proteção contra a corrosão}

A corrosão pode ser definida como a deterioração de um material, geralmente metálico, por ação química ou eletroquímica do meio ambiente aliada, ou não, a esforços mecânicos [63,64]. Sendo a corrosão, em geral, um processo espontâneo, ela está constantemente transformando os materiais metálicos de modo que a durabilidade e desempenho dos mesmos deixem de satisfazer os fins a que se destinam. No seu todo, esse fenômeno assume uma grande importância na vida moderna, pois representa investimentos volumosos em manutenção e reparos que exigem durabilidade e resistência contra a corrosão que justifiquem 

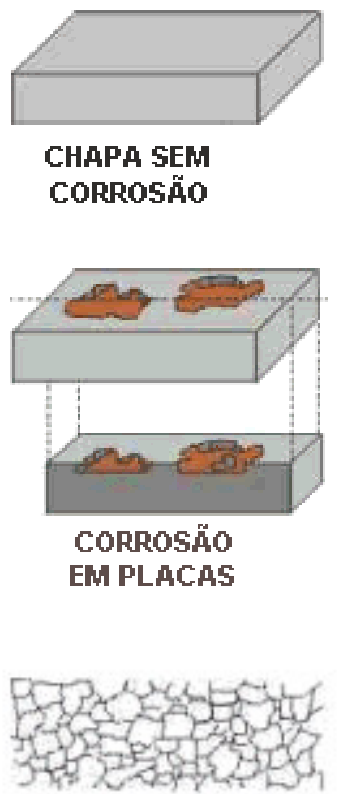

CORROSÃO IHTERGRAHULAR (MICROGRAFIA)

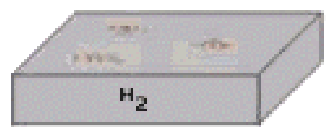

EMPOLAMEHTO PELO HIDROGËHIO
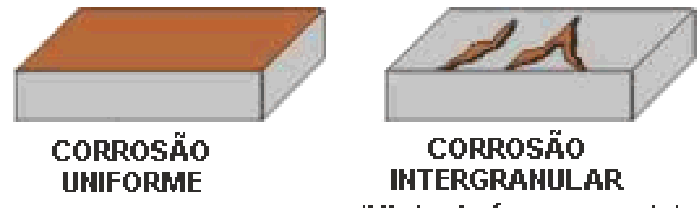

(Vista da área exposta)

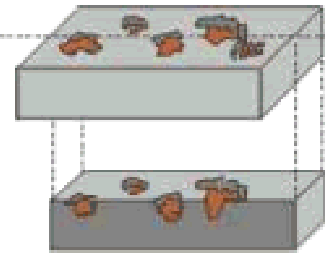

CORROSR̈O

ALVEOLAR

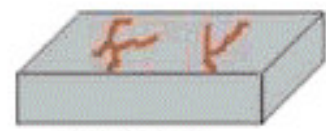

CORROSÃO

FILIFORME

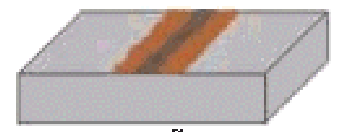

CORROSĂO EHTORHO DE SOLDA
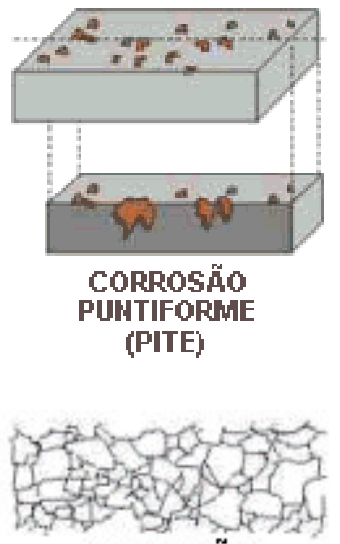

CORROSÃO INTRAGRAHULAR (MICROGRAFIA)

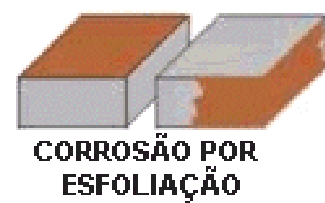

Figura 5. Principais formas de corrosão [66].

os valores investidos e evitem acidentes com danos materiais ou pessoais irreparáveis [64]. Um exemplo encontrado na literatura [65] é que a corrosão nos Estados Unidos promove um custo entre 100 a 300 bilhões de dólares anualmente. Por outro lado dados oficiais no Brasil são inexistentes, levando-nos a uma imaginação sobre os custos [65].

Os ambientes mais propícios para a corrosão metálica são as águas naturais, misturas atmosféricas, chuvas e soluções feitas pelo homem [64]. Várias classificações, em geral são usadas para descrever a corrosão que afeta as infraestruturas. Na Figura 5 estão demonstradas esquematicamente algumas das formas de corrosão, as quais podem ser classificadas em: corrosão geral ou uniforme, corrosão galvânica, corrosão por pite, quebra induzida ambientalmente, fratura por hidrogênio, corrosão intergranular, de ligamento e corrosão por erosão [66]. 


\subsection{Aço inoxidável e corrosão por pite}

Os aços inoxidáveis são ligas de ferro-carbono contendo no mínimo 11\% de cromo, o que previne a formação de óxidos (ferrugem) em atmosferas não poluídas. A resistência a corrosão dos aços inoxidáveis é fornecida por um filme superficial muito fino conhecido como "filme passivante"[67].

Em alguns aços inoxidáveis o conteúdo de cromo pode chegar a $30 \%$, e muitos outros elementos são adicionados para fornecerem propriedades específicas ou facilitar a fabricação. Por exemplo, níquel e nitrogênio podem ser adicionados para resistência a corrosão, carbono, molibdênio, nitrogênio, titânio, alumínio e cobre para resistência mecânica; enxofre e selênio para tratabilidade e níquel para formabilidade e dureza.

Alguns progressos têm sido feitos na identificação de certos parâmetros na superfície de filmes que determinam onde o filme passivante permanecerá intacto (ficando conseqüentemente passivo) ou rompido, causando o chamado "pite".

Muitos modelos têm sido propostos para a manutenção de filmes passivos e sua quebra por íons cloreto. Um desses modelos está esquematicamente ilustrado na Figura 6.

Esse modelo assume que o filme passivante é um filme de óxido hidratado com estrutura de gel (Figura 6 a). Na situação na qual a passividade é mantida, os íons metálicos, que são produzidos por dissolução através da parte do filme não desenvolvida, forma intermediários denotados como $\mathrm{MOH}^{+}$. $\mathrm{O}$ íon $\mathrm{MOH}^{+}$é capturado pelas moléculas de $\mathrm{H}_{2} \mathrm{O}$ vizinhas e se liga dentro do filme tipo gel, com a liberação de prótons.

Quando os íons cloreto são introduzidos na solução, eles substituem as moléculas de água mais facilmente na parte do filme não desenvolvida (nos sítios em ponte $\mathrm{H}_{2} \mathrm{O}-\mathrm{M}-\mathrm{OH}_{2}$ ), como mostrado na Figura 6 b. A introdução de íons cloreto nesses sítios em ponte resulta na formação de complexos de cloreto metálico solúveis e sua remoção deste filme (Figura 6 b’). Esta reação constitui a quebra da passividade e o início do pite (Figura 7). 


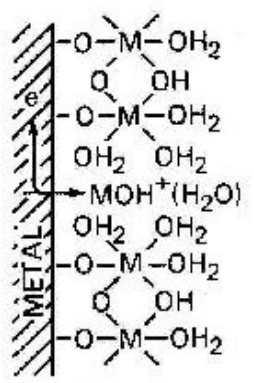

(a)

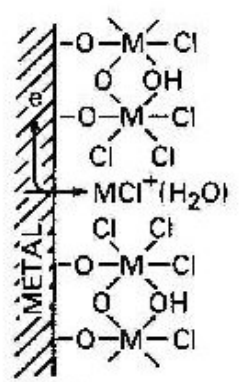

(b)

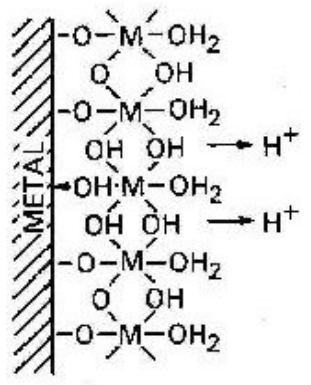

\{a'\}

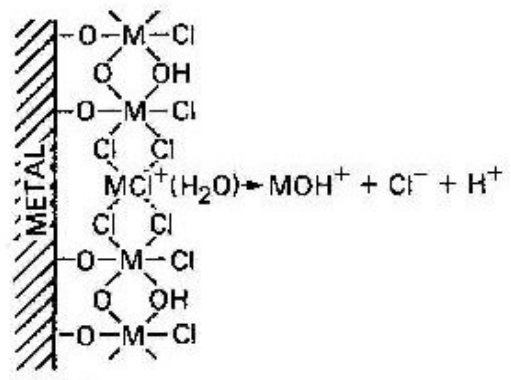

(b')

Figura 6. Os íons metálicos dissolvidos através de uma parte do filme não desenvolvida (a) são capturados para formar um filme (a') resultante das ligações em ponte com o grupo $\mathrm{OH}$. Os íons cloreto substituem as moléculas de água (b) prevenindo a reação em ponte (b'), resultando na quebra do filme [66].

\subsubsection{Formação de pites}

Uma vez que os pites desenvolvem-se, eles podem continuar a crescer por mecanismo de auto-alimentação. Um grande número de teorias tem sido proposto para tentar explicar o início da formação dos pites em superfícies perfeitas (superfícies sem defeitos físicos como inclusões ou heterogeneidade na composição) que consideram a iniciação dos pites como resultado de certas interações entre espécies discretas no meio ambiente (como íons cloreto) e a superfície passiva. Dentre essas teorias estão as teorias cinéticas, que explicam a quebra da passividade em termos de adsorção competitiva entre os íons cloreto e oxigênio, e as termodinâmicas que consideram o potencial de pite o potencial no qual o íon cloreto está em equilíbrio com o óxido.

Imagina-se que a propagação dos pites envolve a dissolução do metal e a manutenção de um alto grau de acidez na base do pite pela hidrólise de íons metálicos dissolvidos. O processo da propagação de pites está esquematicamente ilustrado na Figura 7 para pites em aço inoxidável numa solução aerada neutra de cloreto de sódio. 


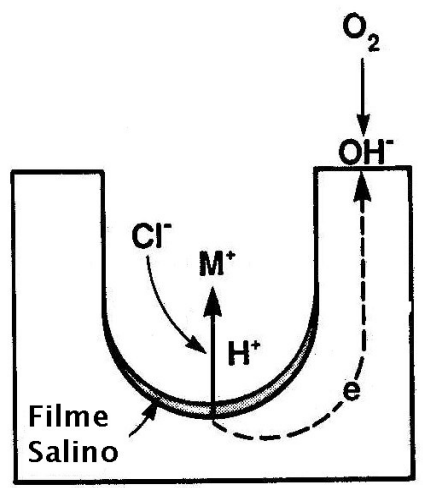

Figura 7. llustração esquemática do mecanismo de crescimento de pites [66].

A reação anódica de dissolução do metal na base do pite:

$$
M \rightarrow M^{+n}+n e,
$$

é balanceada pela reação catódica na superfície adjacente:

$$
\mathrm{O}_{2}+2 \mathrm{H}_{2} \mathrm{O}+4 \mathrm{e} \rightarrow 4 \mathrm{OH}^{-}
$$

$\mathrm{O}$ aumento da concentração de $\mathrm{M}^{+}$dentro do pite resulta na migração dos íons cloreto $\left(\mathrm{Cl}^{-}\right)$para manter a neutralidade. $\mathrm{O}$ cloreto metálico formado, $\mathrm{M}^{+} \mathrm{Cl}^{-}$, é hidrolizado pela água para hidróxido e ácido livre:

$$
\mathrm{M}^{+} \mathrm{Cl}+\mathrm{H}_{2} \mathrm{O} \rightarrow \mathrm{MOH}+\mathrm{H}^{+} \mathrm{Cl}^{-}
$$

A fim de retardar ou prevenir a corrosão, os inibidores da corrosão que atuam pelo efeito barreira, tais como as coberturas orgânicas, de fosfato e outras coberturas de conversão (CC) têm sido empregados [68]. Muitas coberturas orgânicas promovem uma barreira que resiste a penetração de espécies agressivas do ambiente. O objetivo dessas coberturas é prevenir a reação catódica (reação 2) que ocorre embaixo da cobertura. Essas coberturas inicialmente apresentam bons resultados, mas com o tempo o efeito barreira da cobertura tende a diminuir devido a exposição prolongada ao ambiente [69].

As coberturas orgânicas podem desenvolver o que é chamado de "cobertura sobre corrosão", quando em frágeis pontos desenvolvidos abaixo da cobertura (bolhas, buracos e fissuras na superfície) conduz a corrosão. As coberturas protetoras orgânicas, freqüentemente atuam como barreira física, entretanto, às vezes falham na separação da interface cobertura/substrato [70]. Este processo de separação é conhecido como "delaminação", o qual 
conduz ao longo do tempo em uma completa perda das propriedades de barreira das coberturas.

Um típico sistema de cobertura compreende três camadas individuais. A primeira camada é uma cobertura de conversão (CC), uma camada inorgânica muito fina (10 - $60 \mathrm{~nm}$ ) que promove proteção contra a corrosão e melhora a adesão entre o substrato e o "primer", que é a segunda camada. O "primer" (com espessura entre $5-20 \mathrm{~nm}$ ) é o promotor principal da proteção contra a corrosão, assumindo funções similares da cobertura de conversão e, freqüentemente, é composto de uma matriz de resina orgânica pigmentada. Finalmente, uma camada superior ("top coat") é aplicada para servir como a barreira principal contra as influências ambientais e raios ultravioleta. Uma típica camada superior (topcoat) consiste de resinas a base de poliuretana.

O cromo hexavalente $\left(\mathrm{Cr}^{+6}\right)$, um material de pré-tratamento típico é um excelente inibidor da corrosão. $\mathrm{O} \mathrm{Cr}^{+6}$ é usado em coberturas de conversão de cromato (CCC) e primers [71]. Entretanto, esta substância $\left(\mathrm{Cr}^{+6}\right)$ é conhecida como carcinogênica [72] e seu uso altamente

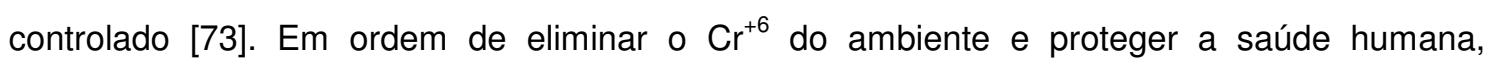
medidas alternativas são necessárias para substituir as coberturas orgânicas que possuem tempo de vida útil limitado e/ou são prejudiciais ao ambiente [74, 75].

Nas últimas décadas, tem sido publicado vários trabalhos que evidenciam que os polímeros condutores, especificamente PAni pode inibir a corrosão metálica. Isso foi reportado primeiramente por DeBerry em1985 [76] e por Ahmad et al. em 1987 [77]. Esses resultados mostram que PAni eletrodepositada sobre aço passivado em um ambiente fortemente ácido aumenta sua proteção contra a corrosão. No decorrer as investigações, a PAni tem sido preferida devido a facilidade de polimerização, excelente estabilidade química e elevada condutividade. Inúmeros trabalhos têm sido publicados sobre a proteção contra a corrosão de aços por polianilina [78-83]. Na ausência de camadas superiores de tinta, a PAni desdopada (não condutora) demonstra ser uma cobertura de melhor resistência a corrosão do que a forma dopada [80]. Isso se deve a formação de uma camada de $\mathrm{Fe}_{2} \mathrm{O}_{3}$, evidenciada em análises de XPS (Espectroscopia Fotoeletrônica de Raios-X).

Várias estudos adicionais têm demonstrados a eficiência de PAni em inibir a corrosão do aço. Santos et al. [81] observaram a proteção contra a corrosão do aço inoxidável e aço 
carbono recobertos com PAni quimicamente sintetizada em solução de $\mathrm{NaCl} 3 \%$. Lu et al. [78] mostraram que amostras de aço cobertas com PAni expostas a atmosfera salina artificial e $\mathrm{HCl}$ diluído exibem maior tempo de proteção contra a corrosão do que quando uma tinta de epóxi é empregada. As áreas expostas da barra metálica mostraram que o aumento da proteção contra a corrosão é devido à uma camada passiva de óxido de ferro. Wessling e Posdorfer [84] empregaram várias técnicas como MEV e XPS e mostraram que uma tinta contendo PAni dispersa (CORRPASSIV ${ }^{\mathrm{TM}}$ ) pode induzir o efeito de passivação como um primer de prevenção a corrosão $[84,85]$. Samui et al. [86] relataram o uso de uma tinta contendo PAni como pigmento para prevenção contra a corrosão. A tinta demonstrou apreciável resistência contra a corrosão em espessuras de $80 \pm 5 \mu \mathrm{m}$ sem a utilização de uma camada superior ("top coat").

Diferentes mecanismos de proteção contra a corrosão metálica por PAni estão propostos na literatura. Wessling [87] propôs etapas em um mecanismo para explicar a proteção contra a corrosão nas quais a proteção do aço por PAni é atribuída a formação de uma camada passiva de óxido metálico. Enquanto, Kilen et al. [83] propuseram que a propriedade eletroquímica dos polímeros condutores eletroativos é responsável pela proteção anódica dos substratos metálicos e também, na estabilidade das coberturas poliméricas a partir do deslocamento da reação catódica. Assim, a proteção anódica ocorre por deslocamento do potencial de corrosão para região passiva do metal no eletrólito de interesse. A reação proposta entre a forma oxidada do polímero $\left(P C E{ }^{m+)}\right.$ e o metal (M) é:

$$
\frac{1}{n} M+\frac{1}{m} P C E^{m+}+\frac{y}{m} H_{2} O \rightarrow \frac{1}{n} M(O H)_{y}^{(n-y)+}+\frac{1}{m} P C E^{0}+\frac{y}{n} H^{+}
$$

O PCE pode ser reoxidado pelo oxigênio atmosférico ou dissolvido:

$$
\frac{m}{4} \mathrm{O}_{2}+\frac{m}{2} \mathrm{H}_{2} \mathrm{O}+P C E^{0} \rightarrow P C E^{m+}+m \mathrm{OH}^{-}
$$

Um outro mecanismo sugere o deslocamento da interface eletroativa a partir da interface metal/solução para a interface polímero/solução, o que altera o estado passivo do metal [88]. Neste mecanismo é considerado que ambos, o gradiente de concentração de $\mathrm{O}_{2}$ no outro lado da camada de PAni e a condutividade eletrônica dessas camadas, promovem a reação catódica preferencialmente, na interface polímero/solução ao invés de na interface 
metal/solução. Esta separação das reações anódicas e catódicas impede o aumento no pH da superfície metálica e, deste modo, mantém os óxidos estáveis como, $\mathrm{Fe}_{3} \mathrm{O}_{4}, \gamma-\mathrm{Fe}_{2} \mathrm{O}_{3}$ e $\alpha$ $\mathrm{Fe}_{2} \mathrm{O}_{3}$.

O deslocamento da reação catódica pela cobertura ocorre quando a redução catódica do $\mathrm{O}_{2}$ ocorre na interface metal/polímero causando um aumento no $\mathrm{pH}$ local:

$$
2 \mathrm{H}_{2} \mathrm{O}+\mathrm{O}_{2}+4 e^{-} \rightarrow 4 \mathrm{OH}^{-}
$$

Quando esta reação ocorre na periferia de uma ranhura, buraco ou poro, o aumento no pH diminui a adesão do polímero e o deslocamento da reação ocorre. O polímero condutor eletrônico minimiza este processo por promover a reação catódica preferencialmente sobre esta superfície do que na interface metal/polímero. O polímero condutor atua primeiro como um eletrocatalítico sendo reduzido:

$$
P C E^{m+}+m e^{-} \rightarrow P C E^{0}
$$

então reoxidado

$$
\frac{m}{4} \mathrm{O}_{2}+\frac{m}{\mathbf{2}} \mathrm{H}_{2} \mathrm{O}+P C E^{0} \rightarrow P C E^{m+}+m O H^{-}
$$

A reação catódica global é dada por:

$$
2 \mathrm{H}_{2} \mathrm{O}+\mathrm{O}_{2}+4 e^{-} \rightarrow 4 \mathrm{OH}^{-}
$$

Embora nesse mecanismo o sal esmeraldina (forma dopada da PAni) limite o aumento do $\mathrm{pH}$ na interface polímero/metal, o valor menor do $\mathrm{pH}$ da interface aumenta a estabilidade para o deslocamento catódico e desacelera a velocidade de corrosão comparado as coberturas convencionais.

Contudo, existe uma concordância de que PAni apresenta bons resultados em retardar a corrosão do aço, apesar do mecanismo para este processo ainda está sob investigação. Várias considerações têm sido sugeridas para o mecanismo de proteção contra a corrosão usando os polímeros condutores, especificamente PAni: (a) PAni contribui para a formação de um campo elétrico na superfície metálica, restringindo o fluxo de elétrons do metal ao oxidante; (b) PAni forma um filme denso, fortemente aderente, de baixa porosidade similar a uma cobertura de 
barreira; (c) PAni promove a formação de camadas protetoras de óxidos metálicos sobre uma superfície metálica [89].

Mas ainda existem controvérsias sobre a forma de PAni (dopada ou desdopada) que promove melhor proteção contra a corrosão, sendo que vários estudos têm demonstrado que a forma de PAni desdopada pode resultar melhor do que a forma dopada de PAni [90]. Epstein [9] mostrou que amostras de aço resfriado a frio e ferro recobertos com PAni na forma desdopada (base esmeraldina) exibiram corrosão quando expostas à umidade em câmaras de umidade no período de 1 a 7 dias. As análises por XPS das amostras evidenciaram uma proteção anódica.

Várias formulações de PAni têm sido também investigadas por suas propriedades inibidoras da corrosão. PAni dopada com ácido lignosulfônico foi investigada como uma cobertura dispersível em água para proteção contra a corrosão [91]. Recentemente, Moraes et al. [92] estudaram a proteção contra a corrosão de PAni eletrodepositada sobre aço inoxidável a partir de soluções tampão fosfato em diferentes valores de $\mathrm{pH}$. A eficiência de PAni em proteger o aço inoxidável em meio de cloreto foi devido a formação de espécies fosfato insolúveis, aliado também a capacidade redox da PAni.

Uma alternativa á cobertura de PAni convencional tem sido a utilização de multicamadas de PAni, Ppy [93] e de PAni obtida a partir de diferentes eletrólitos [94], eletropolimerizadas sobre aço carbono e inoxidável para a proteção contra a corrosão metálica. Segundo, os autores [93,94] as multicamadas são mais eficientes em proteger a superfície metálica, especificamente na proteção contra a corrosão por pites.

\subsection{Blendas de PAni-DBSA contra a corrosão}

Alguns estudos sobre as propriedades inibidoras da corrosão metálica por PAni dopada com ácido dodecilbenzenosulfônico (DBSA) estão reportados na literatura [95-97]. Nesses estudos, a PAni foi quimicamente polimerizada a partir de ácidos inorgânicos (por exemplo: ácido clorídrico), desdopada e posteriormente re-dopada com DBSA. 
Tabela 1. Parâmetros eletroquímicos extraídos de diferentes estudos sobre a proteção contra a corrosão de blendas de PAni-DBSA

\begin{tabular}{|c|c|c|c|c|}
\hline $\begin{array}{c}\text { Meio } \\
\text { corrosivo }\end{array}$ & Amostras & - $E_{\text {corr }} / V$ & $\mathrm{i} / \mu \mathrm{A} \mathrm{cm}$ & Referências \\
\hline $\mathrm{NaCl} 3 \%$ & $\begin{array}{c}\text { Ferro } \\
\text { Fe/PAni-DBSA/epoxi }\end{array}$ & $\begin{array}{l}0,631 \\
0,366\end{array}$ & $\begin{array}{l}73,96 \\
37,24\end{array}$ & [95] \\
\hline $\mathrm{NaCl} 3,5 \%$ & $\begin{array}{c}\text { Aço doce } \\
\text { PAni desdopada } \\
\text { PAni-DBSA/epoxi }\end{array}$ & $\begin{array}{l}0,57 \\
0,49 \\
0,63\end{array}$ & $\begin{array}{c}3,45 \\
4,8 \\
1,1\end{array}$ & \multirow[t]{2}{*}{ [96] } \\
\hline $\mathrm{HCl} 0,1 \mathrm{M}$ & $\begin{array}{c}\text { Aço doce } \\
\text { PAni desdopada } \\
\text { PAni-DBSA/epoxi }\end{array}$ & $\begin{array}{l}0,46 \\
0,47 \\
0,49\end{array}$ & $\begin{array}{l}11,1 \\
13,7 \\
14,4\end{array}$ & \\
\hline
\end{tabular}

Os filmes de PAni dopada com DBSA e suas blendas foram formados a partir de uma solução em N-metil-pirrolidona (NMP) e por "casting solution" depositados sobre a superfície de ferro, aço doce e aço resfriado a frio e em alguns casos recobertos com resina epoxi [95-97]. A Tabela 1 descreve os resultados obtidos pelos diferentes autores para as blendas de PAniDBSA. Para o metal recoberto variações no potencial de corrosão de cerca de 45 a $60 \mathrm{mV}$ são observadas, além de aumentos nos valores de densidade de corrente de corrosão, comparados ao do metal sem revestimento, indicando a ocorrência de um aumento de área e deslocamento das reações redox devido a presença do filme. Comparativamente, esses resultados são divergentes e evidenciam as diferenças das propriedades dos filmes, tais como condutividade, permeabilidade, natureza do óxido e composição (contra-íon) dos materiais, além do meio corrosivo.

Estudos sobre PAni eletropolimerizada sobre aço, em específico aço inoxidável, a partir de soluções de DBSA ainda não estão descritos em literatura, assim como, sobre os efeitos inibidores da corrosão metálica pelos filmes eletropolimerizados. Todavia, em um recente estudo sobre a interface polímero/substrato Prissanaroon et al. [31] eletropolimerizaram filmes de polipirrol sobre aço inoxidável a partir de solução aquosa de DBSA. Os autores analisaram a interface polímero/substrato por diferentes técnicas, concluindo que durante a polimerização há a formação de: (i) uma camada rica em $\mathrm{Fe}_{2} \mathrm{O}_{3}$ devido à dissolução do eletrodo e (ii) uma outra camada fina de DBSA na região interfacial entre o polímero e o substrato. Os autores visaram o 
estudo da região de interface, não se preocupando com as propriedades inibidoras da corrosão promovidas pelo filme.

\subsection{PAni-CMC contra a corrosão}

Os compósitos de polímeros condutores e isolantes podem exibir boas propriedades mecânicas associadas à boa propriedade elétrica. Nos últimos anos, muitos grupos de pesquisa tem estudado a atividade anticorrosiva de materias contendo polipirrol, PAni e suas blendas ou compósitos [98-102]. Entretanto, cabe ressaltar que as propriedades protetoras dos filmes poliméricos são dependentes das condições de sínteses, tais como eletrólito, método de preparação, etc.

Uma revisão na literatura sobre o uso de PAni-CMC como inibidor da corrosão metálica é inexistente até o momento. Contudo, é encontrado um estudo sobre filmes compósitos de polipirrol e CMC, como revestimento contra a corrosão, cuja revisão propiciou a base do estudo de PAni-CMC, desde a eletropolimerização até a aplicação contra a corrosão.

Herrasti et al. [60], eletropolimerizaram compósitos de polipirrol e CMC sobre aço inoxidável a partir de solução aquosa de $\mathrm{LiClO}_{4} 0,25 \mathrm{~mol} \mathrm{~L}^{-1}$, contendo $0,1 \mathrm{~mol} \mathrm{~L}^{-1}$ de CMC e $0,25 \mathrm{~mol} \mathrm{~L}^{-1}$ de pirrol pelos métodos galvanostático e potenciostático. A preparação desses filmes visaram prevenir os processos de corrosão do aço em meio de $\mathrm{NaCl}$. Entretanto, os autores não descrevem a influência da concentração de reagentes sobre a eletropolimerização dos filmes, o qual para PAni-CMC deve ser alvo de análise no presente estudo. Em contrapartida, observaram que para baixas densidades de corrente os filmes são mais uniformes e apresentam boa estabilidade contra a corrosão. Quando altas densidades de correntes são usadas para a eletropolimerização, os filmes não são estáveis e não protegem o metal contra a corrosão. Todavia, os filmes depositados potenciostaticamente são mais estáveis e protegem o aço contra a corrosão. Esses filmes deslocam o potencial de corrosão $\left(E_{\text {corr }}\right)$ em cerca de $250 \mathrm{mV}$ e, mesmo após serem submetido a um tratamento térmico a 150 ${ }^{\circ} \mathrm{C}$, os filmes compósitos permanecem estáveis e protetores. Para o estudo de PAni-CMC o método potenciodinâmico (VC) será utilizado, o qual, não foi utilizado por Herrasti et al. [60] e, é freqüentemente citado em literatura como o mais viável à formação de filmes mais aderentes a superfície do substrato [103]. 
Segundo os autores [60], a densidade de corrente de corrosão do aço recoberto com PPy-CMC aumenta, quando comparado ao do aço sem recobrimento, sendo este aumento atribuído á (i) variação do filme polimérico para a forma mais condutora e, também (ii) devido as reações redox acontecerem sobre a matriz polimérica, as quais contribuem para aumentar a densidade de corrente do processo. Em relação à taxa de corrosão, estimada por análise gravimétrica, não foi observada variação devido as massas das amostras de aço recobertas com PPy e PPy-CMC serem similares. Na determinação da taxa de corrosão, o interessante é que, a massa para o aço recoberto com PPy-CMC apresenta um valor similar ao do aço recoberto com PPy, indicando que: (i) pode haver perda de massa no revestimento e assim, variação na composição dos filmes após o ensaio de corrosão, ou (ii) a metodologia adotada é imprópria para estimar a taxa de corrosão dos eletrodos recobertos. Assim, no estudo de PAniCMC pretende-se estudar esses pontos e analisar as composições dos filmes.

O recobrimento total da superfície metálica é um dos mais importantes parâmetros para prevenção contra a corrosão. Os autores [60] relatam não haver diferenças no recobrimento da superfície do aço quando os filmes de PPy e PPy-CMC são os revestimentos. A imersão das amostras de aço recoberto com PPy -CMC em solução de $\mathrm{NaCl} 3 \%$, durante um longo tempo, não altera a morfologia do polímero. Em continuidade, afirmam que uma análise quantitativa da proteção contra a corrosão promovida por filmes de PPy-CMC se torna díficil devido à complexidade do sistema como um todo (o próprio processo de corrosão e as variáveis envolvidas). Diante disto, é descrita uma análise qualitativa do sistema, na qual é considerada a estrutura do material: (i) filmes de PPy e PPy-CMC têm uma estrutura globular, com diferenças intersticiais entre os glóbulos, menores no caso de PPy-CMC; (ii) o aço inoxidável recoberto com PPy-CMC apresenta uma diminuição da área efetiva exposta ao meio corrosivo. Contudo, é evidente que a presença de CMC nos filmes compósitos conduz a um efeito barreira mais eficiente, conseqüência de uma morfologia com menos interstícios, ou seja com menos poros. Assim, para o estudo de PAni-CMC serão analisados a influência da concentração de CMC na morfologia dos compósitos e sua correlação aos efeitos protetores contra a corrosão. 


\section{Objetivos}

Com base no fato de que blendas e compósitos de PAni apresentam boa resistência mecânica, elevada condutividade e, de um modo geral, melhores propriedades do que os polímeros componentes isoladamente, essa nova classe de material mereceu ser alvo de investigação. Sendo assim, o presente trabalho tem como objetivo geral sintetizar, caracterizar e analisar as blendas ou compósitos de polianilina com carboximetilcelulose e dodecilbenzeno sulfônico (DBSA) e aplicá-las como agentes protetores contra a corrosão.

As metas que constituíram este estudo foram:

a) Polimerização de PAni em presença de (a) carboximetilcelulose e ácido fosfórico e, (b) em presença de ácido dodecilbenzeno sulfônico. Para tal, foram utilizados os métodos de polimerização químico e eletroquímico;

b) Análise da influência da concentração de CMC, DBSA e do monômero nas condições de síntese eletroquímica e química do material polimérico, com consequente otimização da metodologia de obtenção dos materiais;

c) Determinação das características dos materiais poliméricos resultantes por diferentes técnicas ((espectroscopia no UV-Vis-NIR e no infravermelho), medidas de condutividade (método quatro pontas), morfológica por MEV, resposta eletroquímica, análise termogravimétrica (TG));

d) Estabelecimento das diferenças nas propriedades finais dos polímeros induzidas pela presença da CMC e de DBSA, mediante a análise dos resultados obtidos por diferentes técnicas;

e) Análise da viabilidade de uso dos materiais poliméricos como revestimento do aço inoxidável, para proteção contra a corrosão, realizando estudos comparativos, para determinar o sistema com maior eficiência em meio de $\mathrm{NaCl} 3 \%$. 


\section{Capítulo II}

\section{Experimental}

Neste capítulo estão descritos os diferentes reagentes, materiais e o procedimento experimental utilizados para a realização das sínteses (química e eletroquímica). Também, são relatadas as técnicas, e os respectivos procedimentos experimentais, empregadas para a caracterização dos materiais poliméricos; bem como, para a realização dos ensaios de corrosão.

\section{2.a. Reagentes e soluções}

Os reagentes utilizados para a sintetizar e caracterizar os polímeros são descritos a seguir.

- Ácido fosfórico $-\mathrm{H}_{3} \mathrm{PO}_{4}$ (Mallinckrodt - 85\%);

- Àcido 4-dodecilbenzenosulfônico - DBSA (Fluka - mistura de isômeros $\approx 90 \%$ )

- Ácido clorídrico - $\mathrm{HCl}$ (Synth - 36,5-38\%);

- Ácido sulfúrico $-\mathrm{H}_{2} \mathrm{SO}_{4}$ (Mallinckrodt - 98\%);

- Hidróxido de amônio $-\mathrm{NH}_{4} \mathrm{OH}$ (Synth $-28-30 \%$ );

- Hidróxido de sódio - $\mathrm{NaOH}$ (Merck - 99\%);

- 1-metil-2-pirrolidona - NMP (Aldrich - 99\%);

- Carboximetilcelulose sódica (CMC) (Synth - U.S.P.);

- $\quad$ Cloreto de sódio - $\mathrm{NaCl}$ (Mallinckrodt - 99,7\%)

Todos os reagentes foram de alto grau de pureza e usados como recebidos, com exceção do monômero de anilina $-\mathrm{C}_{6} \mathrm{H}_{5} \mathrm{NH}_{2}$ (Mallinckrodt - 99,5\%) que foi destilado sob pressão reduzida, em presença de óxido de zinco em pó, e mantido a temperatura entre 0 a $4{ }^{\circ} \mathrm{C}$. 
Tabela 2. Composição nominal e a obtida por análise de EDX do aço inoxidável AISI-304 em \% atômica

\begin{tabular}{l|c|c|c|c|c}
\hline & $\mathrm{Cr}$ & $\mathrm{Ni}$ & $\mathrm{C}$ & $\mathrm{Si}$ & $\mathrm{Fe}$ \\
\hline Nominal $\left({ }^{*}\right)$ & 19 & 9,0 & 0,08 máx & - & restante \\
\hline EDX $\left(^{* *}\right)$ & 19,6 & 9,40 & - & 0,60 & 70,4 \\
\hline
\end{tabular}

$\left(^{*}\right)$ dados da referência [104]; $\left.{ }^{* *}\right)$ valores médios de dois pontos na amostra.

Todas as soluções eletrolíticas foram preparadas com água obtida de um sistema de purificação MILLI-Q da Millipore (Ultra-Pure Water System).

\section{2. b. Célula eletroquímica e eletrodos}

Os eletrodos e a célula eletroquímica utilizados para sintetizar os polímeros estão representados na Figura 8 e são:

(a) Célula eletroquímica: de único compartimento, construída em vidro Pyrex ${ }^{\circledR}$ com uma tampa de Teflon $^{\circledR}$ com múltiplas perfurações para acoplamento dos eletrodos, um termômetro e entrada e saída de gás, conforme o esquema na Figura 8.

Eletrodos de trabalho: (b) chapa de platina (Pt) e (c) disco de aço inoxidável (AISI-304) com área geométrica $1,0 \mathrm{~cm}^{2}$ e $0,95 \mathrm{~cm}^{2}$, respectivamente. Os eletrodos de aço inoxidável foram embutidos em resina acrílica comercial. Todos os contatos foram feitos com fio de cobre soldados.

(d) Contra eletrodo constituído de chapa de Pt com área geométrica de $4,12 \mathrm{~cm}^{2}$ (considerando os lados da chapa).

(e) Eletrodo de referência utilizado foi de calomelanos saturado (ECS).

A confirmação da classificação do aço inoxidável como AISI-304 foi constatada após análise local de composição realizada por EDX (conforme descrito na Tabela 2). 
(a)

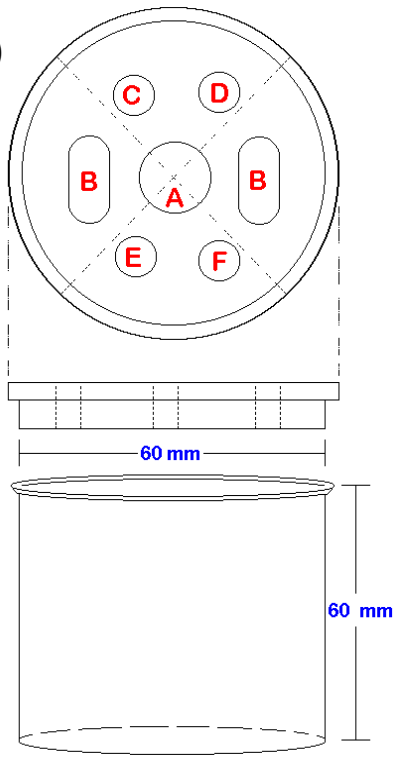
A. Eletrodo de trabalho
B. Contra-eletrodo
C. Eletrodo de referência
D. Termômetro
E. Entrada de gás
F. Saída de gás
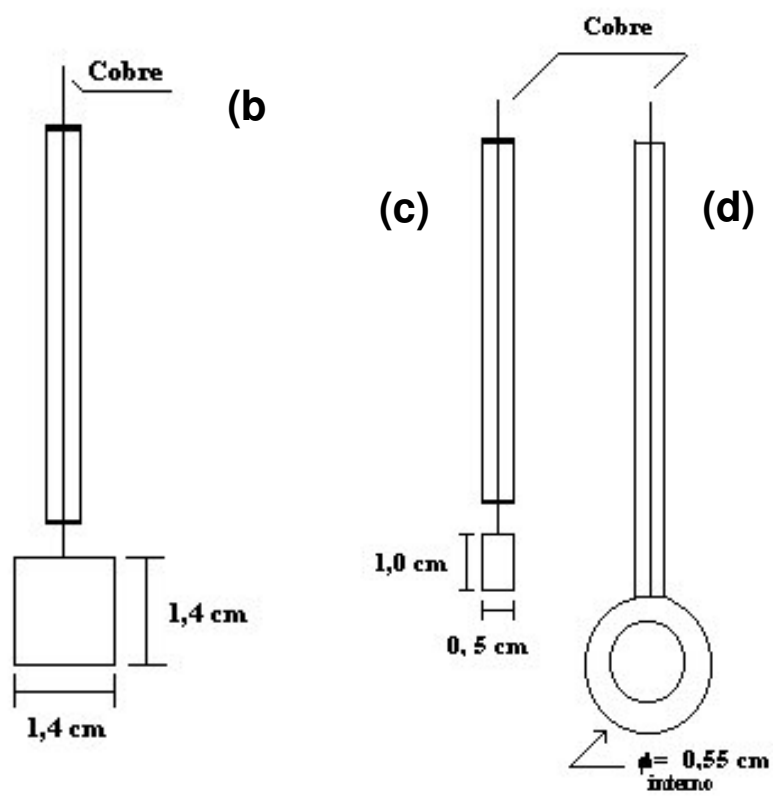

Figura 8. Esquema da (a) célula eletroquímica; do (b) contra-eletrodo de platina e dos eletrodos de trabalho de (b) platina e (c) aço inoxidável utilizados nos experimentos.

\section{2.c. Limpeza dos eletrodos, dos materiais de vidro e de Teflon ${ }^{\circledast}$}

Os eletrodos de trabalho e contra eletrodo de Pt foram expostos repetidamente a uma chama oxidante e imersão em água a temperatura de $25^{\circ} \mathrm{C}$. Este procedimento tem por finalidade a remoção de resíduos ácidos e orgânicos sobre a superfície metálica.

Sucessivas lavagens com água a temperatura de $25^{\circ} \mathrm{C}$ foram realizadas no eletrodo de referência para sua limpeza.

Os eletrodos de aço inoxidável foram polidos mecanicamente com lixas de silício carbono de granulometria de 100 a 1200 mesh. Posteriormente, o desengraxamento em etanol e lavagens com água foram realizadas em um sonicador . 


\subsection{Procedimento da síntese eletroquímica.}

Para eletropolimerizar os polímeros foram preparadas soluções aquosas de $\mathrm{H}_{3} \mathrm{PO}_{4}$ $1 \mathrm{~mol} \mathrm{~L}^{-1}$ contendo CMC de concentração de 0,1 a $1 \%$ em peso e anilina na concentração de 0,1 a $0,5 \mathrm{~mol} \mathrm{~L}^{-1}$. Também, para eletropolimerizar polianilina em presença de DBSA foram preparadas soluções aquosas de DBSA de concentrações entre 0,04 a $0,1 \mathrm{~mol} \mathrm{~L}^{-1}$ contendo anilina na concentração de 0,01 a $0,1 \mathrm{~mol} \mathrm{~L}^{-1}$

\subsubsection{Eletropolimerização sobre eletrodo de platina}

Para as eletropolimerizações dos polímeros sobre platina em presença de CMC ou DBSA, o intervalo de potencial empregado foi de $-0,2$ a $0,8 \vee$ e, este foi mantido invariável durante os demais ciclos de potenciais.

\subsubsection{Eletropolimerização sobre eletrodo de aço inoxidável}

Para as eletropolimerizações dos polímeros em presença de CMC sobre aço inoxidável o intervalo de potencial empregado, determinado empiricamente, consistiu de:

- Três ciclos de potenciais de $-0,6$ a $1,4 \mathrm{~V}$, processo de formação dos núcleos do polímero sobre a superfície do eletrodo.

- Demais ciclos de $-0,2$ a 1,2 V.

Por outro lado, para eletropolimerizar dos polímeros em presença de DBSA sobre aço inoxidável o intervalo de potencial empregado foi:

- Um ciclo de potencial de $-0,6$ a 1,5 V;

- Demais ciclos de $-0,2$ a 0,8 V.

As variações nos limites de potenciais foram adotadas para que fosse promovido aderência do filme a superfície do eletrodo.

Todas as sínteses foram realizadas a temperatura de $20 \pm 2^{\circ} \mathrm{C}$, empregando a técnica de voltametria cíclica, a velocidade de varredura de $50 \mathrm{mV} \mathrm{s}^{-1}$, com um potenciostato/galvanostato da EG\&G/PAR modelo 273A, acoplado a um microcomputador para a aquisição dos dados feita pelo programa M270 da EG\&G/PAR. 

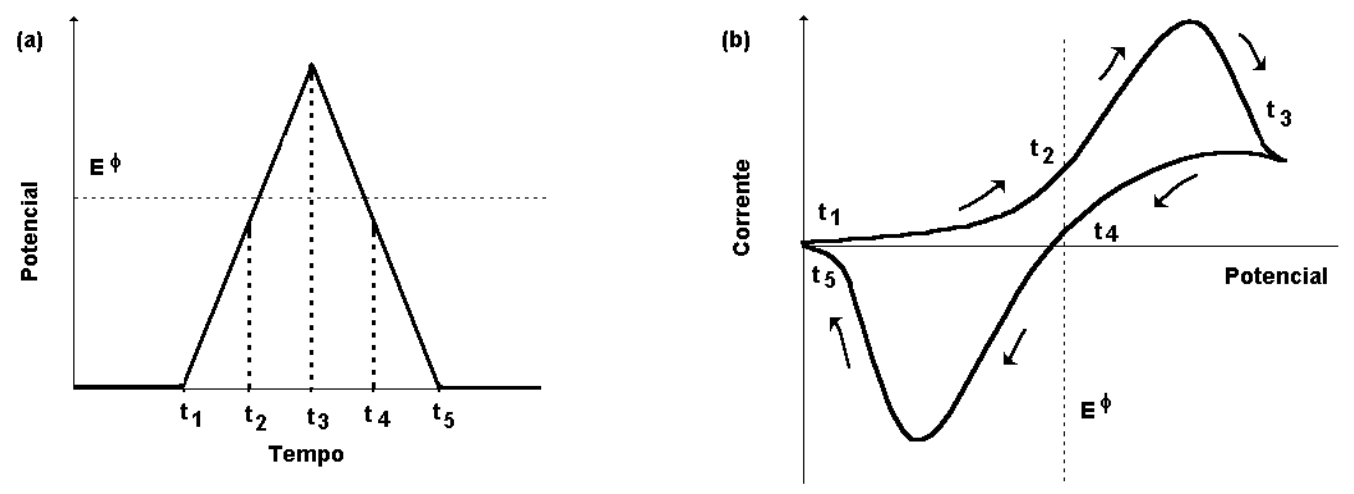

Figura 9. (a) Variação do potencial com o tempo e (b) curva resultante da corrente por potencial em um experimento de voltametria cíclica.

\subsubsection{Voltametria cíclica}

A cinéticas de processos eletródicos é comumente estudada por voltametria cíclica [105 106], a qual se trata de uma técnica em que a corrente é monitorada enquanto que o potencial do eletrodo de trabalho é variado no tempo. A Figura. 9(a) ilustra o voltamograma cíclico (VC), na qual o potencial é variado linearmente entre $E_{1}$ e $E_{2}$ e em seguida, entre $E_{2}$ e $E_{1}$. A taxa de variação do potencial com o tempo é conhecida como velocidade de varredura de potencial.

Um VC pode fornecer indicações da reversibilidade das reações de transferência de elétrons, das reações de transferências de elétrons precedidas ou seguidas por reações químicas, relativamente lentas e dos efeitos de adsorção [105]. Quando um estudo de voltametria cíclica é realizado para um sistema (Figura 9(b)), inicialmente o potencial é baixo e a corrente catódica é devida a migração de íons em solução.

Entretanto, quando o potencial aproxima-se do potencial de redução das espécies em solução, a corrente catódica aumenta. Logo após o potencial exceder ao potencial de redução, uma rápida variação na corrente acontece devido à elevada concentração de espécies oxidáveis nas proximidades do eletrodo. Quando o potencial aproxima-se do potencial requerido para oxidar as espécies reduzidas, ocorre o aparecimento de valores de corrente substanciais, até que toda oxidação se complete, e a corrente retorna a zero [106].

Entre as várias aplicações da técnica de voltametria cíclica, sua utilização nos estudos envolvendo polímeros condutores é de grande importância Esta técnica fornece vários 
parâmetros relacionados aos estágios de crescimento e pode proporcionar um excelente controle sobre a qualidade dos polímeros [107].

\subsection{Procedimento da síntese química}

\subsubsection{Procedimento da síntese química}

Os polímeros em presença de CMC obtidos quimicamente, foram preparados como descritos por Moraes et al. [108], com algumas modificações. Por este método, duas soluções forem preparadas:

- Solução A: 6,7091 g de persulfato de amônio $\left(\left(\mathrm{NH}_{4}\right)_{2} \mathrm{~S}_{2} \mathrm{O}_{8}\right)$ foram dissolvidos em $10 \mathrm{~mL}$ de água ultra pura.

- Solução B: $3,0 \mathrm{~mL}$ de anilina dissolvidos em $130 \mathrm{~mL}$ de solução aquosa $1 \mathrm{~mol} \mathrm{~L}^{-1} \mathrm{H}_{3} \mathrm{PO}_{4}$, contendo CMC em diferentes concentrações $(0,1$ a $1 \% \mathrm{~m} / \mathrm{v})$

A solução A foi acondicionada em um condensador com uma torneira adaptada, enquanto que a solução B foi colocada em uma célula de vidro Pirex ${ }^{\circledR}$ encamisada (capacidade total de $250 \mathrm{~mL}$ ), conforme o esquema da Figura 10. Ambas soluções foram mantidas a $20^{\circ} \mathrm{C}$ por cerca de 10 minutos antes do início da síntese, através de um sistema de circulação de um banho termostatizado ligado a ambos os recipientes.

A solução B foi mantida sob agitação constante por meio de um agitador mecânico, enquanto que a solução $A$ era adicionada lentamente $\left(30 \mathrm{~mL} \mathrm{~min}{ }^{-1}\right)$ à solução $B$. A variação do potencial de circuito aberto e da temperatura do sistema foram constantemente monitoradas [109]. A imersão de um eletrodo de trabalho $(\mathrm{Pt})$ e um eletrodo de referência (ECS) no recipiente de reação permitiu monitorar a variação do potencial durante a síntese e, com o auxílio de um termômetro digital (modelo MT-520 da Minipa), a variação de temperatura foi acompanhada.

A síntese foi interrompida quando o potencial de circuito aberto atingiu um valor aproximadamente constante, o qual ocorreu quando decorrido 30 minutos de polimerização. 0 polímero precipitado (de cor azul-escuro) foi filtrado com um funil de Buchner $(9 \mathrm{~cm}$ de diâmetro, papel de filtro $n^{\circ} 5$ - Whatmann), com o auxílio de um sistema de filtração a vácuo. 
(1) Banho termostatizado.

(2) Agitador magnético.

(3) Célula de vidro Pirex ${ }^{\circledR}$ encamisada.

(4) Condensador adaptado com torneira.

(5) Tampa de Teflon perfuradas:

(a) Condensador;

(b) Termômetro;

(c) Eletrodo de trabalho;

(d) Eletrodo de referência.

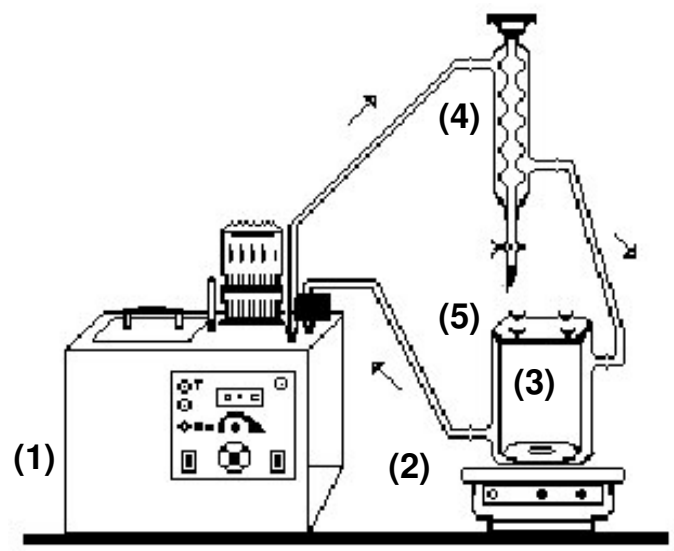

Figura 10. Esquema geral do sistema de polimerização química.

Conjuntamente a filtração, lavagens sucessivas com água foram realizadas, até o filtrado tornar-se incolor. Finalmente, o polímero foi transferido para uma placa de Petri e seco sob vácuo dinâmico, a $40^{\circ} \mathrm{C}$, por 48 horas.

\subsubsection{Técnica de perfil de potencial}

O monitoramento do potencial de circuito aberto e da temperatura de polimerização do meio reacional, durante o processo polimerização oxidativa da anilina, permite a obtenção de curvas potenciométricas e calorimétricas, respectivamente. Mediante a curva potenciométrica monitora-se o estado de oxidação do polímero durante o processo de polimerização química. Esta curva assume um perfil que passa por um máximo e decai rapidamente, estabilizando-se num patamar. O polímero no máximo da curva encontra-se no estado de oxidação pernigranilina (totalmente oxidado). Na região de inflexão da curva ocorre a precipitação de todo o polímero obtido, finalizando a polimerização. Isto foi constatado por alguns autores $[13,14,110]$ quando acompanharam o rendimento em função do tempo de polimerização. Estes estudos mostraram que a pernigranilina é um agente oxidante suficientemente forte para polimerizar o monômero de anilina residual e produzir o polímero no estado de oxidação esmeraldina, enquanto que ela também se reduz para este estado de oxidação intermediário (esmeraldina) [13].

A partir das curvas (calorimétricas e potenciométricas) podem ser obtidos alguns parâmetros relacionados à cinética do processo de polimerização. Estes parâmetros são: (a) 
temperatura máxima $\left(T_{\max }\right)$ : a temperatura máxima atingida no decorrer do processo de polimerização; (b) tempo total de polimerização $\left(t_{\text {total }}\right)$ : tempo decorrido para que o polímero se encontre no estado de oxidação sal esmeraldina; (c) potencial máximo $\left(E_{\max }\right)$ : o maior valor alcançado para o potencial de circuito aberto durante a polimerização; (d) tempo relacionado ao máximo das curvas de potencial e temperatura $\left(t_{\max }\right): 0$ tempo decorrido para se alcançar à temperatura máxima ou o segundo ponto de inflexão da curva de potencial durante a polimerização.

\subsection{Caracterização}

As características físico-químicas dos materiais poliméricos foram observadas por diferentes técnicas, as quais estão descritas a seguir. Assim, foram observadas as possíveis diferenças entre os materiais em função da forma e condições de sínteses.

\subsubsection{Caracterização voltamétrica}

A resposta eletroquímica pode promover informações a respeito da estabilidade do material frente a variação de potencial, uma vez que as transferências de cargas no interior do filme polimérico não são totalmente reversíveis. Assim, as respostas eletroquímica dos materiais poliméricos foram realizadas no intervalo de potencial de $-0,2$ a $0,8 \mathrm{~V}$, a $50 \mathrm{mV} \mathrm{s}^{-1}$ em solução de $\mathrm{H}_{2} \mathrm{SO}_{4} \quad 0,5 \mathrm{M}$, empregando a técnica de voltametria cíclica para observar o comportamento eletroquímico dos polímeros obtidos.

Após as eletropolimerizações dos polímeros sobre Pt, os filmes foram lavados com água e, em seguida, obtida sua resposta eletroquímica.

\subsubsection{Estimativa da espessura dos filmes poliméricos}

Uma estimativa da espessura dos filmes de PAni/CMC e PAni sobre AISI-304 e platina foi realizada a partir da quantidade de carga anódica necessária para a conversão da leucoesmeraldina (LE), a forma reduzida de PAni, para a esmeraldina (EM), a forma oxidada de PAni, conforme representado pela Figura 11. 

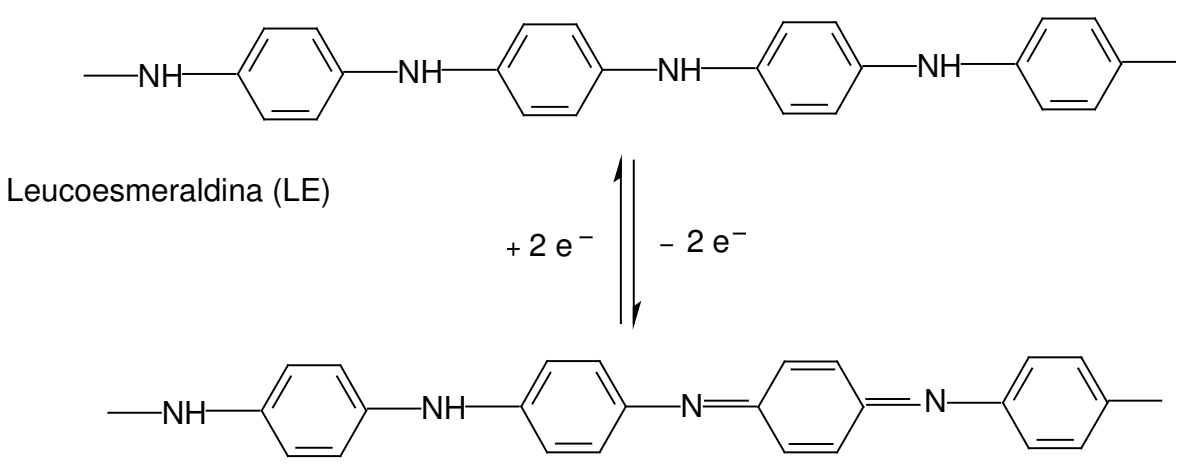

Esmeraldina (LE)

Figura 11. Conversão da leucoesmeraldina (LE), a forma reduzida de PAni, para a esmeraldina (EM), a forma oxidada de PAni.

Esta conversão, no voltamograma cíclico de crescimento de PAni, é atribuída como o pico $A$ e é realizada de acordo com a equação: $d=Q_{A} M_{w} / z F A \rho$, na qual $Q_{A}$ é a carga sob o pico(A) do voltamograma cíclico de crescimento; $M_{w}$ : é a massa molar de anilina, $z=0,5$ (número de elétrons / unidade de anilina), A é a área do eletrodo; $\rho$, a densidade específica de anilina e F: é a constante de Faraday.

A utilização deste método implica na não consideração do fator de porosidade e o volume do contra íon, quanto das moléculas da matriz polimérica (p.ex. CMC e DBSA) e portanto os valores calculados fornecem somente uma estimativa da espessura para efeito de comparação entre si $[100,111,112]$.

\subsubsection{Espectroscopia na região do ultravioleta, do vísivel e do infravermelho próximo} (UV-Vis-NIR)

A espectroscopia na região do ultravioleta $(200-400 \mathrm{~nm})$ e visível $(400-750 \mathrm{~nm})$ e infravermelho próximo (770 a $3000 \mathrm{~nm}$ ) permite visualizar o comportamento eletrônico de determinados materiais, uma vez que os níveis de energia empregados correspondem aos níveis de excitação eletrônica do material. Esses níveis de excitação eletrônica são dependentes dos tipos de elétrons que formam as ligações químicas do composto (os elétrons $\sigma$ absorvem fótons de elevadas energias, enquanto que os elétrons $\pi$ absorvem fótons de baixa energia). 
Nos espectros de PAni e seus derivados pode ser notado um comportamento de mudança na configuração eletrônica do polímero pela adição de ácidos (agentes protonadores). Esta mudança é observada pela diminuição de bandas na região de alta energia (baixos comprimentos de onda) e deslocamentos de bandas em regiões de menores energias (comprimentos de onda altos).

Para realização de estudos espectroscópicos nas regiões do UV-Vis-NIR, as amostras foram preparadas adotando o seguinte procedimento: (a) o polímero foi desprotonado na presença de solução de $\mathrm{NH}_{4} \mathrm{OH} 0,1 \mathrm{~mol} \mathrm{~L}^{-1}$ (processo de desdopagem), permanecendo em contato com a solução de $\mathrm{NH}_{4} \mathrm{OH}$ durante 24 horas; (b) lavagem com água e secagem do polímero em um dessecador sob vácuo dinâmico durante 48 horas; (c) dissolução do polímero em NMP. A dopagem do polímero foi realizada com o agente dopante $\left(\mathrm{HCl} 5 \mathrm{~mol} \mathrm{~L}^{-1}\right)$, adicionado uma gota $(\approx 23 \mu \mathrm{L})$ à solução de polímero minutos antes da análise espectral.

Os espectros de UV-Vis-NIR dos polímeros foram obtidos em um equipamento da VARIAN CARY modelo 2315, utilizando-se cubetas de quartzo com caminho óptico de $1 \mathrm{~cm}$ e como referência (branco), uma solução de NMP isenta de polímero.

\subsubsection{Espectroscopia na região do infravermelho}

A espectroscopia na região do infravermelho é uma técnica de análise utilizada para melhor identificação de um composto, pois é capaz de fornecer informações detalhadas sobre a estrutura do material. A espectroscopia no infravermelho baseia-se nas transições entre níveis de energia nas moléculas, que resultam em vibrações das ligações químicas, ou seja, quando vibrações moleculares resultam em uma mudança no momento de dipolo da ligação, como conseqüência da mudança de distribuição eletrônica na ligação. Por meio de interação com radiação eletromagnética apropriada, ou seja, de comprimento de onda e energia suficiente relativo ao estado fundamental e o primeiro nível de energia vibracional excitado da molécula, é possível estimular a transição entre os níveis de energia vibracionais. Quando a interação ocorre, existe uma absorção da radiação pelo material e então a detecção é feita por diferença entre as intensidades de radiação emitida (inicial) e absorvida (final) na amostra. Desta forma, diversos grupos funcionais podem ser identificados através dos diferentes modos vibracionais das ligações químicas presentes na amostra. 
Os materiais poliméricos, para sua caracterização foram sintetizados de forma análoga aos preparados para a análise de espectroscopia de UV-Vis-NIR. As etapas de lavagem, desdopagem e secagem dos polímeros foram realizadas como descrito na seção 3.3.3. Após estas etapas, o polímero foi levado para trituração em presença de $\mathrm{KBr}$ para confecção de pastilhas que foram utilizadas no equipamento de infravermelho.

Os espectros na região do infravermelho dos polímeros foram obtidos com um equipamento da Bomem, modelo MB-102 com FTIR, com auxílio do programa Spectra Calc.

\subsubsection{Medidas de condutividade}

A condutividade superficial dos polímeros foi determinada pelo método de quatros pontas $[113,114]$. Para a realização das medidas foi utilizado o polímero eletrossintetizado sobre o eletrodo de aço inoxidável. Os filmes foram lavados com água e secos sob vácuo dinâmico por um período de 24 horas. Para as medidas de condutividade dos polímeros quimicamente preparados foram utilizadas pastilhas do polímero. A partir de uma quantidade suficiente de polímero (cerca de 0,5 g) levada a um pastilhador e sob a aplicação de uma pressão de $10 \mathrm{Kgf} \mathrm{cm}^{-2}$ foram obtidas pastilhas de polímero de espessura entre 0,1 a 0,5 cm.

Para a medida de condutividade, o material foi colocado em um dispositivo com quatro contatos elétricos pontiagudos em linha, igualmente separados, que foram mantidos em contato com a superfície das mesmas. Em seguida, uma corrente elétrica, que variou de $\mu \mathrm{A}$ a $\mathrm{mA}$, foi aplicada ao sistema e a diferença de potencial gerada entre os contatos elétricos internos, foi medida. A condutividade $(\sigma)$ superficial da amostra pode então, ser calculada mediante a expressão: $\sigma=(\mathrm{i} \times \ln 2) / \pi \mathrm{dV}$, onde: i é a corrente aplicada; $\mathrm{d}$ : a espessura da amostra e V, o valor da diferença de potencial medido [114]. Para as medidas de condutividade com a técnica de quatro pontas foi utilizada uma fonte de corrente programável KEITHLEY 224 e um multímetro de precisão KEITHLEY 617.

\subsubsection{Microscopia eletrônica de varredura (MEV)}

Os sistemas de análises microscópicas utilizam um microscópio eletrônico, que possibilita a formação de imagem pelo bombardeamento de elétrons na amostra. A imagem desta forma é assim aumentada em até 300.000 vezes e com profundidade de até $10 \mathrm{~nm}$. Essa 
imagem é formada pela varredura de um feixe eletrônico através da amostra em sincronismo com o feixe de varredura dentro do tubo de raios catódicos ao monitor de vídeo, por intermédio de um detector de elétrons secundários ou elétrons retroespalhados.

Os ensaios de microscopia eletrônica de varredura (MEV) foram realizados nos polímeros obtidos química e eletroquimicamente nas mesmas condições descritas das técnicas anteriores. Após estas etapas preparatórias, o contato elétrico foi feito com uma fita de carbono adesiva condutora apropriada para utilização no microscópio. Também, foi realizada a deposição de uma camada de ouro ou carbono, espessura $(20 \mathrm{~nm})$ para melhorar a visualização morfológica da superfície observada.

Para a obtenção da micrografia da blenda PAni-CMC 1\% de CMC um filme com espessura de 22,17 $\mu \mathrm{m}$ foi preparado a partir da dispersão de PAni-CMC. A dispersão foi depositada sobre uma placa de vidro e seca a $40^{\circ} \mathrm{C}$ sob vácuo dinâmico durante 168 horas. Em seqüência, uma camada de ouro de cerca de $20 \mathrm{~nm}$ foi depositada (por "sputtering) sobre a superfície da amostra e as imagens registradas.

A morfologia dos filmes de PAni foi investigada através de microscopia eletrônica de varredura (MEV) utilizando um microscópio ZEISS LEICA modelo DSM 960, operado com um feixe de elétrons de 15 - 20 kV e amplificações de 1000 a 40000 vezes.

\subsubsection{Espectroscopia por energia dispersiva de raio-X (EDX)}

A associação de um espectrômetro de energia dispersiva de raios-x a um microscópio eletrônico de varredura possibilita a análise química da amostra, mediante a medida de energia e da distribuição da intensidade do sinal de raios- $x$, gerado por um feixe de elétrons focado. Durante a colisão inelástica, dos elétrons incidentes do feixe de elétrons podem ser formados raios-x por dois processos distintos: (a) desaceleração do feixe de elétrons no campo coulômbico no interior do átomo, levando a formação de um espectro contínuo de energias de raios-x , do zero ao valor de energia do elétron incidente; (b) interação entre um feixe de elétrons com um elétron de camada interna pode resultar na ejeção de um elétron que deixa o átomo em um estado excitado com uma vacância na camada eletrônica. Isto resulta em uma transição eletrônica que envolve uma mudança de energia que pode se manifestar na forma de raios-x ou elétron ejetado (Auger). 
A energia de raios- $x$ emitidos está relacionada com a diferença na energia de níveis bem definidos do átomo e, esta é referida como raio-x característico. A análise do espectro de EDX se promove em termos da energia em que ocorrem as radiações características (análise qualitativa) e da intensidade relativa dos picos (análise quantitativa). Com a utilização de dados proveniente de um banco de dados, como forma de comparação com a amostra, conduz a uma análise semi-quantitativa. Sendo assim, conjuntamente a análise por MEV houve a possibilidade de ser realizada uma análise semi-quantitativa por EDX, visando observar a composição local do filme em áreas definidas.

Para as análises foi utilizado um microscópio ZEISS LEICA modelo DSM 960, operado com um feixe de elétrons de 15 - 20 kV acoplado a um espectrômetro de dipersão de raios-X, Oxford 7060 de 133 eV de resolução.

\subsubsection{Análise termogravimétrica (TG)}

A termogravimetria (TG) é um ramo da análise térmica que avalia a mudança de massa de um material em função da temperatura ou em função do tempo. A TG é usada para caracterizar a decomposição e estabilidade térmica sob condições variadas e para examinar a cinética de processos físicos e químicos ocorridos na amostra. As características sobre a mudança de massa da amostra são bastante dependentes das condições experimentais empregadas. Fatores como a massa da amostra, volume, forma (líquido, pó, uma ou várias partículas) e modo de disposição do suporte de amostra, a natureza e a pressão da atmosfera utilizada e o monitoramento de análise, têm influência sobre as características da curva termogravimétrica [115].

A termogravimetria acompanha a variação de propriedade física permitindo observar a perda de massa da amostra em função da temperatura. Para que se tenham resultados apropriados é preciso que se originem produtos de decomposição térmica voláteis, ou que ocorra incorporação de átomos ou moléculas, provenientes dos gases da atmosfera do forno, respectivamente, aumentando ou diminuindo a massa original da amostra [116]. Assim, a TG promove informações sobre a da perda de massa relacionada a um processo de degradação térmica da amostra. 


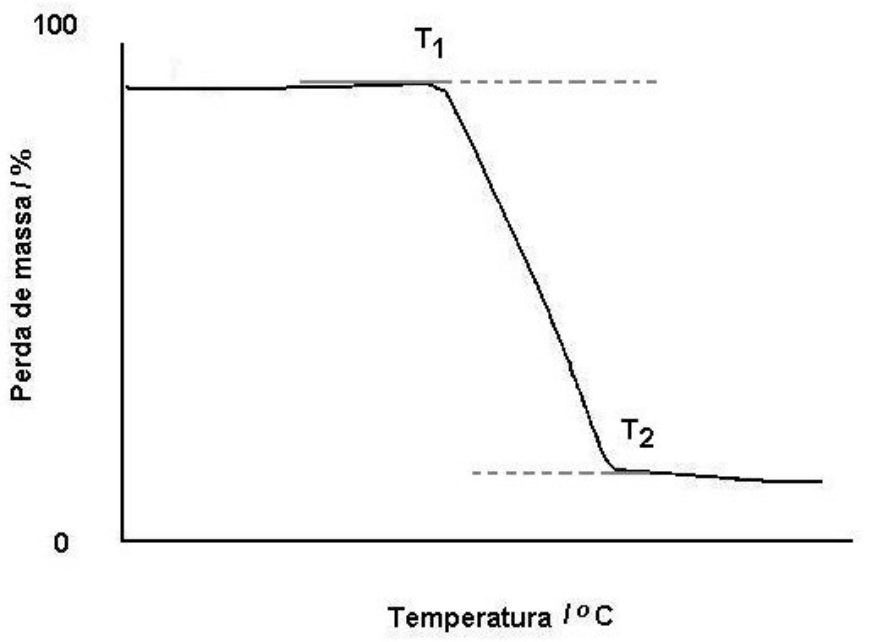

Figura 12. Curva termogravimétrica de um processo em um estágio [115].

No entanto, nem todas as transições da amostra resultam em perda de massa, tais como a fusão, cristalização e transição vítrea, mas fenômenos como desorção, absorção, sublimação e decomposição podem ser observados [116]. Mediante as retas tangentes traçadas á linha de base (linha horizontal) na curva termogravimétrica são obtidos os valores de temperatura, como é exemplificado na Fig 12, na qual: $T_{1}$ é a temperatura do início da transição, também chamada de "onset". O valor desta temperatura é determinado pela interseção da primeira e segunda tangente. $T_{2}$ é a temperatura do final da transição, também chamada de "endset" ou "offset". Seu valor corresponde ao ponto de interseção da segunda e terceira tangente.

Em se tratando de análise termogravimétrica, as temperaturas $T_{1}$ e $T_{2}$ são suficientes para caracterizar a transição. Além destas temperaturas, determina-se também a temperatura de início da degradação, cujo valor é obtido quando a curva começa a se desviar da horizontalidade na etapa de degradação [115,117-119].

As curvas termogravimétrica dos materiais poliméricos foram obtidas dos polímeros obtidos quimicamente (PAni, blendas de PAni-CMC nas diferentes concentrações de CMC (dopadas)) e da CMC comercial, com um equipamento Perkin Elmer Series Thermal Analysis System, modelo TGA7, utilizando cela de platina, massa de amostra de $10-15 \mathrm{mg}$, atmosfera dinâmica de nitrogênio (com velocidade de fluxo de $20 \mathrm{~mL} \mathrm{~min}^{-1}$ ), taxa de aquecimento de 10 ${ }^{\circ} \mathrm{C} \min ^{-1}$ e temperatura variando de $30^{\circ} \mathrm{C}$ até $1000^{\circ} \mathrm{C}$. 


\subsection{Ensaios de corrosão}

Os estudos de corrosão foram realizados por medida de potencial de circuito aberto e utilizando a técnica de curva de polarização potenciodinâmica para relacionar os parâmetros eletroquímicos a velocidade de corrosão. Os estudos foram realizados em solução aquosa de cloreto de sódio $(\mathrm{NaCl} 3 \%)$, aerada e a $25 \pm 2{ }^{\circ} \mathrm{C}$.

\subsubsection{Potencial de circuito aberto}

As medidas de potencial de circuito aberto em função do tempo de imersão ( $E_{c a}$ versus $t$ ) em solução aquosa de $\mathrm{NaCl} 3 \%$ foram realizadas para os eletrodos de AISI-304 sem recobrimento e recoberto com os polímeros. Os valores de potencial de circuito aberto foram obtidos com um potenciostato/galvanostato da EG\&G/PAR, modelo $273 \mathrm{~A}$ acoplado a um microcomputador, controlado pelo programa M352/252 (EG\&G/PAR).

\subsubsection{Polarização potenciodinâmica}

A curva de polarização potenciodinâmica sob controle potenciostático é uma técnica freqüentemente utilizada em estudos de corrosão [63,120,121]. Essa curva é obtida em uma lenta varredura linear de potencial para valores mais positivos, a partir de um determinado potencial na região catódica, até um valor pré-estabelecido. A curva experimental obtida utilizando este procedimento denomina-se curva de polarização potenciodinâmica ou quase estacionária (representada pela Figura 13). Inicialmente, o eixo de potencial está dividido entre as regiões catódicas e anódica, identificadas como região ativa, passiva e transpassiva, conforme se observa na Figura 13. Na região catódica, a intensidade de dissolução do metal pode ser lenta com pequeno ataque eletroquímico, isto dependendo do $\mathrm{pH}$ da solução eletrolítica, da composição química da liga e de outros fatores que influenciam o ataque eletroquímico.

$\mathrm{Na}$ ocorrência simultânea dos processos catódicos e anódico, estabelecem-se as correntes catódicas $\left(\mathrm{i}_{\mathrm{c}}\right)$ e anódica $\left(\mathrm{i}_{\mathrm{a}}\right)$ na superfície do metal, conduzindo-se a um potencial de equilíbrio, o potencial de corrosão $\left(E_{c o r}\right)$, entre a região catódica e anódica, conforme se observa na Figura 13. 


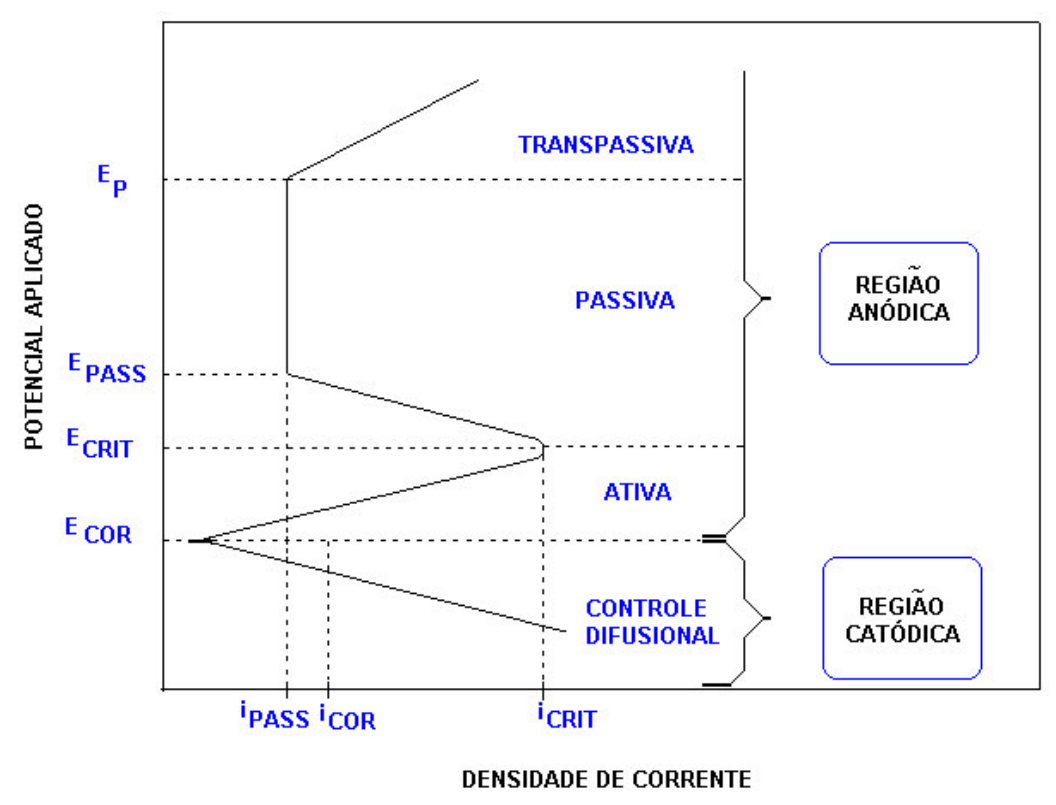

Figura 13. Curva de polarização potenciodinâmica padrão para um material metálico que sofre uma dissolução ativo-passiva, indicando as diferentes regiões que formam a curva de polarização e os parâmetros eletroquímicos de interesse [121].

O potencial de corrosão $\left(\mathrm{E}_{\mathrm{cor}}\right)$ pode ser definido como aquele em que a taxa de oxidação é exatamente igual à taxa de redução, o potencial a partir do qual se inicia o processo de corrosão metálica. No $E_{c o r}$ as correntes catódicas $\left(i_{c}\right)$ e anódica $\left(i_{a}\right)$ são iguais em magnitude, compondo a corrente de corrosão ( $\left.\mathrm{i}_{\text {cor }}\right)$.

A partir de $E_{c o r}$, observa-se na Figura 13 que, á medida que aumenta o potencial, a densidade de corrente também aumenta (esta medida de densidade de corrente é diretamente proporcional à taxa de corrosão) até serem atingidos os valores de potencial crítico de passivação $\left(E_{\text {crit }}\right)$ e de densidade crítica de passivação ( $\left.I_{\text {crit }}\right)$, na qual a transição ativo-passivo ocorre.

$O$ intervalo de potencial de $E_{c o r}$ a $E_{c r i t}$ representa a primeira divisão da região anódica, denominada de região de dissolução ativa, que é caracterizada pela adsorção ativa do oxigênio presente na solução. Na segunda divisão da região anódica, a formação de uma película de óxido sobre a superfície do metal faz com que ocorra um equilíbrio dinâmico entre a superfície metálica e os íons em solução, ou seja, a velocidade de formação da película passiva é praticamente igual à velocidade de dissolução desta. 
A região passiva, que corresponde à segunda divisão da região anódica, inicia-se no potencial crítico de passivação $\left(E_{\text {crit }}\right)$ e estende-se até o potencial de pite $\left(E_{p}\right)$, apresentando uma densidade de corrente mínima de passivação $\left(I_{\text {pass }}\right)$. Após atingir um determinado valor de potencial, o potencial de pite $\left(E_{p}\right)$, este equilíbrio deixa de existir e o material metálico volta a apresentar dissolução devido à ruptura da película passivadora superficial. Esta região é denominada de transpassiva.

Quanto menores os valores de densidade de corrente crítica de passivação $\left(I_{\text {crit }}\right)$ e o potencial crítico de passivação $\left(E_{c r i t}\right)$, maior facilidade o material metálico terá para se passivar, em um determinado meio. Quanto menor a densidade de corrente de passivação ( $\left.I_{\text {pass }}\right)$, menor será a taxa de corrosão na passividade.

A densidade de corrente ( $\left.\mathrm{i}_{\text {cor }}\right)$ é um parâmetro que permite relacionar, a partir de uma curva de polarização, os resultados dos testes eletroquímicos de corrosão ao tempo de vida útil do material no meio. A equação abaixo é uma expressão matemática derivada da equação de Faraday que permite relacionar a corrente de corrosão com a velocidade de corrosão ( $\left.v_{\text {cor }}\right)$, $\mathrm{v}_{\text {cor }}=\left(\mathrm{Mi}_{\text {cor }} / \mathrm{n} \rho \mathrm{F}\right)$, onde $\mathrm{M}$ é a massa molar dada em $\mathrm{g}$-eq; $\mathrm{n}$ é o número de elétrons envolvidos na reação, $\mathrm{F}$ é a constante de Faraday em A s e $\mathrm{i}_{\text {cor }} \mathrm{em} \mathrm{mg} \mathrm{cm}^{-2}$. A densidade do metal $(\rho)$ é dada em $\mathrm{g} \mathrm{cm}^{-3}$. Esta equação mostra a proporcionalidade entre a perda de massa por unidade de tempo e por unidade de área e a densidade de corrente de corrosão. Assim, pode ser calculada a taxa de corrosão em $\mathrm{mm} \mathrm{s}^{-1}$.

Após imersão do eletrodo de AISI-304 com ou sem revestimento, em solução de $\mathrm{NaCl}$ $3 \%$, foram registradas as curvas de polarização potenciodinâmica. A varredura de potencial ocorreu entre $-0,5$ à $+0,4 \mathrm{~V}$, a uma velocidade de varredura de $0,5 \mathrm{mV} \mathrm{s}^{-1}$.

Os ensaios de corrosão foram realizados em um potenciostato/galvanostato da EG\&G/PAR modelo 273A, com a aquisição de feita pelo programa M352/252 (EG\&G/PAR). 


\section{Capítulo III}

\section{Síntese e Caracterização de PAni-CMC Eletropolimerizada}

Neste capítulo estão descritos os resultados obtidos com a polimerização eletroquímica dos compósitos de PAni-CMC sobre AISI-304 e Pt. No geral, estes estudos consistiram em fases distintas. $\mathrm{Na}$ primeira delas, foram realizados estudos exploratórios da eletropolimerização de filmes de PAni-CMC sobre os diferentes eletrodos. A segunda fase consistiu de estudos sobre a influência das concentrações de monômero e CMC sobre a eletropolimerização, resultando na otimização dessas concentrações, obtenção da ordem de reação de eletropolimerização sobre os diferentes eletrodos, além de propiciar uma distinção entre as diferentes velocidades envolvidas na velocidade global do processo de polimerização. Em uma terceira fase, a caracterização dos compósitos de PAni-CMC está apresentada na forma de análise do comportamento eletroquímico dos filmes, espectros no UV-Vis-NIR e no infravermelho, no estado dopado e desdopado do material, medidas de condutividade, além de análises de morfologia por MEV e de composição dos filmes por EDX. Adicionalmente, a partir dos resultados foi proposto um esquema de interação entre PAni e CMC que finalizam este capítulo.

\subsection{Estudos preliminares sobre a eletropolimerização de PAni-CMC}

Os estudos iniciais sobre a eletropolimerização de PAni e CMC sobre aço inoxidável foram realizados baseados no trabalho de Herrasti et al. [60] com algumas modificações. A escolha do eletrólito $\mathrm{H}_{3} \mathrm{PO}_{4}$ foi baseada em resultados anteriores obtidos em nosso grupo de pesquisa e na literatura. Em concordância com essa última, a concentração de anilina utilizada inicial foi de $0,1 \mathrm{~mol} \mathrm{~L}^{-1}$. Quanto a escolha do método, a formação do filme por voltametria 
cíclica em condições já preditas na parte experimental, resultou em um filme aderente à superfície do eletrodo e nestes, foram realizados testes de adesão (sellotape test), revelando a boa aderência, caracterizada pelo não desprendimento do filme da superfície do eletrodo. Os intervalos de potenciais e números de ciclos foram empiricamente variados e otimizados, resultando em: (i) três ciclos com potenciais de $-0,2$ a 1,4 $\mathrm{V}$ e (ii) dezessete ciclos de $-0,2 \mathrm{a}$ 1,2 V. Esta redução no limite de potencial anódico tende a evitar a formação de um material superoxidado.

\subsubsection{Eletropolimerização de PAni-CMC sobre aço inoxidável}

As Figuras 14 ((a) e (b)) demonstram os voltamogramas cíclicos de crescimento dos filmes de PAni-CMC, obtidos a partir de solução de $\mathrm{H}_{3} \mathrm{PO}_{4} \quad 1,0 \mathrm{~mol} \mathrm{~L}^{-1}$ contendo $\mathrm{CMC}$ 0,1\% e $0,1 \mathrm{~mol} \mathrm{~L}^{-1}$ de anilina, a $50 \mathrm{mV} \mathrm{s}^{-1}$. As eletropolimerizações dos filmes foram realizadas até que o número de varreduras de potencial atingisse 20 ciclos. Na primeira varredura de potencial um ombro largo aparece ao redor de $1,0 \mathrm{~V}$, o qual diminui consideravelmente na segunda varredura e aumenta nos ciclos seguintes (Fig. 14 (a)). Esse ombro pode ser atribuído a oxidação de anilina e simultânea oxidação da carboximetilcelulose sobre a superfície do eletrodo modificada pela deposição de PAni-CMC. Logo após a segunda varredura de potencial pode ser observada a formação do polímero de PAni-CMC, a qual se apresenta sobre a superfície do eletrodo como um filme de coloração verde. Os voltamogramas cíclicos de PAni-CMC nos demais ciclos (Fig. 14 (b)) mostram um comportamento similar ao de PAni obtida em meio ácido $[10,12,76]$ um par de pico redox ao redor de $-0,08 / 0,36 \mathrm{~V}$ (descrito como pico A) atribuído ao processo de interconversão do estado de oxidação leucoesmeraldina a esmeraldina, outro par redox a cerca de $-0,38 / 1,14 \mathrm{~V}$ correspondente à interconversão do estado leucoesmeraldina a pernigranilina e um pico anódico a $0,92 \mathrm{~V}$ atribuído a processos anódicos ocorridos na superfície do filme.

Os voltamogramas cíclicos em uma solução de $\mathrm{H}_{3} \mathrm{PO}_{4} 1,0$ mol L $\mathrm{L}^{-1}$ contendo CMC $0,1 \%$ e mantendo as mesmas condições para a eletropolimerização, sem anilina, estão apresentados na Figura $14((\mathrm{c})$ e (d)). Ao redor de 0,9 V a degradação da molécula de CMC ocorre e nenhum pico de oxidação pode ser observado, contudo ao redor de $0,9 \mathrm{~V}$ também ocorre um aumento na densidade de corrente na região anódica,. 


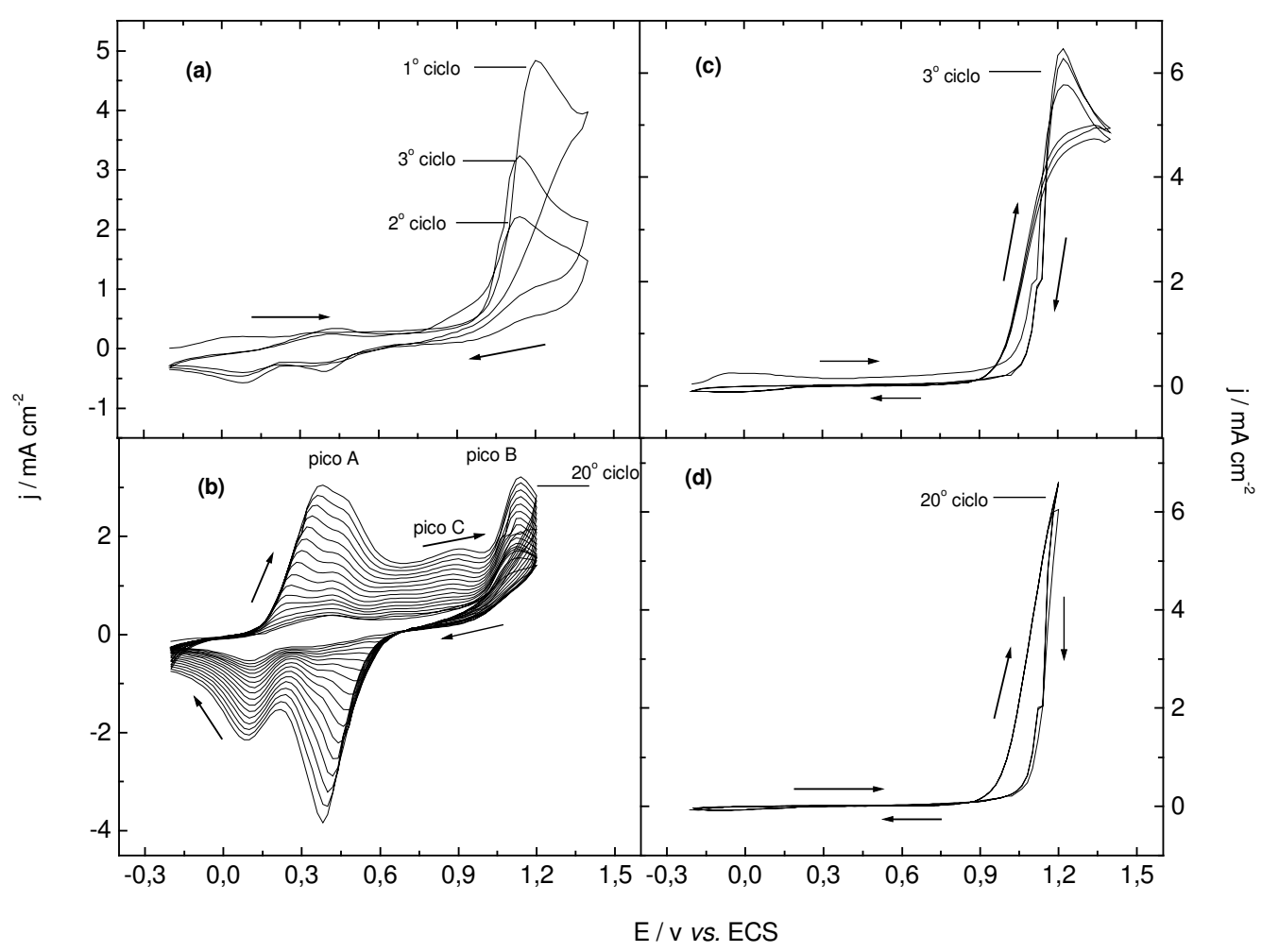

Figura 14. Voltamogramas cíclicos de aço inoxidável em solução de $\mathrm{H}_{3} \mathrm{PO}_{4} \quad 1,0 \mathrm{~mol} \mathrm{~L}^{-1}$ contendo $0,1 \%$ de $\mathrm{CMC}$ (a) anilina $0,1 \mathrm{~mol} \mathrm{~L}^{-1} \mathrm{e}$ (b) sem anilina. $\mathrm{v}=50 \mathrm{mV} \mathrm{s}^{-1}$.

$\mathrm{O}$ aumento de densidade de corrente em potenciais superiores a $0,9 \mathrm{~V}$, tem sido relacionado com a descarga de água, quando a CMC é degradada [59].

\subsubsection{Efeito da concentração de monômero.}

Para ser estudado o efeito da concentração de monômero foram mantidos constantes alguns parâmetros na eletrossíntese, tais como: velocidade de varredura, intervalo de potencial, número de ciclos, concentração de eletrólitos $\left(1 \mathrm{~mol} \mathrm{~L}^{-1}\right.$ de $\left.\mathrm{H}_{3} \mathrm{PO}_{4}\right)$ e concentração de CMC $(0,1 \%)$. Para um efeito de comparação esse mesmo estudo foi realizado na ausência de CMC. Sendo assim, apenas a concentração de anilina foi variada de 0,1 a $0,5 \mathrm{~mol} \mathrm{~L}^{-1}$, a fim de ser observada a influência do monômero na eletropolimerização de PAni-CMC sobre AISI-304.

A Figura 15 demonstra a densidade de corrente do primeiro processo anódico do polímero (descrito como pico A no voltamograma de crescimento) em função da concentração 


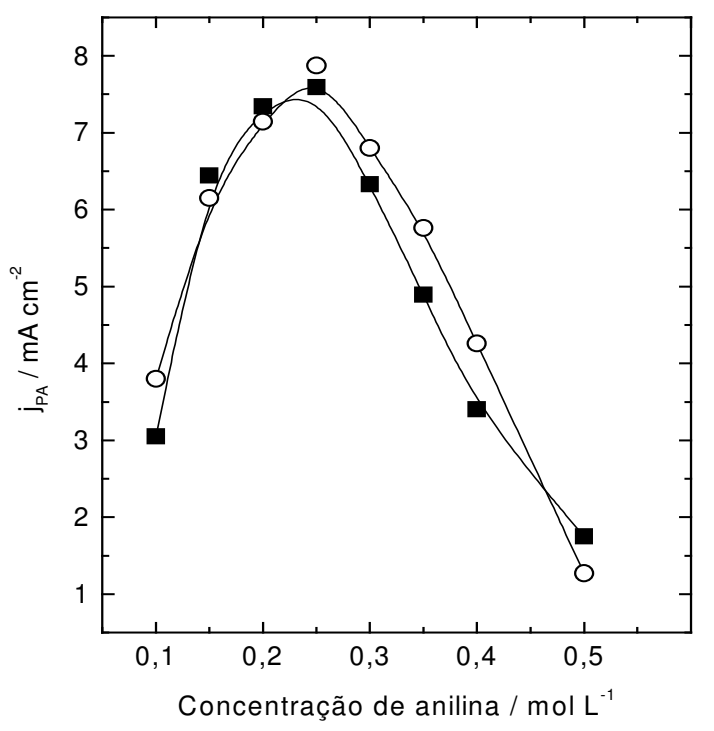

Figura 15. Valores da densidade de corrente do pico A dos voltamogramas de crescimento dos filmes eletropolimerizados sobre AISI-304 obtidos a partir de solução $\mathrm{H}_{3} \mathrm{PO}_{4} \quad 1,0 \mathrm{~mol} \mathrm{~L}{ }^{-1}$ em função da concentração de anilina. (O) sem CMC e ( $)$ contendo 0,1\% CMC.

de monômero. De acordo com a literatura [122-125], esse pico se relaciona com a quantidade de material polimérico eletrodepositado sobre o eletrodo e assim, com a velocidade de polimerização. Duas regiões distintas podem ser observadas com o aumento na concentração de anilina de 0,1 a 0,5 $\mathrm{mol} \mathrm{L}^{-1}$. Entre 0,1 a $0,25 \mathrm{~mol} \mathrm{~L}^{-1}$, a densidade de corrente aumenta e, consequentemente, a velocidade de polimerização também. Isto indica que para esta faixa de concentração de monômero a reação de polimerização é favorecida devido a disponibilidade de monômero nos sítios de reação do polímero. Acima de $0,25 \mathrm{~mol} \mathrm{~L}^{-1}$, a densidade de corrente diminui com a elevação da concentração de monômero e a velocidade de polimerização é reduzida. Em altas concentrações de monômero (superiores a $0,25 \mathrm{~mol} \mathrm{~L}^{-1}$ ), a possibilidade dos monômeros reagirem com os radicais cátions formados é limitada pelo bloqueio dos sítios ativos. Desta forma, a velocidade de polimerização de PAni-CMC sobre AISI-304 é fortemente influenciada pela concentração de monômero em solução.

Na Figura 16 estão demonstrados os valores de densidade de corrente anódica do pico (A) com o número de ciclos obtidos dos voltamogramas de crescimento de filmes de PAni-CMC eletrodepositados sobre AISI-304, em diferentes concentrações de anilina, os quais indicam a relação entre a velocidade de crescimento do polímero e a concentração de anilina. 


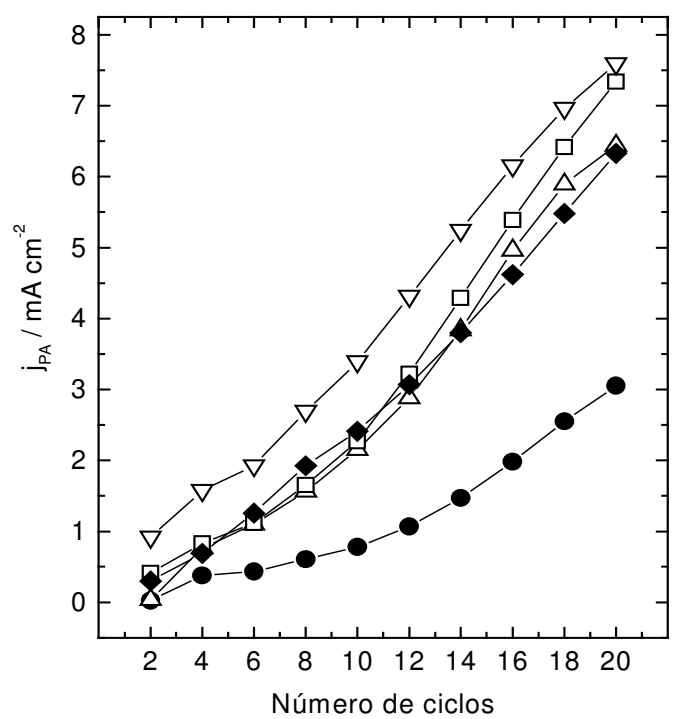

Figura 16. Dependência da corrente do primeiro pico anódico com o número de ciclos em

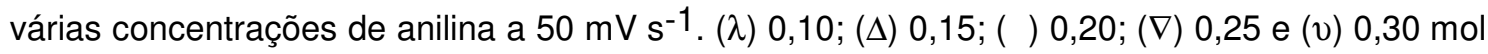
$\mathrm{L}^{-1}$.

A partir dessa relação foi possível determinar a ordem de reação de PAni-CMC sobre AISI-304 com relação a concentração de monômero. A velocidade de crescimento de PAniCMC em um ponto determinado pode ser obtida a partir da inclinação da curva em pontos específicos [124]. Quando as inclinações foram determinadas para cada concentração de anilina em diferentes números de ciclos, foi obtida a dependência mostrada na Figura 17. Uma dependência não linear, neste caso, indica que a velocidade de crescimento de PAni-CMC não é de primeira ordem, com relação a concentração de anilina, para a eletropolimerização sobre AISI-304 e que, realmente, a velocidade de formação de PAni-CMC atinge um máximo quando a concentração de monômero é de $0,25 \mathrm{~mol} \mathrm{~L}^{-1}$.

Diversos autores $[103,124,126]$ relatam que o aumento da concentração de monômero aumenta a velocidade de crescimento de PAni eletropolimerizada sobre platina e que, a velocidade de polimerização de PAni é de primeira ordem com relação a concentração de anilina. 


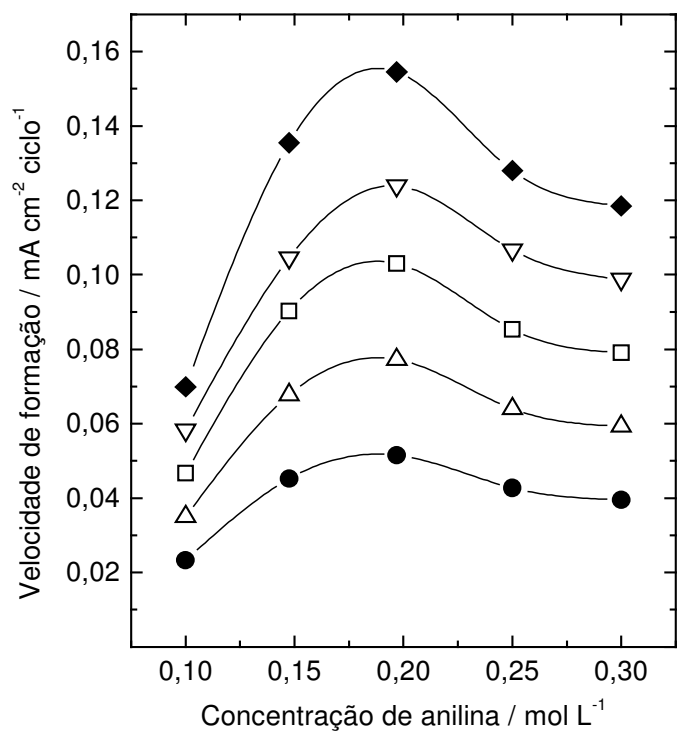

Figura 17. Velocidade de formação $\left.\left((\lambda) v_{1},(\Delta) v_{2},() v_{3},(\nabla) v_{4},(v) v_{5}\right)\right)$ em vários valores de corrente de pico anódico em diferentes concentrações anilina em $\mathrm{H}_{3} \mathrm{PO}_{4} \quad 1,0$ mol L ${ }^{-1}$ e CMC $0,1 \%$.

Afim, de se confirmar o comportamento observado para PAni-CMC sobre AISI-304 foi realizado um estudo sobre o efeito da concentração de monômero utilizando também, um substrato de platina.

\subsubsection{Eletropolimerização de PAni-CMC sobre platina}

A eletropolimerização de PAni-CMC sobre platina foi realizada no intervalo de potencial de $-0,2$ a $0,8 \mathrm{~V}$ em 30 ciclos de potenciais, e, também foi realizado a eletropolimerização na ausência de CMC. Conforme pode ser observado na Figura 18, o comportamento para PAni e PAni-CMC sobre Pt com o aumento da concentração de monômero está em concordância com os relatados em literatura $[103,124,126]$, porém difere do comportamento obtido para o AISI304.

Assim, obtidos os valores de densidade de corrente anódica do pico (A) para PAni-CMC sobre platina esses foram submetidos ao mesmo tratamento, já descrito anteriormente para PAni-CMC sobre AISI-304, resultando na Figura 19. A velocidade de crescimento de PAni-CMC sobre platina é de primeira ordem com relação à concentração de anilina, como pode ser observado pela linearidade na Figura 19. 


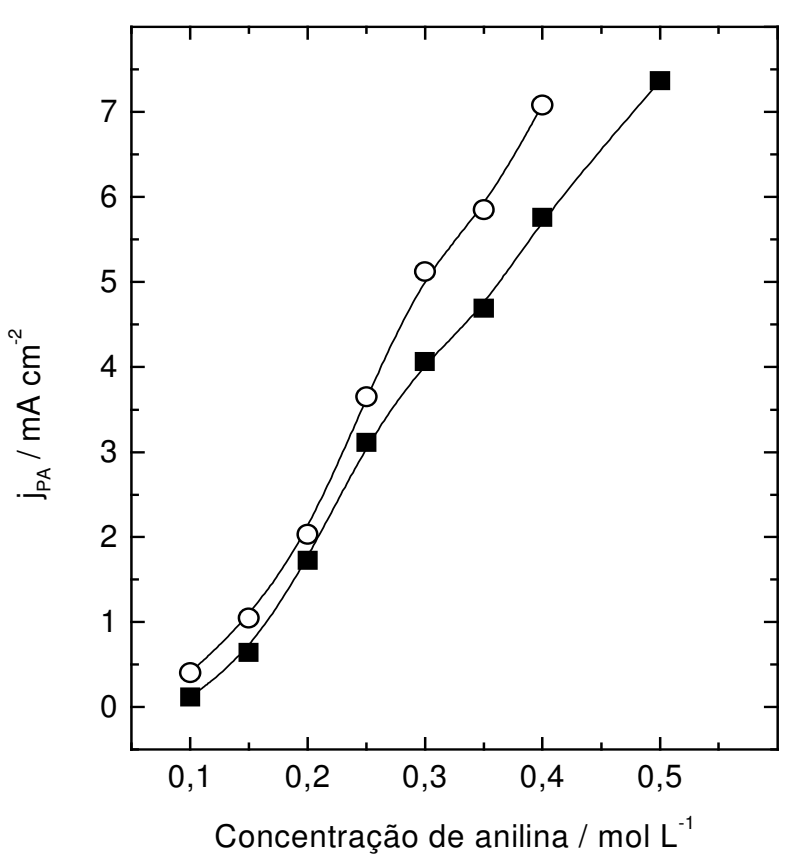

Figura 18. Dependência da corrente do primeiro pico anódico com o número de ciclos em várias concentrações de anilina sobre Pt, a $50 \mathrm{mV} \mathrm{s}^{-1}$. ( $\mu$ ) PAni e (v) PAni-CMC.

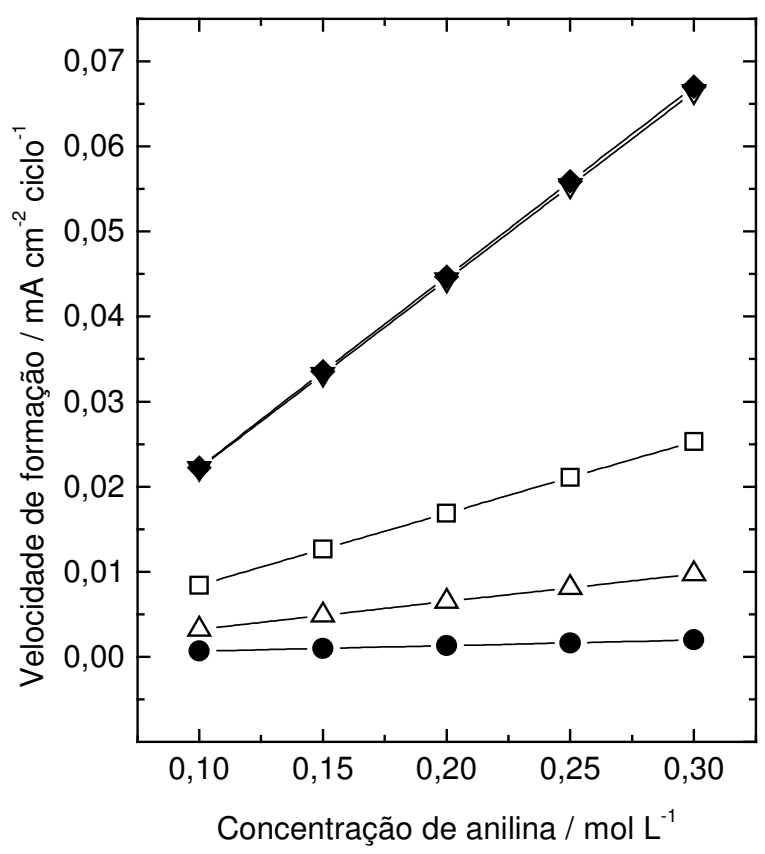

Figura 19. Velocidade de formação $\left.\left((\lambda) v_{1},(\Delta) v_{2},() v_{3},(\nabla) v_{4},(v) v_{5}\right)\right)$ de PAni-CMC sobre Pt em diferentes concentrações anilina em $\mathrm{H}_{3} \mathrm{PO}_{4}$ 1,0 M e CMC 0,1\%. 
De forma geral, pode ser dito que a velocidade de polimerização de PAni-CMC é dependente da natureza da superfície metálica. Um rápido processo de oxidação na polimerização de PAni-CMC sobre AISI-304 ou platina ocorre com o aumento na concentração de monômero em solução com $\mathrm{CMC}$, entretanto, este aumento é limitado. Isto indica que o mecanismo de polimerização da PAni está sendo influenciado pela presença de CMC. Altas concentrações de monômero (superiores a $0,2 \mathrm{M}$ ) são desfavoráveis quando o substrato é AISI-304, uma vez que a velocidade de polimerização é reduzida.

\subsubsection{Efeito da concentração de CMC}

O efeito da concentração de CMC na polimerização dos filmes de PAni-CMC sobre AISI-304 foi estudado a partir de solução de $\mathrm{H}_{3} \mathrm{PO}_{4} \quad 1,0 \mathrm{~mol} \mathrm{~L}^{-1}$ contendo $0,2 \mathrm{~mol} \mathrm{~L}^{-1}$ de anilina e concentrações $\mathrm{CMC}$ de 0,1 a 1\%. A Figura 20 mostra o último voltamograma de crescimento de PAni-CMC daqueles obtidos para as diferentes concentrações de CMC. O voltamograma cíclico obtido em solução de $\mathrm{H}_{3} \mathrm{PO}_{4} 1,0 \mathrm{~mol} \mathrm{~L}^{-1}$ contendo $0,2 \mathrm{~mol} \mathrm{~L}^{-1}$ anilina (sem CMC) também é apresentado para comparação (Fig. 20, curva a).

O aumento na concentração de CMC de 0,1 a $1 \%$ não aumenta os valores de densidade de corrente anódica do pico A, ou seja, a velocidade de polimerização. A hipótese é que para altas concentrações de CMC (superiores a 0,3\%) ocorre uma competição entre a adsorção das moléculas de CMC, o monômero de anilina e as demais espécies em solução por sítios ativos na estrutura polimérica formada ou pela superfície do substrato. Em estudos anteriores [58,59] foram relatados a forte adsorção de moléculas de CMC sobre superfície metálica (tais como óxido de estanho, platina).

Quando uma molécula de anilina é oxidada, o radical cátion intermediário pode seguir diferentes caminhos de reação como função do ambiente químico, do potencial elétrico aplicado e de sua estabilidade. Sendo assim, ele pode reagir com outras espécies do meio (monômero ou oligômero, radicais cátions, etc.) e o mecanismo de eletropolimerização ocorrendo a uma dada velocidade de polimerização $\left(V_{p}\right)$. 


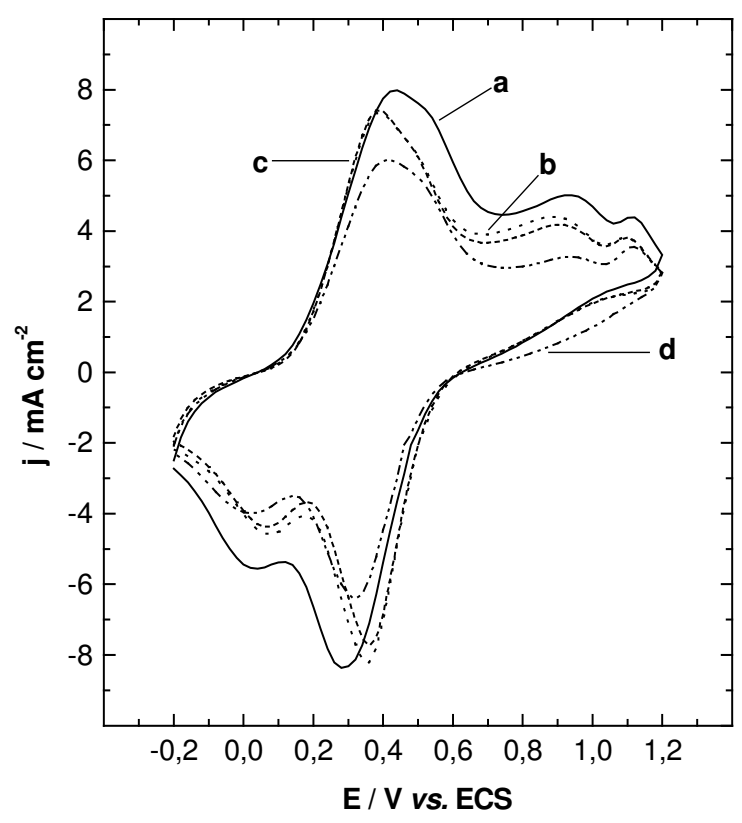

Figura 20. Voltamogramas cíclicos $\left(20^{\circ}\right.$ ciclo) de PAni-CMC obtidos sobre aço inoxidável a partir de solução de $\mathrm{H}_{3} \mathrm{PO}_{4}$ 1,0 mol L-1 contendo $0,2 \mathrm{~mol} \mathrm{~L}^{-1}$ de anilina: (a) sem CMC e com (b) $0,1 \%$, (c) $0,3 \%$, (d) $1 \%$ de CMC a $50 \mathrm{mV} \mathrm{s}^{-1}$.

O radical cátion também pode difundir para longe do eletrodo, com velocidade de difusão $V_{d}$, ou reagir com outras espécies do meio reacional (radicais cátions monoméricos, solvente, impurezas ou ânions), com velocidade global $V_{t}$. Em presença de CMC, em particular, as partículas primárias de PAni (por exemplo radical cátion, espécies monoméricas) podem ser adsorvidas pelas moléculas de CMC no meio reacional a uma dada velocidade de adsorção $\bigvee_{a d}$. Desta forma, a velocidade de reação global do mecanismo de eletropolimerização de PAniCMC é dada por: $V_{t}=V_{p}+V_{a d}+V_{d}$.

A eletropolimerização de PAni em presença de CMC é fortemente influenciada pela concentração de $\mathrm{CMC}$ e a estabilidade do radical cátion em presença de CMC é alcançada. Então, a baixas concentrações de CMC (concentrações inferiores a $0,3 \%$ ) pode ser assumido que $V_{p}+V_{d}$ é muito maior que $V_{a d}$ e a velocidade global do mecanismo de polimerização é dominada por $V_{p}+V_{d}$. A eletropolimerização é suprimida ou reduzida a altas concentrações de CMC (superiores a 0,3\%) e $V_{a d}$ tornasse muito maior que $V_{p}+V_{d}$. Neste caso, então, a adsorção de CMC sobre os sítios de PAni é predominante. 
Vários fatores podem estar associados a estas hipóteses devido aos diferentes processos, simultâneos e competitivos, que ocorrem durante a eletropolimerização de PAni (por exemplo os processos de degradação) e, esses processos também podem influenciar a velocidade global de eletropolimerização.

\subsection{Caracterização de PAni-CMC}

\subsubsection{Resposta Eletroquímica}

A eletroatividade de misturas de polímeros condutores e isolantes eletropolimerizados é conhecida desde 1984 [127]. As diferenças observadas entre os CV's obtidos para uma mistura polimérica e um polímero condutor puro inclui aumento na resistividade da mistura (polímero condutor e isolante) e variações em sua permeabilidade iônica e capacidade de absorção do solvente, devido á adição de um material isolante. Em vista disso, os CV's de filmes de mistura polimérica podem apresentar uma grande corrente capacitiva devido à um aumento de área efetiva do eletrodo $[128,129]$. Como esses fatores são influenciados pela presença de um polímero isolante, eles dependem da matriz usada e da espessura do filme e, sendo assim, variações podem ser observadas na eletroatividade dos filmes de misturas poliméricas.

Na Figura 21 estão apresentados os VCs referentes ao comportamento eletroquímico dos filmes de PAni e PAni-CMC 0,1\% e 1\% de CMC, eletropolimerizados sobre Pt, com 60 ciclos de potenciais, em solução de $\mathrm{H}_{2} \mathrm{SO}_{4} 0,5 \mathrm{~mol} \mathrm{~L}^{-1}$.

Para PAni (Fig. 21(a)) três pares de pico redox podem ser observados, os quais estão em concordância com os resultados descritos em literatura [12,13]. PAni-CMC apresenta um comportamento eletroquímico similar ao de PAni (Figuras 21 (b) e (c)) e os VCs dos filmes de PAni-CMC são representados pelos pares redox :

- pico $A / A^{\prime}$ : ao redor de $0,2 / 0,02 \mathrm{~V}$ atribuído ao primeiro processo de oxidação da PAni (interconversão do estado leucoesmeraldina a esmeraldina); 


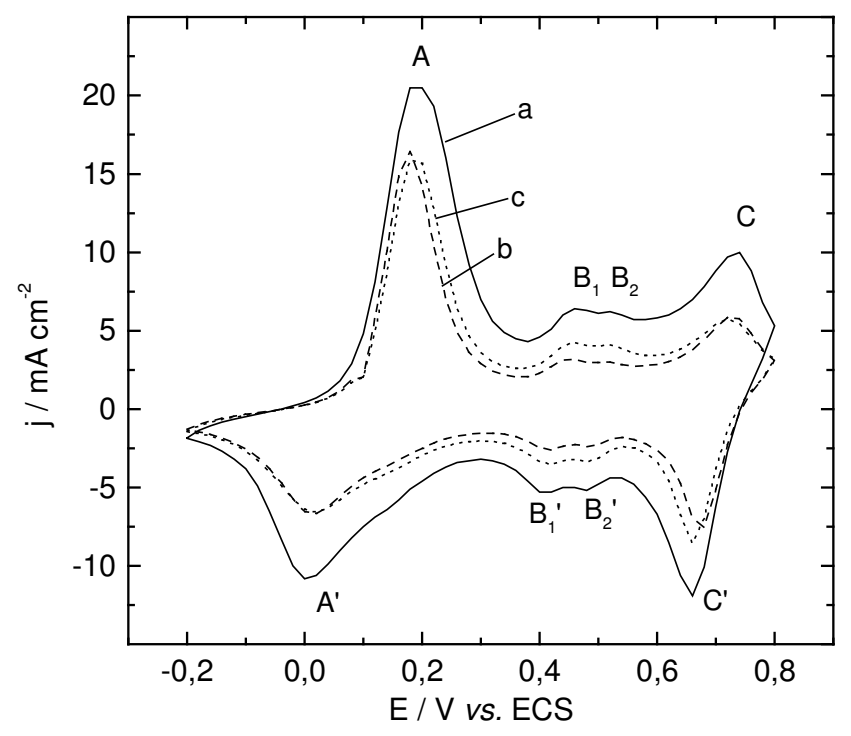

Figura 21. Voltamogramas cíclicos $\left(5^{\circ}\right.$ ciclo) dos polímeros eletropolimerizados sobre Pt por 60 ciclos de potenciais, a partir de uma solução de $\mathrm{H}_{3} \mathrm{PO}_{4} 1 \mathrm{~mol} \mathrm{~L}^{-1}$ e $0,2 \mathrm{~mol} \mathrm{~L}^{-1}$ de anilina (a) PAni (sem CMC) e PAni-CMC com (b) $0,1 \%$ e (c) $1,0 \%$ de $\mathrm{CMC}$, em $\mathrm{H}_{2} \mathrm{SO}_{4} 0,5 \mathrm{~mol} \mathrm{~L}^{-1}$, a $50 \mathrm{mV} \mathrm{s}^{-1}$.

- dois picos $B_{1} / B_{1}$ e $B_{2} / B_{2}$ : (cerca de 0,46 and $0,42 V$, respectivamente) devido a processo de degradação do polímero (formação do par quinona/hidroquinona) [12,13].

- pico C/C': (cerca de 0,72/0,66 V) correspondente ao segundo processo de oxidação do polímero (interconversão do estado esmeraldina a pernigranilina).

O comportamento eletroquímico de PAni e PAni-CMC é similar, no entanto, para PAniCMC os valores de densidade de corrente são menores e os valores de potenciais de pico são deslocados para valores menos positivos, comparados ao da PAni. Os parâmetros (densidade de corrente e potencial de pico) não são influenciados pela concentração de CMC utilizada, quando comparados os filmes de PAni-CMC. De fato, a presença de um polímero isolante na mistura polimérica influencia o comportamento eletroativo do polímero condutor, sendo isto um indicativo de interação entre os componentes poliméricos. 


\subsubsection{Espectroscopia no UV-VIS-NIR}

Para a realização dos espectros de UV-Vis-NIR da PAni e PAni-CMC eletropolimerizadas sobre Pt e AISI-304 os polímeros foram primeiramente desdopados e dissolvidos em n-metilpirrolidona, originando uma solução de coloração azul.

O espectro dos polímeros desdopados foram registrados e estão representados na Figura 22 (I) e (II). Em seguida, uma gota $(\approx 0,5 \mu \mathrm{L})$ de $\mathrm{HCl} 5 \mathrm{~mol} \mathrm{~L}^{-1}$ foi adicionada às amostras, variando a cor da solução para verde e, o espectro do polímero dopado registrado. Os espectros correspondentes à PAni e PAni-CMC na forma dopada sobre Pt e AISI-304 estão representados na Figura 23 (I) e (II).

Desdopados os polímeros (Figura 22 (I) e (II)) apresentam um comportamento típico, caracterizado por duas bandas de absorção: uma a 330 e outra a $630 \mathrm{~nm}$ pode ser observada, as quais são atribuídas á transições $\pi-\pi^{*}$ dos anéis benzênicos e as excitações de seguimentos iminas (bandas excitônicas), respectivamente. Na forma dopada Figura 23 (I) e (II) os espectros demonstram três bandas de absorção ao redor de 340, 420 e $820 \mathrm{~nm}$. A banda a $420 \mathrm{~nm}$ atribuída aos radicais cátions que se formam. A banda larga ao redor de $830 \mathrm{~nm}$ se associa aos transportadores de carga na cadeia polimérica, ou seja a transição da banda excitônica para a banda bipolarônica [12,13,15].

A transição da banda excitônica $(630 \mathrm{~nm})$ à banda bipolarônica $(830 \mathrm{~nm})$, uma região de baixa energia, caracteriza um aumento na mobilidade eletrônica na estrutura. Assim, é possível observar que PAni-CMC $(0,1 \% \mathrm{CMC})$ dopada apresenta um nível de absorção maior entre os demais blendas e a PAni. Isto pode ser devido a presença de CMC na estrutura polimérica para essa concentração. Este efeito é dependente da condição de síntese (concentração de CMC), mas independe da natureza do substrato. 


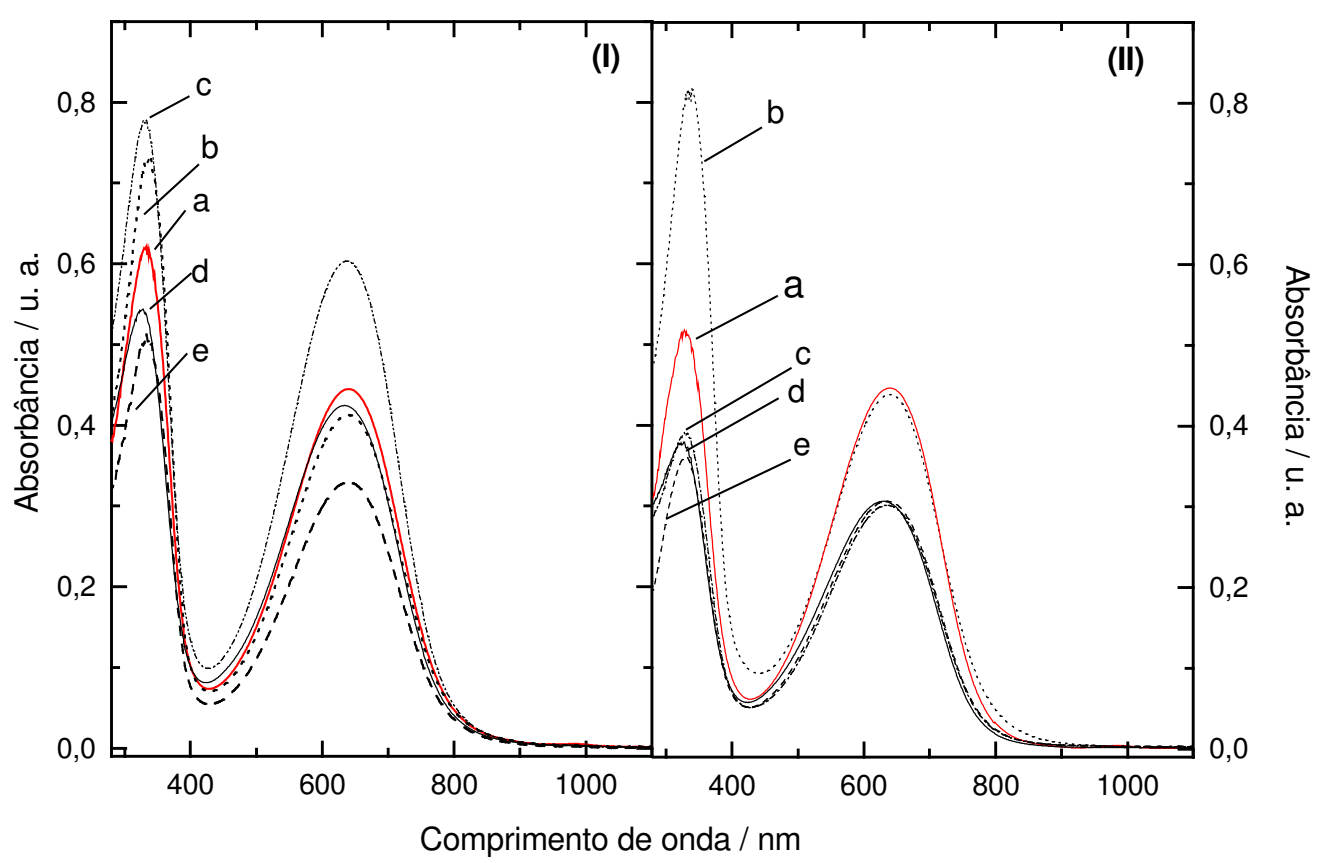

Figura 22. Espectro no UV-Vis-NIR dos polímeros eletropolimerizados sobre (I) Pt e (II) AISI304 de (a) PAni; PAni-CMC (b) $0,1 \%$; (c) $0,3 \%$; (d) $0,6 \%$ e (e) $1 \%$ CMC. Polímeros desdopados.

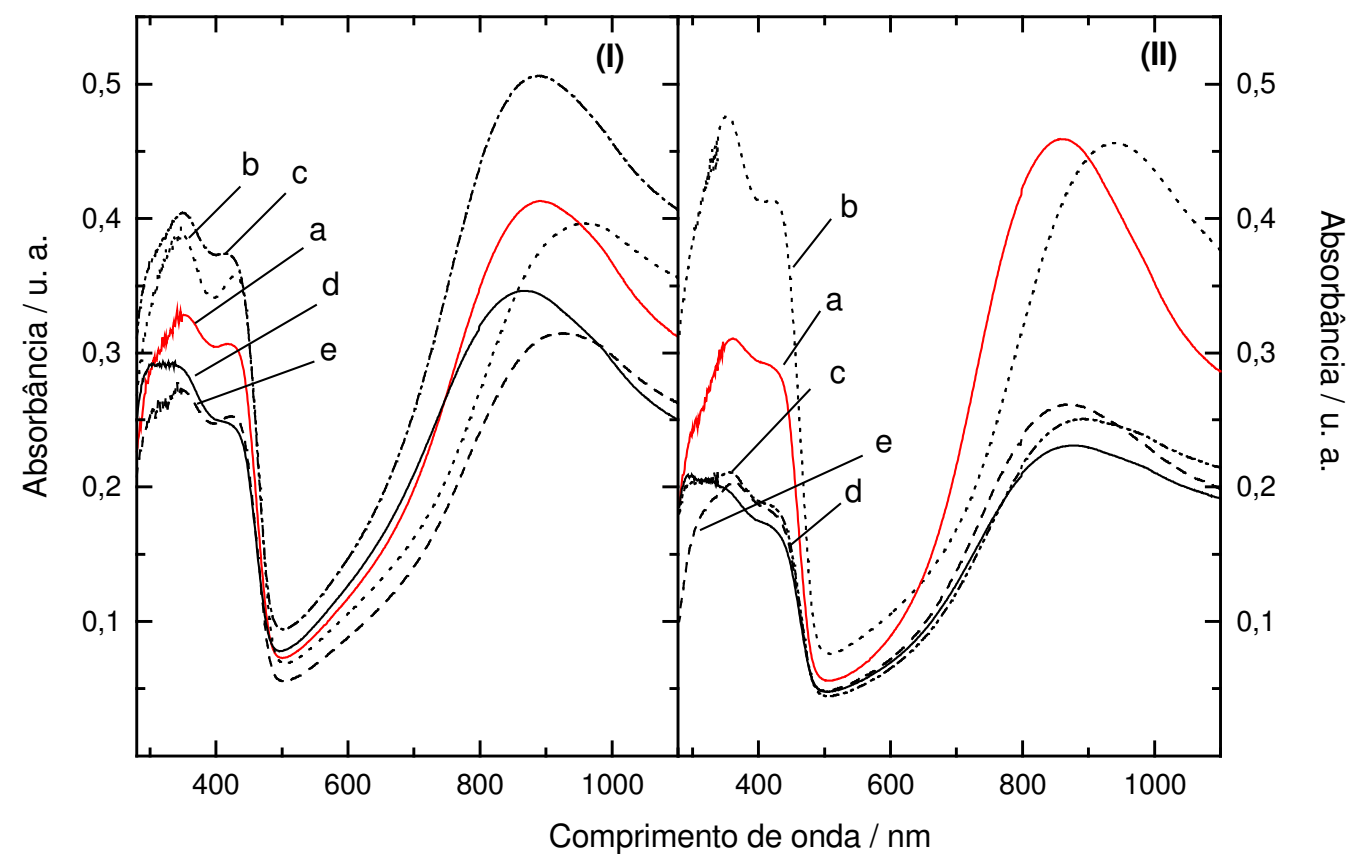

Figura 23. Espectro no UV-Vis-NIR de eletropolimerizado sobre (I) Pt e (II) AISI-304 de (a) PAni e PAni-CMC (b) 0,1\%; (c) 0,3\%; (d) 0,6\% e (e) 1\% CMC. Polímeros dopados. 
Os espectros de PAni-CMC mantém as características do espectro de PAni, independente da concentração de CMC na mistura polimérica. Desdopados é observado o espectro da base esmeraldina enquanto dopados o do sal esmeraldina.

\subsubsection{Espectroscopia no infravermelho (IV)}

Os espectros de IV para os polímeros de CMC (comercial), PAni e PAni-CMC, obtidas a partir de 0,1 e 1\% de CMC eletropolimerizada sobre Pt e AISI-304 são mostrados na Figura 24 (I) e (II), respectivamente. Diversas bandas do CMC e da PAni são sobrepostas e assim, isolar todos os efeitos da CMC no polímero torna-se difícil. Entretanto, algumas bandas na PAni-CMC demonstram pequenos deslocamentos quando comparada a da PAni. A presença de CMC em PAni-CMC é evidente a partir da presença no espectro (Fig. 24 (a) (curvas b e c)) de bandas na região de $2855-2926 \mathrm{~cm}^{-1}$, correspondentes ao estiramento de ligação $\mathrm{C}-\mathrm{H}$, e bandas ao redor de $1774 \mathrm{~cm}^{-1}$, correspondentes ao modo de ligação $\mathrm{C}=\mathrm{O}$. Um desdobramento da banda a 1774 $\mathrm{cm}^{-1}$ em $1740 \mathrm{~cm}^{-1}$ é observado para PAni-CMC e, quando a concentração de CMC aumenta, esta se torna mais evidente. Esta banda que corresponde ao CMC, na PAni-CMC se transfere para baixos comprimentos de onda e, este efeito pode ser um indicativo da ligação de hidrogênio entre os grupos $\mathrm{N}-\mathrm{H}$ da PAni e $\mathrm{C}=\mathrm{O}$ da CMC. A intensidade da banda a $1294 \mathrm{~cm}^{-1}$ presente na PAni e PAni-CMC pode também ser atribuída a interação química (tipo ligação de hidrogênio) entre a CMC e a PAni. Com a diminuição na concentração de CMC, a intensidade das bandas na região de 1230-1150 $\mathrm{cm}^{-1}$ aumenta e o espectro da PAni-CMC se aproxima àquele da PAni. A evidência de bandas no espectro de PAni-CMC ao redor de 1400 e de 1440 $\mathrm{cm}^{-1}$, correspondente ao estiramento da ligação $\mathrm{N}-\mathrm{H}$ e a deformação $\mathrm{N}-\mathrm{H}$, respectivamente, suportam a presença de ligações de hidrogênio. A banda para estiramento $\mathrm{N}-\mathrm{H}$ na PAni aparece ao redor de $3448 \mathrm{~cm}^{-1}$. Entretanto, para PAni-CMC a banda de estiramento $\mathrm{N}-\mathrm{H}$ não aparece devido provavelmente à significativa ocorrência de ligações de hidrogênio entre a PAni e a CMC. Neste contexto, é possível sugerir que a formação das ligações de hidrogênio tem maior contribuição, mediante os átomos de nitrogênio dos seguimentos benzenóides da PAni com os hidrogênios da CMC . 

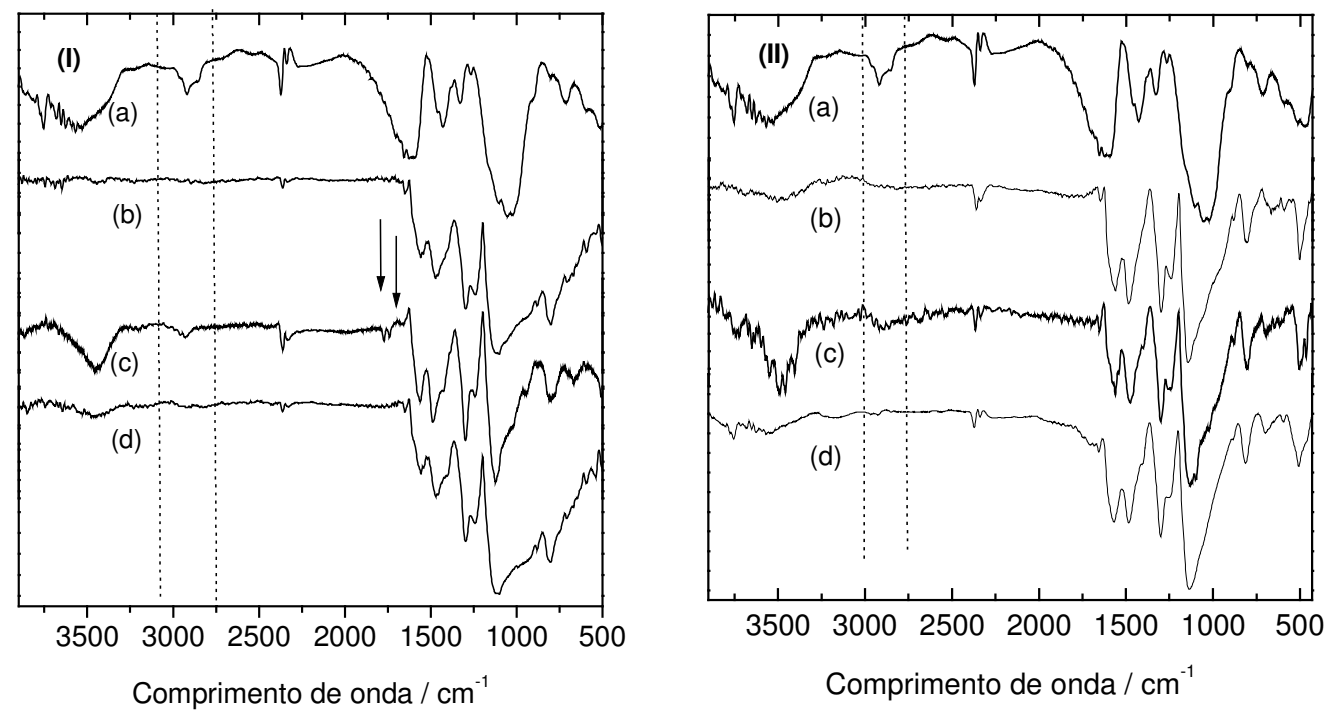

Figura 24. Espectro no infravermelho de (a) CMC, PAni-CMC (b) $0,1 \%$, (c) $1 \%$ CMC e (d) PAni, dopados. Polímeros eletropolimerizado sobre (I) Pt e (II) AISI-304.
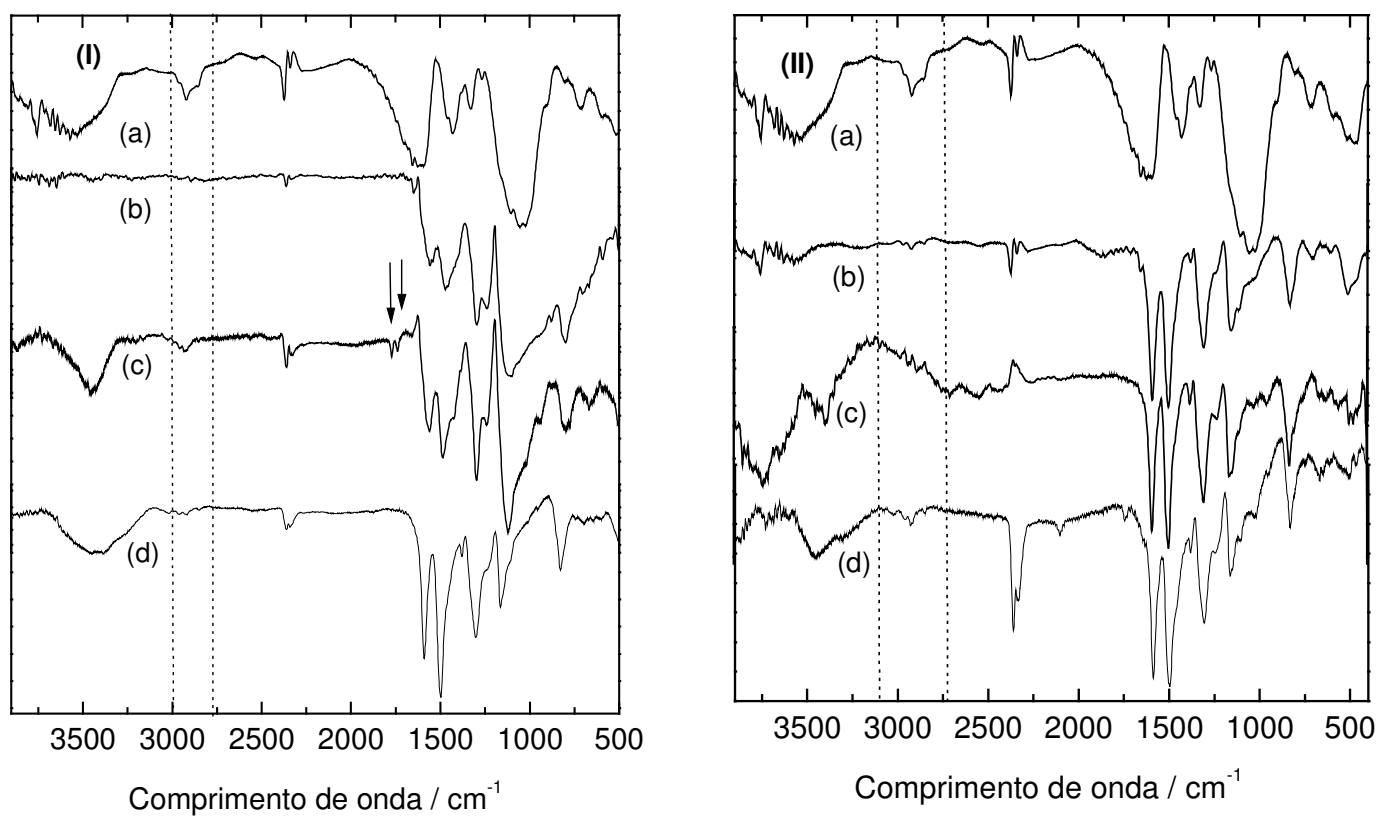

Figura 25. Espectro no infravermelho de (a) CMC, PAni-CMC (b) $0,1 \%$, (c) $1 \%$ CMC e (d) PAni desdopados. Polímeros eletropolimerizados sobre (I) Pt e (II) AISI-304. 
Em geral, o espectro da PAni-CMC desdopada (Figura 25) pode ser explicado com base nos principais modos de vibração da PAni banda a $3280-3400 \mathrm{~cm}^{-1}$ atribuída à estiramento $\mathrm{N}-\mathrm{H}$ de amina aromática; a $2930 \mathrm{~cm}^{-1}$; banda referente ao estiramento $\mathrm{C}-\mathrm{H}$ de anel aromático; bandas a 1585 e $1490 \mathrm{~cm}^{-1}$ atribuídas à deformação dos anéis benzenóides e quinóides, respectivamente; banda a $1310 \mathrm{~cm}^{-1}$ correspondente ao estiramento C-N de amina secundária aromática; banda a $820 \mathrm{~cm}^{-1}$ do modo de ligação $\mathrm{C}-\mathrm{H}$ fora e no plano. Além disto, na região de 1010-1170 $\mathrm{cm}^{-1}$ modos de ligação C-H no plano são usualmente observados. Os modos de ligação C-H no plano e fora do plano têm sido usados para identificar a posição de substituição do anel benzeno $[12,109]$.

\subsubsection{Condutividade}

As medidas de condutividade foram realizadas com o método de quatro pontas estabelecer os valores relativos de condutividade da PAni e das blendas de PAni-CMC. Os valores de condutividade dos polímeros eletrodepositados sobre AISI-304 estão apresentados na Figura 26, podendo ser observado que a condutividade de PAni-CMC inicialmente aumenta com a concentração de $\mathrm{CMC}$, entretanto um valor máximo é obtido e, em seguida, o valor decaí e se mantém constante.

Geralmente, existe uma forma de variar a condutividade até a fração de um componente condutor atingir um limite de percolação. O limite de percolação é definido como a quantidade mínima do material condutor que deve ser adicionado a uma matriz isolante para promover o início "onset" da condutividade elétrica. O limite de percolação depende da forma e da distribuição das partículas condutoras na matriz polimérica [49].

A condutividade da PAni está de acordo com o descrito em literatura [109]. Para PAniCMC a concentração de CMC $0,3 \%$ pode favorecer a incorporação de CMC em sítios da cadeia de PAni promovendo pouca interação inter ou intra cadeia. 


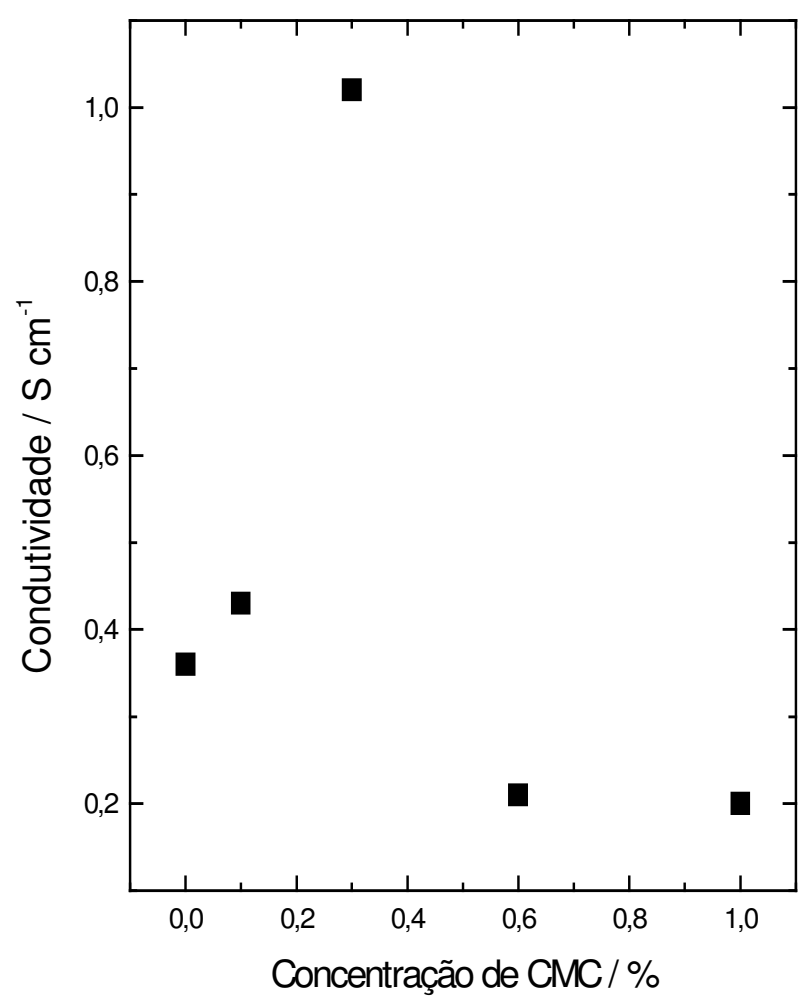

Figura 26. Condutividade dos polímeros eletropolimerizados sobre AISI-304, na forma dopada, em função da concentração de CMC.

Então, para baixas concentrações de CMC (abaixo de 0,3\%) nenhum impedimento no transporte elétrico da PAni ocorreria. Enquanto, para altas concentrações de CMC (superiores a 0,3\%), devido a interação entre o polímero condutor e não condutor serem mais intensa, esta tende a promover um grande número de sítios na cadeia de PAni ocupados pelo CMC, ocasionando maior impedimento no transporte de elétrons. Este resultados correlacionam com os descritos em seções seguintes.

Em suma, os valores de condutividade de PAni-CMC são dependentes da concentração de CMC empregada na eletropolimerização e são inferiores ao valores descritos em literatura [61] devido ao meio (aquoso), ao método (eletroquímico) e ao eletrólito $\left(\mathrm{H}_{3} \mathrm{PO}_{4}\right)$ utilizado neste trabalho, que diferem do citado em literatura [61]. 


\subsubsection{Microscopia eletrônica de varredura (MEV) e EDX}

As imagens obtidas por MEV de PAni e PAni-CMC foram empregadas para diferenciar a morfologia dos compósitos em relação a da PAni e determinar a homogeineidade da mistura polimérica.

Na Figura 27 estão mostradas as micrografias de PAni e PAni-CMC 0,1 a 1\% de CMC eletropolimerizadas sobre AISI-304 a partir de uma solução de $\mathrm{H}_{3} \mathrm{PO}_{4} 1 \mathrm{~mol} \mathrm{~L}^{-1}$ e anilina 0,2 mol $\mathrm{L}^{-1}$, na presença e na ausência de CMC. A PAni (Fig. 27 (a)) apresenta uma estrutura homogênea, porosa e globular (constituída de pequenos glóbulos) em concordância com o descrito na literatura $[109,130]$. Os filmes de PAni-CMC (Figura 27 (b) a (d)) apresentam morfologia similar a de PAni, no entanto, pode ser observado que a presença do CMC favorece uma estrutura mais empacotada e menos porosa. Além disto, o aumento na concentração de CMC favorece a formação de uma estrutura compacta e homogênea conforme a Figura 27 (e). Sendo assim, pode ser assumido que a CMC atua como um modificador estrutural e que pode estar influenciando na interação do ânion fosfato (o dopante) em sítios da PAni.

A valência do contra-íon pode influenciar no processo de formação estrutural da CMC [5,131]. Então, quando presentes contra-íons divalentes ou multivalentes, esses podem atuar como centros de ligações cruzadas via intra e/ou ligações intermoleculares [5,131]. Desta forma, a CMC atuaria como um modificador estrutural quando em mistura com a PAni.

Mediante análises dos espectros de EDX de PAni e PAni-CMC (Figura 28) e por uma análise semi-quantitativa (Tabela 3) pode ser observado um significativo conteúdo de ferro $(\mathrm{Fe})$. A presença desse elemento é atribuída ao substrato e/ou a dissolução do eletrodo durante a eletropolimerização. Outros elementos como $\mathrm{Si}, \mathrm{Cr}$ e Ni presentes são devidos a esses elementos serem constituintes da liga de aço. 

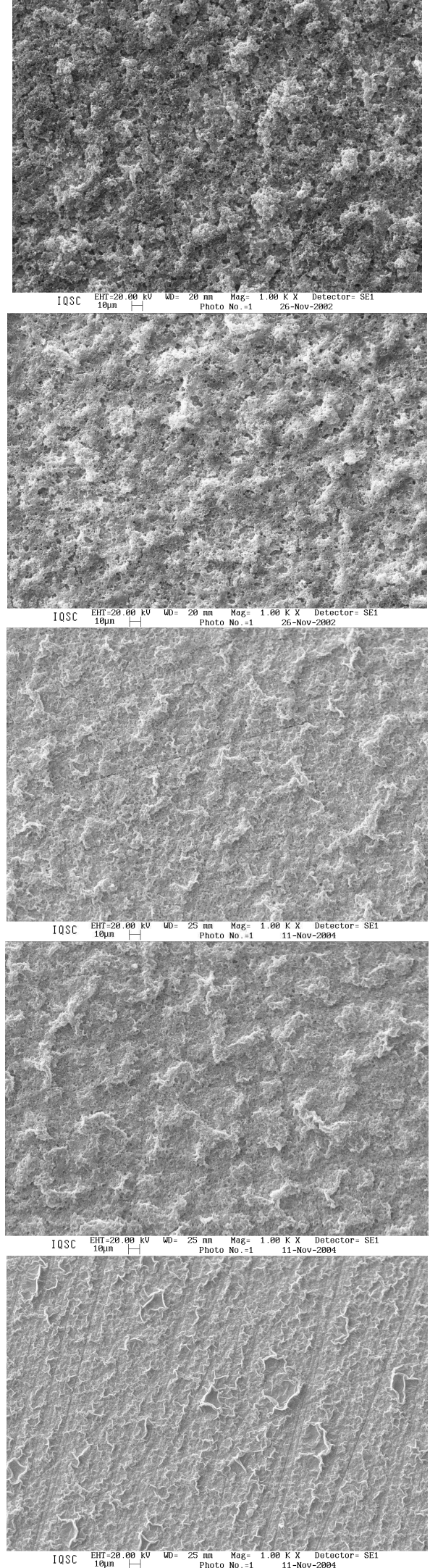

(e)

(c)

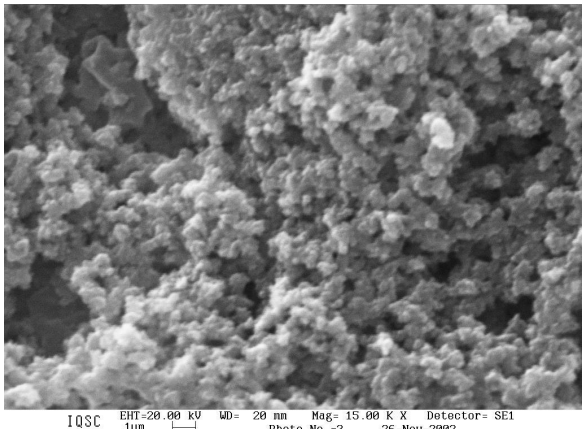

(b)
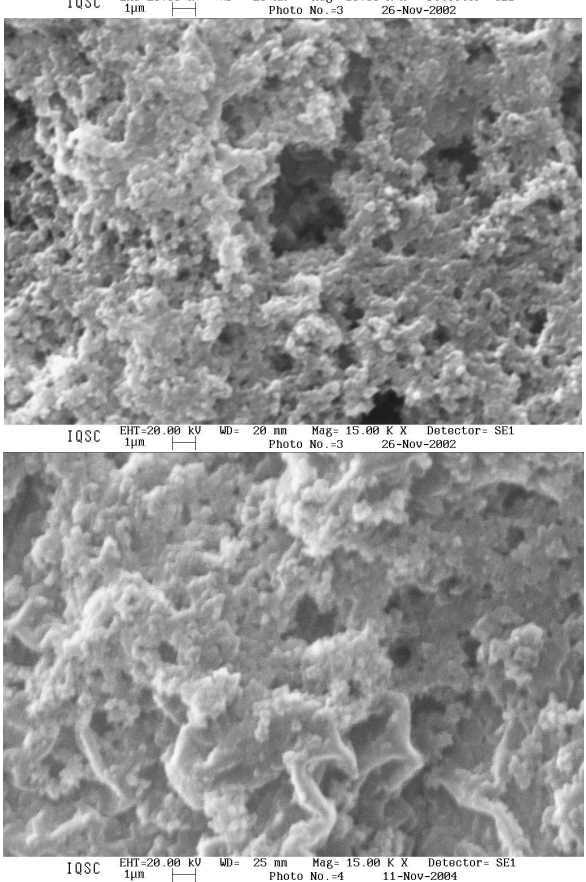

(d)
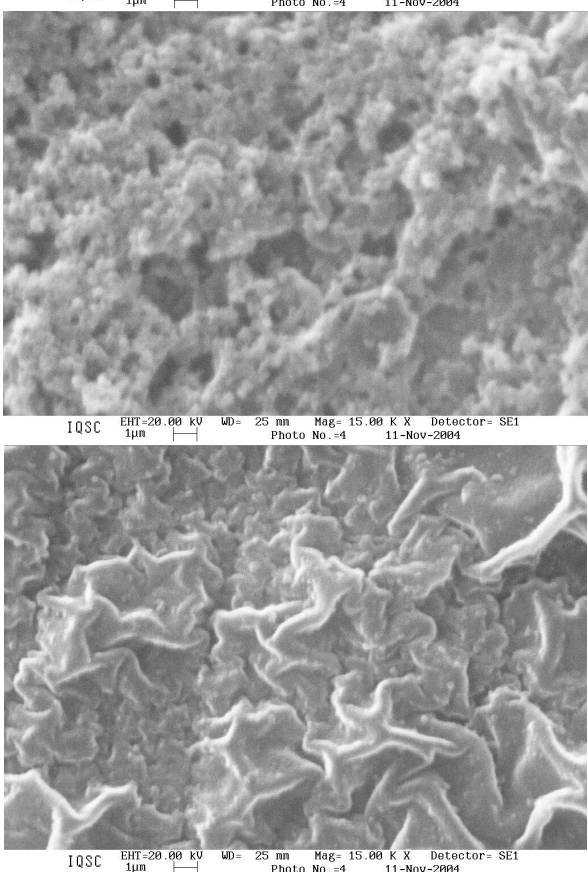

Figura 27. Micrografias dos polímeros eletrodepositados sobre AISI-304 a partir de $\mathrm{H}_{3} \mathrm{PO}_{4}$

$1 \mathrm{~mol} \mathrm{~L}^{-1}$ e $0,2 \mathrm{~mol} \mathrm{~L}^{-1}$ de anilina, (a) PAni e em presença de CMC: (b) $0,1 \%$; (c) $0,3 \%$; (d) $0,6 \%$ e (e) $1 \%$. Ampliações: 1000 vezes (a esquerda) e 15.000 vezes (a direita). 


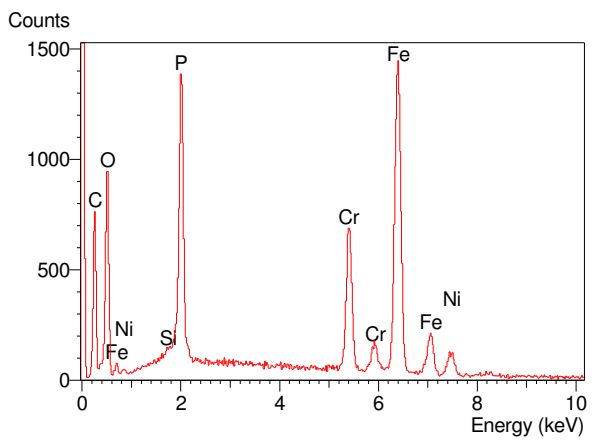

(a)

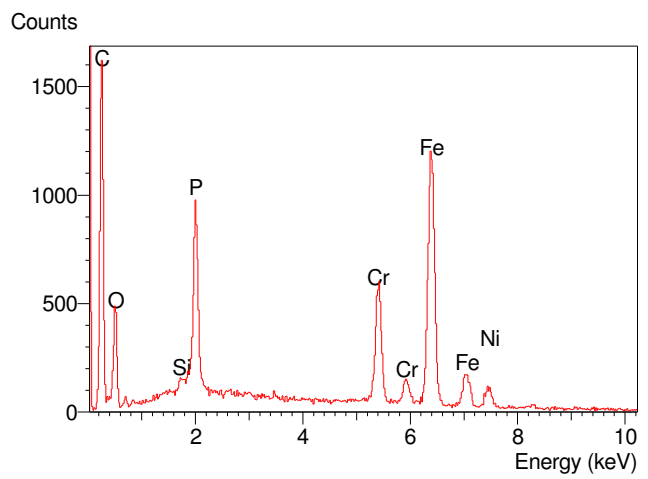

(b)

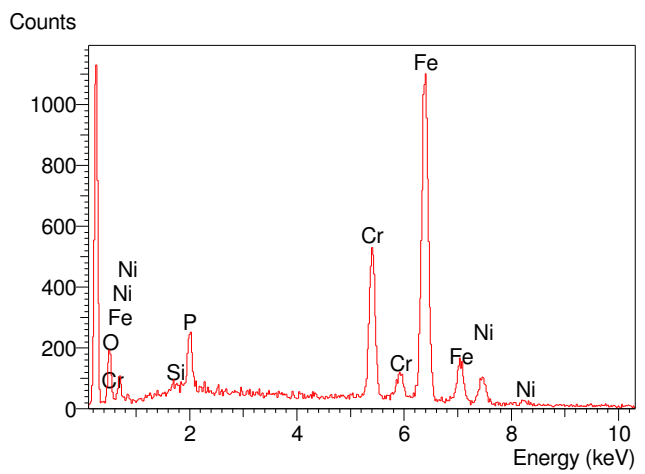

(d)

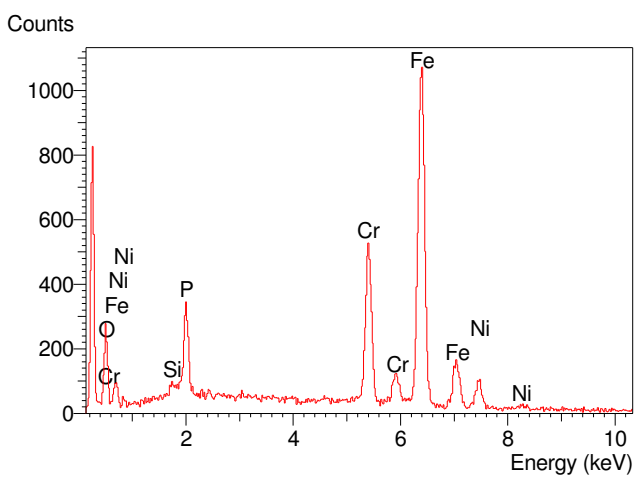

(c)

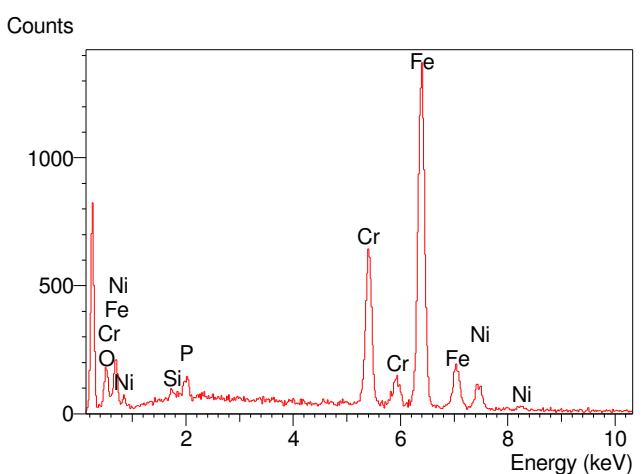

(e)

Figura 28. Espectros de EDX dos polímeros eletrodepositados sobre AISI-304 a partir de $\mathrm{H}_{3} \mathrm{PO}_{4} 1 \mathrm{~mol} \mathrm{~L}^{-1}$ e $0,2 \mathrm{~mol} \mathrm{~L}^{-1}$ de anilina, (a) PAni e PAni-CMC: (b) $0,1 \%$; (c) $0,3 \%$; (c) $0,6 \%$ e (d) $1 \%$. 
Tabela 3. Valores dos teores dos elementos, obtidos por EDX, dos filmes de PAni e PAni-CMC eletropolimerizados sobre AISI-304

\begin{tabular}{l|c|c|c|c|c}
\hline \multirow{2}{*}{ Amostras } & \multicolumn{5}{c}{ Teor (\% at.) } \\
\cline { 2 - 6 } & $\mathrm{Si}$ & $\mathrm{P}$ & $\mathrm{Cr}$ & $\mathrm{Fe}$ & $\mathrm{Ni}$ \\
\hline PAni & ${ }^{*}$ & 24,13 & 16,90 & 52,79 & 5,63 \\
\hline PAni-CMC 0,1\% & 0,66 & 19,75 & 17,28 & 55,30 & 6,48 \\
\hline PAni-CMC 0,3\% & 0,82 & 6,59 & 17,04 & 56,54 & 6,69 \\
\hline PAni-CMC 0,6\% & 0,99 & 4,47 & 18,46 & 61,36 & 7,34 \\
\hline PAni-CMC 1\% & 0,90 & 2,65 & 19,88 & 65,12 & 6,99 \\
\hline Vayyyyyy
\end{tabular}

Valores médios de duas amostras. $\left({ }^{*}\right)$ valor inferior ao limite de detecção da técnica.

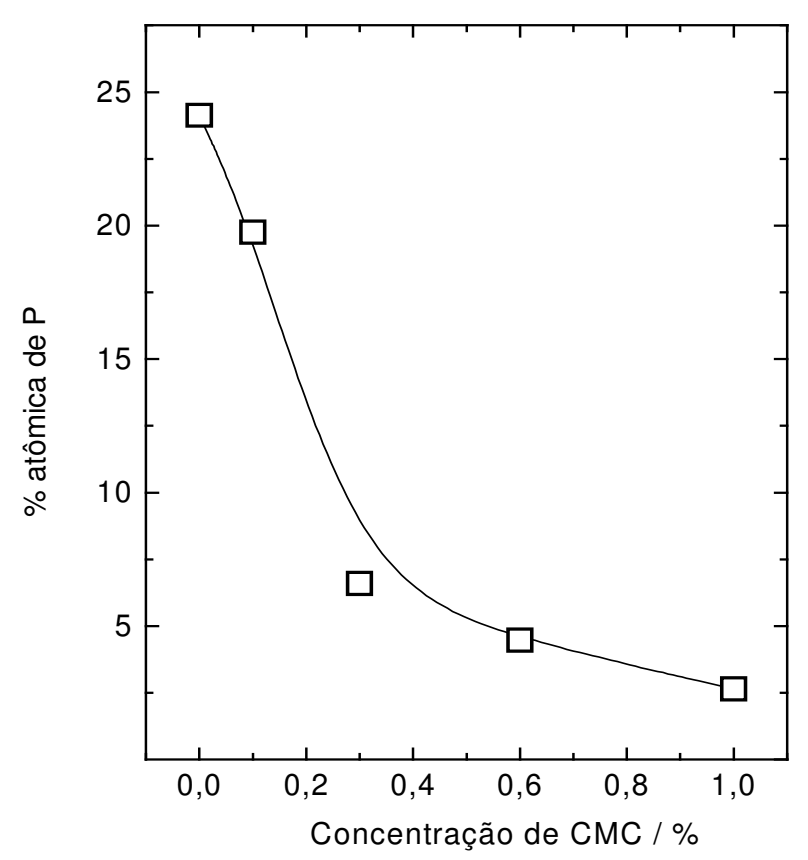

Figura 29. Dependência do conteúdo de P nos polímeros eletrodepositados sobre AISI-304 a partir de $\mathrm{H}_{3} \mathrm{PO}_{4} 1 \mathrm{~mol} \mathrm{~L}^{-1}$ e $0,2 \mathrm{~mol} \mathrm{~L}^{-1}$ de anilina em presença de diferentes concentrações de CMC.

$\mathrm{O}$ conteúdo de $\mathrm{P}$ que é proveniente do ácido dopante $\left(\mathrm{H}_{3} \mathrm{PO}_{4}\right)$ diminui em presença de CMC quando comparado ao da PAni e também com o aumento na concentração de CMC, como mostra a Figura 29. Isto indica que a incorporação de CMC ocorre em sítios que seriam ocupados pelo dopante (grupos - $\mathrm{NH}$ da estrutura da PAni). 


\subsection{A proposta de interação entre a PAni e a CMC}

Com base no predito, em específico espectroscopia no IV e EDX, pode ser proposto que CMC e PAni estão ligadas entre si por ligações de hidrogênio. A diminuição relativa ao conteúdo de fósforo $(\mathrm{P})$ na PAni devido á CMC presente pode ser um indicativo de que a CMC interage com PAni, mediante a formação de ligações de hidrogênio entre os grupos amina da PAni e carbonila presente na CMC (de ácidos carboxílicos, etc.), como sugerido no esquema 1.

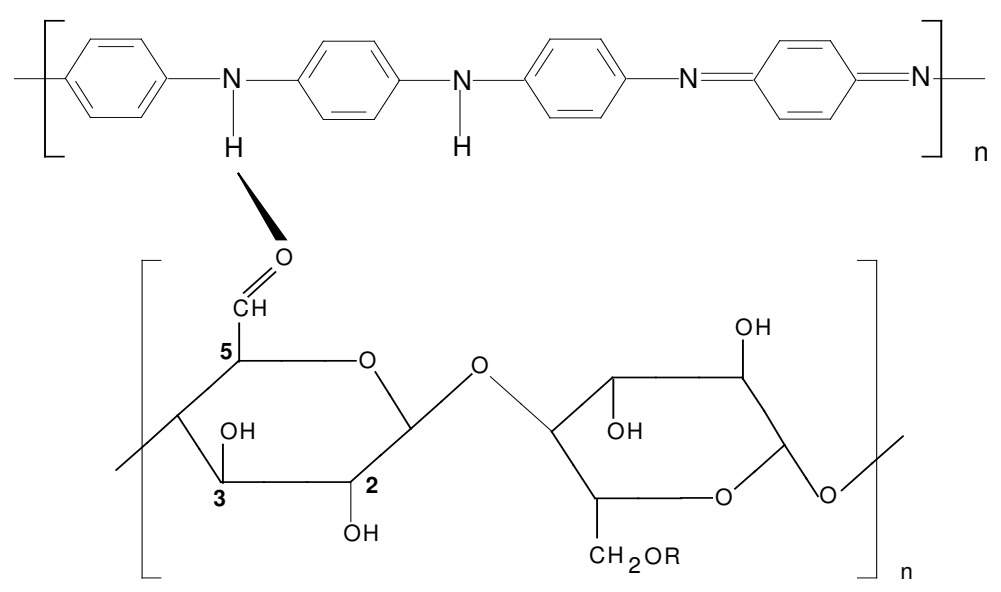

Esquema 1. Interação entre os polímeros de PAni e CMC.

A diminuição no conteúdo de $\mathrm{P}$ observado para a PAni-CMC pode ser atribuído a protonação (em menor extensão) dos nitrogênios imina na PAni devido à interação destes com o grupo hidroxila presente na CMC, como no esquema 2.

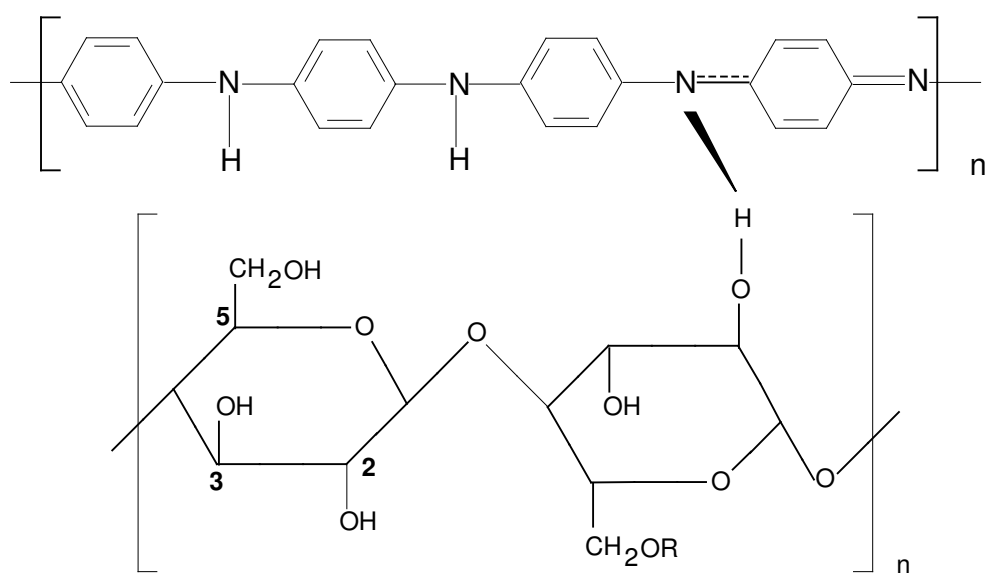

Esquema 2. Interação entre os polímeros de PAni e CMC.

Neste caso, a interação da PAni com a CMC por ligações de hidrogênio se favorecem pela presença de grupos carboxílicos na CMC e de grupamentos imina na PAni. 


\section{Capítulo IV}

\section{Síntese Química e Caracterização de PAni-CMC}

Neste capítulo, dividido em partes, está contida a descrição dos resultados referentes ao estudo sobre a polimerização química de blendas de PAni-CMC. A primeira etapa, trata da obtenção de PAni em presença de diferentes concentrações de CMC, a temperatura constante, propiciando a obtenção dos parâmetros cinéticos de síntese, extraídos das curvas potenciométricas e calorimétricas, além de uma abordagem sobre as diferentes velocidades envolvidas na polimerização. Na etapa seguinte é apresentada a caracterização das blendas de PAni-CMC por espectros no UV-Vis-NIR e infravermelho, do polímero nas formas dopada e desdopada, análises de morfologia por MEV, medidas de condutividade e análise termogravimétrica (TG). Adicionalmente aos resultados deste capítulo, estão feitas comparações das diferenças nas propriedades dos materiais, polimerizados química e eletroquimicamente.

\subsection{Polimerização química de PAni-CMC}

A polimerização química de PAni a partir de solução de $\mathrm{H}_{3} \mathrm{PO}_{4} 1 \mathrm{~mol} \mathrm{~L}^{-1}$ contendo anilina $0,2 \mathrm{~mol} \mathrm{~L}^{-1}$ na presença de diferentes concentrações de CMC, foram realizadas a temperatura de $20^{\circ} \mathrm{C}$ e o tempo total de polimerização foi de 1800 segundos.

O potencial de circuito aberto obtido para PAni-CMC, em diferentes concentrações de CMC é similar ao da PAni, conforme é mostrado na Figura 30. Entretanto, o tempo para obter os valores máximos de potencial $\left(E_{C A}\right)_{\text {máx }}$ aumenta na presença de $0,1 \%$ de $C M C$, quando comparado à PAni. 


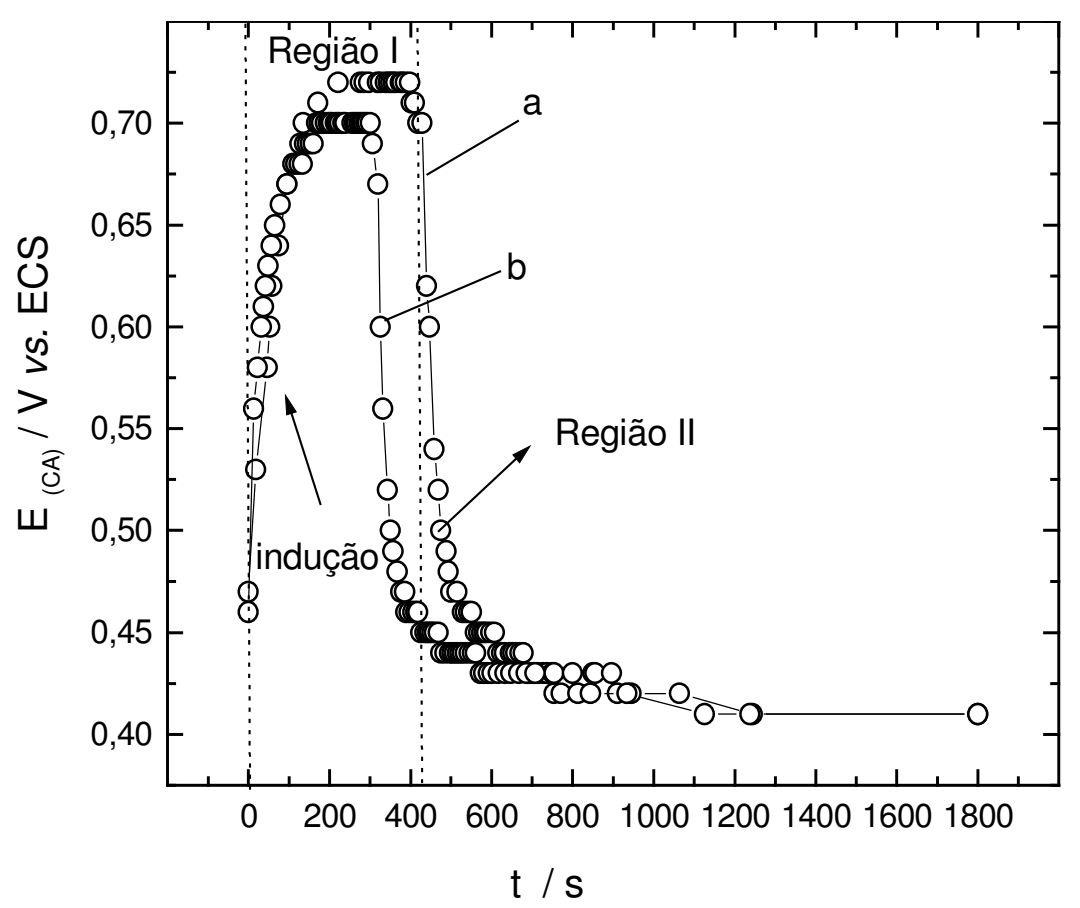

Figura 30. Curvas potenciométricas dos polímeros obtidos a partir de solução de $\mathrm{H}_{3} \mathrm{PO}_{4} 1 \mathrm{~mol}$ $\mathrm{L}^{-1}$ contendo $0,2 \mathrm{~mol} \mathrm{~L}^{-1}$ anilina e CMC nas concentrações de: (a) $0,1 \%$ e (b) $1 \%$.

Um aumento na concentração de $\mathrm{CMC}(0,1$ a $1 \%)$ diminui o tempo para que $\left(\mathrm{E}_{\mathrm{CA}}\right)_{\text {máx }}$ seja atingido, indicativo de que a presença de $\mathrm{CMC}$ no meio reacional reduz o tempo de polimerização da PAni, ou seja, para alcançar o estado pernigranilina (auto catalítico). Também, em presença de CMC o tempo de ocorrência do estágio de propagação da cadeia de PAni é reduzido (Fig. 30, região I). Isto pode ser atribuído ao aumento de espécies no meio reacional com o aumento na concentração de CMC, o qual torna difícil o transporte e difusão das espécies, bloqueando o acoplamento de monômero em sítios ativos da cadeia. Assim, o CMC que está presente em excesso mais facilmente ocupa estes sítios na cadeia.

No início da polimerização, todos os componentes do meio reacional (monômero, agente oxidante e $\mathrm{CMC}$ ) são solúveis em meio aquoso e a reação prossegue sob condições homogêneas. A PAni é insolúvel sob as mesmas condições e pequenas partículas primárias de PAni precipitam na fase aquosa, enquanto a polimerização prossegue. Uma fração de partículas primárias têm a incorporação (enxertada ou adsorvida) de CMC sobre elas. 


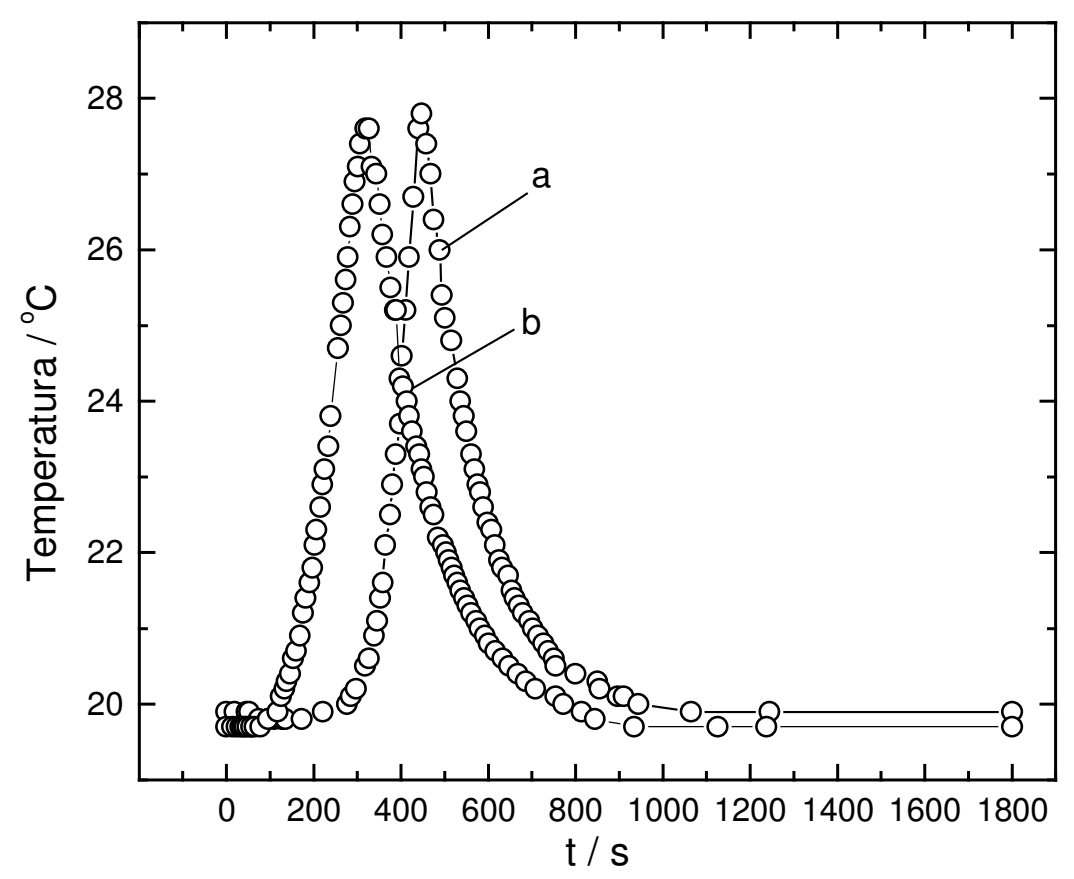

Figura 31. Curvas calorimétricas dos polímeros obtidos a partir de solução de $\mathrm{H}_{3} \mathrm{PO}_{4} 1 \mathrm{~mol} \mathrm{~L}^{-1}$ contendo $0,2 \mathrm{~mol} \mathrm{~L}^{-1}$ anilina e CMC nas concentrações de: (a) $0,1 \%$ e (b) $1 \%$.

Então, ambas partículas primárias, com e sem $\mathrm{CMC}$, podem se agregar e originar partículas em dispersão.

Três fatores podem afetar a formação de partículas em dispersão: (i) a velocidade na qual PAni é produzida (velocidade de polimerização $\left(V_{p}\right)$; (ii) a eficiência com que a $C M C$ incorpora-se na partícula primária (velocidade de adsorção $\left(\mathrm{V}_{\mathrm{ad}}\right)$; e (iii) processos de difusão e transporte que envolve a formação das partículas em dispersão a partir das partículas primária $\left(\mathrm{V}_{\mathrm{d}}\right)$.

Quando a velocidade de formação de PAni é mais rápida do que a difusão de CMC, uma diminuição local de CMC livre por partículas primárias de PAni pode ocorrer em sítios da cadeia de PAni, no qual a polimerização tem lugar. Neste elemento de volume a polimerização prossegue então na ausência de CMC (no modo de precipitação). Assim, mais e mais partículas primárias sem CMC são produzidas pelo mecanismo auto-catalítico da PAni. Neste caso, as partículas não difundem por longas distâncias e portanto, podem se agregar, o que ocorre quando a concentração de CMC varia de 0,1 a 0,6 \%. 
Entretanto, para concentrações de CMC superiores a 0,6\%, quando as partículas primárias de PAni são produzidas lentamente durante a polimerização, elas podem ser eficientemente adsorvidas pela CMC. A concentração localmente reduzida de CMC livre é compensada pela difusão de CMC a partir de outras regiões. Uma quantidade suficiente de CMC é incorporada e a agregação controlada por difusão das partículas primárias conduz à formação de partículas em dispersão [46,132]. Devido ao mecanismo auto-catalítico da PAni, a polimerização predomina preferencialmente em sítios muito próximos da PAni (por exemplo, em superfície das partículas em dispersão). A sobrecamada superficial de CMC impede as esferas de PAni de se agregarem [47].

Apesar disso, a PAni produzida que é o único componente insolúvel da mistura reacional, todos reagentes e produtos estão presentes, principalmente como íons, e se agrupam em formas de ácidos e sais. Essas partículas tendem a ser de tamanho submicrométricos e esféricas, devido a sobrecamada superficial de CMC impedir os núcleos de PAni de se agregarem [43].

Estes resultados, em parte, estão em concordância com os de Banerjee [61], o qual relata que a polimerização de PAni a $2^{\circ} \mathrm{C}$, usando $\mathrm{CMC}$ em meio aquoso resulta na precipitação macroscópica de partículas de PAni, somente quando a quantidade de CMC for inferior à $1 \%$ em peso, sendo que para quantidades elevadas, superiores a $5 \%$, podem ser obtidas dispersões estáveis. A precipitação macroscópica de partículas de PAni, neste trabalho, ocorre para baixas concentrações de CMC (menores que 0,6 \% de CMC) e, tais diferenças podem ser atribuídas á temperatura de polimerização utilizada que neste estudo foi de $20^{\circ} \mathrm{C}$.

O valor máximo de temperatura de polimerização $\left(T_{\text {máx }}\right)$, obtido a partir da Figura 31 , diminui quando 0,1\% CMC está presente, isto comparado a PAni $\left(29,2^{\circ} \mathrm{C}\right)$, conforme a Figura 32. Isto é indicativo de que a incorporação de CMC, em sítios da PAni, torna o processo de polimerização menos exotérmico. Entretanto, quando a concentração de CMC varia de $0,1 \mathrm{a}$ 1\% um máximo valor para $T_{\text {máx }}$ é obtido quando a concentração de CMC utilizada é 0,3\%, sendo que para as demais concentrações $T_{\text {máx }}$ se mantém constante. 


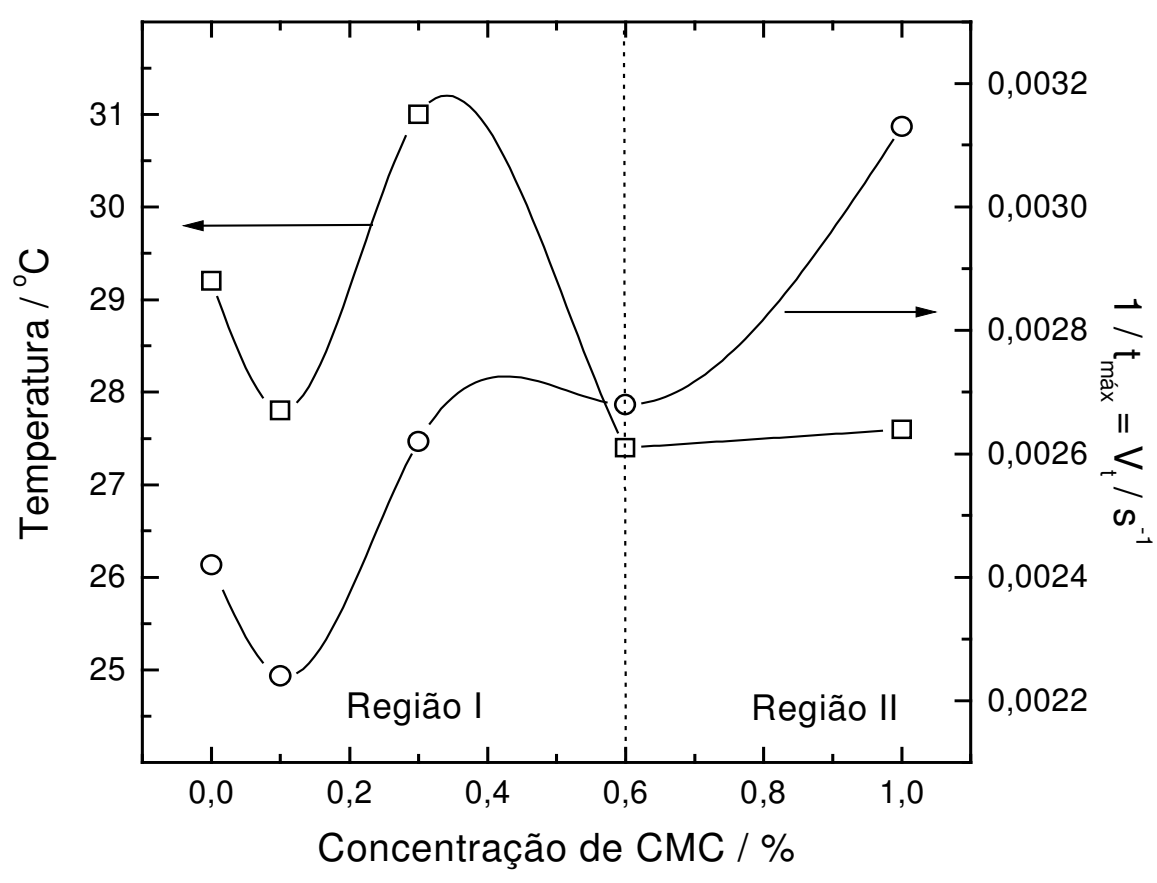

Figura 32. Máxima temperatura de síntese de PAni-CMC e o inverso do máximo do tempo $\left(1 / t_{\text {máx }}\right)$ para obter essa temperatura (equivalente a velocidade global do sistema) quando diferentes concentrações de CMC foram utilizadas.

$\mathrm{Na}$ polimerização de PAni-CMC pode ser considerado que tanto a velocidade de polimerização $\left(\mathrm{V}_{\mathrm{p}}\right)$ quanto a velocidade de adsorção $\left(\mathrm{V}_{\mathrm{ad}}\right)$ são as velocidades que controlam o sistema. Assim, a velocidade global do sistema $\left(V_{t}\right)$ é composta da soma de $V_{a d}, V_{p}$ e $V$, onde $V$ constitui todas as velocidade dos demais processos que possam ocorrer, como por exemplo processo de difusão, etc.

Todas essas velocidades são dependentes das concentrações de espécies no meio, entretanto, aqui somente a concentração de CMC será considerada. A partir disto, podem ser propostas duas regiões na Fig.32, para curva da velocidade global do sistema, quando diferente concentrações de CMC foram utilizadas (Figura 33).

A região I da Fig.32, na qual a $V_{p}$ é maior que a soma de $V_{a d}$ e $V$, com a promoção de precipitados macroscópicos de PAni, nas concentrações de 0,1 a 0,6 \% de CMC. Uma outra, região II (Fig.32), cuja soma de $V_{a d}$ e $V$ é maior que a $V_{p}$ e dispersão de PAni é obtida, para concentração de CMC superior a 0,6\%. 

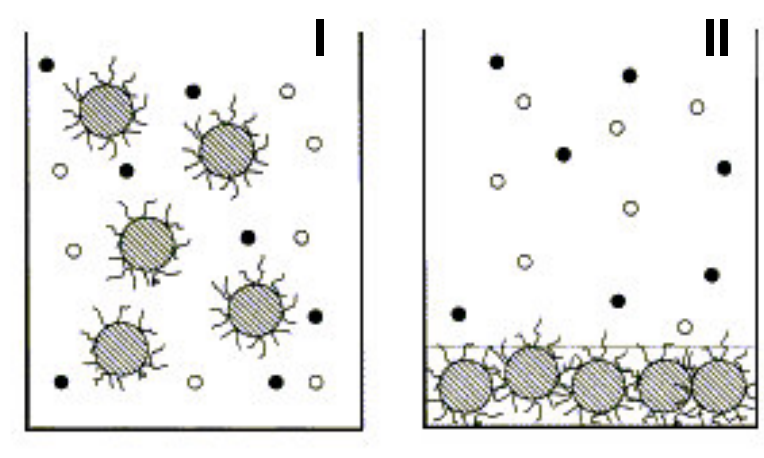

Concentrações de CMC de 0,1 a 0,6\%
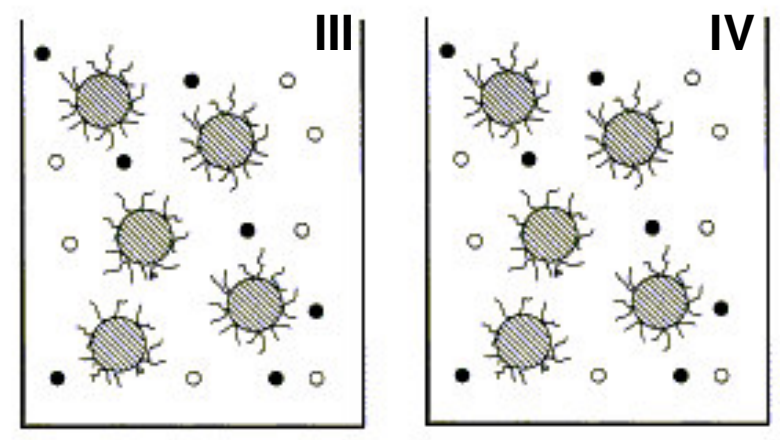

Concentrações de $\mathrm{CMC}>$ que $0,6 \%$

Figura 33. Esquema de formação de precipitados de PAni-CMC e dipersão de PAni-CMC (PAni, esfera rachurada) obtida a partir da agregação de sobrecamda superficial de CMC. Cátions $(\bullet$ ) e ânions $(\mathbf{0})$ em dispersão no meio. (I e II) concentrações de CMC $<0,6$ \% e (III e IV) concentrações de CMC maior que $0,6 \%$.

Com base nesses resultados pode ser proposto um esquema geral para a polimerização química de PAni em presença de solução aquosa de CMC, na qual o efeito da concentração de CMC é considerado. Para uma polimerização por dispersão ocorrer, a CMC deve adsorver sobre a partícula precipitada e o meio de polimerização deve ter um solvente adequado para o estabilizador (esquema I e III). A polimerização por dispersão usando CMC (o estabilizador estérico em água) resulta em precipitados macroscópicos de partículas de PAni, quando a quantidade de CMC for menor que $0,6 \%$ (esquema II).

Entretanto, usando altas quantidades de CMC, por exemplo maiores que 0,6 \% de CMC, dispersões estáveis podem ser obtidas (esquema IV). Isto é devido à elevada viscosidade das soluções concentradas de CMC que não promovem a sedimentação das partículas no meio reacional, ocorrendo a formação de uma suspensão de PAni. 


\subsection{Caracterização de PAni-CMC química}

\subsubsection{Espectroscopia no UV-Vis-NIR}

Os polímeros obtidos quimicamente, na forma desdopada, foram dissolvidos em 1-metil2-pirrolidona (NMP) e o espectro de UV-VIS-NIR registrado. Também, foram registrados os espectros de UV-Vis-NIR de PAni-CMC e PAni dopados com $\mathrm{HCl} 5 \mathrm{~mol} \mathrm{~L}^{-1}$, os quais são mostrados na Figura $34(\mathrm{~A})$.

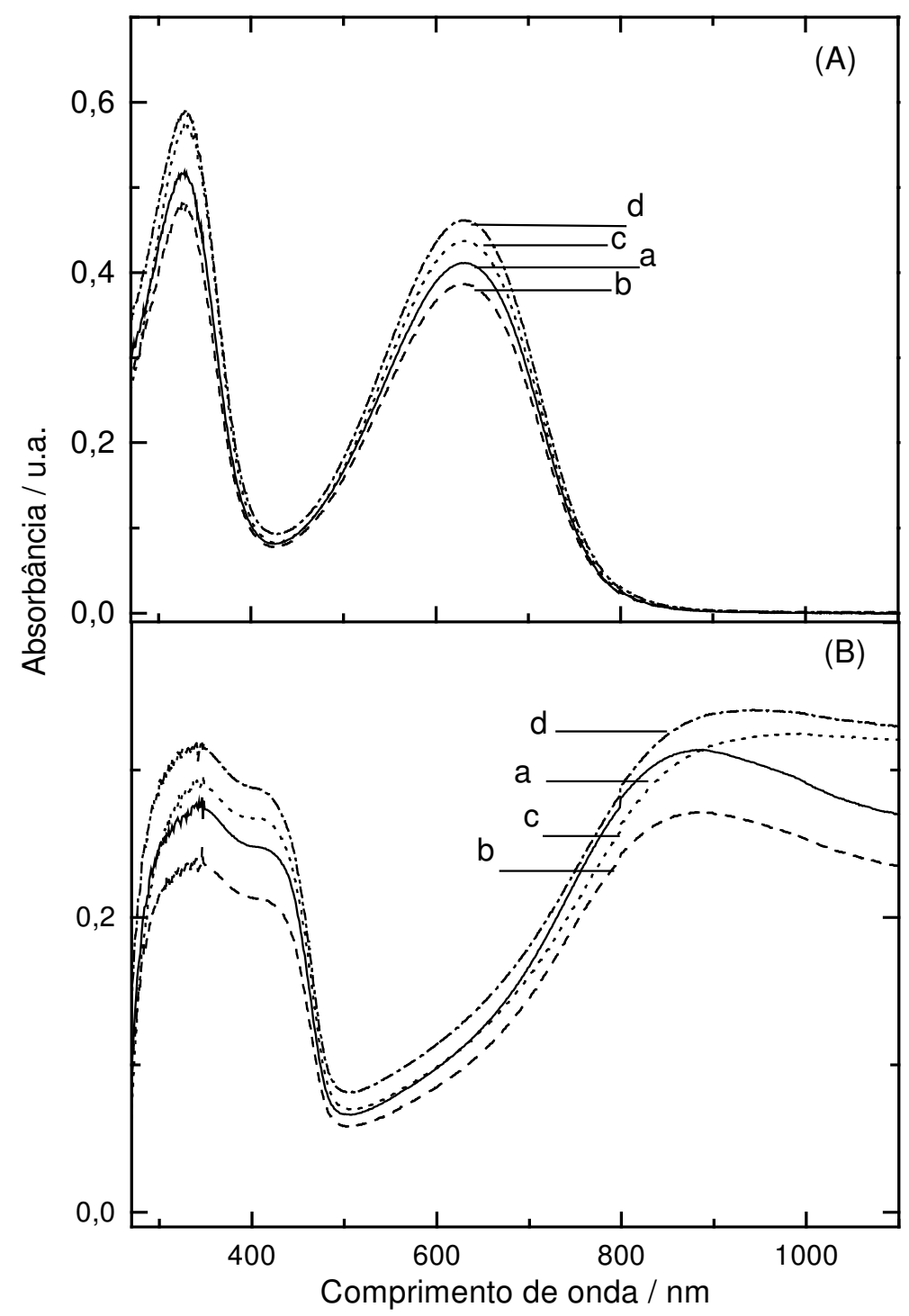

Figura 34. Espectro no UV-Vis-NIR dos polímeros quimicamente sintetizados: (a) PAni e PAniCMC (b) 0,1; (c) 0,3 e (d) 0,6\% de CMC. Polímeros (A) desdopados e (B) dopados. 
Assim como, para PAni-CMC eletropolimerizada, os espectros dos polímeros quimicamente obtidos desdopados apresentam banda de absorção a 320 e a $630 \mathrm{~nm}$ atribuídas à transições $\pi-\pi^{\star}$ dos anéis benzênicos e as excitações de seguimentos iminas (bandas excitônicas), respectivamente $[12,13,15,126]$.

Quando dopados (Fig. 34 (b)), três bandas de absorção ao redor de 340, 420 e 820 nm são observadas no espectro. A banda a $420 \mathrm{~nm}$ é atribuída aos radicais cátions que se formam devido ao processo de dopagem. Enquanto que, a banda larga ao redor de $830 \mathrm{~nm}$ é atribuída aos transportadores de carga na cadeia polimérica, ou seja, a transição da banda excitônica para a banda bipolarônica $[12,13,15,126]$.

Para os polímeros obtidos quimicamente há indícios de que o aumento na concentração de CMC promove maior mobilidade eletrônica na estrutura. Isto pode ser constatado pelo deslocamento da transição da banda excitônica (630 nm) à banda bipolarônica (830 nm), uma região de baixa energia, quando a concentração de CMC na estrutura polimérica aumenta.

Comparativamente, o comportamento eletrônico de PAni-CMC, química ou eletroquimicamente preparada, apresentam pequenas diferenças que podem ser atribuídas simplesmente ao método de síntese.

\subsubsection{Espectroscopia no infravermelho (IV)}

Os espectros no infravermelho dos polímeros obtidos quimicamente (PAni e PAni-CMC), a partir de diferentes concentrações de $\operatorname{CMC}(0,1$ a 0,6\%), são mostrados na Figuras 35 e 36, nas formas dopada e desdopada, respectivamente.

Os espectros das blendas de PAni-CMC obtidas quimicamente não diferem significativamente dos obtidos eletroquimicamente. No entanto, algumas bandas foram mais evidenciadas e essas receberam maior atenção. A PAni demonstra suas principais bandas de absorção para os anéis quinóides e benzenóides a 1458 e $1560 \mathrm{~cm}^{-1}$, respectivamente [133], os quais, em geral para PAni-CMC são similares. 


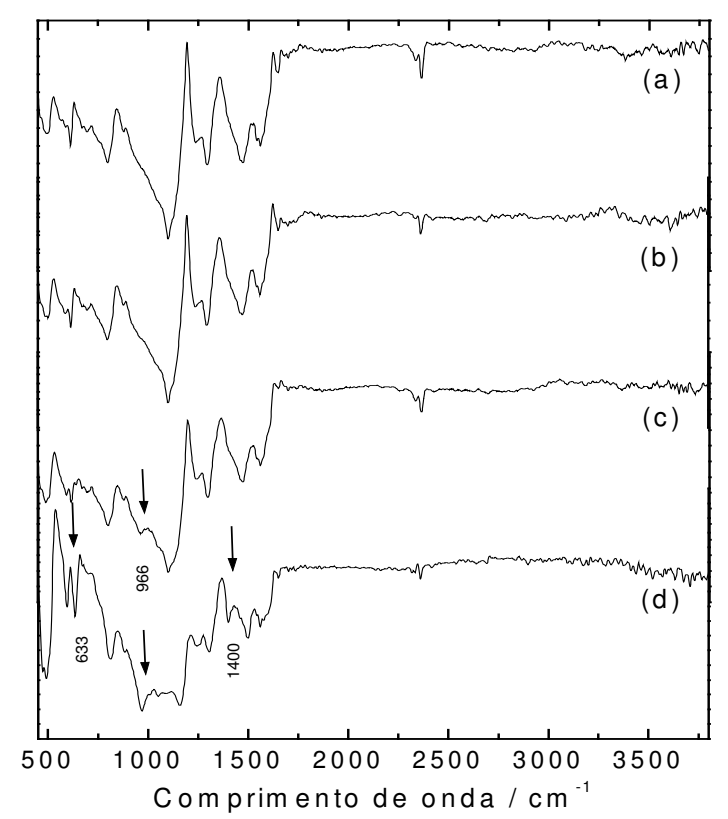

Figura 35. Espectro no infravermelho de (a) PAni e da blendas PAni-CMC obtidas a partir de $\mathrm{H}_{3} \mathrm{PO}_{4} 1 \mathrm{~mol} \mathrm{~L}^{-1}$ contendo $0,2 \mathrm{~mol} \mathrm{~L}^{-1}$ anilina e CMC na concentração de (b) 0,$1 ;$ (c) 0,3 e (d) $0,6 \%$. Na forma dopada.

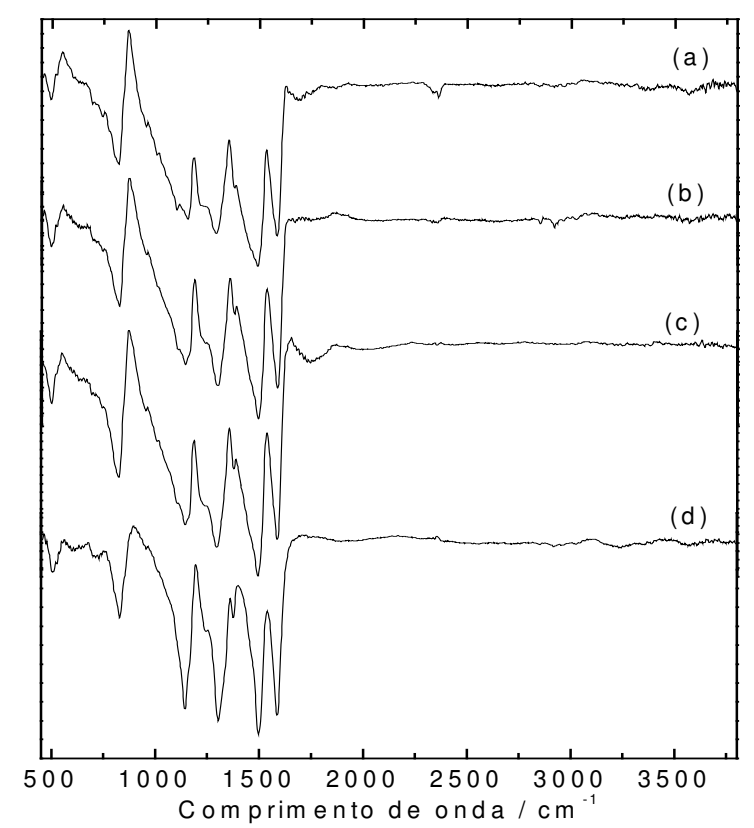

Figura 36. Espectro no infravermelho de (a) PAni e da blendas PAni-CMC obtidas a partir de $\mathrm{H}_{3} \mathrm{PO}_{4} 1 \mathrm{~mol} \mathrm{~L}^{-1}$ contendo $0,2 \mathrm{~mol} \mathrm{~L}^{-1}$ anilina e CMC na concentração de (b) 0,1 ; (c) 0,3 e (d) $0,6 \%$. Na forma desdopada. 
A blenda de PAni-CMC $0,6 \%$ demonstra um maior desdobramento das bandas como resultado da modificação estrutural, primeiramente devido á ligações de hidrogênio formadas entre as ligações $\mathrm{N}-\mathrm{H}$ da PAni e os grupos $\mathrm{C}=\mathrm{O}$ da $\mathrm{CMC}$.

A forte banda da ligação C-H de aromático no plano para a PAni evidencia na região ao redor $1163 \mathrm{~cm}^{-1}$, no entanto, para PAni-CMC uma banda franca ou desdobrada pode ser observada, indicando também uma significativa modificação estrutural da PAni pela interação com CMC [134]. A banda referente ao modo de estiramento da carbonila da CMC, para a blenda PAni-CMC, evidencia-se entre $1450-1400 \mathrm{~cm}^{-1}$ como resultado da interação por ligação de hidrogênio. A presença de duas bandas adicionais no espectro de PAni-CMC a 1043 e 966 $\mathrm{cm}^{-1}$, atribuídas a modos de vibração da ligação $\mathrm{O}-\mathrm{H}$ e deformação $\mathrm{O}-\mathrm{H}$, respectivamente, suportam a existência das ligações de hidrogênio [135].

A fraca banda de estiramento da ligação N-H na PAni aparece ao redor de $3448 \mathrm{~cm}^{-1}$. No entanto, essa banda para blenda PAni-CMC se torna mais fraca ou inexiste. Isto indica uma significativa ocorrência de ligação de hidrogênio entre a PAni e a CMC, indicando que átomos de nitrogênio dos segmentos benzenóides da PAni formam ligações de hidrogênio com a CMC.

Os espectros das blendas de PAni-CMC desdopadas (Fig. 36) mostram-se similares ao da PAni independente da concentração de CMC. Isto evidencia que durante o processo de desdopagem do material houve uma solubilização de parte do $\mathrm{CMC}$ da estrutura polimérica. Solubilização parcial, porque, no espectro da PAni-CMC em concentrações superiores a 0,3 \%, ainda se evidência a presença da banda ao redor de $1400 \mathrm{~cm}^{-1}$, a qual indica que a CMC está incorporada à estrutura da blenda.

\subsubsection{Condutividade}

A Figura 37 ilustra a dependência da condutividade das blendas de PAni CMC como uma função da concentração de CMC utilizada na polimerização.

A condutividade diminui com a presença de CMC (polímero não condutor) nas blendas, indicativo de que as interações estruturais entre os dois polímeros promovem um impedimento

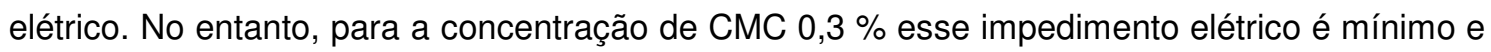
as interações estruturais nessas condições favorecem a condução elétrica. 


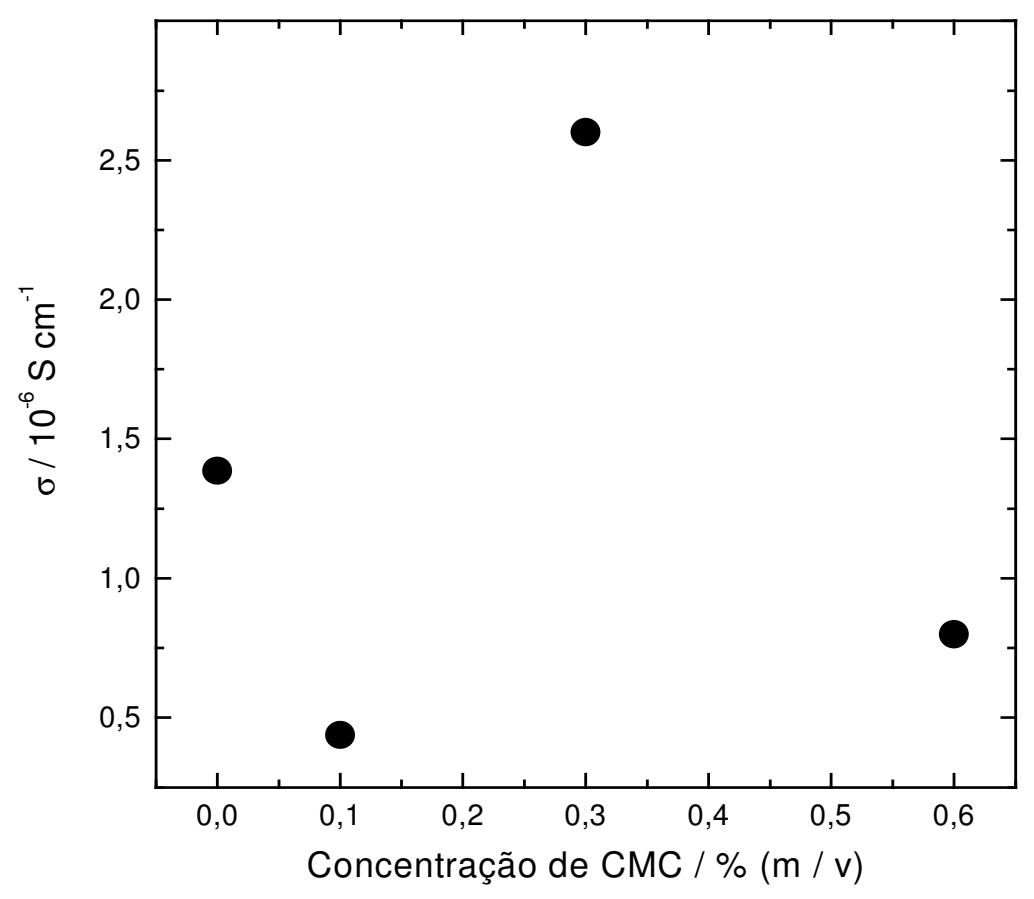

Figura 37. Condutividade elétrica de PAni e PAni-CMC como uma função das diferentes concentrações de CMC.

A condutividade das blendas PAni-CMC é em geral, menor do que a da PAni, o que foi também observado por Banerjee [61], apesar das diferenças nas condições de polimerização (meio não aquoso, eletrólito, etc.).

Comparativamente, a condutividade de PAni-CMC eletropolimerizada é superior a das obtidas quimicamente, isto devido ao fato do método eletroquímico promover uma estrutura mais regular e ordenada. Para ambos os métodos, quando se utiliza a concentração de CMC 0,3\%, um valor máximo de condutividade é obtido.

\subsubsection{Microscopia eletrônica de varredura (MEV)}

As micrografias de PAni e de PAni-CMC (0,1 a $1 \% \mathrm{CMC})$ quimicamente obtidas são mostradas na Figura 38. As estruturas morfológicas das blendas de PAni-CMC não dependem da concentração de CMC e apresentam uma estrutura globular similar a de PAni. 


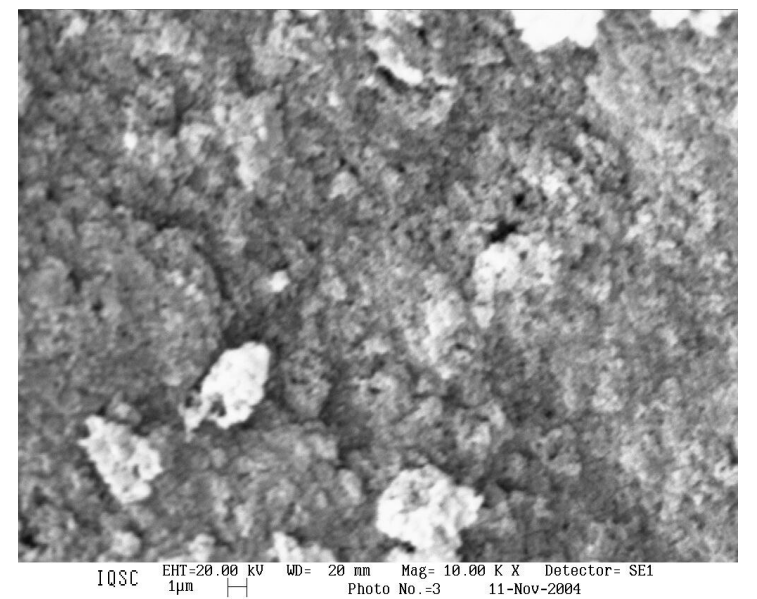

(a)

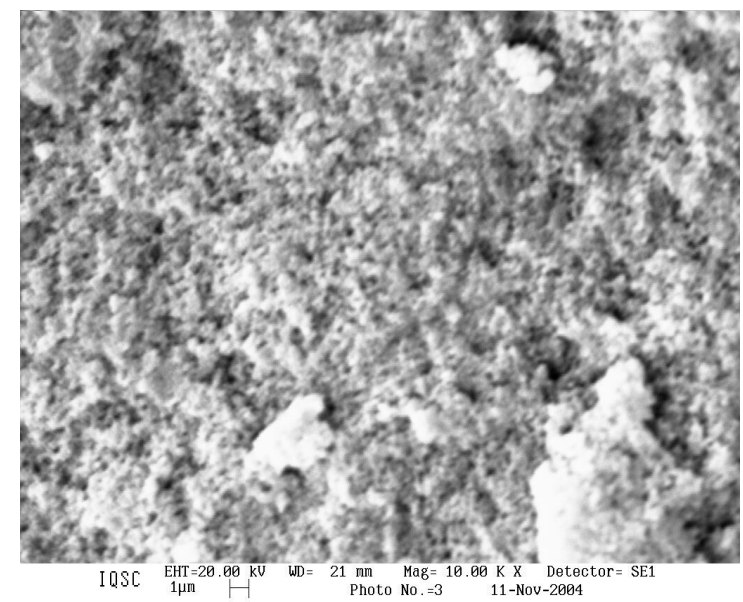

(c)

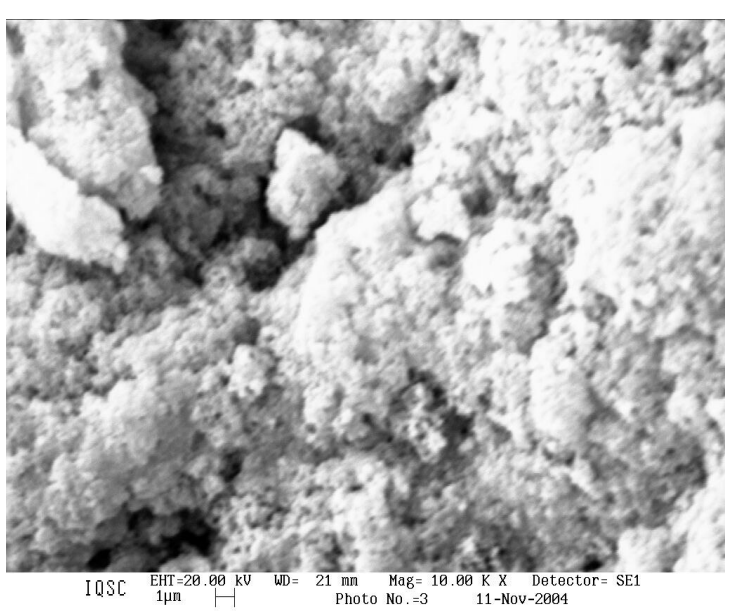

(b)

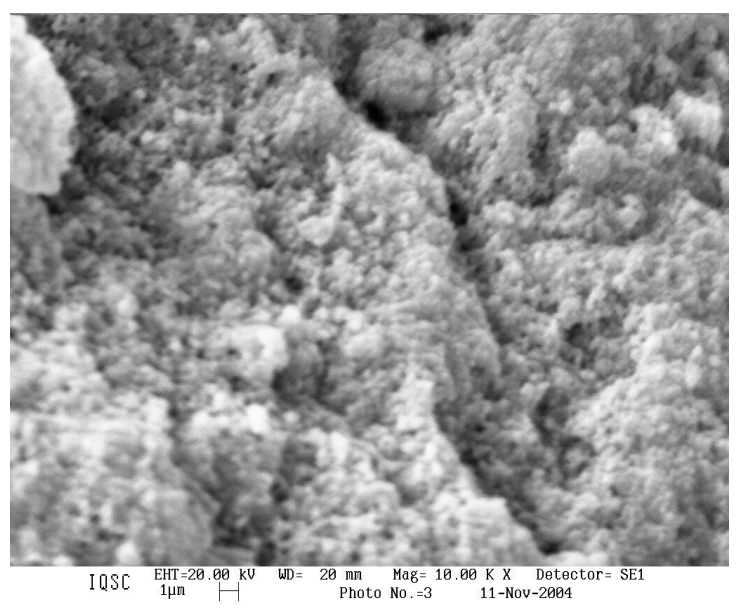

(d)

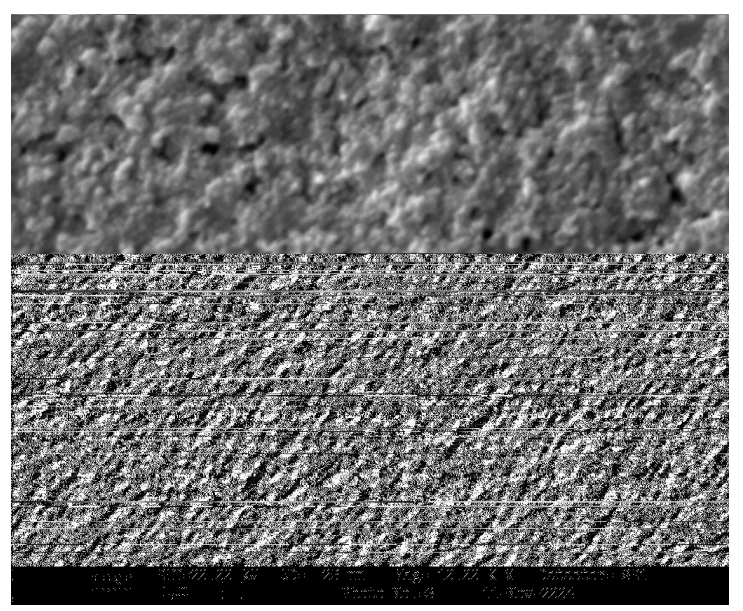

(e)

Figura 38. Micrografias das partículas dos polímeros dopados (a) precipitados de PAni e blendas de PAni-CMC preparadas a partir de (b) $0,1 \%$; (c) $0,3 \%$ e (d) $0,6 \%$ de CMC; (e) filme obtido a partir da dispersão de PAni-CMC 1\%. 
O aumento na concentração de CMC de 0,1 a $0,6 \%$ (Fig. 38 (b) a (d) promove um material polimérico de aspecto esponjoso, aerado comparado ao da PAni. Isso pode ser devido à interação da PAni com a CMC via as ligações de hidrogênio e também, como resultado da incorporação de CMC na estrutura da PAni.

Similarmente, a dispersão de PAni-CMC (Fig.38 (e)) apresenta uma estrutura globular similar ao precipitado de PAni-CMC.

No geral, a estrutura de PAni-CMC, quimicamente obtida, difere significativamente da PAni-CMC obtida eletroquimicamente. A influência da concentração de CMC sobre a morfologia de PAni-CMC eletropolimerizada é mais pronunciada, devido ao efeito da concentração de CMC sobre a velocidade de polimerização, a qual tende a reduzir com o aumento da concentração de CMC, favorecendo um maior ordenamento estrutural.

\subsubsection{Análise termogravimétrica (TG)}

A estabilidade térmica da CMC, PAni e das blendas de PAni-CMC obtidas quimicamente, a partir de diferentes concentrações de CMC, foi estudada por análise termogravimétrica (Figura 39). Para a CMC (Fig. 39 (a)) a primeira perda de massa ocorre entre 25 e $120^{\circ} \mathrm{C}$, sendo atribuída a água contida no polímero. A temperaturas superiores, o processo de degradação da CMC ocorre em duas etapas: uma segunda perda de massa ao redor de $48 \%$ entre 230 a $270{ }^{\circ} \mathrm{C}$, e uma terceira perda de massa cerca de $19,5 \%$, entre $590{ }^{\circ} \mathrm{C}$ a $664{ }^{\circ} \mathrm{C}$, as quais são atribuídas a degradação térmica da CMC. Na degradação térmica da CMC ocorre a formação de cerca de $17,4 \%$ de resíduo, correspondente ao óxido de sódio proveniente da CMC [51]. 


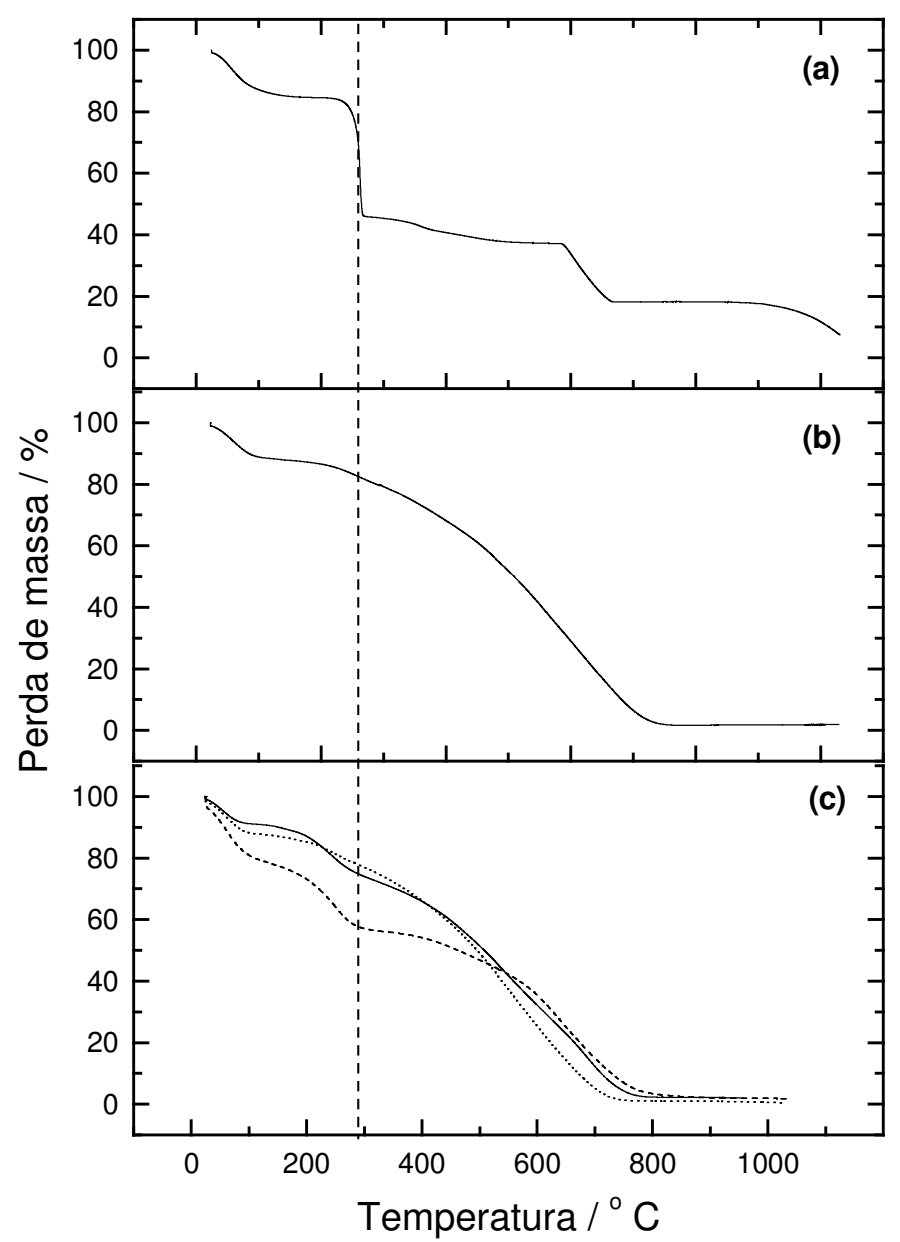

Figura 39. Curvas termogravimétricas para (a) CMC comercial; (b) PAni; (c) blendas PAni-CMC obtidas a partir de CMC: (-) 0,1\%; (…) 0,3\% e (-----) 0,6\% de CMC.

Para a PAni (Fig. 39 (b)) uma perda de massa entre 25 a $120^{\circ} \mathrm{C}$ é atribuída à perda de água absorvida pelo polímero e ao dopante (alguma das espécies do ácido $\mathrm{H}_{3} \mathrm{PO}_{4}$ ). Ao elevar a temperatura, o processo de degradação da PAni ocorre em uma etapa, com uma significativa perda de massa, cerca de $86,5 \%$ entre 180 a $700{ }^{\circ} \mathrm{C}$. Na degradação térmica completa da PAni (acima de $700{ }^{\circ} \mathrm{C}$ ) ocorre a formação de 1,71\% de resíduo, o qual pode ser atribuído a alguma espécie de óxido (tal como óxido de fósforo) proveniente do dopante.

O comportamento termogravimétrico de PAni-CMC (Fig. 39 (c)) é muito mais similar ao da PAni, apresentando uma perda de massa entre $25^{\circ} \mathrm{C}$ e $120^{\circ} \mathrm{C}$ referente à perda de água absorvida e ao dopante (proveniente do ácido $\mathrm{H}_{3} \mathrm{PO}_{4}$ ) [136]. 


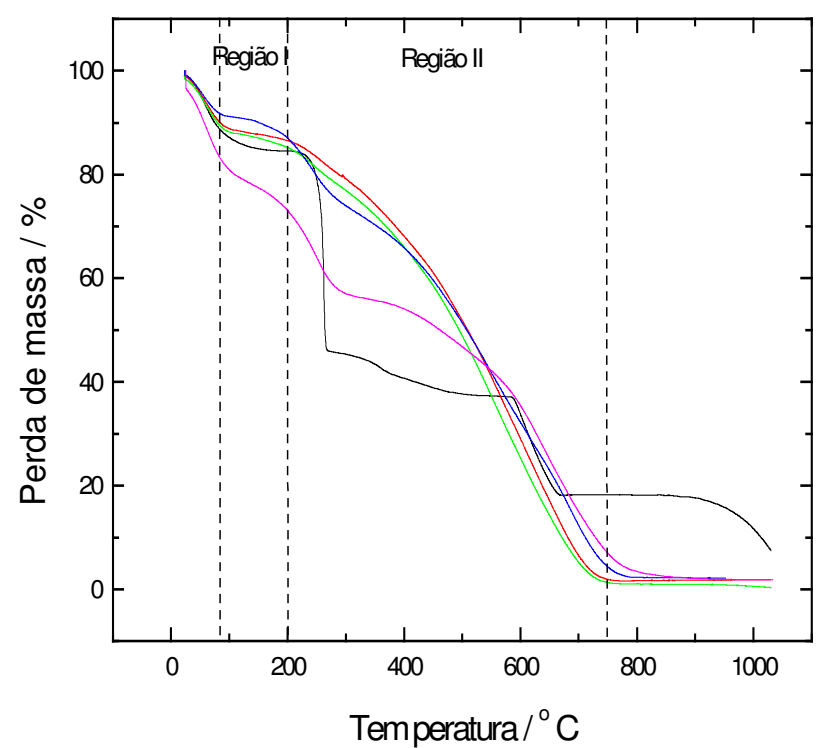

Figura 40. Curvas termogravimétricas para $(-)$ CMC comercial e $(-)$ PAni; Blendas de PAniCMC obtidas a partir de $(-)$ 0,1\%; (-) 0,3\% e (- ) 0,6\% CMC.

A perda de massa nesse estágio da degradação térmica varia de acordo com o conteúdo de CMC utilizado na síntese (entre 12,6 a 12,0\%). A degradação de PAni-CMC ocorre entre 180 a $730^{\circ} \mathrm{C}$. O conteúdo em resíduos varia entre 1,27 a 2,55\%, na degradação completa da PAni-CMC, os quais podem ser atribuídos aos óxidos de sódios (provenientes da CMC) e de fósforo (proveniente do dopante) e, obviamente, quanto maior a concentração de CMC, maior a quantidade de resíduo.

Embora as curvas termogravimétricas para as blendas de PAni-CMC tenham a mesma forma, comparando as curvas com as da PAni e da CMC (conforme a Figura 40), observa-se que: (i) quando a concentração de $\mathrm{CMC}$ aumenta $(0,1$ a $0,3 \%$ de $\mathrm{CMC})$ a blenda apresenta menor perda de água e ácido $\mathrm{H}_{3} \mathrm{PO}_{4}$ (região I), lembrando que $\mathrm{CMC}$ e PAni são substâncias higroscópicas $[5,6,12]$. No entanto, as blendas de PAni-CMC demonstram menor perda de massa correspondente à perda de umidade, indicando que a interação entre a PAni e a CMC promove características mais hidrofóbicas às blendas do que aos polímeros individuais.

Este aumento na estabilidade térmica (Fig. 40 - região II) pode ser devido ao tipo de interação que ocorre entre os dois polímeros. Um comportamento similar foi observado por diferentes autores em estudos por análise termogravimétrica de blendas de PAni-poliacrilamida [137] e de PAni-lignina [138], tendo sido sugerindo a formação de interação do tipo ligação de 
hidrogênio entre os polímeros, a qual promoveu uma maior estabilidade térmica as blendas. Neste trabalho, esta observação está suportada pelos estudos de infravermelho que evidenciaram a interação entre a PAni e a CMC por ligação de hidrogênio. 


\section{Capítulo V}

\section{Síntese e Caracterização de PAni-DBSA Eletropolimerizada}

Este capítulo é constituído pelos resultados sobre a polimerização eletroquímica de PAni-DBSA sobre eletrodos de Pt e AISI-304. Nele estão descritas as investigações preliminares sobre os comportamentos do DBSA em meio aquoso, eletroquímico dos eletrodos em solução de DBSA e sobre a estabilidade da solução de DBSA em presença de diferentes concentrações de monômero. Em continuidade, estão relatados os estudos da influência de concentração de monômero e uma abordagem cinética sobre a eletropolimerização dos filmes de PAni-DBSA sobre os diferentes substratos (Pt e AISI-304). Posteriormente, a caracterização dos filmes de PAni-DBSA é descrita na forma de análises sobre o comportamento eletroquímico dos filmes, espectros no UV-Vis-NIR, infravermelho, análises morfológicas por MEV e medidas de condutividade.

\subsection{Estudos preliminares sobre a eletropolimerização de PAni-DBSA}

O processo de eletropolimerização de PAni a partir de soluções contendo DBSA consistiu de investigações preliminares: (i) do comportamento do DBSA em meio aquoso; (ii) do comportamento eletroquímico dos eletrodos de Pt e AISI-304 em solução de DBSA, sem anilina e; (iii) sobre a estabilidade da solução de DBSA em presença de anilina. A importância desses estudos está no fato da inexistência em literatura sobre a eletropolimerização de PAni-DBSA por métodos eletroquímicos, visto que, alguns parâmetros, tais como, a concentração micelar crítica do DBSA, o intervalo de potencial de polimerização e o pH da solução de DBSA em presença de anilina, são relevantes na polimerização eletroquímica, não estão ainda determinados. 


\subsubsection{Comportamento do DBSA em meio aquoso}

A determinação da concentração micelar crítica $(\mathrm{cmc})$ do DBSA em meio aquoso, foi realizada pelo método condutimétrico. Para tal, alíquotas de DBSA foram adicionadas a volumes conhecidos de água. Em seqüência a adição, a solução foi agitada e observado o valor de condutividade da amostra. O valor de condutividade resultante foi convertido em condutância e, após a determinação da concentração final de DBSA para cada alíquota, esta foi representada em função da condutância, conforme a Figura 41. A concentração micelar crítica do DBSA em meio aquoso foi determinada no ponto onde ocorre uma variação brusca da dependência da condutância da solução em função da concentração de DBSA.

A investigação da concentração micelar crítica do DBSA foi motivada pela ausência de estudos em literatura sobre o comportamento da forma ácida, sendo que a concentração micelar crítica da forma sódica (dodecilbenzeno sulfonato de sódio - SDS) pode ser encontrada em literatura [139-141]. Conforme pode ser observado pela Figura 41 a concentração micelar crítica do DBSA em meio aquoso é $1,34 \times 10^{-3} \mathrm{~mol} \mathrm{~L}^{-1}$. Sharma et al. [141] determinaram a concentração micelar crítica do dodecilbenzeno sulfonato de sódio a $25^{\circ} \mathrm{C}$ em presença e em ausência de aditivos (piridina e picolinas) e determinaram o valor da cmc em 2,1 $\times 10^{-3} \mathrm{~mol} \mathrm{~L}^{-1}$.

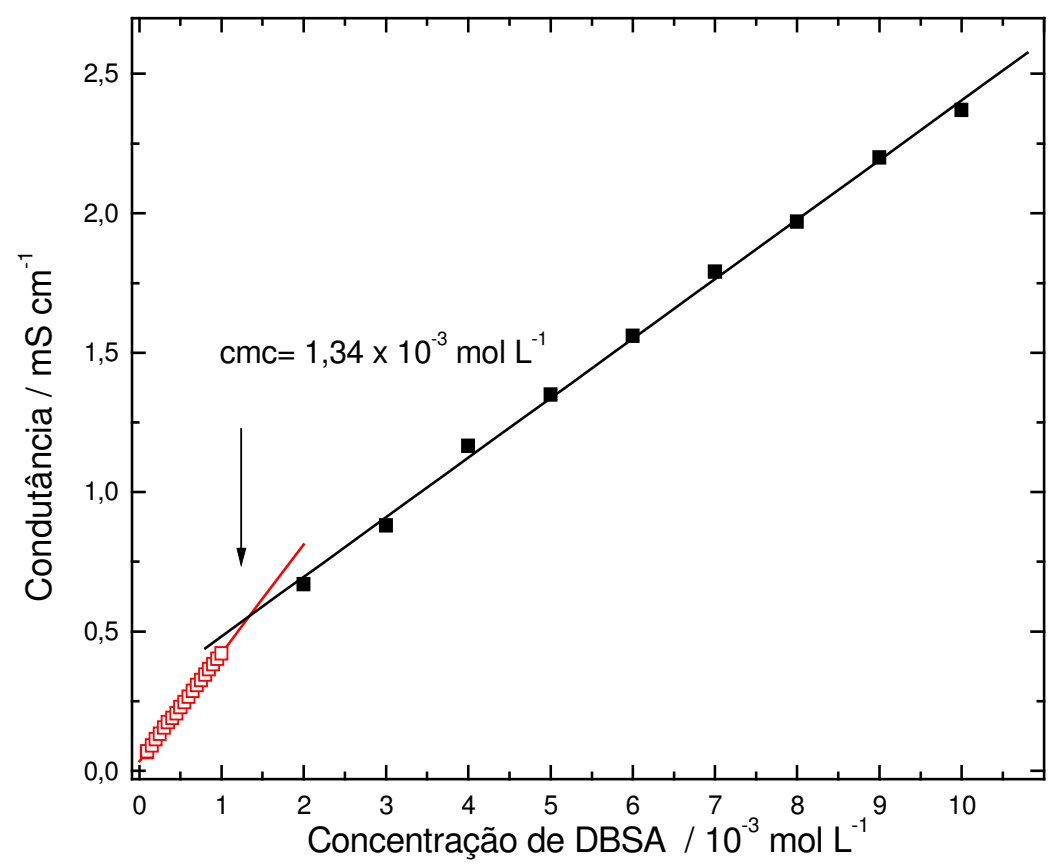

Figura 41. Dependência da condutância do DBSA em meio aquoso, a $25^{\circ} \mathrm{C}$. 
Adicionalmente, o valor da $\mathrm{cmc}$ a $25^{\circ} \mathrm{C}$ do dodecilbenzeno sulfonato de sódio em meio aquoso relatada por [139] é de $8,3 \times 10^{-3} \mathrm{~mol} \mathrm{~L}^{-1}$, isto demonstra a divergência nos valores da concentração micelar crítica do SDS descritos na literatura.

\subsubsection{Comportamento eletroquímico em presença de DBSA}

Para esse estudo, foi empregada a VC, a uma velocidade de varredura de $50 \mathrm{mV} \mathrm{s}^{-1}$ e a concentração da solução de DBSA utilizada foi $0,05 \mathrm{~mol} \mathrm{~L}^{-1}$. Esta concentração inicial foi escolhida por ser citada como ótima em diversos trabalhos sobre a síntese química de PAniDBSA $[25,29,31]$. Desta forma, é interessante ressaltar que as investigações foram realizadas em concentrações de DBSA acima de sua cmc.

\subsubsection{Eletrodo de aço inoxidável}

O comportamento eletroquímico do AISI-304 foi obtido no intervalo de potencial de $-0,6$ a $1,8 \mathrm{~V}$, em um ciclo de potencial. Inicialmente, o intervalo de potencial de $-0,6$ a $0,9 \mathrm{~V}$ foi utilizado, sendo posteriormente, o limite anódico aumentado, sucessivamente, em $50 \mathrm{mV}$ até atingir $1,8 \mathrm{~V}$.

Na Figura 42 está demonstrado que ao ser variado o limite anódico de potencial de $-0,6$ a 1,0 V (curvas a e b), nenhum processo na região anódica ocorre e, o eletrodo não se dissolve estando no estado passivo. A região de dissolução e o estado ativo do eletrodo podem ser observados entre 1,0 a $1,5 \mathrm{~V}$ (curvas (b) a (g)).

Em seguida, a passivação do eletrodo ocorre e óxidos são formados sobre a superfície metálica. Ao redor de 1,6 V (curva (h) a região de transpassivação é atingida e a evolução de oxigênio ocorre.

$\mathrm{Na}$ varredura de potencial inversa (curvas $(\mathrm{g})$ e $(\mathrm{h})$ ), a despassivação é observada quando o potencial atinge $+0,7 \mathrm{~V}$. No entanto, como o DBSA é uma molécula orgânica é provável que durante o intervalo de potencial de dissolução do AISI-304 moléculas de DBSA estejam também, sendo oxidadas (entre 1,0 a $1,5 \mathrm{~V}$ ). 


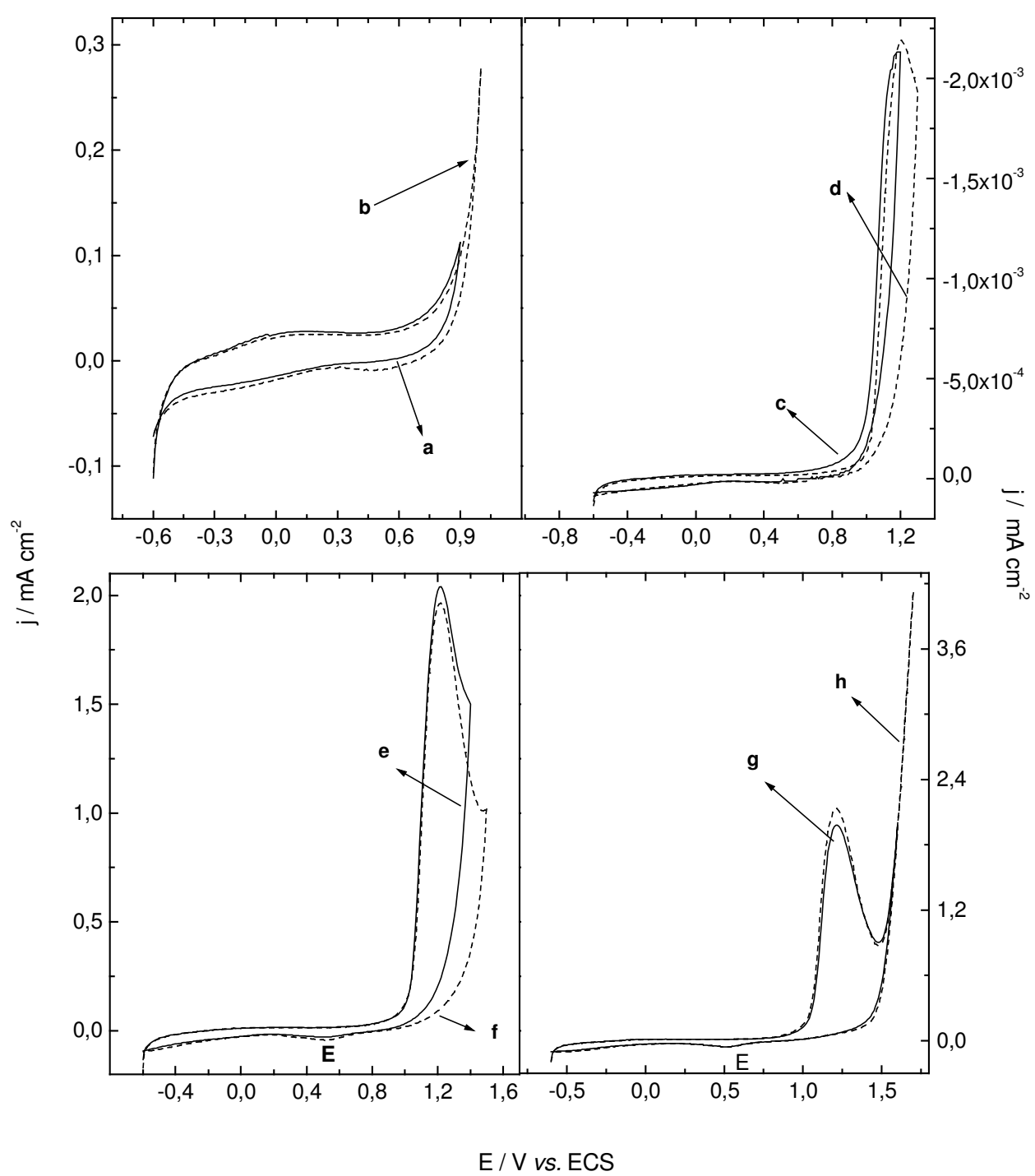

Figura 42. Voltamograma cíclico do AISI-304 em DBSA 0,05 mol L-1. Curva (a) -0,6 a 0,9 V; (b) $-0,6$ a 1,0 V; (c) $-0,6$ a 1,1 V; (d) $-0,6$ a 1,2 V; (e) $-0,6$ a 1,3 V; (f) $-0,6$ a 1,4 V; (g) $-0,6$ a 1,5 $\mathrm{V}$; (h) $-0,6$ a $1,6 \mathrm{~V}$; a $50 \mathrm{mV} \mathrm{s}^{-1}$. Um ciclo de potencial de varredura.

Assim, uma onda observada na região catódica, indicada como E, nas curvas de (e) a (h) da Figura 42, pode estar relacionada à redução de alguma espécie em solução. Esse processo ocorreria em conjunto ao processo de despassivação do eletrodo. Em suma, o intervalo de potencial de passivação do eletrodo AISI-304 varia entre $-0,6$ a $1,0 \mathrm{~V}$, o qual possibilita que a eletropolimerização de PAni ocorra simultaneamente. 


\subsubsection{Eletrodo de platina}

O comportamento eletroquímico do eletrodo de $\mathrm{Pt}$,em solução de DBSA $0,05 \mathrm{~mol} \mathrm{~L}^{-1}$, foi obtido nos intervalos de potenciais, de $-0,2$ a $0,8 \mathrm{~V}$ e de $-0,2$ a 1,2 V, a $50 \mathrm{mV} \mathrm{s}^{-1}$ (Figura 43). O eletrodo de Pt em solução de DBSA não demonstra os picos representativos de adsorção de hidrogênio. Na região anódica, entre 0,9 a 1,2 V, ocorre a dissolução e o estado ativo do eletrodo (Fig. 43 curva (b)). Neste intervalo de potencial ocorre a formação do óxido de Pt sobre a superfície metálica, no entanto, como o DBSA é uma molécula orgânica, é possível que durante o intervalo de potencial de oxidação da Pt as moléculas de DBSA tenham sido também oxidadas.

$\mathrm{Na}$ varredura de potencial inversa, curva (b), a redução do óxido de platina ou/e produtos de DBSA oxidado é observado ao redor de $+0,4 \mathrm{~V}$. O comportamento eletroquímico da Pt em solução de DBSA, comparado ao descrito em literatura [105,142], as quais usualmente são apresentados resultados em solução de $\mathrm{H}_{2} \mathrm{SO}_{4}$ mostra diferenças que se devem principalmente às características químicas e físicas dos eletrólitos usados.

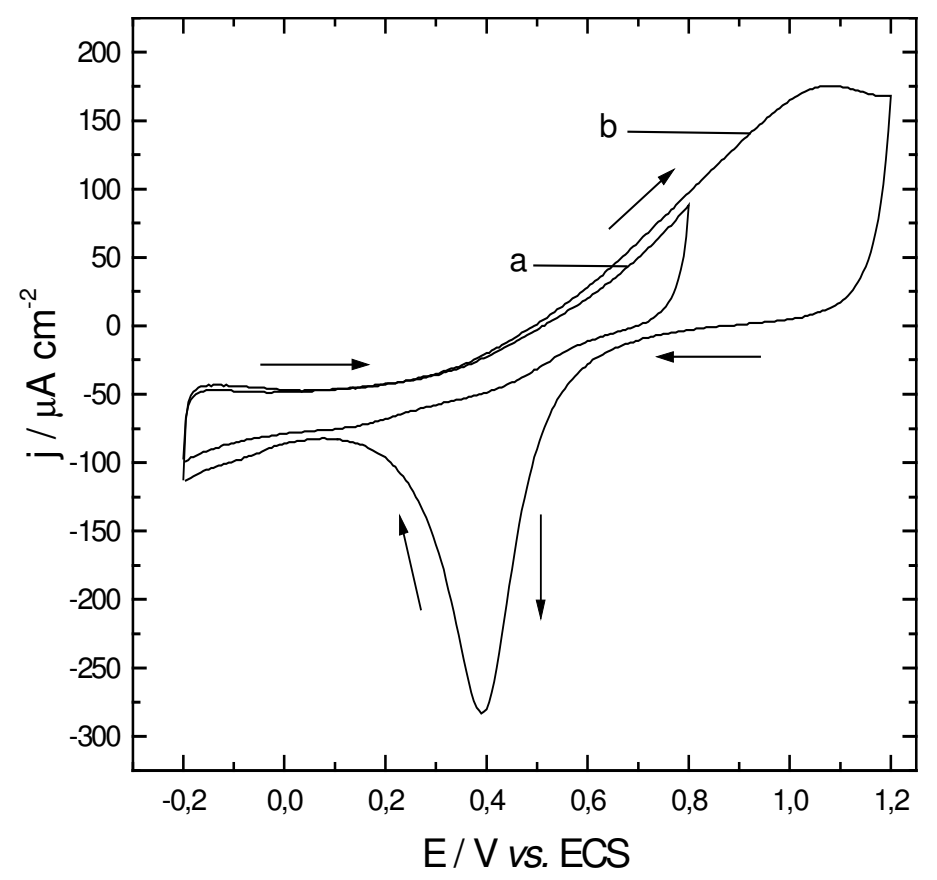

Figura 43. Voltamograma cíclico da Pt em presença de DBSA 0,05 mol L-1. Curva (a) $-0,2$ a $0,8 \mathrm{~V}$; (b) $-0,2$ a 1,2 V; a $50 \mathrm{mV} \mathrm{s}^{-1}$. Um ciclo de potencial de varredura. 


\subsubsection{A estabilidade da solução de DBSA em presença de anilina}

A razão de DBSA/Anilina 1:1 é citada por diferentes autores, para síntese química, como a razão ótima [25,143]. No entanto, durante a eletropolimerização utilizando esta razão, pode ocorrer a formação de emulsão, o que é indesejável, pois pode diminuir a difusão das espécies em solução para a superfície do eletrodo.

A formação de uma emulsão (dispersões coloidais constituídas por líquidos imiscíveis solubilizados pelo surfactante presente), assim como, a polimerização de PAni dependem de vários fatores, dentre eles: temperatura, concentração, $\mathrm{pH}$, etc. O parâmetro selecionado para estimar a formação da emulsão quando diferentes concentrações de anilina é adicionada a uma de DBSA $0,05 \mathrm{~mol} \mathrm{~L}^{-1}$, foi o valor de $\mathrm{pH}$ da solução. Com este procedimento foi possível observar em qual valor de pH se inicia a formação da emulsão, em função da concentração de anilina adicionada, conforme demonstrado na Figura 44.

A solução de DBSA $0,05 \mathrm{~mol} \mathrm{~L}^{-1}$ apresenta inicialmente, um valor de $\mathrm{pH}$ de 1,1. A adição à solução de anilina (concentrações de 0,010 a $0,015 \mathrm{~mol} \mathrm{~L}^{-1}$ ) promove a formação do complexo DBSA-anilina. Para essas concentrações o complexo apresenta-se solúvel e o valor de $\mathrm{pH}$ entre 1,18 - 1,30. Em concentrações de anilina superiores a 0,015 $\mathrm{mol} \mathrm{L}^{-1}$, aumenta a formação do complexo DBSA-anilina e também do valor de pH. Nesse ponto, a emulsão se forma e pode ser observada visualmente, por uma nítida mudança na cor e no aspecto (leitoso e viscoso) da mistura, quando comparada a solução inicial (com 0,010 $\mathrm{mol} \mathrm{L}^{-1}$ de anilina).

Com este estudo foi possível determinar qual o intervalo de concentração de anilina a ser empregado para eletropolimerizar PAni em uma solução de DBSA $0,05 \mathrm{~mol} \mathrm{~L}^{-1}$, sem 0 inconveniente da ocorrência da formação de emulsão, durante a eletropolimerização. 


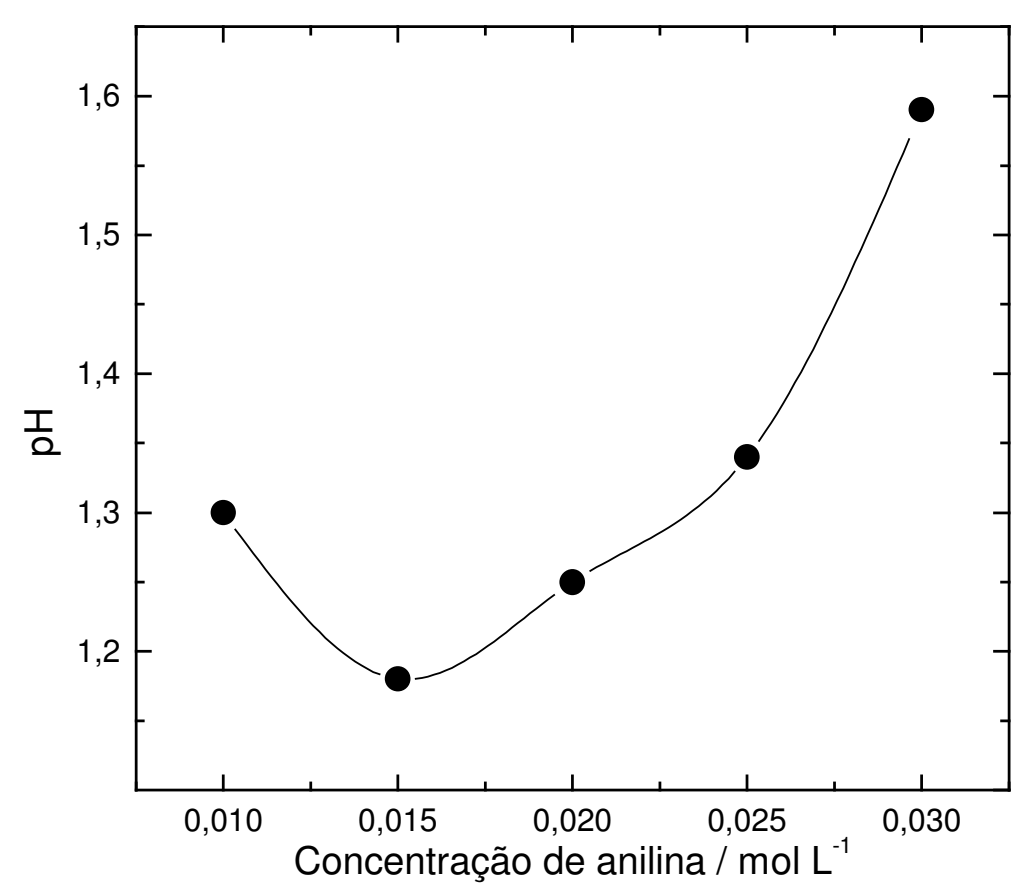

Figura 44. Dependência do $\mathrm{pH}$ de uma solução de DBSA $0,05 \mathrm{~mol} \mathrm{~L}^{-1} \mathrm{com}$ a adição de diferentes concentrações de anilina.

Apesar de ocorrer uma elevação no valor de $\mathrm{pH}$ quando anilina na concentração de $0,010 \mathrm{~mol} \mathrm{~L}^{-1}$ foi adicionada à solução de DBSA, não há formação de emulsão, assim, os estudos sobre a eletropolimerização de PAni-DBSA sobre Pt e AISI-304 foram iniciados a partir dessa concentração.

\subsection{Eletropolimerização de PAni-DBSA sobre platina e aço inoxidável}

Neste estudo foi utilizada uma solução de DBSA 0,05 mol L-1 contendo anilina 0,010 mol $\mathrm{L}^{-1}$. Assim, as eletropolimerizações de PAni-DBSA sobre Pt e sobre AISI-304 foram realizada por VC, a $50 \mathrm{mV} \mathrm{s}^{-1}$, nos intervalos de potenciais empiricamente determinados. Para eletropolimerizar PAni-DBSA sobre AISI-304 o intervalo de potencial utilizado foi (i) um ciclo de: $-0,6$ a 1,5 V (nucleação do eletrodo) e (ii) 90 ciclos de: $-0,2$ a 0,8 V. Enquanto, sobre Pt o intervalo de potencial empregado foi constante de $-0,2$ a $0,8 \mathrm{~V}$, totalizando 90 ciclos.

Nas Figuras 45 e 46 são mostrados os voltamogramas de crescimento de PAni-DBSA sobre Pt e sobre AISI-304, respectivamente. Sobre AISI-304 (Fig. 45a) na primeira varredura de potencial são observados dois picos na região anódica: 


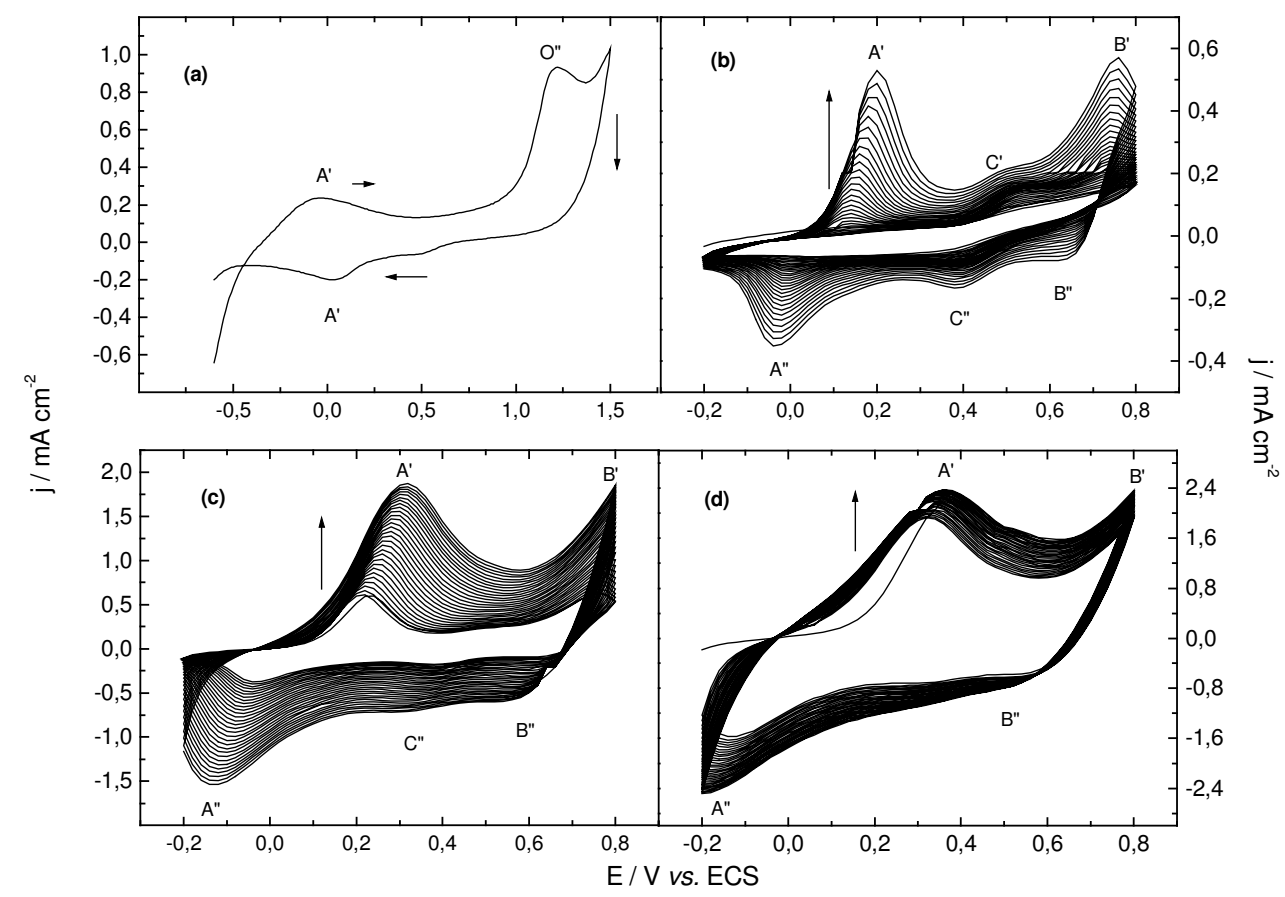

Figura 45. Voltamogramas de crescimento de PAni-DBSA sobre aço inoxidável a partir de uma solução de DBSA $0,05 \mathrm{~mol} \mathrm{~L}^{-1}$ contendo anilina $0,01 \mathrm{~mol} \mathrm{~L}^{-1}$, a $50 \mathrm{mV} \mathrm{s}^{-1}$. (a) $1^{\circ}$ ciclo; (b) 2-30 , (c) $31-60^{\circ}$ e (d) $61-90^{\circ}$ ciclos.

- Pico $A^{\prime}( \pm 0,0$ V): correspondente ao primeiro processo de oxidação da PAni (passagem do estado de oxidação leucoesmeraldina a esmeraldina);

- Pico O" ( $\pm 1,0$ V): atribuído a processos de oxidação que ocorrem conjuntamente (oxidação do monômero, da molécula de DBSA e da superfície metálica). Na varredura inversa de potencial, região catódica apenas um pico é observado;

- Pico A" (- 0,04 V): correspondente ao primeiro processo de redução da PAni (passagem do estado de redução da esmeraldina a leucoesmeraldina).

Após 30 ciclos de potenciais (Fig. 45 b), os picos característicos do primeiro processo redox da PAni se mantêm presentes e podem ser observados mais dois processos redox ocorrendo, referenciados na Figura 45 (b) como: 


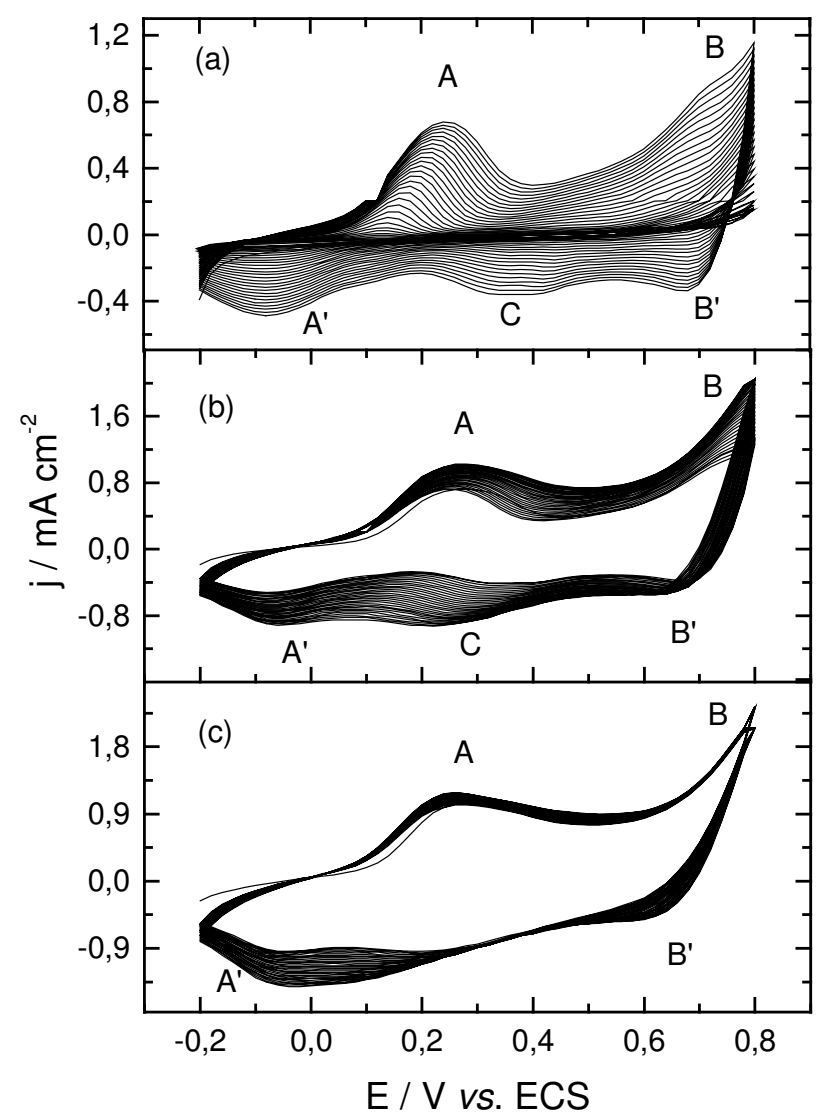

Figura 46. Voltamogramas de crescimento de PAni-DBSA sobre platina a partir de uma solução de DBSA $0,05 \mathrm{~mol} \mathrm{~L}^{-1}$ contendo anilina $0,01 \mathrm{~mol} \mathrm{~L}^{-1}$, a $50 \mathrm{mV} \mathrm{s}^{-1}$. (a) 30 ciclos, (b) 60 ciclos e (d) 90 ciclos.

- $\quad$ Picos B’ e B" ( \pm 0,77 e 0,64 V): segundo par redox da PAni, correspondentes ao segundo processo de oxidação e redução da PAni (interconversão da esmeraldina a pernigranilina e da pernigranilina a esmeraldina, respectivamente).

- $\quad$ Picos C' e C" ( \pm 0,46 e 0,40 V): par redox que freqüentemente são atribuídos a processos de oxidação e redução de produtos de degradação do polímero. Esses processos são competitivos ao processo de polimerização da PAni conforme descrito em [103].

Para o AISI-304, ao ser aumentado o número de ciclos de potencial para 61 ciclos (Fig. 45 (c)) as reações de polimerização de PAni são favorecidas e o pico C', na região anódica não é mais evidenciado devido ao acoplamento com o pico A'. Entretanto, o pico C", na região catódica, mantém-se presente. Isto ocorre mesmo após um aumento no número de ciclos para 
91 (Fig. 45 d), ou seja, com o aumento de espessura do filme os processos de oxidação correspondentes ao pico C' são acoplados ao pico A'.

Em seqüência foram investigadas as influências da concentração de monômero e de DBSA na eletropolimerização do polímero.

\subsubsection{Efeito da concentração de monômero.}

Neste estudo a concentração da solução de DBSA foi mantida $0,05 \mathrm{~mol} \mathrm{~L}^{-1}$, enquanto a concentração de monômero foi variada de 0,01 a $0,03 \mathrm{~mol} \mathrm{~L}^{-1}$. O intervalo de potencial e a velocidade de varredura foram os mesmos empregados anteriormente, tanto para eletropolimerização sobre Pt quanto para AISI-304.

Nas Figuras 47 a 50 estão apresentados os voltamogramas de crescimento da eletropolimerização de PAni-DBSA sobre AISI-304 em solução de DBSA 0,05 mol L-1 e nas concentrações de anilina de 0,01 a $0,03 \mathrm{~mol} \mathrm{~L}^{-1}$.

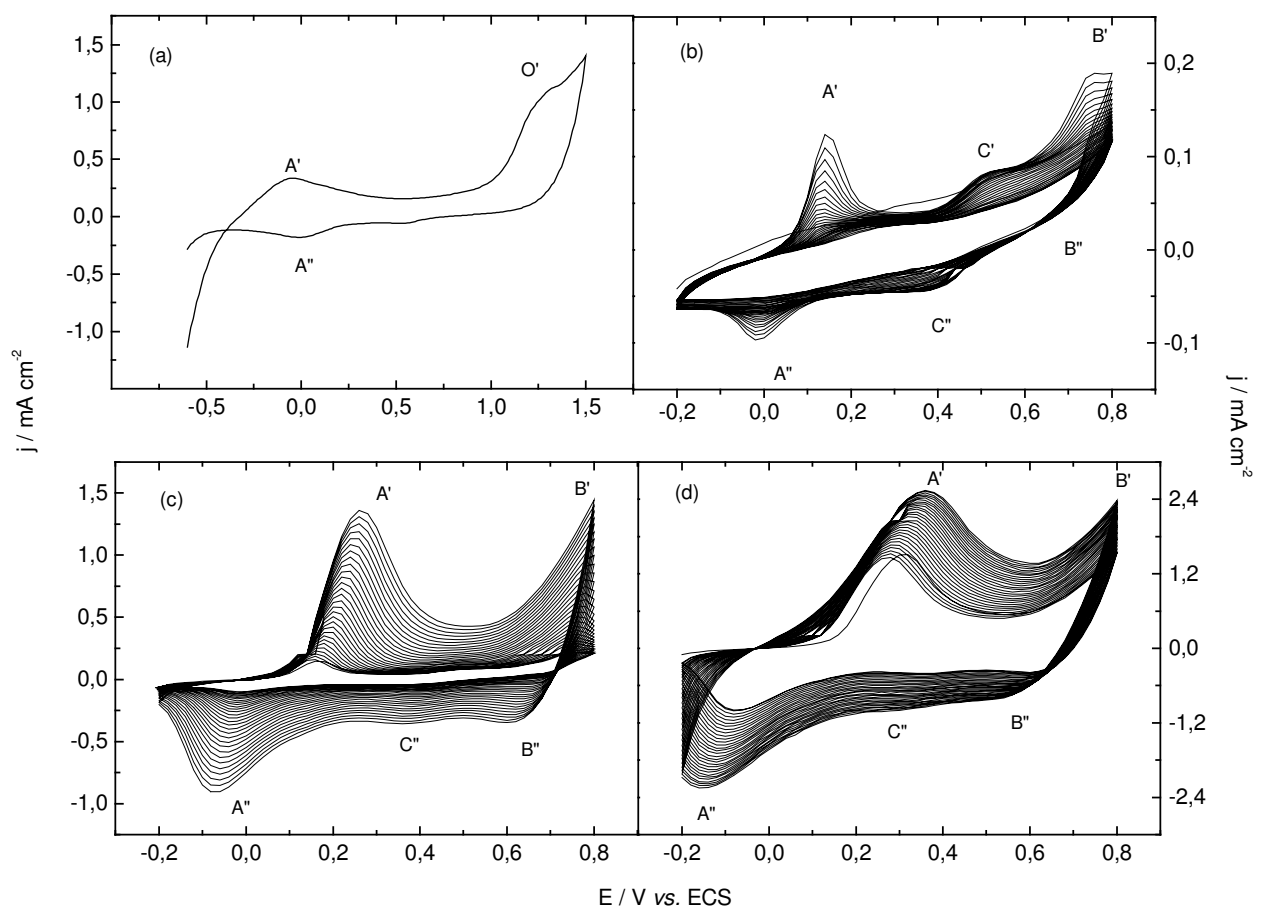

Figura 47. Voltamogramas cíclicos de crescimento de PAni-DBSA sobre AISI-304 a partir de uma solução de DBSA $0,05 \mathrm{~mol} \mathrm{~L}^{-1}$ contendo anilina $0,015 \mathrm{~mol} \mathrm{~L}^{-1}$. Número de ciclos: (a) $1^{\circ}$ ciclo; (b) $2-30^{\circ}$, (c) $31-60^{\circ} \mathrm{e}$ (d) $61-90^{\circ}$ ciclos. $\mathrm{v}=50 \mathrm{mV} \mathrm{s}^{-1}$. 


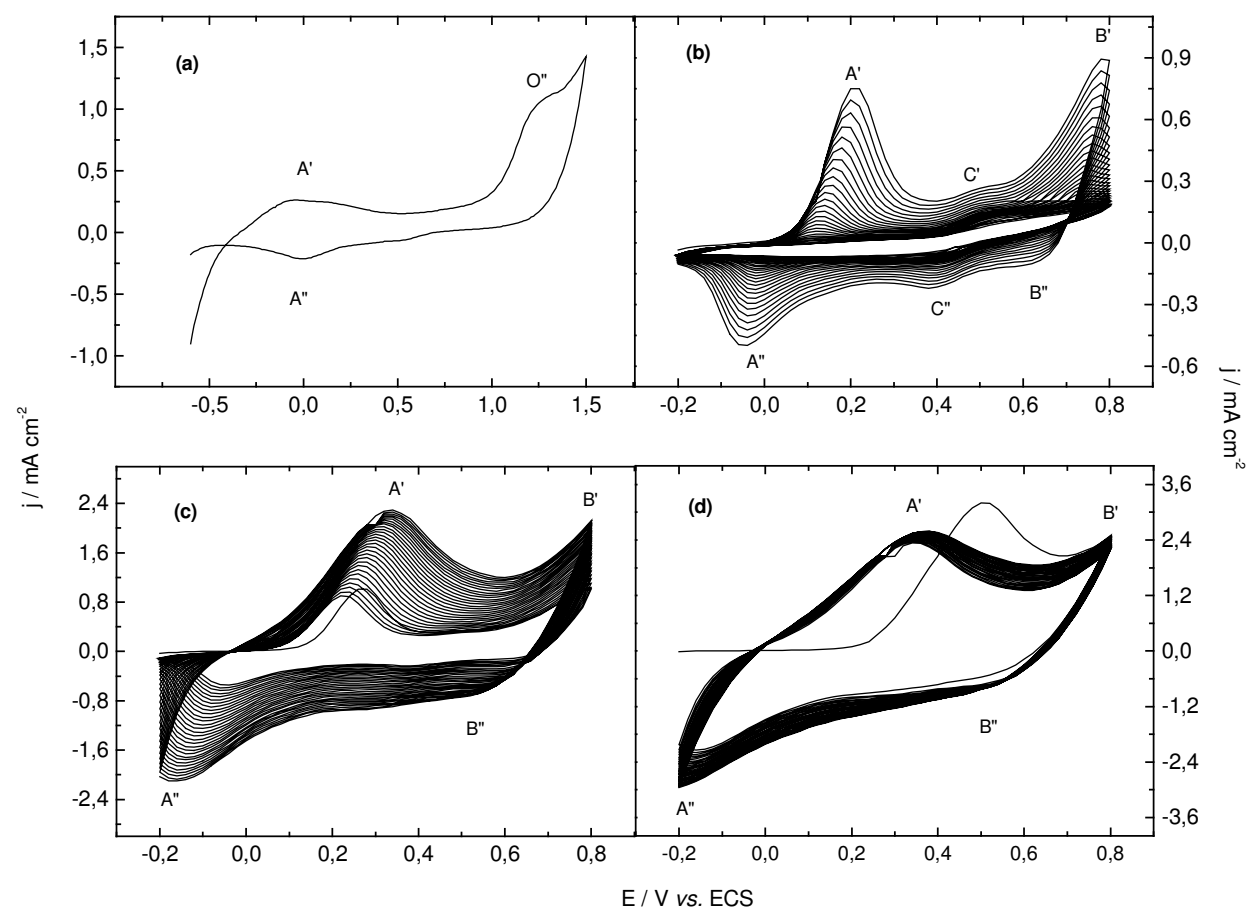

Figura 48. Voltamogramas de crescimento de PAni-DBSA sobre AISI-304 a partir de uma solução de DBSA $0,05 \mathrm{~mol} \mathrm{~L}^{-1}$ contendo anilina $0,020 \mathrm{~mol} \mathrm{~L}^{-1}$. Número de ciclos: (a) $1^{\circ}$ ciclo; (b) $2-30^{\circ}$, (c) $31-60^{\circ}$ e (d) $61-90^{\circ}$ ciclos. $\mathrm{V}=50 \mathrm{mV} \mathrm{s}^{-1}$.

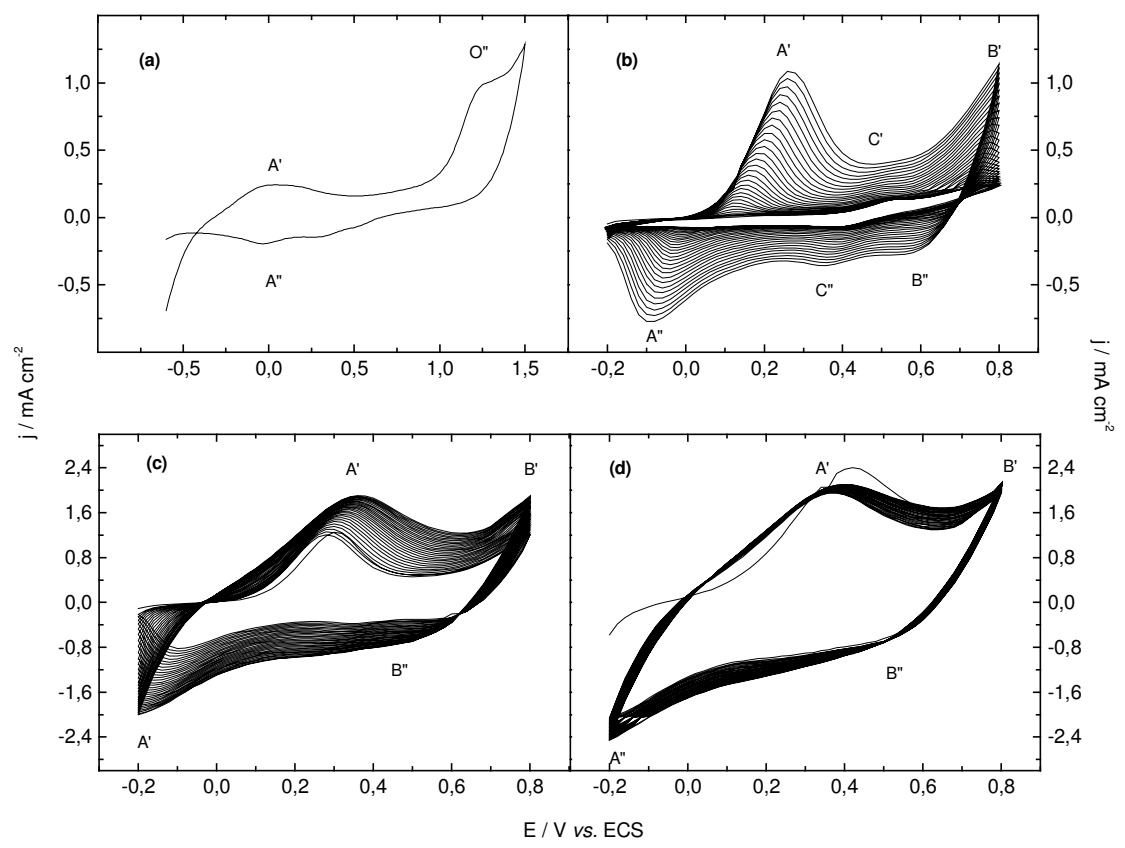

Figura 49. Voltamogramas de crescimento de PAni-DBSA sobre AISI-304 a partir de uma solução de DBSA $0,05 \mathrm{~mol} \mathrm{~L}^{-1}$ contendo anilina $0,025 \mathrm{~mol} \mathrm{~L}^{-1}$. (a) $1^{\circ}$ ciclo; (b) 2-30 , (c) $31-60^{\circ}$ e (d) $61-90^{\circ}$ ciclos. $v=50 \mathrm{mV} \mathrm{s}^{-1}$. 


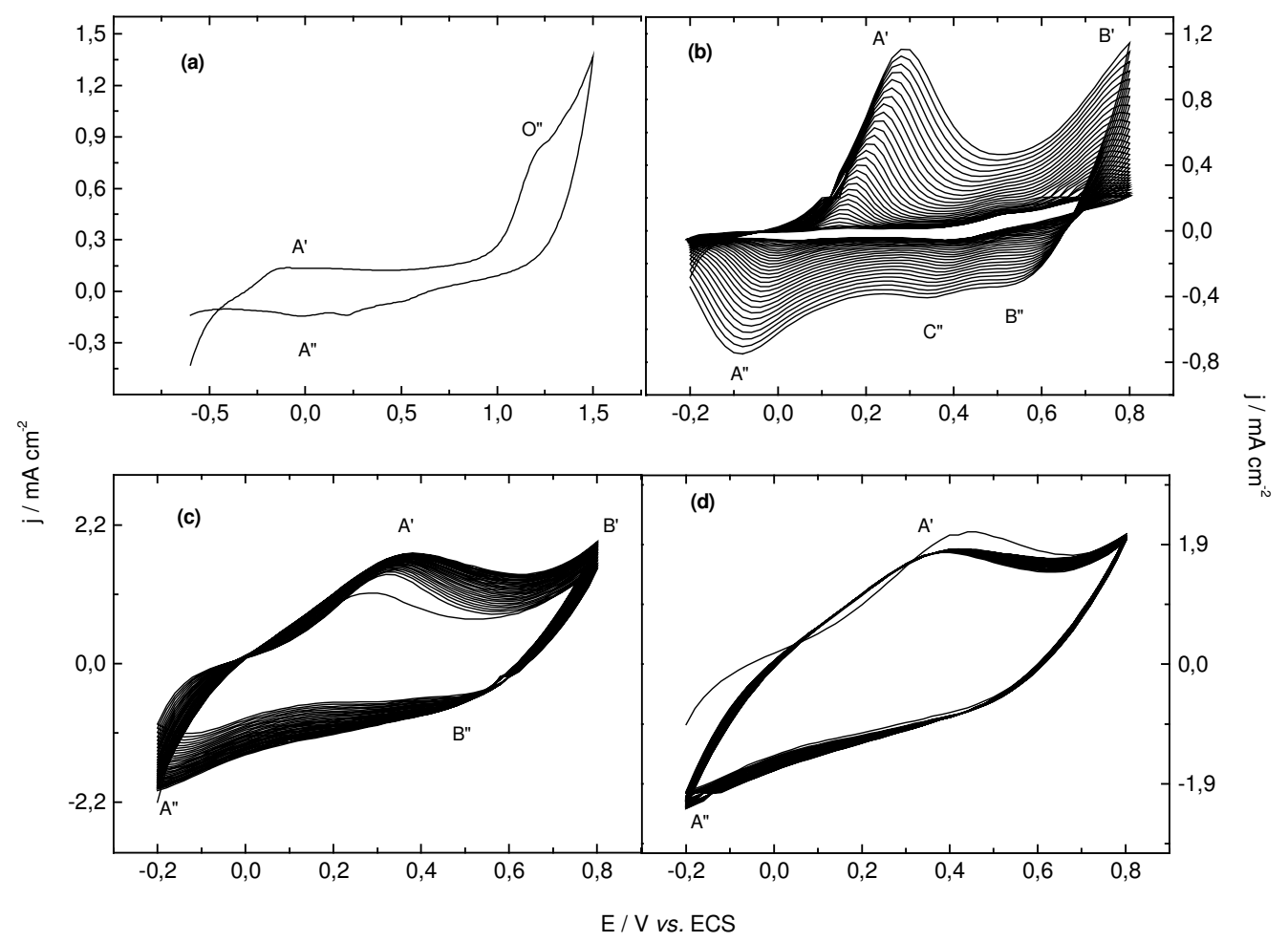

Figura 50. Voltamogramas de crescimento de PAni-DBSA sobre AISI-304 a partir de uma solução de DBSA 0,05 mol L-1 contendo anilina $0,030 \mathrm{~mol} \mathrm{~L}^{-1}$. Número de ciclos: (a) $1^{\circ}$ ciclo; (b) $2-30^{\circ}$, (c) $31-60^{\circ}$ e (d) $61-90^{\circ}$ ciclos. $\mathrm{V}=50 \mathrm{mV} \mathrm{s}^{-1}$.

Na Figura 51 são mostrados os voltamogramas de crescimento de PAni-DBSA sobre Pt, a partir de solução de DBSA $0,05 \mathrm{~mol} \mathrm{~L}^{-1}$, nas concentrações de anilina de 0,01 a 0,03 $\mathrm{mol} \mathrm{L}^{-1}$. Para todas as concentrações de anilina a eletropolimerização de PAni-DBSA ocorre e, os voltamogramas de crescimento, tanto sobre Pt quanto sobre AISI-304, apresentam os pares redox característicos de PAni descritos anteriormente.

A densidade de corrente (j) do primeiro pico anódico (pico A') é indicativo do crescimento do polímero como relatado por diferentes autores [122-125]. Assim, a velocidade de polimerização de PAni em diversas concentrações de anilina pode ser acompanhada pela magnitude do pico A'. 

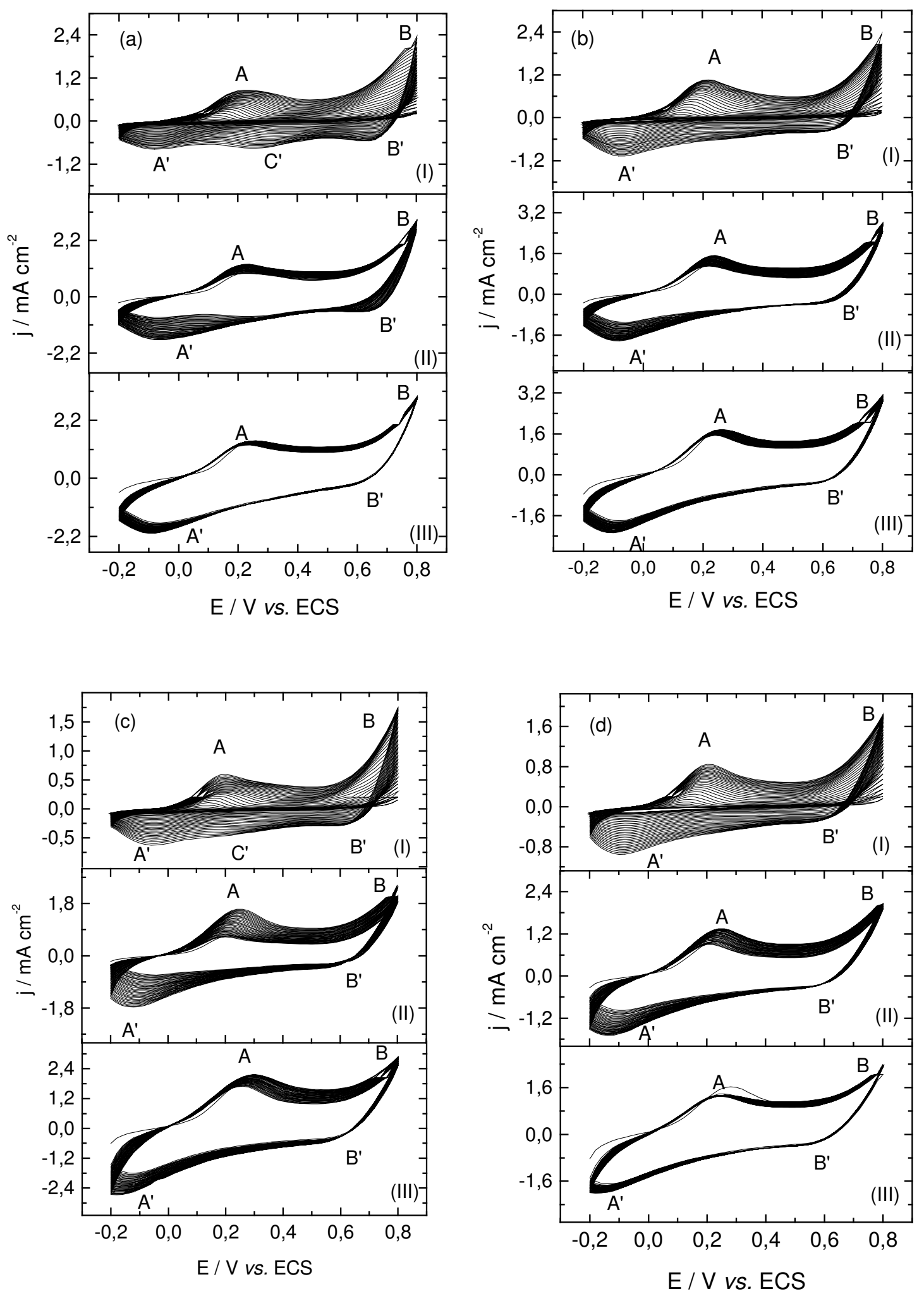

Figura 51. Voltamogramas de crescimento de PAni-DBSA sobre Pt a partir de uma solução de DBSA 0,05 mol L-1 contendo anilina (a) 0,015; (b) 0,020; (c) 0,025; (d) 0,030 $\mathrm{mol} \mathrm{L}^{-1}$. Número de ciclos: (I) 30; (II) 60 e (III) 90 ciclos. $\mathrm{V}=50 \mathrm{mV} \mathrm{s}^{-1}$. 


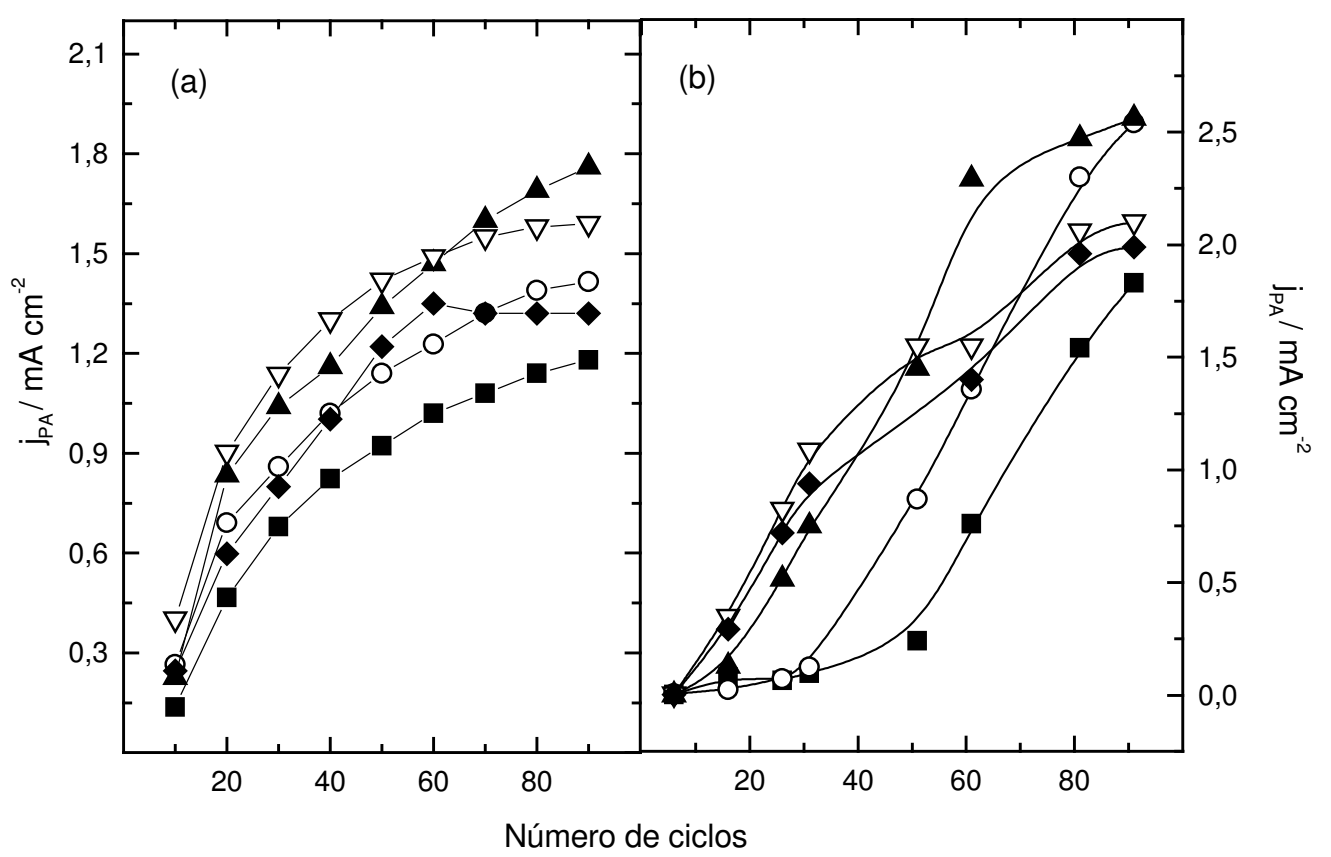

Figura 52. Valores de densidade de corrente do primeiro pico anódico $\left(\mathrm{j}_{A}\right)$ em relação ao número de ciclos. PAni eletropolimerizada em solução de DBSA $0,05 \mathrm{~mol} \mathrm{~L}^{-1}$ contendo diferentes concentrações de anilina $(v)$ 0,010; $(\mu)$ 0,015; $(\sigma)$ 0,020; $(\nabla)$ 0,025; $(v)$ 0,030 $\mathrm{mol} \mathrm{L}^{-1}$; sobre (a) Pt e (b) AISI-304.

A Figura 52 mostra a variação dos valores de densidade de corrente do pico $A\left(j_{A}\right)$ com o número de ciclos, a partir dos voltamogramas de crescimento de PAni-DBSA, sobre Pt e sobre AISI-304, em diferentes concentrações de anilina. O aumento na concentração de anilina de 0,01 para $0,03 \mathrm{~mol} \mathrm{~L}^{-1}$ não aumenta a magnitude do pico $\mathrm{A}$. Um rápido aumento é observado ao redor de 50 ciclos de potenciais com aumento da concentração de anilina de 0,01 para $0,025 \mathrm{~mol} \mathrm{~L}^{-1}$. Para sucessivos ciclos de potenciais (superiores a 50 ), altas concentrações $\left(0,025\right.$ a $\left.0,03 \mathrm{~mol} \mathrm{~L}^{-1}\right)$ fornecem características ao filme que configuram um retardo do crescimento, e assim a velocidade de crescimento é reduzida. Enquanto, para concentrações baixas $\left(0,01\right.$ a $\left.0,02 \mathrm{~mol} \mathrm{~L}^{-1}\right)$ o crescimento do polímero é mais favorecido.

Altas concentrações de anilina parecem favorecer a formação do complexo PAni-DBSA, ou seja, da emulsão. Isso impossibilitaria os monômeros de reagirem com os radicais cátions formados devido a um bloqueio dos sítios ativos pelos complexos de PAni-DBSA e moléculas de DBSA livres. 
A baixas concentrações de anilina, a formação da emulsão é pouco favorecida e a estabilidade da solução de DBSA anilina é mantida (seção 5.1.3). Então, as moléculas de DBSA contribuiriam para o acoplamento dos monômeros aos radicais cátions formados. Segundo os autores [144], o aumento de surfactante pode promover a formação de micelas e a reação de oxidação. Assim, um excesso de DBSA favorece as reações de oxidação do meio e, o DBSA estaria auxiliando as reações de acoplamento do monômero em sítios disponíveis, para o crescimento da cadeia.

Para a concentração de anilina $0,015 \mathrm{~mol} \mathrm{~L}^{-1}$ a eletropolimerização de PAni-DBSA é mais favorecida, visto que esta apresenta o maior valor e um aumento linear nos valores de $\mathrm{j}_{\mathrm{A}}$ para número de ciclos superior a 30. Sendo assim, a concentração ótima para eletropolimerizar PAni-DBSA sobre AISI-304, a partir de uma solução de DBSA $0,05 \mathrm{~mol} \mathrm{~L}^{-1}$, é $0,015 \mathrm{~mol} \mathrm{~L}^{-1}$. Enquanto, sobre $\mathrm{Pt}$, uma concentração de anilina maior seria a ótima $\left(0,020 \mathrm{~mol} \mathrm{~L}^{-1}\right)$. Isto evidencia que o eletropolimerização de PAni-DBSA sofre forte influência da natureza do substrato (oxidável ou inerte).

\subsubsection{Efeito da concentração de DBSA.}

Uma vez otimizada a concentração de anilina, a influência da concentração de DBSA na eletrodepolimerização de PAni-DBSA foi investigada. Para tanto, a concentração de anilina usada foi $0,015 \mathrm{~mol} \mathrm{~L}^{-1}$ e os demais parâmetros eletroquímicos (intervalo de potencial, velocidade de varredura e número de ciclos) foram mantidos os mesmos descritos anteriormente, enquanto, a concentração de DBSA foi variada de 0,04 a $0,1 \mathrm{~mol} \mathrm{~L}^{-1}$.

Ao variar a concentração de DBSA, o parâmetro de acompanhamento da síntese com o aumento no número de ciclos foi a carga anódica do primeiro processo de oxidação do polímero $\left(Q_{a}\right)$. Os valores de $\left(Q_{a}\right)$ foram obtidos a partir dos voltamogramas de crescimento de PAni-DBSA nas diferentes concentrações de DBSA utilizadas.

$\mathrm{Na}$ Figura 53 os valores de $Q_{a}$ estão representados em relação ao número de ciclos, com variação da concentração de DBSA. A partir desta figura, pode ser observado que a velocidade de polimerização de PAni-DBSA aumenta quando a concentração de DBSA aumenta de 0,04 a $0,05 \mathrm{~mol} \mathrm{~L}^{-1}$, alcançando um valor máximo ao redor de $0,05 \mathrm{~mol} \mathrm{~L}^{-1}$ de DBSA. 


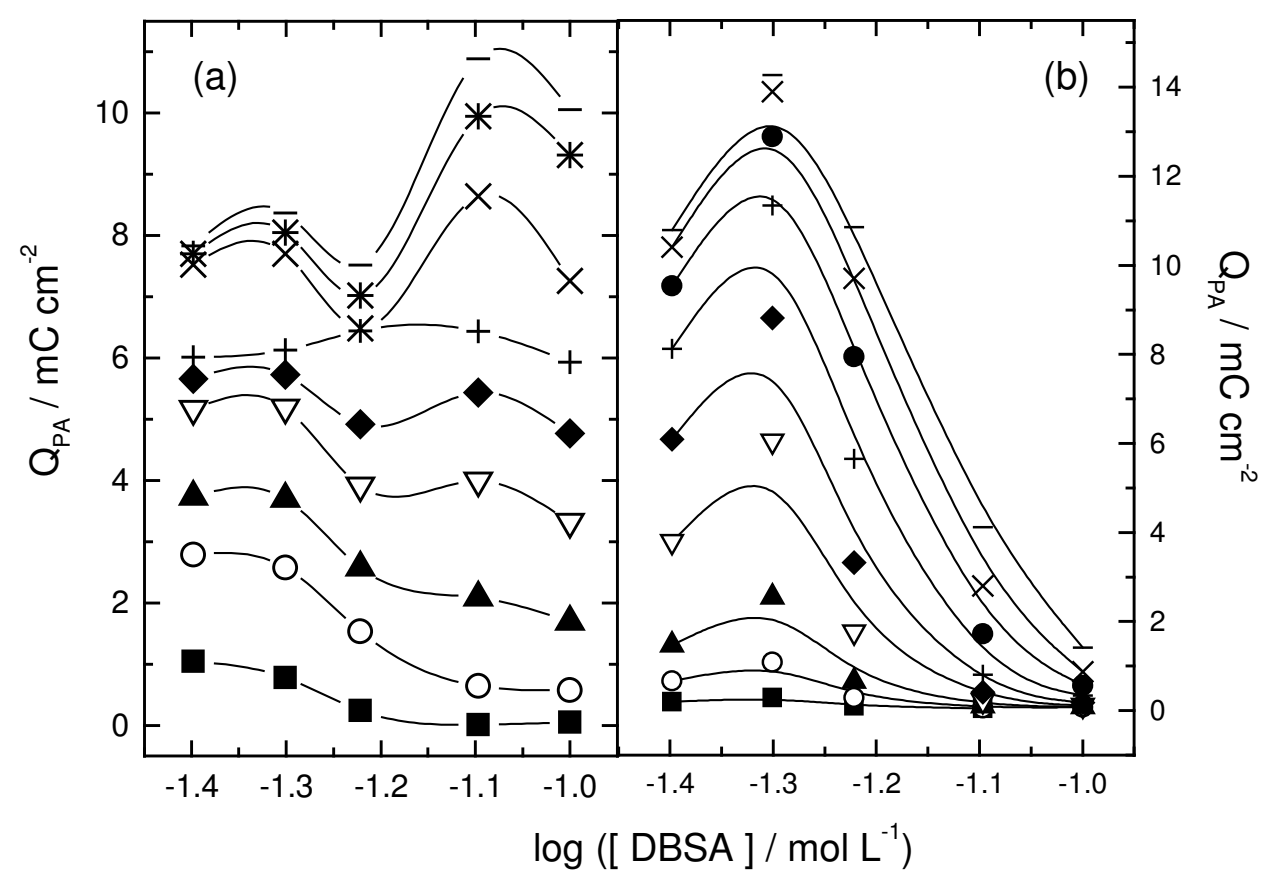

Figura 53. Dependência da carga anódica referente ao primeiro pico de oxidação de PAniDBSA sobre (a) Pt e (b) AISI-304, em diferentes concentrações de DBSA e números de ciclos de potenciais. $(v)$ 10; $(\mu)$ 20; ( $\sigma$ ) 30; ( $\nabla)$ 40; (v) 50; (B) 60; (6) 70; (P) 80 e (- ) 90 ciclos.

A partir desta concentração, a velocidade de polimerização diminui rapidamente, sendo inibida ao redor de $0,08 \mathrm{~mol} \mathrm{~L}^{-1}$. A velocidade de polimerização para concentrações iguais e/ou superiores a $0,08 \mathrm{~mol} \mathrm{~L}^{-1}$ diminui significativamente.

A Figura 53 pode ser dividida em três regiões. A primeira região ocorre de 0,04 a 0,05 mol $\mathrm{L}^{-1}$ de DBSA, na qual a velocidade de polimerização é a mais elevada. Uma segunda região a partir de $0,05 \mathrm{~mol} \mathrm{~L}^{-1}$ de DBSA a aproximadamente $0,08 \mathrm{~mol} \mathrm{~L}^{-1}$, na qual a velocidade de polimerização rapidamente diminui. A terceira região que é caracterizada pela inibição do crescimento, abrange concentrações maiores que $0,08 \mathrm{~mol} \mathrm{~L}^{-1}$.

Na primeira região, o aumento na velocidade de polimerização pode ser atribuído à formação de um complexo entre o DBSA e o cátion "anilinium", sendo isto concordante com os resultado obtidos na eletropolimerização com dodecilsulfato de sódio (SDS) $[145,146]$. O DBSA tende à se acumular na interface eletrodo/eletrólito atraindo para si os monômeros, aumentando assim, a concentração local de monômero. 
Acima de $0,05 \mathrm{~mol} \mathrm{~L}^{-1}$ de DBSA, concentração na qual já se pode ter estrutura micelares, os cátions "anilinium" estariam interagindo mais fortemente com as micelas. Assim, o suplemento de monômero até o eletrodo seria limitado por difusão das micelas.

Como a velocidade de chegada do monômero à superfície do eletrodo pode ser reduzida, isto resulta em diminuição da velocidade de polimerização. O aumento na concentração de DBSA, na terceira região, estaria aumentando o número de estruturas micelares e, devido a esse aumento, uma emulsão estaria sendo formada, inibindo o crescimento do polímero sobre o AISI-304. Entretanto, sobre Pt o crescimento do polímero, para um número de ciclos de potenciais acima de 70 , é mais favorecido, devido às características físicas e químicas que o polímero adquire com o aumento de espessura.

\subsection{Algumas considerações cinéticas da eletropolimerização de PAni-DBSA}

Na Figura 54 está representada a velocidade de crescimento das camadas de PAniDBSA, exemplificada pela carga anódica $\left(Q_{a}\right)$ em função do número de ciclos $(N)$ durante a eletrodeposição de PAni em solução de DBSA 0,05 $\mathrm{mol} \mathrm{L}^{-1}$ sobre Pt e sobre AISI-304. A eletropolimerização de PAni é mais lenta sobre o eletrodo de Pt do que sobre AISI-304.

Uma razão considerada para a síntese ser mais lenta sobre $\mathrm{Pt}$, e ocorrência da transferência do potencial de pico para potenciais mais positivos, é a camada de óxido formada sobre o substrato de aço, a qual nesta condição demonstra ter baixa resistividade (ou seja boa condutividade) que favorece a eletropolimerização da PAni em DBSA sobre o aço.

A Figura 54 indica que diferentes velocidades de crescimento de PAni-DBSA podem ser distinguidas durante a eletropolimerização. A inclinação $\left(\Delta Q_{P A} / \Delta N\right)$ fornece a velocidade de aumento da carga $\left(Q_{P A}\right)$ em função do número de ciclos $(N)$, conforme descrito na Tabela 4. No início, estágio I, a velocidade de eletropolimerização sobre AISI-304 é duas vezes menor do que sobre Pt, mas no estágio II, a velocidade de eletropolimerização sobre AISI-304 é sete vezes mais rápida que sobre $\mathrm{Pt}$. 


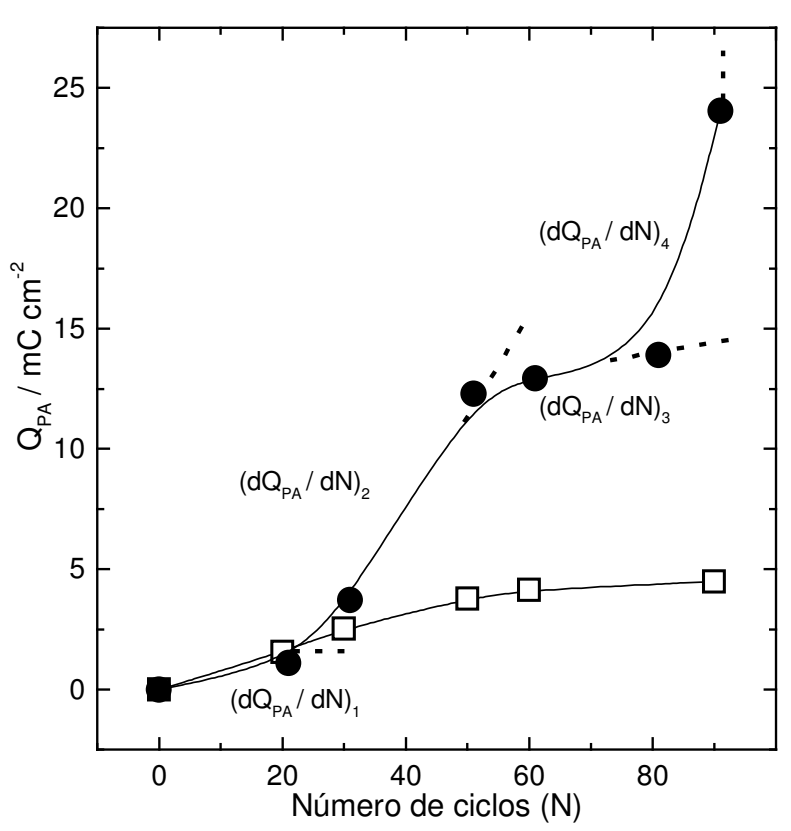

Figura 54. Carga anódica do pico $A, Q_{P A}$, versus o número de ciclos $(N)$ durante a eletropolimerização de PAni em solução de DBSA 0,05 mol L-1 sobre ( ) Pt e ( $\lambda$ ) AISI-304.

Tabela 4. A velocidade de crescimento de PAni-DBSA $\left(\Delta Q_{P A} / \Delta N\right)$ sobre eletrodos de platina e de aço inoxidável

\begin{tabular}{c|c|c|c|c}
\hline & $\begin{array}{c}\text { Estágio I } \\
\left(\mathrm{Q}_{\mathrm{PA}} / \Delta \mathrm{N}\right)_{1} \\
\mathrm{mC} / \text { número de } \\
\text { ciclos }\end{array}$ & $\begin{array}{c}\text { Estágio II } \\
\left(\mathrm{Q}_{\mathrm{PA}} / \Delta \mathrm{N}\right)_{2} \\
\mathrm{mC} / \text { número de } \\
\text { ciclos }\end{array}$ & $\begin{array}{c}\text { Estágio III } \\
\left(\mathrm{Q}_{\mathrm{PA}} / \Delta \mathrm{N}\right)_{3} \\
\mathrm{mC} / \text { número de } \\
\text { ciclos }\end{array}$ & $\begin{array}{c}\text { Estágio IV } \\
\left(\mathrm{Q}_{\mathrm{PA}} / \Delta \mathrm{N}\right)_{4} \\
\mathrm{mC} / \text { número de } \\
\text { ciclos }\end{array}$ \\
\hline $\begin{array}{c}\text { Aço Inoxidável / } \\
\text { PAni-DBSA }\end{array}$ & 0,05 & 0,43 & 0,05 & 1,01 \\
\hline $\begin{array}{c}\text { Platina / PAni - } \\
\text { DBSA }\end{array}$ & 0,08 & 0,06 & 0,02 & $-\cdots$ \\
\hline $\begin{array}{c}\left(\Delta \mathrm{Q}_{\mathrm{a}} / \Delta \mathrm{N}\right)_{\text {aço }} / \\
\left(\Delta \mathrm{Q}_{\mathrm{a}} / \Delta \mathrm{N}\right)_{\text {platina }}\end{array}$ & $1,6{ }^{*}$ & 7,02 & 2,5 & 50,5 \\
${ }^{*}\left(\Delta Q_{P A} / \Delta N\right)_{\text {Platina }} /\left(\Delta Q_{P A} / \Delta N\right)_{\text {aço }}$ & & &
\end{tabular}

Entretanto, após alguns números de ciclos, a velocidade lentamente apresenta redução (estágio III). A menor velocidade neste estágio pode ser atribuída ao aumento de espessura do filme, seguido da dificuldade de adsorção das espécies em solução, em sítios ativos da cadeia de PAni-DBSA sobre a camada de óxido. Uma vez formada a camada de PAni-DBSA sobre 
AISI-304, o crescimento do polímero é favorecido, devido a isto a velocidade de síntese no estágio IV é superior a da Pt.

\subsection{Caracterização}

A caracterização dos polímeros de PAni-DBSA foi feita por da resposta eletroquímica dos filmes em diferentes meios, análises de espectroscopia nas regiões do ultravioleta, do visível, do infravermelho próximo (UV-VIS-NIR) e no infravermelho (IV), nas formas dopada e desdopada. As micrografias dos polímeros obtidas por microscopia eletrônica de varredura (MEV) complementaram a caracterização.

\subsubsection{Caracterização voltamétrica}

O comportamento voltamétrico da PAni-DBSA sobre Pt (30 e 60 ciclos) e sobre AIS-304 (31 e 61 ciclos) foi observado em solução de $\mathrm{H}_{2} \mathrm{SO}_{4} 0,5 \mathrm{~mol} \mathrm{~L}^{-1}$ e DBSA 0,05 mol L ${ }^{-1}$, sem monômero, a $50 \mathrm{mV} \mathrm{s}^{-1}$, no intervalo de potencial de $-0,2 \mathrm{~V}$ a $0,8 \mathrm{~V}$, em um total de 5 ciclos. Todos os filmes de PAni-DBSA foram eletropolimerizados a partir de uma solução de DBSA $0,05 \mathrm{~mol} \mathrm{~L}^{-1}$ contendo $0,015 \mathrm{~mol} \mathrm{~L}^{-1}$ de anilina.

Conforme pode ser observado nas Figuras 55 ((a) e (b)), os voltamogramas apresentam os picos característicos de PAni, os quais já foram mencionados anteriormente. O filme de PAni-DBSA eletropolimerizado sobre AISI-304 demonstra máximo mais elevado de densidade de corrente do que PAni-DBSA sobre Pt, em ambos os meios. Isto indica que PAni-DBSA sobre AISI-304 tem uma maior eletroatividade, quando comparado ao depositado sobre platina.

Os valores de carga anódica e potenciais de pico, referente ao primeiro processo redox de PAni-DBSA descritos na Tabela 5, também evidenciam as diferenças no comportamento eletroquímico.

Esse máximo mais elevado da densidade de corrente para PAni-DBSA sobre AISI-304 indica: (i) "maior eletroatividade"; (ii) a estrutura de PAni-DBSA sobre AISI-304 tende a ser mais porosa do que PAni-DBSA sobre Pt e que também; (iii) a cinética de polimerização de PAniDBSA sobre os diferentes substratos seria diferente e, dependente do substrato (o que está de acordo com os resultados anteriores). 


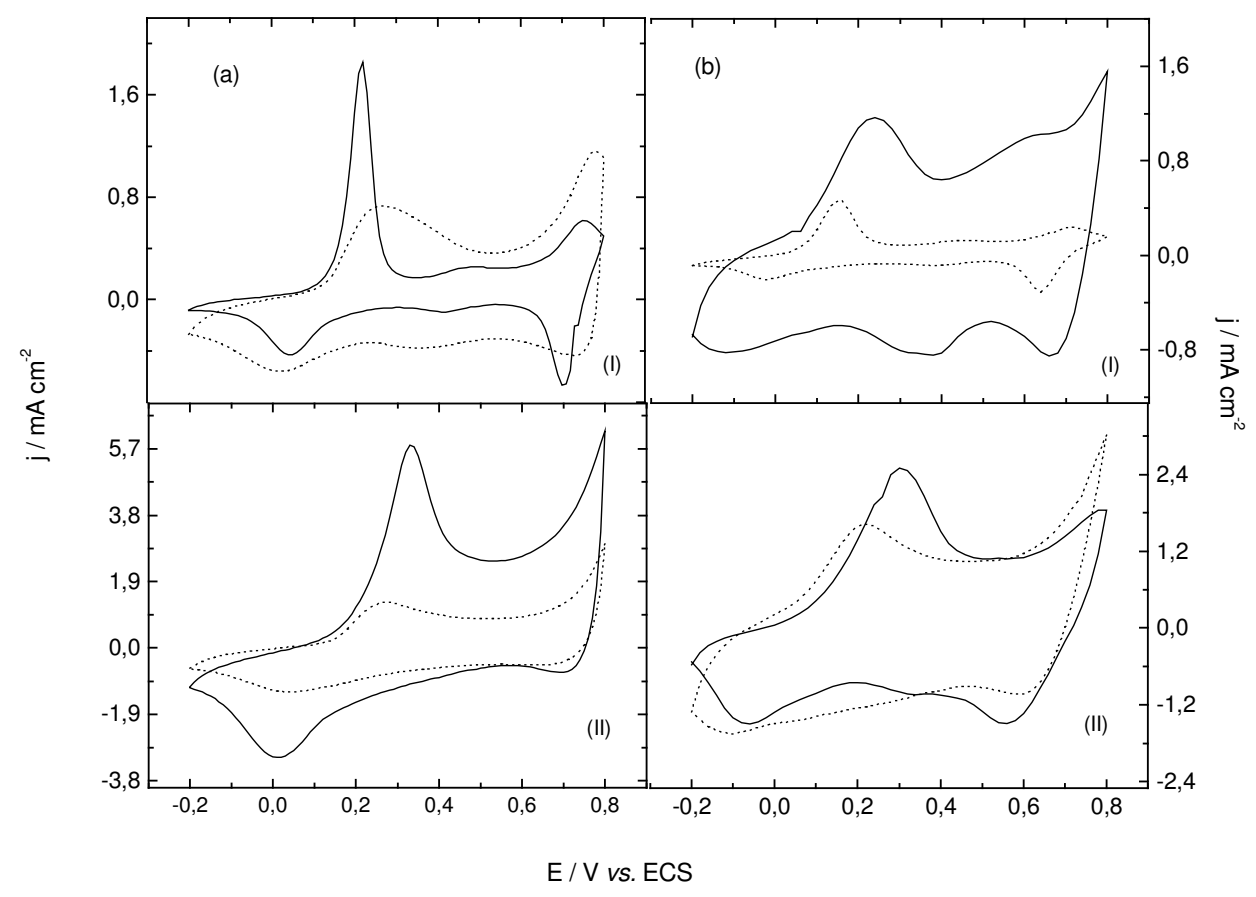

Figura 55. Resposta eletroquímica em solução de (a) $\mathrm{H}_{2} \mathrm{SO}_{4} 0,5 \mathrm{~mol} \mathrm{~L}^{-1}$ e (b) DBSA 0,05 $\mathrm{mol} \mathrm{L}^{-1}$ de PAni-DBSA eletropolimerizada sobre (.....) Pt e (-) AISI-304. $\mathrm{V}=50 \mathrm{mV} \mathrm{s}^{-1}$. Filmes eletropolimerizados em (I) 30 ciclos e (II) 60 ciclos.

Tabela 5. Valores de carga anódica e potenciais de pico do primeiro processo redox de PAniDBSA, obtidos da resposta eletroquímica dos filmes em $\mathrm{H}_{2} \mathrm{SO}_{4} 0,5 \mathrm{~mol} \mathrm{~L}^{-1}$ e DBSA 0,05 mol L-1

\begin{tabular}{c|c|c|c|c|c}
\hline \multicolumn{2}{c|}{} & \multicolumn{2}{c|}{ PAni-DBSA / Pt } & \multicolumn{2}{c}{ PAni-DBSA / AISI-304 } \\
\hline $\begin{array}{c}\text { Meio } \\
\text { eletrolítico }\end{array}$ & $\begin{array}{c}\text { Número de } \\
\text { ciclos }\end{array}$ & $\mathrm{E}_{\mathrm{PA}} / \mathrm{mV}$ & $\mathrm{Q}_{\mathrm{PA}} / \mathrm{mC}$ & $\mathrm{E}_{\mathrm{PA}} / \mathrm{mV}$ & $\mathrm{Q}_{\mathrm{PA}} / \mathrm{mC}$ \\
\hline \multirow{2}{*}{$\begin{array}{c}\mathbf{H}_{2} \mathbf{S O}_{4} \\
0,5 \mathrm{M}\end{array}$} & 30 & 270 & 3,39 & 220 & 2,98 \\
\cline { 2 - 6 } & 60 & 270 & 5,65 & 330 & 21,0 \\
\hline $\begin{array}{c}\boldsymbol{D} B S A \\
0,05 \mathrm{M}\end{array}$ & 30 & 240 & 5,82 & 160 & 1,22 \\
\cline { 2 - 6 } & 60 & 220 & 8,84 & 300 & 12,24 \\
\hline
\end{tabular}

As diferenças observadas nos perfis voltamétricos dos filmes em solução de $\mathrm{H}_{2} \mathrm{SO}_{4} \mathrm{e}$ DBSA refletem também, a mobilidade dos diferentes íons em solução, ou, seja o processo de troca iônica entre o polímero e a solução (saída do íon do polímero para a solução e vice versa). 


\subsubsection{Espectroscopia no UV-Vis-NIR}

Os espectros no UV-VIS-NIR de PAni-DBSA eletropolimerizada sobre AISI-304 e Pt foram realizados no estado desdopado e dopado. O polímero desdopado foi dissolvido em NMP originando uma solução de coloração azul, característico da PAni desdopada. Posteriormente, o espectro do polímero desdopado foi registrado. Ao ser dopado com $\mathrm{HCl} 5$ mol L $\mathrm{L}^{-1}$ a coloração da solução varia de azul para verde, caracterizando a PAni em sua forma dopada (Figura 56).

Nos espectros dos polímeros em sua forma desdopada (Fig. 56 (a)) podem ser observadas duas bandas de absorção: uma banda entre 335 - $341 \mathrm{~nm}$ correspondente à transição $\pi-\pi^{*}$ dos anéis benzenóides. Outra banda entre 641 - 654 nm atribuída à transferência de cargas entre os anéis quinóides e benzenóides, ou seja, a banda excitônica [12,13,15,126]. Entretanto, para os polímeros dopados Fig. 56 (b), uma nova banda entre 426 $429 \mathrm{~nm}$ pode ser observada, a qual é freqüentemente atribuída aos radicais cátions que se formam no processo de dopagem. Também pode ser observada uma banda larga entre 889 e $891 \mathrm{~nm}$ associada aos transportadores de carga da cadeia polimérica. Essa última banda se refere à transição da banda excitônica para as bipolarônicas da cadeia [15]. A PAni-DBSA obtida sobre AISI-304 e Pt apresenta o comportamento óptico característicos da PAni $[12,13,126]$.

Os espectros dos polímeros desdopados constituem um espectro típico da base esmeraldina e quando dopado o espectro corresponde ao sal esmeraldina. Contudo, os espectros apresentam algumas diferenças nos comprimentos de ondas atribuídas as diferentes condições de sínteses nas quais os polímeros foram eletropolimerizados. 


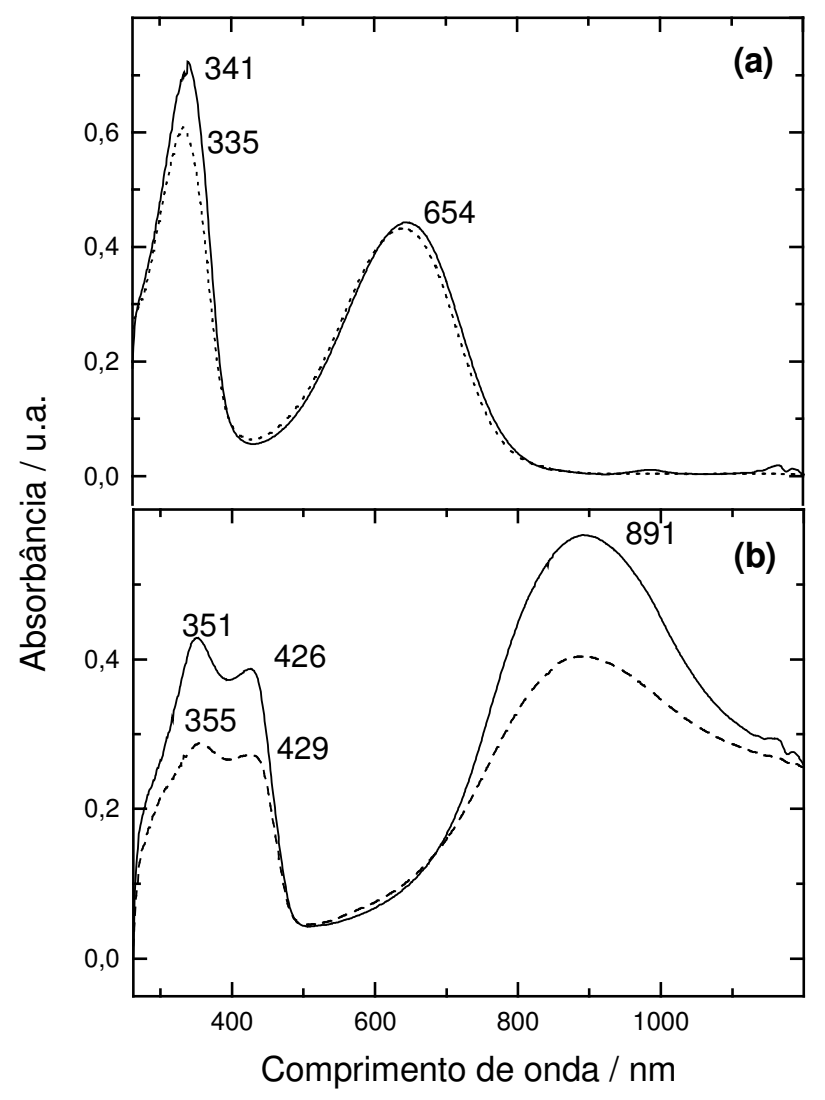

Figura 56. Espectros de UV-VIS-NIR de PAni DBSA eletropolimerizada sobre (一) Pt e (----) AISI-304 a partir de uma solução de DBSA 0,05 $\mathrm{mol} \mathrm{L}^{-1}$ contendo $0,015 \mathrm{~mol} \mathrm{~L}^{-1}$ de anilina. (a) desdopado e (b) dopado.

As análises dos espectros de UV-VIS-NIR dos filmes de PAni-DBSA sobre AISI-304 e Pt confirmam a obtenção de PAni-DBSA no estado mais condutor do polímero.

\subsubsection{Espectroscopia no Infravermelho (IV)}

A Figura 57 demonstra os espectros na região do infravermelho de PAni eletropolimerizada em solução de DBSA $0,05 \mathrm{~mol} \mathrm{~L}^{-1}$ contendo $0,015 \mathrm{~mol} \mathrm{~L}^{-1}$, de anilina, sobre Pt e AISI-304, no estado dopado. PAni-DBSA é caracterizada por estiramentos das ligações N$\mathrm{H}$ ao redor de $3436 \mathrm{~cm}^{-1}$ e, o processo de dopagem por DBSA pela presença de bandas ao redor de 2960, 2920 e $2850 \mathrm{~cm}^{-1}$, correspondentes aos estiramentos das ligações C-H da molécula de DBSA. 
Segundo diversos autores [144,147,148] a presença das bandas a 2960, 2920 e 2850 $\mathrm{cm}^{-1}$ são consistentes com a grande quantidade de ligações $\mathrm{C}-\mathrm{H}$ presentes na molécula de DBSA, que resultam a partir do comprimento da cadeia alquílica. Essas bandas são mais evidentes para PAni-DBSA eletropolimerizada sobre Pt, indicando uma presença maior de DBSA no polímero.

As bandas ao redor de 1585 e $1497 \mathrm{~cm}^{-1}$ são atribuídas aos estiramentos vibracionais das ligações $\mathrm{C}-\mathrm{C}$ correspondentes aos anéis quinóides (Q) e benzenóides (B), respectivamente. A intensidade da banda ao $1570-1590 \mathrm{~cm}^{-1}$ relativa a banda ao redor de $1500 \mathrm{~cm}^{-1}$ é uma medida do grau de oxidação do polímero de PAni [12]. Comparativamente, a intensidade de absorção das bandas Q e B de PAni-DBSA sobre Pt e AISI-304 é diferente, indicativo de que, sobre AISI-304, o polímero é mais oxidado do que sobre Pt.

A presença de uma fraca banda a $1375 \mathrm{~cm}^{-1}$, no espectro de PAni-DBSA sobre Pt, é atribuída ao modo de vibração da ligação C-N da estrutura semiquinóide (QBQ), a qual não é evidenciada no espectro de PAni-DBSA sobre AISI-304.

As bandas ao redor de 1303 e $1263 \mathrm{~cm}^{-1}$ são correspondentes aos modos de vibração das ligações $\mathrm{N}-\mathrm{H}$ e dos componentes simétricos dos modos de estiramentos das ligações $\mathrm{C}-\mathrm{C}$ ou C-N. No caso de PAni-DBSA sobre AISI-304 a banda ao redor de $1263 \mathrm{~cm}^{-1}$ é menos intensa do que sobre Pt.

As bandas a 1143 e $1103 \mathrm{~cm}^{-1}$ são atribuídas aos modos de vibração das ligações C-H no plano e aos componentes simétricos dos modos de estiramentos de ligações $\mathrm{SO}_{2}$, respectivamente. No entanto, essas bandas são mais evidentes no espectro de PAni-DBSA sobre Pt, enquanto para PAni-DBSA sobre AISI-304 sofrem um acoplamento (banda a 1126 $\left.\mathrm{cm}^{-1}\right)$.

A interação do DBSA na PAni, também pode ser observada por uma fraca banda ao redor de $1020 \mathrm{~cm}^{-1}$. Essa banda corresponde ao modo de vibração das bandas de sulfatos $(\mathrm{S}=\mathrm{O})$ sendo freqüentemente observada em muitos ácidos sulfônicos [144,147,148].

O efeito ressonante na estrutura sobre os ligantes fora do plano dos anéis aromáticos substituídos na posição $1,2,4$ é observado pela presença da banda a $1143 \mathrm{~cm}^{-1}$ e na posição 1,2 e pelas bandas a $800 \mathrm{~cm}^{-1}$ para PAni-DBSA sobre Pt, enquanto sobre AISI-304, a $875 \mathrm{e}$ $667 \mathrm{~cm}^{-1}$. 


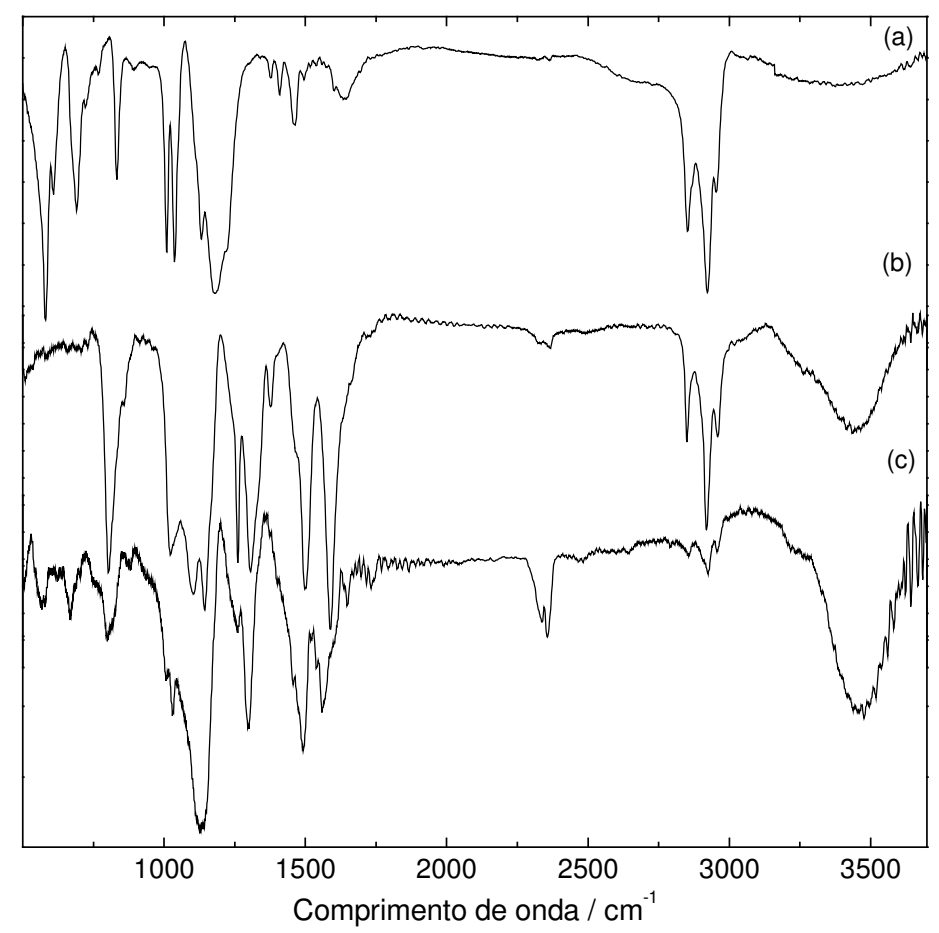

Figura 57. Espectro no infravermelho de (a) DBSA (comercial) e PAni-DBSA dopada, eletropolimerizada sobre (b) Pt e (c) AISI-304 a partir de uma solução aquosa de DBSA $0,05 \mathrm{~mol} \mathrm{~L}^{-1}$ contendo $0,015 \mathrm{~mol} \mathrm{~L}^{-1}$ de anilina.

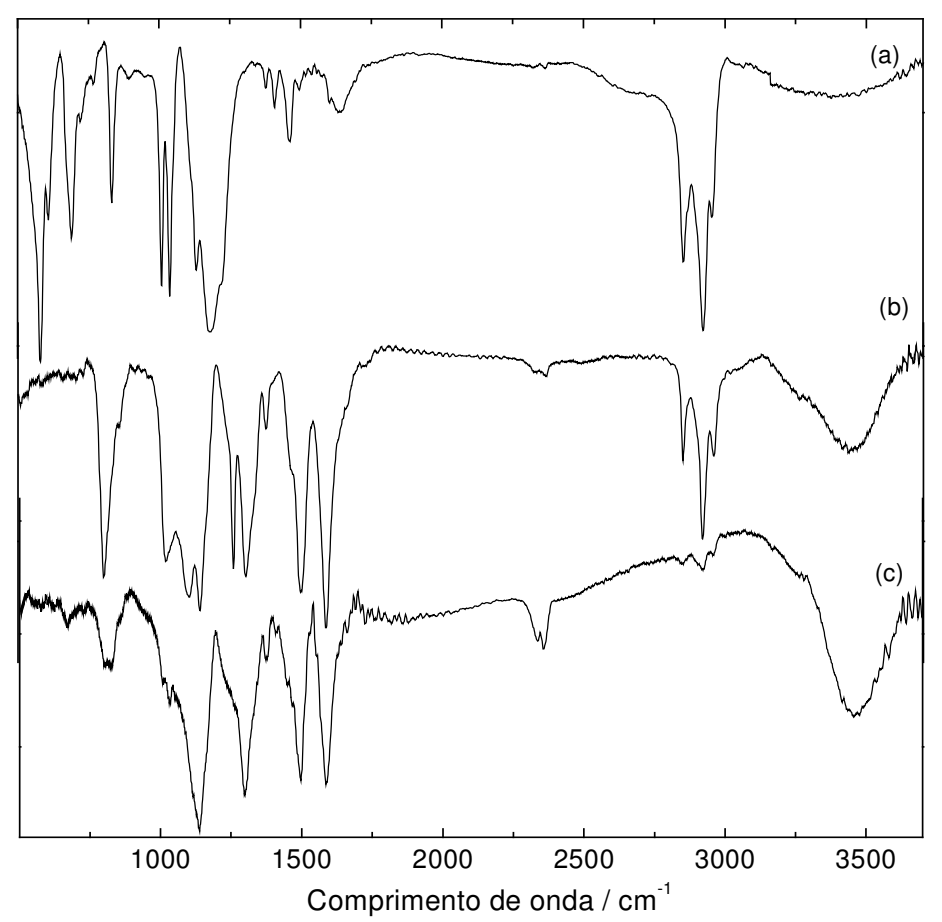

Figura 58. Espectro no infravermelho de (a) DBSA (comercial) e de PAni-DBSA desdopada, eletropolimerizada sobre (b) Pt e (c) AISI-304 a partir de uma solução aquosa de DBSA $0,05 \mathrm{~mol} \mathrm{~L}^{-1}$ contendo $0,015 \mathrm{~mol} \mathrm{~L}^{-1}$ de anilina. 
A banda a $575 \mathrm{~cm}^{-1}$, no espectro de PAni-DBSA sobre AISI-304, atribuída à deformação das ligações $\mathrm{C}-\mathrm{H}$ do anel aromático, está ausente no espectro de PAni-DBSA sobre Pt. A presença de um maior número de bandas na região de substituição do anel aromático no espectro de PAni-DBSA sobre AISI-304 evidencia que, um maior número de substituintes é incorporado à estrutura polimérica.

A presença de $\mathrm{Fe}_{2} \mathrm{O}_{3}$, formado quando PAni-DBSA é eletropolimerizada sobre AISI-304, também constatada por Prissanarron et al. [31], pode estar promovendo a diferença na região inferior a $1000 \mathrm{~cm}^{-1}$ no espectro de PAni-DBSA sobre aço.

Os espectros de PAni-DBSA dopada sobre AISI-304 e Pt apresentam significativas diferenças que permanecem, nos espectros dos polímeros desdopados (Figura 58 (b) e (c)). No espectro de PAni-DBSA desdopada sobre Pt (Fig. 58 (b)) foi observado um acoplamento das bandas entre $2850-3436 \mathrm{~cm}^{-1}$. Entretanto, o mesmo não foi observado para PAni-DBSA sobre AISI-304 (Fig. 58 (c)), o que parece indicar que o ânion DBSA está fortemente incorporado à estrutura do polímero. A banda referente ao modo de vibração da ligação C-N da estrutura semiquinóide (QBQ) em PAni-DBSA sobre AISI-304 se evidencia a $1369 \mathrm{~cm}^{-1}$.

Com o processo de desdopagem algumas bandas são evidenciadas, ocorrendo também transferências para região de menor comprimento de onda. A região de diferenças marcantes entre PAni-DBSA sobre Pt e AISI-304 é a de comprimento de onda inferior a $1000 \mathrm{~cm}^{-1}$. No espectro de PAni-DBSA sobre Pt as bandas que caracterizam a substituição de anel aromático na posição 1,2,4 e deformação de ligações C-H de anel aromático $(513,604,702,802,833$ $\mathrm{cm}^{-1}$ ) são evidenciadas. Mediante os espectros de PAni-DBSA desdopada, pode ser afirmado que os polímeros possuem estrutura similar à base esmeraldina.

\subsubsection{Microscopia eletrônica de varredura (MEV)}

Na Figura 59 são apresentadas as micrografias obtidas por MEV das superfícies dos filmes de PAni-DBSA obtidas sobre Pt e AISI-304. Mediante as imagens pode ser observado que a estrutura morfológica de PAni-DBSA depende do substrato empregado. 


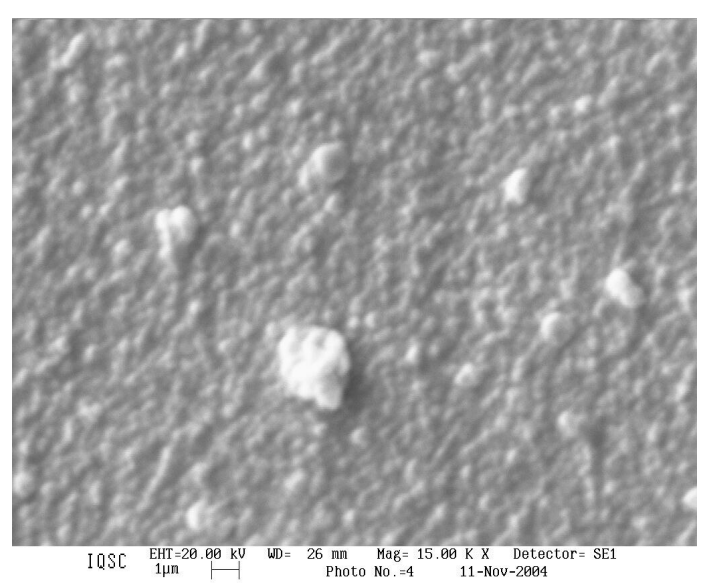

(a)

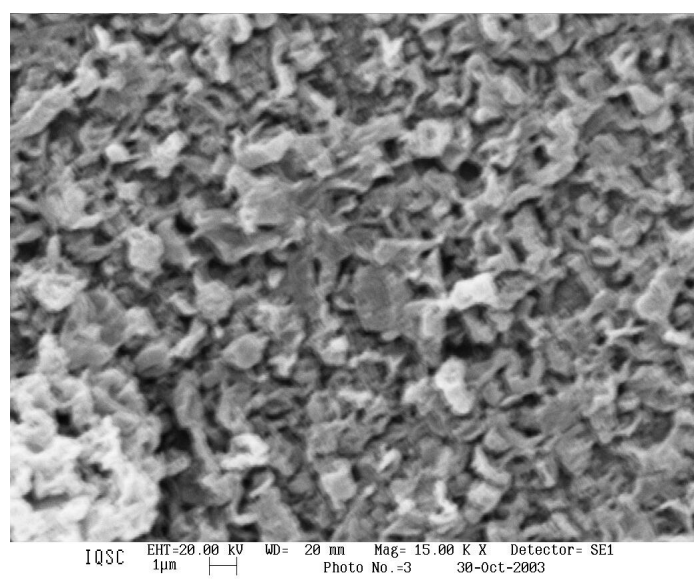

(c)

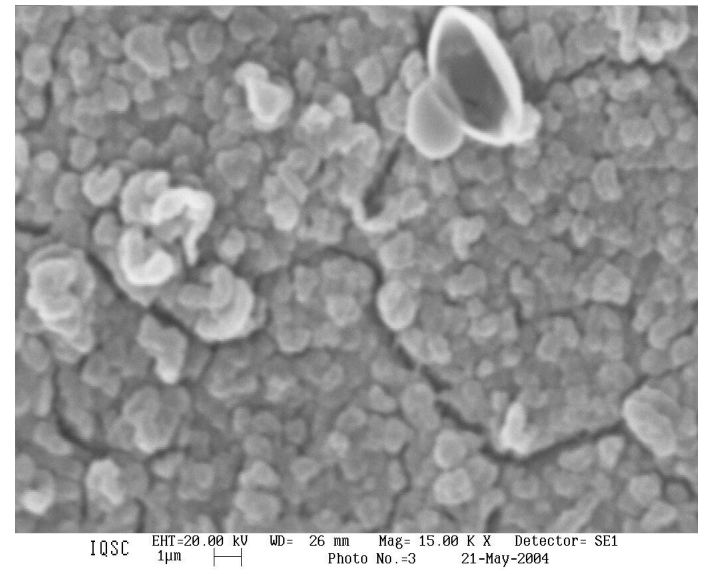

(b)

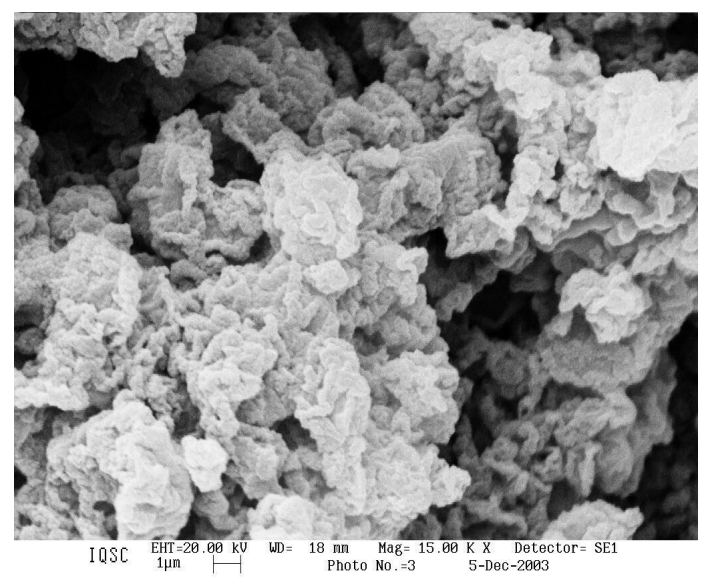

(d)

Figura 59. Micrografias de PAni-DBSA eletropolimerizada sobre Pt : (a) (50) e (b) 90 ciclos; sobre AISI-304: (c) 51 ciclo e (d) 91 ciclos.

Para PAni-DBSA eletropolimerizada sobre Pt foi observada uma estrutura granular compacta e homogênea (Fig. 59 (a) e (b)) enquanto, para PAni-DBSA eletropolimerizada sobre AISI-304, a estrutura é porosa e homogênea (Fig. 59 (c)), com aspecto de couve-flor (Fig. 59 (d)). Essa diferença na morfologia da PAni-DBSA pode ser decorrente da camada de óxido que se forma durante o processo de eletropolimerização sobre AISI-304, promovendo assim uma estrutura porosa. Esse resultado se correlaciona diretamente com os resultados das respostas eletroquímicas dos filmes.

Durante a eletropolimerização de PAni-DBSA sobre AISI-304, há formação de uma camada de óxido e misturada a essa camada, núcleos de PAni-DBSA seriam também formados. A continuidade da eletropolimerização de PAni-DBSA, sobre um o arranjo estrutural 
pré-formado pode estar originando uma estrutura mais aberta. Isto também ocorreria para PAni-DBSA sobre Pt, no entanto sem a presença de um arranjo estrutural do óxido préexistente, promove uma estrutura compacta.

Quando comparadas as micrografias de PAni-DBSA sobre AISI-304, em diferentes estágios de eletropolimerização (51 e 91ciclos de potenciais) (Figuras 59 (c) e (d), respectivamente foi observado que a morfologia com o aspecto de couve-flor é promovida pelo aumento da espessura do filme. Para um número de ciclos menor que 91 a estrutura obtida sobre AISI-304 é semelhante à sobre $\mathrm{Pt}$, no entanto mais porosa.

\subsubsection{Condutividade}

A condutividade determinada pelo método de quatro pontas do filme de PAni-DBSA ,eletropolimerizado sobre AISI-304 a partir de uma solução de DBSA $0,05 \mathrm{~mol} \mathrm{~L}^{-1}$ contendo $0,015 \mathrm{~mol} \mathrm{~L}^{-1}$ (91 ciclos de potencial; espessura estimada em $\left.0,30 \mu \mathrm{m}\right)$, foi de $4,65 \mathrm{~S} \mathrm{~cm}^{-1}$. Comparado aos valores descritos em literatura para PAni-DBSA quimicamente obtida, esse valor é menor (cerca de 2,1 a 3,2 a vezes), no entanto a ordem de grandeza é similar. Usualmente, o polímero obtido eletroquimicamente demonstra condutividade superior àquele obtido quimicamente. Devido ao fato do método eletroquímico promover maior controle da síntese e, a geração de um polímero mais ordenado estruturalmente [1,12].

Para PAni-DBSA sobre AISI-304, a mistura da camada de óxido ao polímero pode conduzir a uma redução no transporte de elétrons na estrutura do material e assim, reduzir a condutividade. Infelizmente, devido a espessura dos filmes eletropolimerizados sobre Pt, não foi possível determinar os valores das medidas de condutividade e constatar esta hipótese. 


\title{
Capítulo VI
}

\section{Ensaios de Corrosão}

\begin{abstract}
A aplicabilidade dos filmes de PAni-CMC e PAni-DBSA, eletropolimerizados sobre eletrodos de AISI-304 como inibidores da corrosão metálica, até o momento é inexistente na literatura. Este capítulo descreve os resultados referentes aos estudos sobre os ensaios de corrosão dos filmes de PAni-CMC e PAni-DBSA sobre o aço. Em uma primeira fase, os estudos de corrosão relatam a influência de alguns parâmetros, tais como, estado de oxidação do polímero, espessura, morfologia e composição, na eficiência dos filmes na proteção contra a corrosão. Posteriormente, são descritas as comparações entre os filmes de PAni-CMC, PAni e PAni-DBSA e a literatura.
\end{abstract}

\subsection{Ensaios de corrosão de PAni-CMC}

Para investigar os efeitos protetores contra a corrosão foram realizados ensaios de corrosão do AISI-304 recobertos com PAni-CMC e PAni, nas formas dopada e desdopada e também, do AISI-304 sem recobrimento para comparação. As curvas potenciodinâmicas foram realizadas no intervalo de potenciais de $-0,5$ a $0,4 \mathrm{~V}$, a $0,5 \mathrm{mV} \mathrm{s}^{-1}$, em solução aquosa de $\mathrm{NaCl}$ $3 \%$, areada e a $25^{\circ} \mathrm{C}$.

Na Figura 60 estão exemplificadas as curvas potenciodinâmicas de PAni-CMC na forma dopada. As amostras recobertas com os diferentes filmes dopados apresentam valores de potenciais de corrosão $\left(E_{c o r}\right)$ similares, entretanto, os valores são maiores do que para AISI-304 sem recobrimento. A partir das curvas potenciodinâmicas foram obtidos os valores de densidade de corrente de corrosão e de potencial de pite $\left(E_{\text {pite }}\right)$, descritos na Tabela 6. 


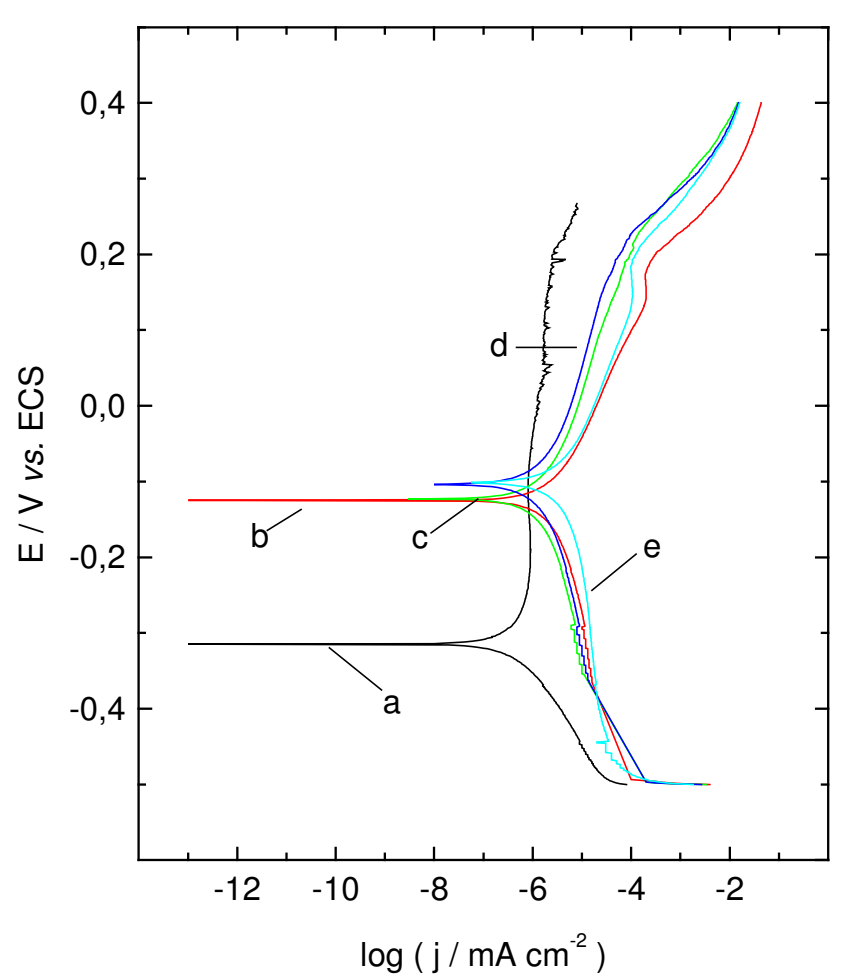

Figura 60. Curvas potenciodinâmicas em solução aquosa de $\mathrm{NaCl} 3 \%$, aerada a $25^{\circ} \mathrm{C}$ do AISI304 (a) sem recobrimento e recoberto com PAni-CMC dopada (b) $0,1 \%$; (c) $0,3 \%$; (d) $0,6 \%$ e (e) $1 \%$ de CMC.

Tabela 6. Potencial de corrosão, densidade de corrente de corrosão, potencial de pite e variação entre o potencial de pite e o potencial de corrosão do AISI-304 sem e com recobrimento de PAni-CMC. \% CMC (m/v)

\begin{tabular}{|c|c|c|c|c|c|c|c|c|c|}
\hline \multirow{3}{*}{ Parâmetros } & \multirow{3}{*}{$\begin{array}{l}\text { AISI-304 } \\
\text { sem rec. }\end{array}$} & \multicolumn{8}{|c|}{ AISI-304 recoberto com PAni-CMC } \\
\hline & & \multicolumn{4}{|c|}{ dopada } & \multicolumn{4}{|c|}{ Desdopada } \\
\hline & & $0,1 \%$ & $0,3 \%$ & $0,6 \%$ & $1 \%$ & $0,1 \%$ & $0,3 \%$ & $0,6 \%$ & $1 \%$ \\
\hline$-E_{\text {cor }}$ & 0,313 & 0,126 & 0,123 & 0,104 & 0,102 & 0,133 & 0,253 & 0,177 & 0,145 \\
\hline $\mathrm{I}_{\mathrm{corr}} / \mu \mathrm{Acm}^{-2}$ & 0,828 & 2,520 & 3,186 & 3,185 & 2,635 & 1,860 & 3,330 & 1,760 & 0,175 \\
\hline$E_{\text {pite }}$ & 0,009 & 0,144 & 0,225 & 0,240 & 0,182 & 0,267 & 0,232 & 0,103 & 0,274 \\
\hline$E_{\text {pite }}-E_{\text {cor }}$ & $-0,304$ & 0,270 & 0,348 & 0,208 & 0,284 & 0,403 & 0,485 & 0,280 & 0,419 \\
\hline
\end{tabular}


O aumento da densidade de corrente de corrosão para o AISI-304 recoberto reflete o aumento de área com a presença do filme condutor sobre o eletrodo, além de caracterizar a soma de todas as reações de oxi-redução que ocorrem no sistema (metal/filme e filme/solução) [149]. O $E_{\text {pite }}$ do AISI-304 é deslocado para valores mais positivos quando PAni-CMC está presente, em relação ao aço sem recobrimento. Para a PAni-CMC dopada, a faixa de potencial de trabalho que antecede a corrosão por pite $\left(E_{\text {pite }}-E_{c o r}\right)$ é significativamente maior para o AISI-304 recoberto com PAni-CMC 0,3\%. Todos esses parâmetros são indicativos da eficiência de passivação da superfície do AISI-304 pelos filmes e são dependentes da concentração de CMC.

O AISI-304 recobertos com os diferentes filmes de PAni-CMC após secagem a vácuo por 24 horas foram imersos em uma solução de $\mathrm{NH}_{4} \mathrm{OH} 0,1 \mathrm{M}$, durante 24 horas para desdopagem. Em seguida, foram lavados sucessivamente com água, secos e as curvas potenciodinâmicas registradas conforme demonstrada pela Figura 61.

Os diferentes filmes desdopados apresentam comportamentos distintos e demonstram uma maior distinção nos valores de $E_{c o r}$, $E_{\text {pite }}$ e densidade de corrosão (Tabela 6) quando comparados aos filmes dopados.

Os parâmetros eletroquímicos obtidos para PAni-CMC desdopada, também, confirmam a eficiência de passivação da superfície do AISI-304 pelos filmes de PAni-CMC desdopados e, esse, também apresenta uma dependência com a concentração de CMC. O estado de oxidação da PAni-CMC (dopado ou desdopado) influencia no comportamento protetor dos materiais. A variação do potencial de corrosão (obtido da subtração do $E_{c o r}$ do aço revestido com PAni-CMC do $E_{c o r}$ aço sem recobrimento) dos filmes desdopados, em relação a concentração de CMC utilizada na eletropolimerização, em geral, são menores em relação aos dopados (Figura 62).

Esses materiais desdopados podem ser capazes de suportar uma maior quantidade de carga (absorção de elétrons) devido a ausência do ânion dopante, na parte condutora. Enquanto que, a presença de uma fase isolante na estrutura pode estar contribuindo para tornar mais eficiente $o$ efeito barreira. 


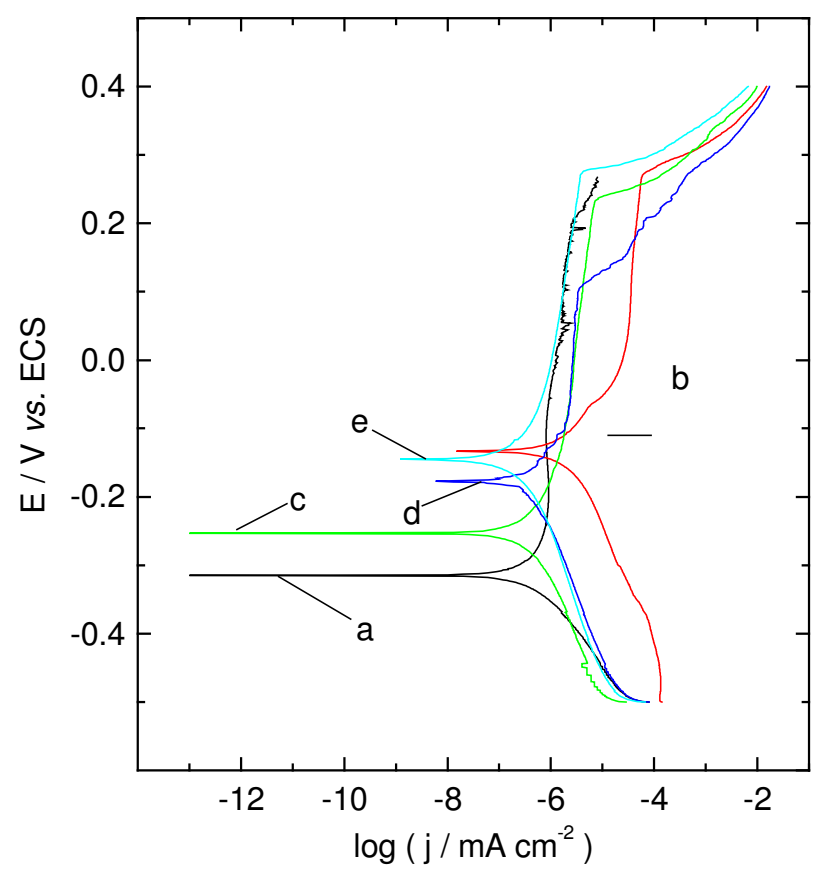

Figura 61. Curvas potenciodinâmicas em solução aquosa de $\mathrm{NaCl} 3 \%$, aerada a $25^{\circ} \mathrm{C}$ do AISI304 (a) sem recobrimento e recoberto com PAni-CMC desdopada (b) $0,1 \%$; (c) $0,3 \%$; (d) $0,6 \%$ e (e) $1 \%$ de CMC.

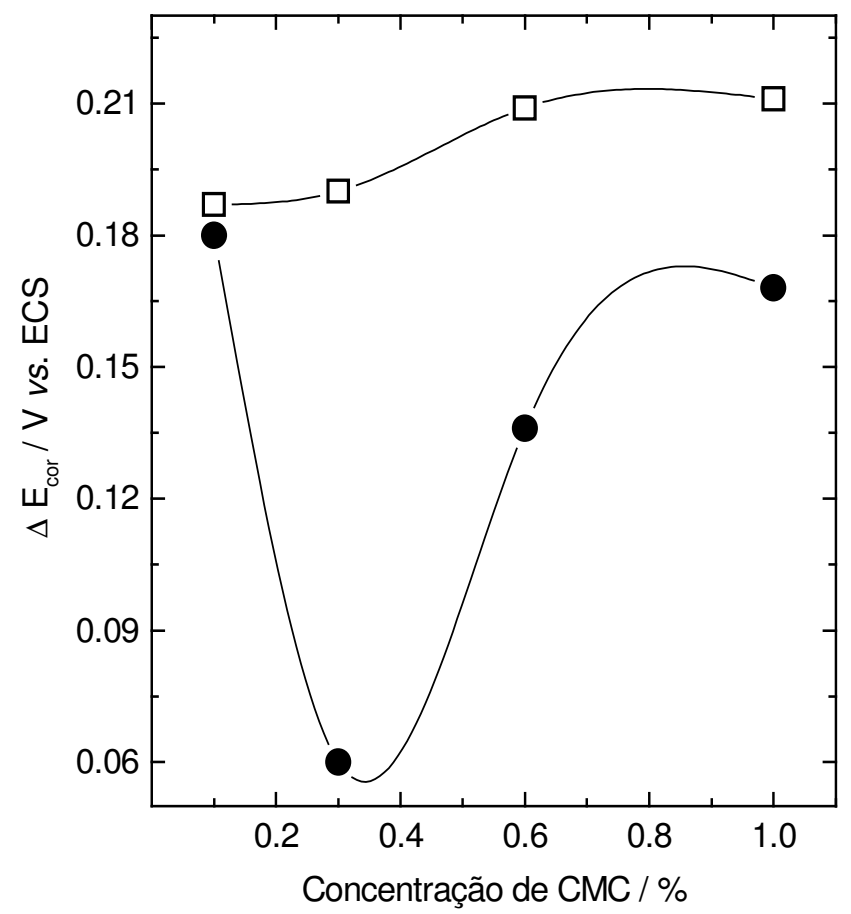

Figura 62. Dependência do potencial de corrosão $\left(\Delta \mathrm{E}_{\text {corr }}\right)$ do AISI-304 recoberto com PAniCMC em relação a concentração de CMC. PAni-CMC na forma ( ) dopada e $(\lambda)$ desdopada. 
Em vista disso, os parâmetros eletroquímicos dos filmes desdopados são superiores aos dos filmes dopados, inclusive a faixa de potencial de trabalho, a qual, para os filmes desdopados, é de cerca de uma vez e meia maior do que para os filmes dopados.

\subsubsection{Comparação de PAni-CMC e PAni}

Dentre os diferentes filmes de PAni-CMC, tanto na forma dopada quando desdopada PAni-CMC 0,1 e $1 \%$ foram selecionadas para comparação com PAni (homopolímero). Esta seleção se deve a tentativa de entender a influência da presença de CMC no compósito. Assim, pode ser observado se o filme de PAni-CMC é mais eficiente em proteger AISI-304 contra a corrosão do que o filme de PAni.

As curvas potenciodinâmicas dos filmes dopados de PAni e PAni-CMC apresentam pequenas diferenças nos $E_{\text {corr }}$ e $E_{\text {pite }}$, conforme pode ser observados na Fig.70. Por outro lado, para os filmes desdopados, uma significativa diferença pode ser observada somente no $E_{\text {pite }}, 0$ qual para PAni-CMC é superior ao da PAni, independente da concentração de CMC $(0,1$ ou 1\%). A eficiência de PAni-CMC em proteger o AISI-304 contra a corrosão é maior quando os filmes estão desdopados (Figuras 63 e 64).

Em resultados anteriores (capítulo III, seção 3.1.3) foi predito que altas concentrações de CMC promovem uma diminuição na velocidade de polimerização da PAni, devido a ocupação de sítios ativos na cadeia polimérica por CMC. Isto conduz a hipótese de que: (i) a baixas concentrações de CMC $(<0,6 \%$ de CMC) ocorre um gradiente maior de concentração de PAni, (fase condutora) e; (ii) a altas concentrações de CMC ( $\geq$ a $0,6 \%$ de $C M C$ ) ocorre um gradiente maior de concentração da fase isolante por unidade de volume e menor da fase condutora. Com base nisto, PAni-CMC (a baixas concentrações de CMC) protege o AISI-304 por dois mecanismos: mecanismo barreira e o mecanismo redox da PAni, sendo que a baixas concentrações de CMC o mecanismo redox e barreira seriam igualmente predominantes. No entanto, em altas concentrações de CMC a hipótese é de que o mecanismo barreira é o predominante e o mecanismo redox atua em menor proporção. 


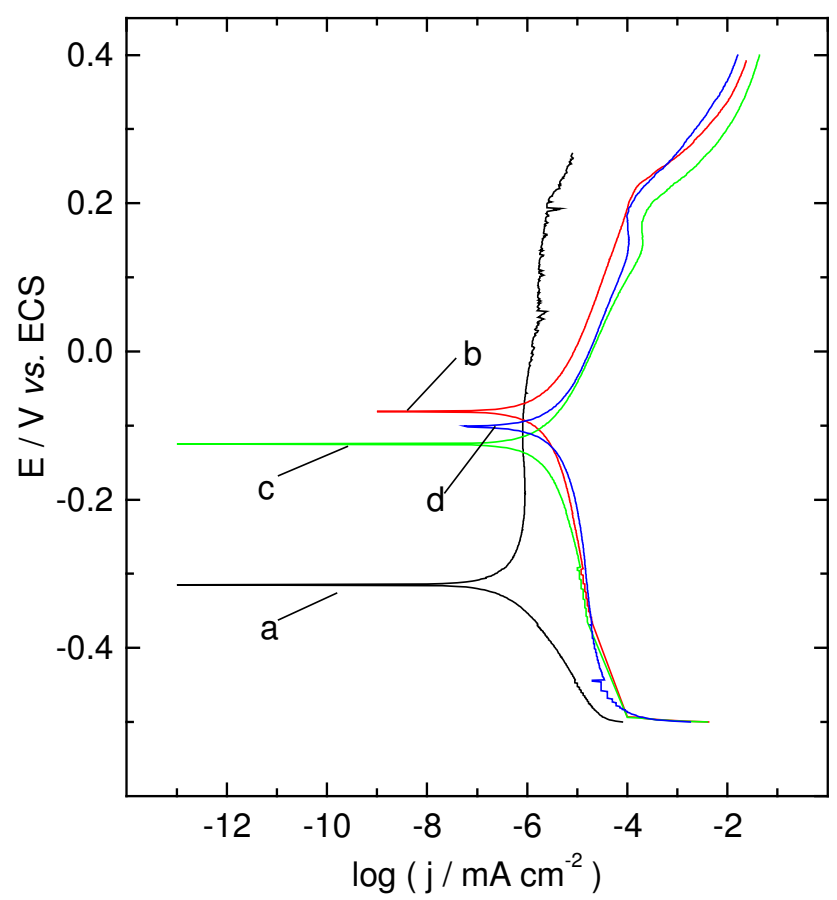

Figura 63. Curvas potenciodinâmicas em solução aquosa de $\mathrm{NaCl} 3 \%$, aerada a $25^{\circ} \mathrm{C}$ do AISI304 (a) sem recobrimento e recoberto com (b) PAni dopada e PAni-CMC dopada (c) 0,1\%; (d) $1 \%$ CMC.

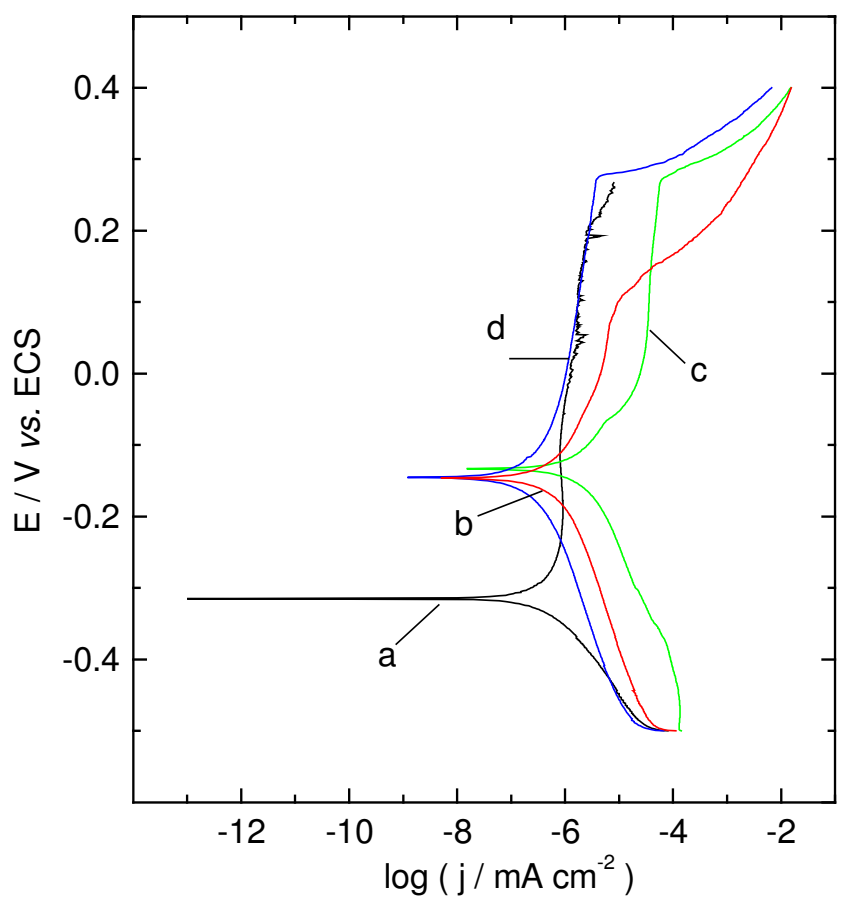

Figura 64. Curvas potenciodinâmicas em solução aquosa de $\mathrm{NaCl} 3 \%$, aerada a $25^{\circ} \mathrm{C}$ do AISI304 (a) sem recobrimento e recoberto com (b) PAni desdopada e PAni-CMC desdopada (c) $0,1 \%$; (d) $1 \%$ CMC. 
Desta forma, os filmes de PAni-CMC desdopados demonstram melhor desempenho, indicando que a formação da interação química de PAni com CMC proporciona ao material polimérico melhores propriedades protetoras do que a PAni isoladamente.

Quando comparada a PAni e PAni-CMC dopada pode ser confirmado os relatos em literatura [89,149], uma vez que, a PAni apresenta o melhor desempenho em proteger o AISI304 na forma dopada (Fig. 63). Entretanto, na forma desdopada o mesmo não pode ser considerado (Fig. 64). PAni apresenta $E_{\text {pite }}$ inferior ao de PAni-CMC.

No processo de desdopagem da PAni o ânion dopante é removido. Tendo em mente, que o íon dopante é uma espécie razoavelmente grande e polivalente, comparada ao íon cloreto, sua remoção ou saída implicaria em uma possível alteração na estrutura do polímero. Então, um íon pequeno como o cloreto mais facilmente se adsorveria sobre o filme ou se difundiria por seus poros. No entanto, isto iria depender da morfologia do material polimérico (se compacta ou porosa) e da quantidade de espécies dopantes que esse tivesse.

A morfologia dos filmes de PAni e de PAni-CMC 0,1 a 1\% (filmes dopados), antes e após os ensaios de corrosão são mostrados na Figura 65. A morfologia dos filmes de PAni-CMC pouco se altera após os ensaios de corrosão, podendo ser apenas notado um desgaste das camadas do filme quando baixas concentrações de CMC são utilizadas $(<0,6 \%$ CMC) (conforme Fig. 65 após corrosão). Isto pode ser uma conseqüência da interação da PAni com a CMC a baixas concentrações. Assim, para altas concentrações de CMC (>0,6\%), PAni-CMC pode promover o efeito barreira de forma mais eficiente devido as interações entre a mistura polimérica (PAni e CMC) e a manutenção das características condutoras da PAni. 

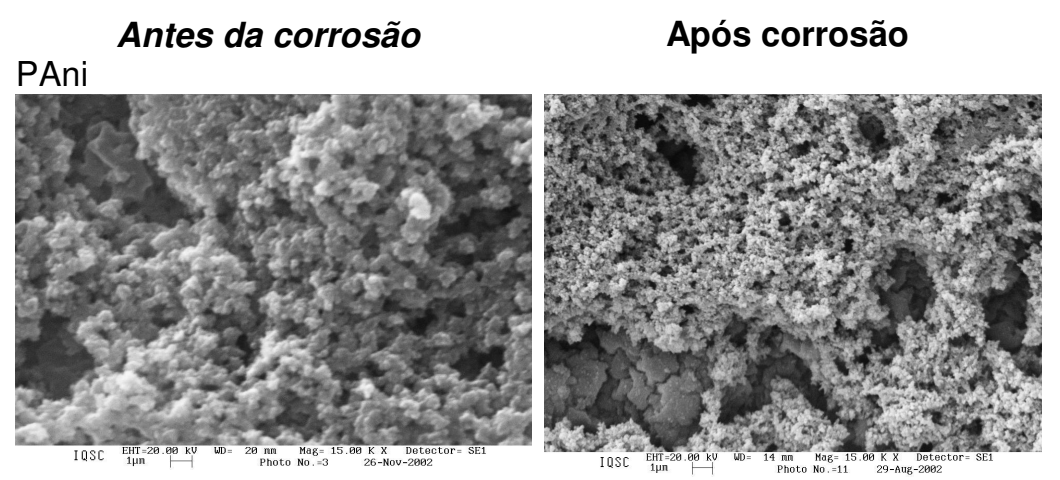

\section{EDX após corrosão}

PAni-CMC $0,1 \%$
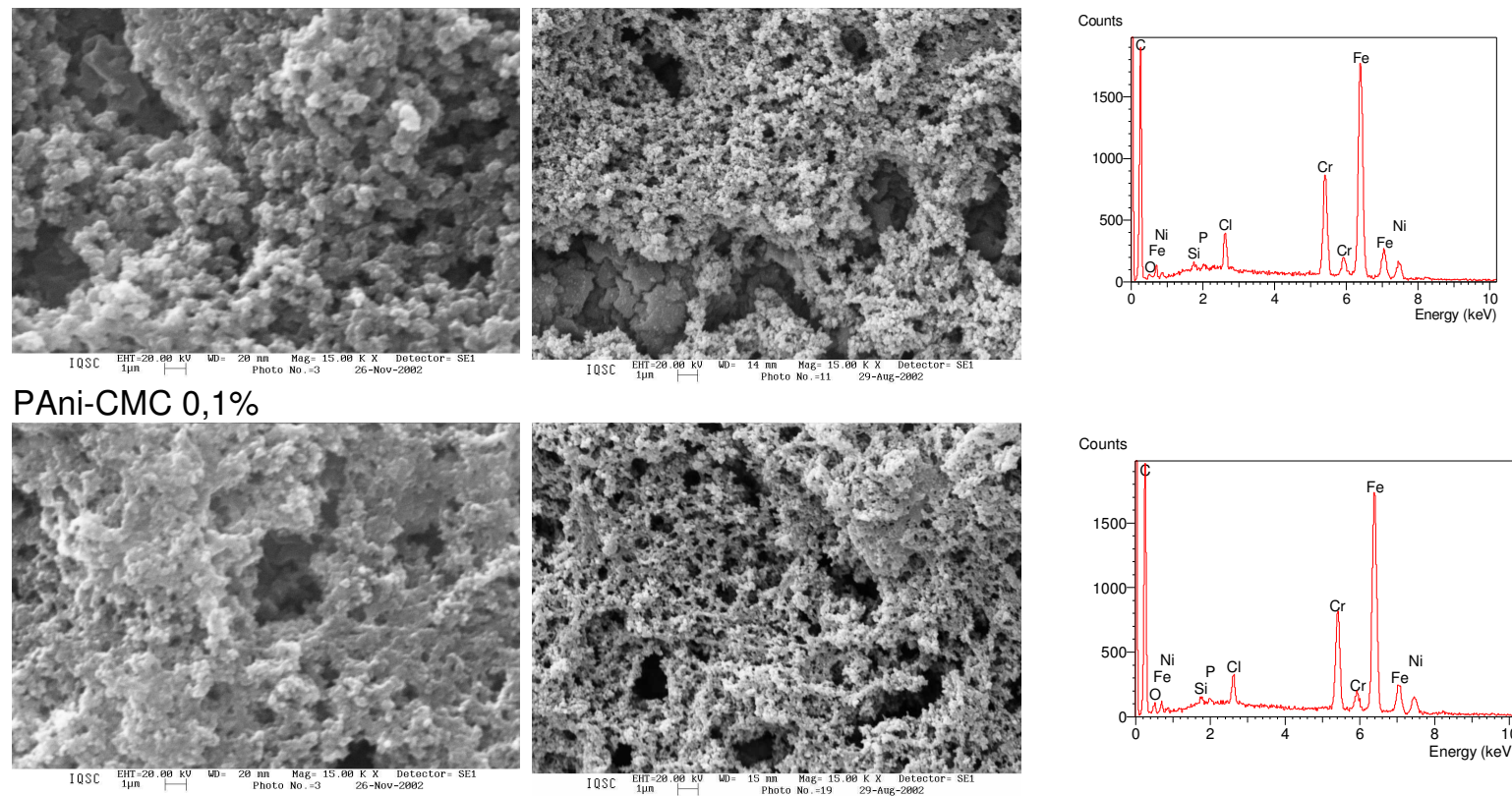

\section{PAni-CMC 0,3\%}
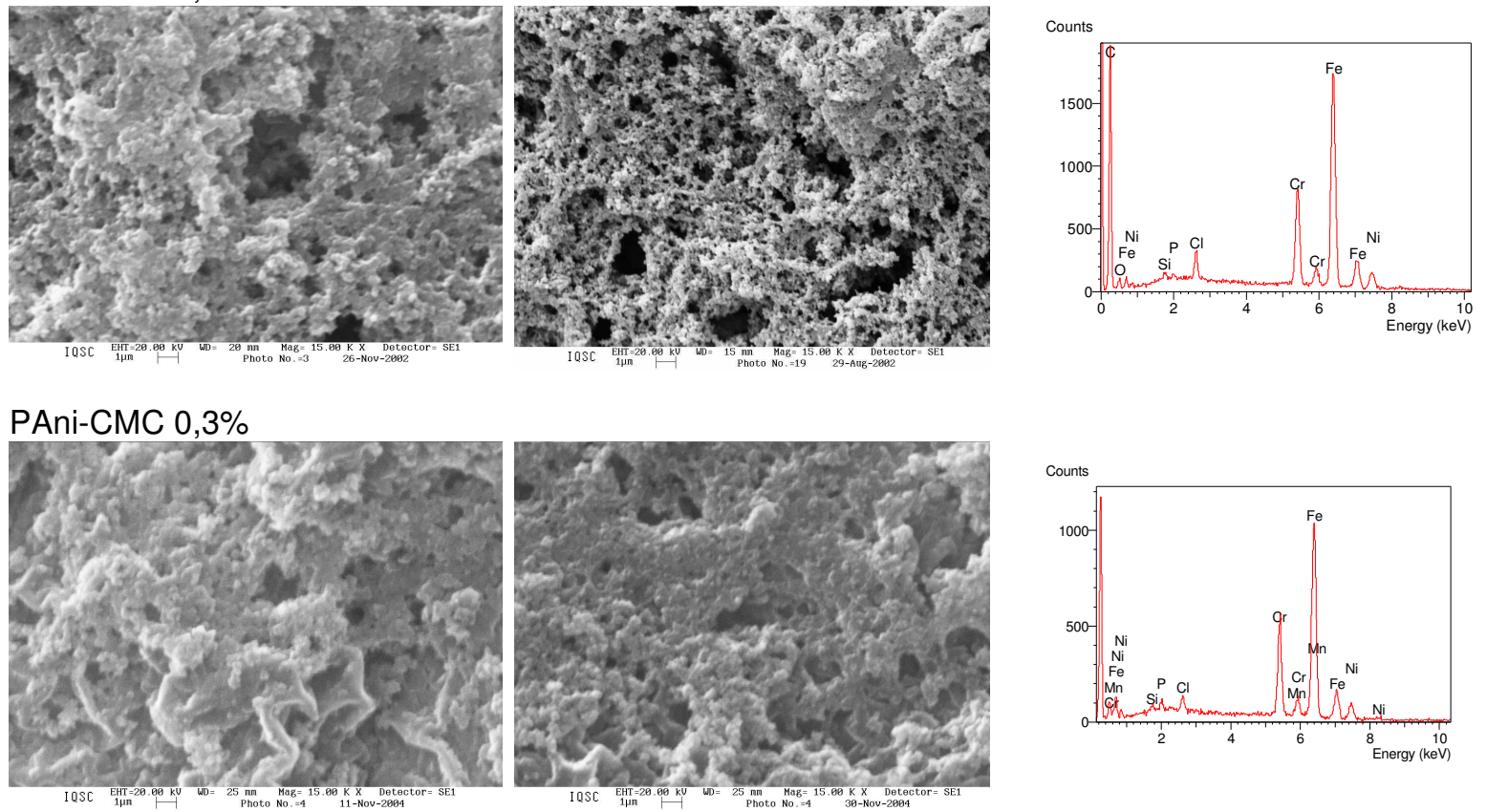

\section{Pani-CMC 0,6\%}
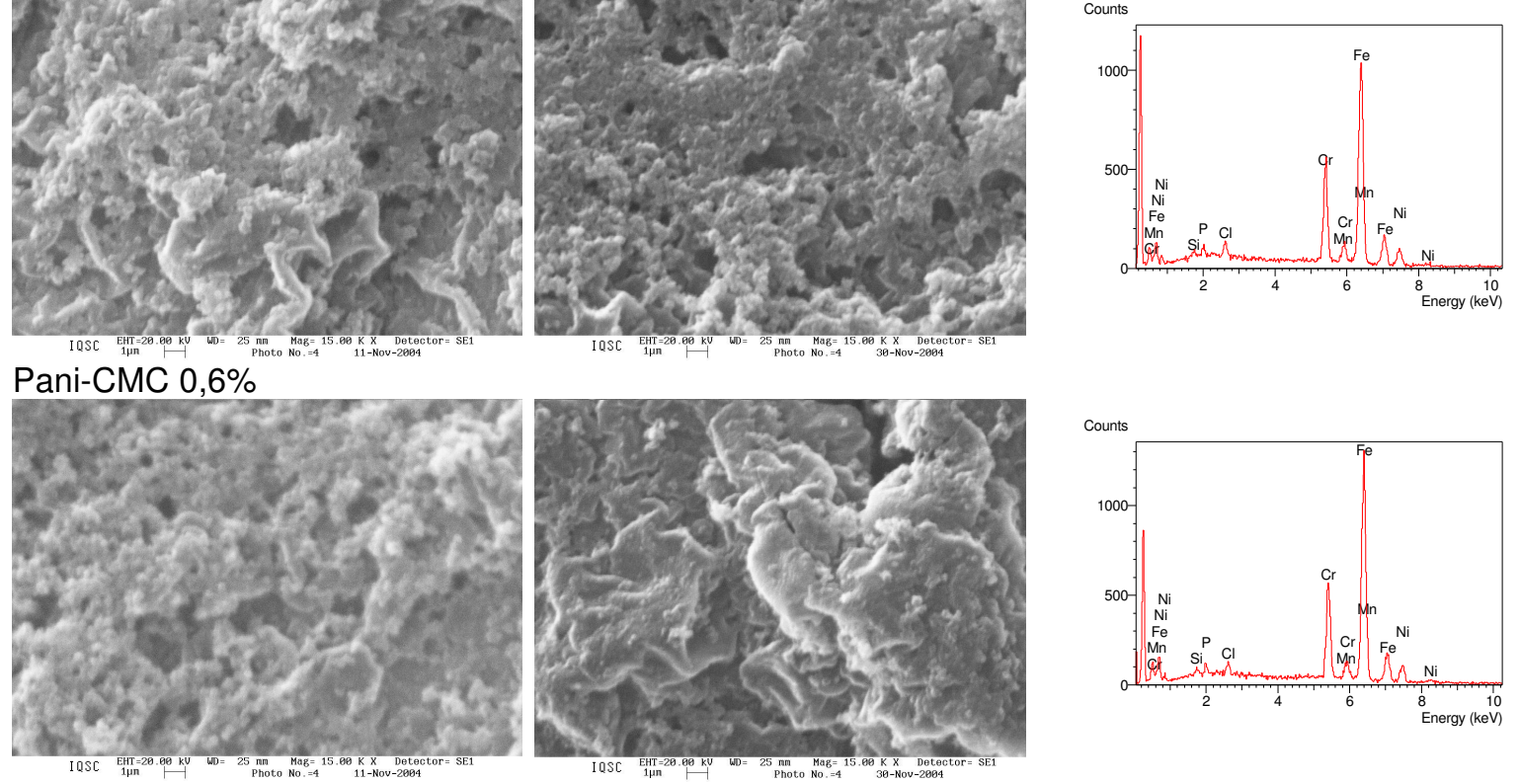

PAni-CMC $1 \%$
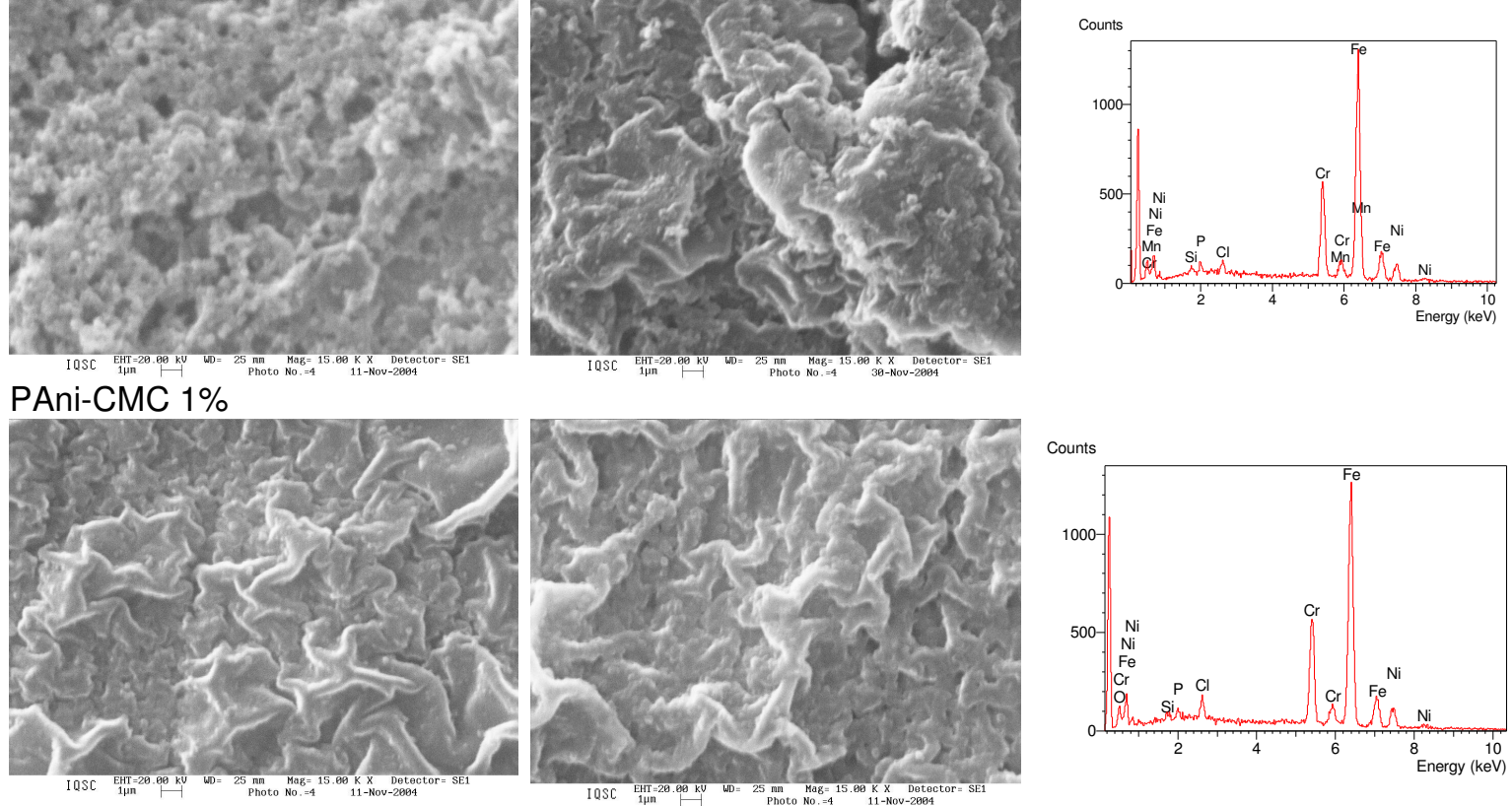

Figura 65. Micrografias do AISI-304 recoberto com diferentes filmes dos polímeros na forma dopada, antes e após corrosão e espectros de EDX após os ensaios corrosivos. 
Durante os ensaios de corrosão, as espécies que se encontram na solução de $\mathrm{NaCl}$ difundem para a superfície do eletrodo (nas distintas interfaces: eletrólito/polímero e polímero/eletrodo). Assim, primeiramente, a camada de polímero atua como uma barreira à penetração dessas espécies em direção ao eletrodo. Simultaneamente, por ser um polímero condutor o mecanismo redox da PAni, como PAni-CMC atua conjuntamente, mediando a reação de redução do oxigênio, como descrito na literatura [83]. Sendo assim, a composição da PAni-CMC pode ser alterada durante os ensaios de corrosão, a qual foi possível de ser monitorada mediante os espectros de EDX.

Os espectros de EDX e a quantificação dos teores dos elementos local evidenciaram que após os ensaios de corrosão ocorre uma variação na composição dos filmes. Uma significativa diminuição no teor de fósforo $(\mathrm{P})$ ocorre, isto com relação aos teores de $\mathrm{P}$ na PAni-CMC antes dos ensaios de corrosão, indicando a difusão desse elemento para a solução. Esta diminuição, no entanto, apresenta uma redução maior para PAni (cerca de 97\%) e para PAni-CMC com o aumento da concentração de CMC de $(0,1$ a $1 \%)$ de $97 \%$ para $51 \%$.

Simultaneamente, o conteúdo de íon cloreto $(\mathrm{Cl})$, que se adsorve no filme e também estaria se difundindo pelos poros do polímero, aumenta, no entanto, com o aumento na concentração de CMC na PAni-CMC (Figura 66 (b)). O conteúdo de cloreto diminui. A variação nos teores desses dois elementos (fósforo $(\mathrm{P})$ e cloro $(\mathrm{Cl})$ ) se correlacionam com os resultados sobre a morfologia dos compósitos e também com os ensaios corrosivos. Visto que, maior empacotamento estrutural (para altas concentrações de CMC > 0,6\%) foi determinado menor teor de cloro, ou seja cloreto.

Com base em dois mecanismos de inibição da corrosão, pode ser suposto que para PAni-CMC o mecanismo redox seria predominante a baixas concentrações de $\mathrm{CMC}$, enquanto para altas concentrações de $\mathrm{CMC}(>0,6 \%)$ o mecanismo por barreira predomina. 


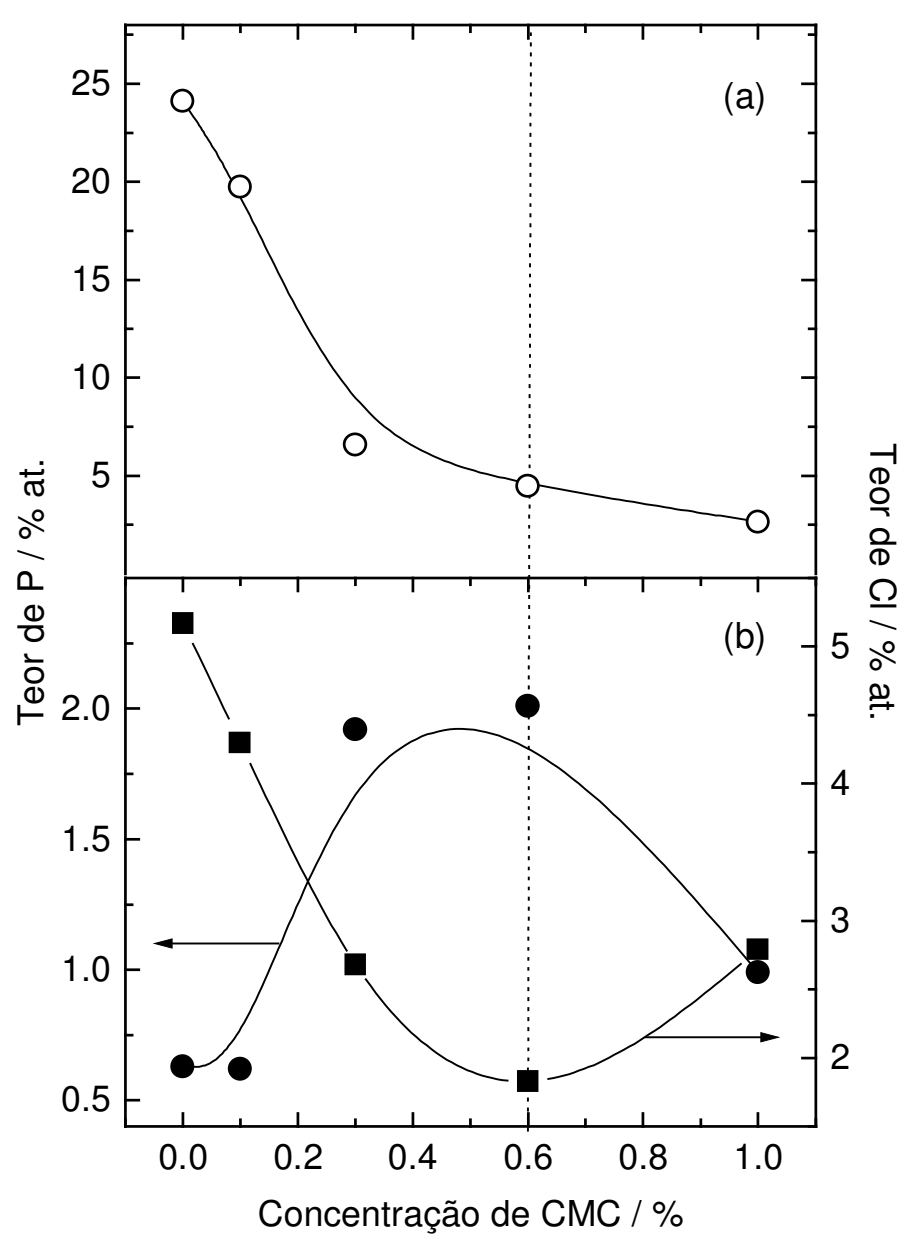

Figura 66. Variação dos teores de fósforo $(\mathrm{P})$ e cloro $(\mathrm{Cl})$ nos filmes eletropolimerizados sobre AISI-304 em presença de diferentes concentrações de CMC. (a) antes e (b) após os ensaios de corrosão.

A determinação de teores residuais de fósforo $(\mathrm{P})$, proveniente do dopante, evidencia que espécies contendo fósforo participam da estrutura polimérica de PAni-CMC, especulativamente participando de ligações inter e intra cadeia, confirmando as hipóteses relatadas nas seções anteriores dos diferentes capítulos.

\subsection{Ensaios de corrosão de PAni-DBSA}

Os estudos de corrosão dos filmes PAni-DBSA como inibidor contra a corrosão do AISI304 estão descritos a seguir, os resultados foram comparados entre si e correlacionados com a literatura, quando possível. 


\subsubsection{Estimativa da espessura dos filmes}

$\mathrm{Na}$ Tabela 7 são mostrados os valores de carga anódica $\left(Q_{A}\right)$ e os valores de espessura calculados para os filmes de PAni-DBSA eletrodepositados sobre AISI-304, em diferentes números de ciclo de potencial. O método utilizado para estimar a espessura não considera o fator de porosidade do filme e nem o volume do contra-íon. Portanto, os valores calculados fornecem apenas uma estimativa da espessura para que possibilitem uma comparação entre estes filmes.

A influência das diferentes espessuras dos filmes de PAni-DBSA na proteção contra a corrosão do AISI-304 foi observada mediante as curvas potenciodinâmicas em $\mathrm{NaCl} 3 \%$. As curvas potenciodinâmicas do AISI-304 sem recobrimento e recoberto com PAni-DBSA com diferente espessura são mostradas na Figura 67. O potencial de corrosão das amostras recobertas com PAni-DBSA, independentemente da espessura, desloca $\circ \mathrm{E}_{\text {cor }}$ para valores mais positivos (entre 89 a $144 \mathrm{mV}$ ), quando comparado ao AISI-304 sem recobrimento. A densidade de corrente de corrosão, devido a presença do filme, aumenta e $E_{\text {pite }}$ é deslocado, sofrendo um aumento de aproximadamente $156 \mathrm{mV}$, comparado ao aço sem recobrimento. PAni-DBSA de espessura $0,25 \mu \mathrm{m}$ (51 ciclos de potenciais) mostra a melhor eficiência em proteger o AISI-304 contra a corrosão.

Tabela 7. Carga anódica, $Q_{a}$ e espessura calculada dos filmes de PAni-DBSA sobre AISI-304.

\begin{tabular}{c|c|c|c}
\hline Amostra & Número de ciclos & Carga $\mathrm{Q}_{\mathrm{a}} / \mathrm{mC} \mathrm{cm}^{-2}$ & Espessura estimada $(\mathrm{d}) / \mu \mathrm{m}$ \\
\hline \multirow{4}{*}{ PAni-DBSA } & 21 & 1,09 & 0,02 \\
\cline { 2 - 4 } & 31 & 3,73 & 0,07 \\
\cline { 2 - 4 } & 51 & 12,3 & 0,25 \\
\cline { 2 - 4 } & 61 & 12,9 & 0,26 \\
\cline { 2 - 4 } & 91 & 24,0 & 0,48 \\
\hline
\end{tabular}




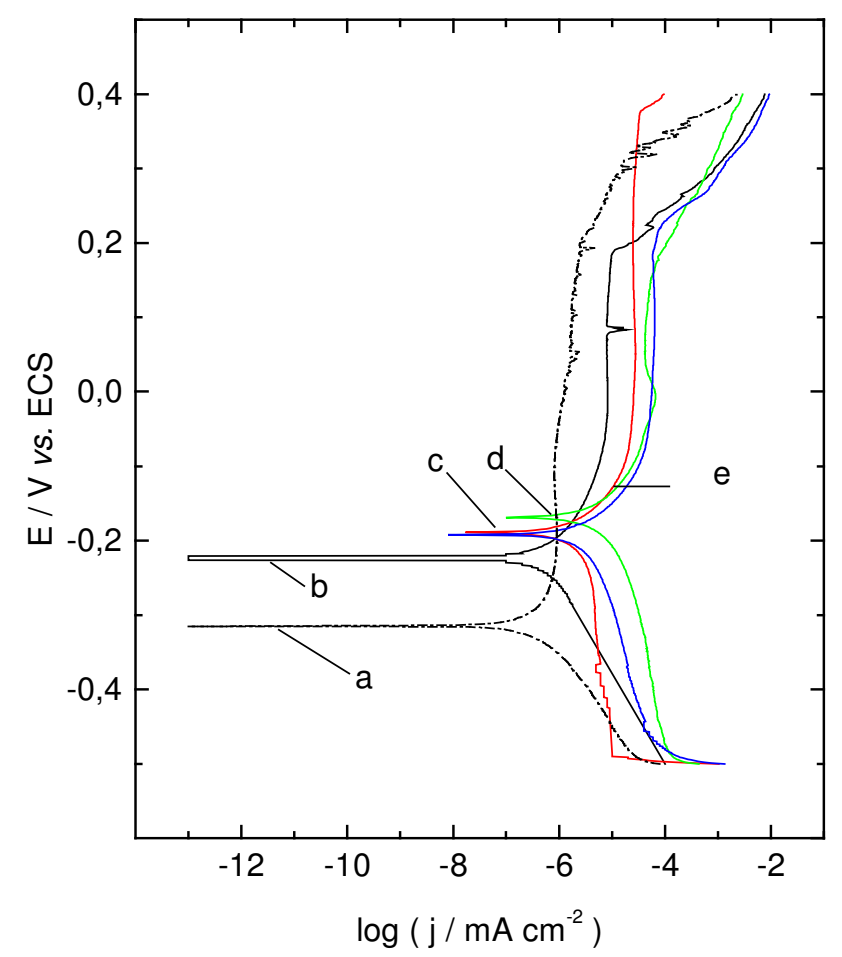

Figura 67. Curvas potenciodinâmicas em solução de $\mathrm{NaCl} 3 \%$ do AISI-304 (a) sem recobrimento e recoberto com filmes de PAni/BSA de diferentes espessuras: (b) 0,07 (c) 0,25 (d) 0,26 e (e) $0,48 \mu \mathrm{m}$.

Um material é considerado mais nobre do que um outro, quando a comparação do seu potencial de corrosão resulta em um valor mais positivo. A partir dos potenciais de corrosão dos AISI-304 recoberto com filmes de PAni-DBSA em relação ao potencial de corrosão do AISI304 sem recobrimento, obtidos das curvas na Figura 67, a variação do potencial de corrosão do aço recoberto com os filmes de PAni-DBSA em função da espessura do filme pode ser observado (Figura 68).

Um aumento linear do $E_{\text {cor }}$ pode ser observado em meio de $\mathrm{NaCl}$ e esta dependência apresenta um máximo valor. A tentativa de explicar o comportamento do potencial de corrosão em relação a espessura dos filmes de PAni-DBSA pode conduzir á uma especulação, pois diferentes variáveis, tais como o efeito barreira, propriedade de permeabilidade seletiva e a difusão dos íons, no sistema podem ser, conjuntamente, responsáveis pela diferença observada no comportamento do potencial de corrosão. 


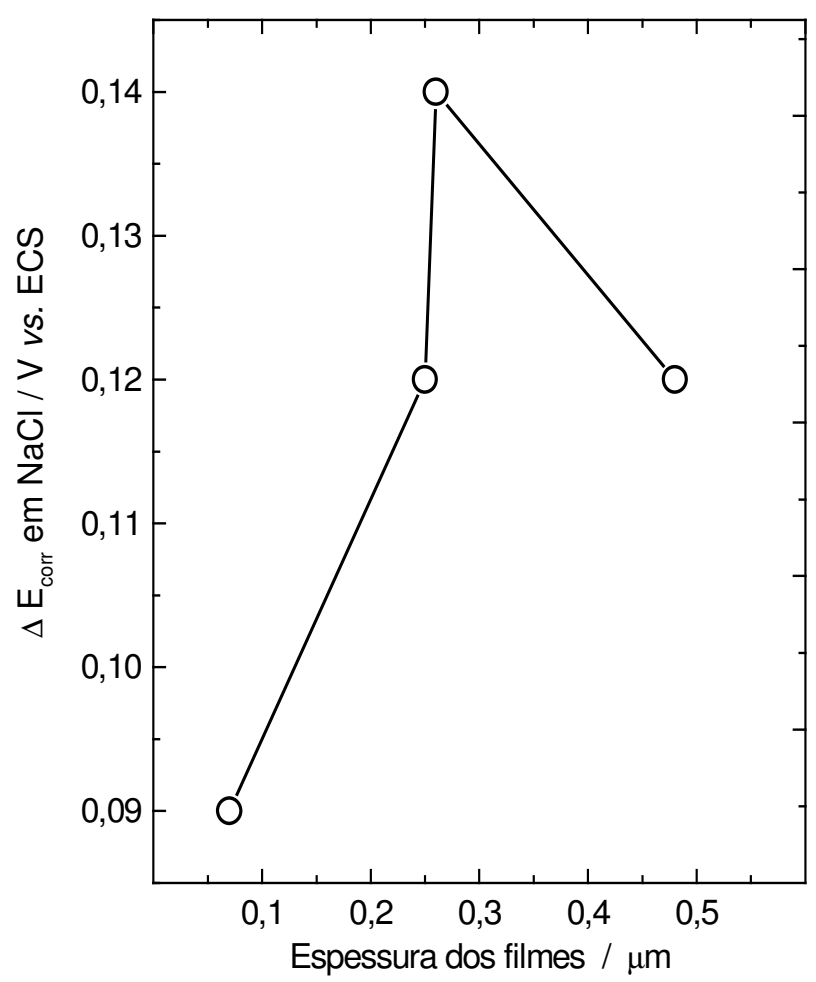

Figura 68. Dependência do potencial de corrosão do AIS-304 recoberto com PAni-DBSA em função da espessura dos filmes, polarização potenciodinâmica em $\mathrm{NaCl} 3 \%$.

Na Tabela 8 são mostrados os valores dos parâmetros eletroquímicos obtidos das curvas potenciodinâmicas (Figura 67). Os filmes de PAni-DBSA demonstram ser eficientes inibidores contra a corrosão do AISI-304, quando na presença de íons cloreto.

Tabela 8. Principais parâmetros eletroquímicos obtidos das curvas potenciodinâmicas do AISI304 sem recobrimento e recoberto com filmes PAni-DBSA de diferentes espessura em $\mathrm{NaCl}$.

\begin{tabular}{c|c|c|c}
\hline PAni-DBSA & \multicolumn{3}{|c}{$\mathrm{NaCl} 3 \%(\mathrm{pH}=6,0)$} \\
\hline Espessura $(\mu \mathrm{m})$ & $\mathrm{E}_{\text {cor }}(\mathrm{V})$ & $\mathrm{E}_{\text {pite }}(\mathrm{V})$ & $\mathrm{I}_{\text {cor }}\left(\mu \mathrm{Acm}^{-2}\right)$ \\
\hline 0,07 & $-0,22$ & 0,18 & 0,60 \\
\hline 0,25 & $-0,19$ & 0,37 & 2,37 \\
\hline 0,26 & $-0,17$ & 0,19 & 19,95 \\
\hline 0,48 & $-0,19$ & 0,21 & 5,16 \\
\hline AISI-304 & $-0,31$ & $+0,09$ & 0,83 \\
\hline
\end{tabular}

Valores médios referentes a duas amostras 


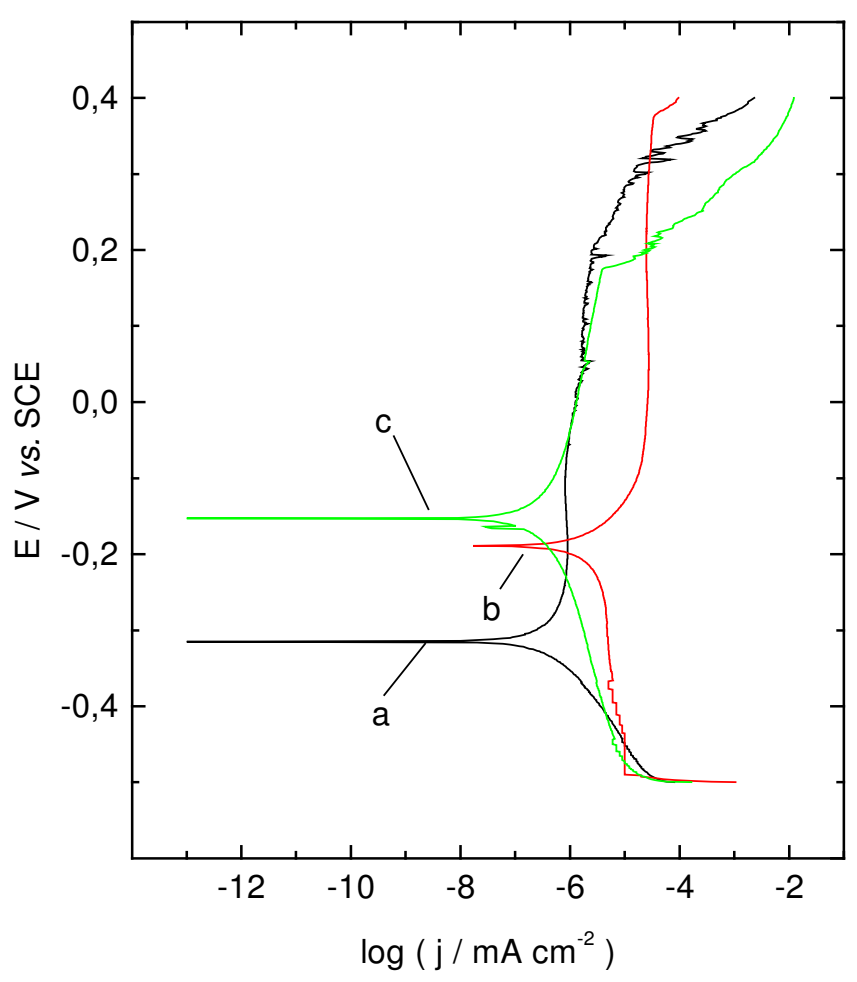

Figura 69. Curvas potenciodinâmicas em solução de $\mathrm{NaCl} 3 \%$ do AISI-304 (a) sem recobrimento e recoberto com filmes de PAni/DBSA (espessura 0,25 $\mu \mathrm{m}$ ) na forma (b) dopada e (c) desdopada.

O filme de PAni-DBSA com espessura 0,25 $\mu \mathrm{m}$ desdopado (Figura 69), em solução de $\mathrm{NaCl} 3 \%$, demonstra valor de potencial de corrosão mais positivo e menor densidade de corrente de corrosão $\left(I_{\text {corr }}=0,70 \mu \mathrm{A}\right) \mathrm{cm}^{-2}$ do que dopado. Entretanto, o valor do potencial de pite é menor $\left(E_{p}=0,17 \mathrm{~V}\right)$. Estes resultados estão em concordância com os descritos em literatura [89,149], confirmando, de um modo geral, que PAni-DBSA desdopada é mais eficiente na proteção contra a corrosão em meio de $\mathrm{NaCl}$.

Quando comparado os parâmetros eletroquímicos (Tabela 8), com os encontrados para os filmes de DBSA na literatura, nota-se que os filmes de PAni-DBSA eletropolimerizados, apresentam melhor desempenho na proteção contra a corrosão metálica do que PAni-DBSA preparada quimicamente, ou blendas de PAni-DBSA descritas em literatura [95-97].

A natureza do substrato e o método de polimerização, neste estudo, são o que promovem divergências nos resultados com o da literatura. Contudo, tanto neste estudo 
quando em literatura são evidenciados a eficiência de PAni-DBSA na proteção contra a corrosão metálica.

\subsubsection{Potencial de circuito aberto}

Quando o eletrodo de AISI-304 sem recobrimento é mantido em solução de $\mathrm{NaCl}$, o potencial de circuito aberto (PCA) é inicialmente negativo $(-22,0 \mathrm{mV})$ (Figura $70(\mathrm{a})$ ), sendo que um valor constante de $-130 \mathrm{mV}$ é atingido, após duas horas (Fig. 70 (a)). Como esperado, ocorre um rápido processo de corrosão da superfície metálica nesse ambiente agressivo.

Quando AISI-304 recoberto com filme PAni-DBSA (espessura de 0,25 $\mu \mathrm{m}$ ) é imerso $\mathrm{NaCl} 3 \%$, o PCA é inicialmente positivo (99 mV), oscilando negativamente e, então, reestabelece o valor e mantém-se em um valor bem negativo ao redor de $-179 \mathrm{mV}$.

Quando mantido imerso por $720 \mathrm{~h}$ em solução de $\mathrm{NaCl}$ não foi observada delaminação do filme de PAni-DBSA sobre AISI-304. No geral, o PCA para AISI-304 recoberto com filme PAni-DBSA inicia em valores muito positivos (relativos ao AISI-304 sem recobrimento). Além disso, nenhuma evolução de gás foi observada. Esses resultados claramente demonstram que a superfície do aço é passivada em meio neutro com PAni-DBSA. A magnitude da queda no PCA e a escala de tempo de recuperação do processo depende sobretudo do meio de imersão dos filmes de PAni. 


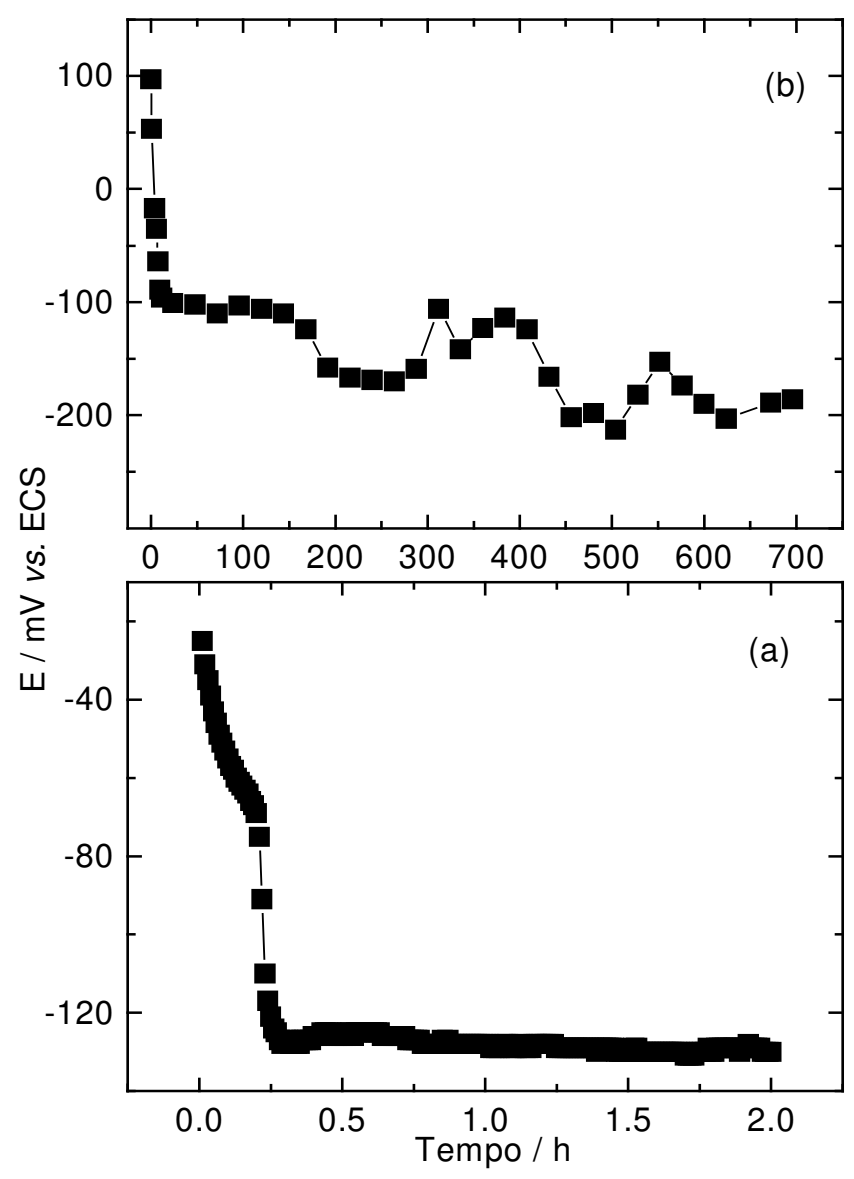

Figura 70. Potencial de circuito aberto do AISI-304 (a) sem recobrimento; e (b) recoberto com PAni-DBSA de espessura $0,25 \mu \mathrm{m}$ em solução de $\mathrm{NaCl} 3 \%$.

Na Figura 71 são mostradas micrografias de AISI-304 recoberto com filme de PAniDBSA de espessura $0,25 \mu \mathrm{m}$, antes e após a obtenção das curvas de polarização, e também, após imersão em solução de $\mathrm{NaCl} 3 \%$.

A morfologia de PAni-DBSA é granular, porosa e uniforme, tanto na forma dopada quanto desdopada (Figura 71 (a) e (c), respectivamente), antes ou após os ensaios de corrosão (Figura 71 (a) e (b)). A micrografia de AISI-304 polido (Fig. 71 (e)) é apresentada como referência, sendo observado riscos sobre a superfície devido ao polimento mecânico. 

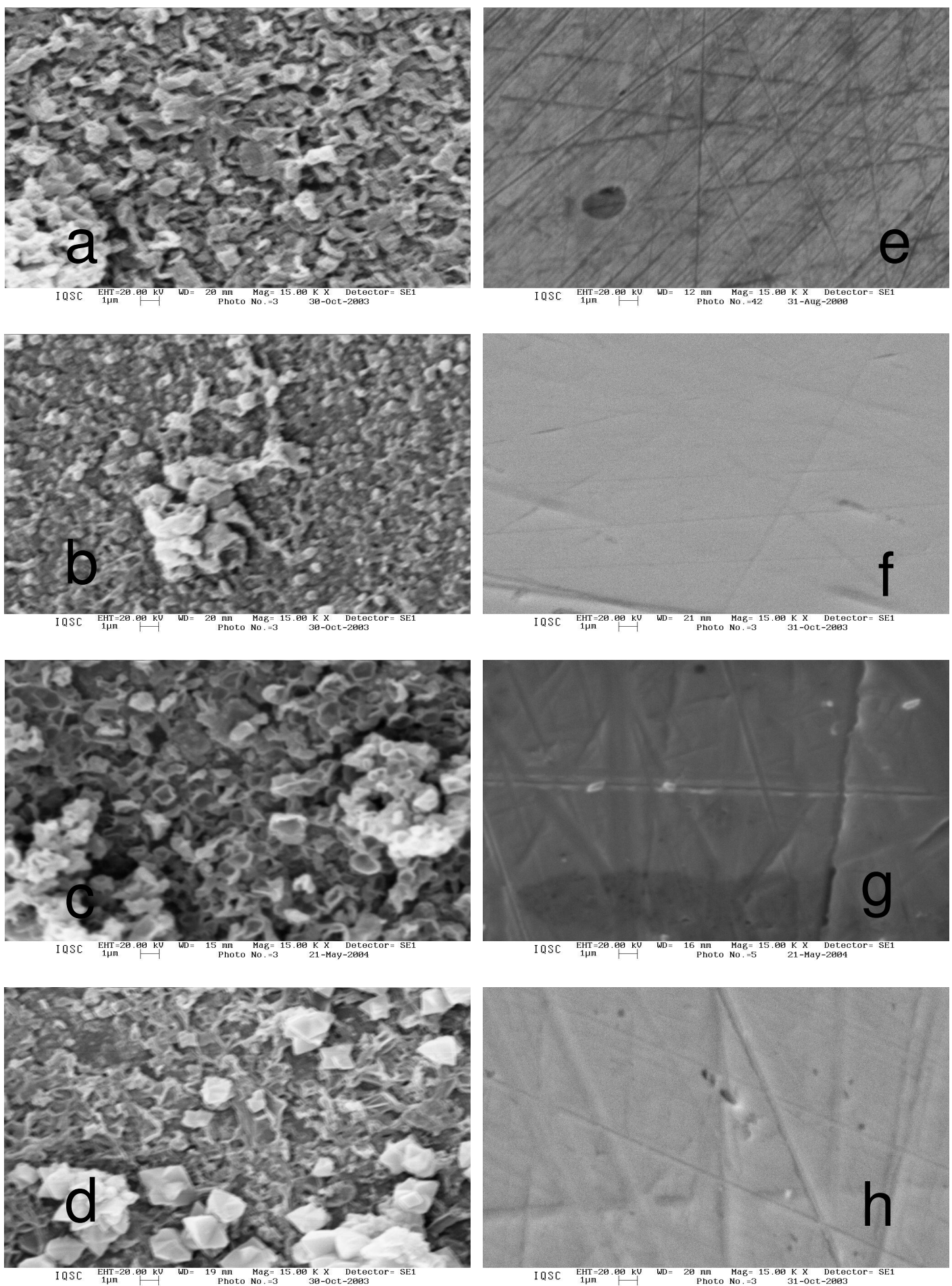

Figura 71. Micrografias do AISI-304 recoberto com PAni-DBSA dopada (a) antes da corrosão e (b) após a corrosão; (c) PAni-DBSA desdopada após a corrosão; (d) PAni-DBSA dopada imersa por 30 dias em solução de $\mathrm{NaCl}$ 3\%. Eletrodo de AISI-304 (e) após polimento mecânico; (f) sem filme PAni-DBSA dopado após corrosão; (g) sem filme de PAni-DBSA desdopada após corrosão; (h) sem filme de PAni-DBSA dopado quando imerso 30 dias em solução de $\mathrm{NaCl} 3 \%$. 
Após os ensaios de corrosão, os filmes foram removidos e a superfície do AISI-304, antes recoberta com PAni-DBSA, não apresentou pites (Fig. 71(f) a (g)), sendo que, mesmo quando a amostra foi imersa por 30 dias em solução de $\mathrm{NaCl}$, poucos pites ocorreram (Fig. 71 (h)). 


\section{Capítulo VII}

\section{Conclusões e Perspectivas de Trabalhos Futuros}

\subsection{Conclusões}

Polianilina pode ser eletropolimerizada a partir de solução aquosa de $\mathrm{H}_{3} \mathrm{PO}_{4}$, na presença de diferentes concentrações de $\mathrm{CMC}$, tanto sobre platina quanto sobre aço inoxidável. A concentração de anilina e de CMC influencia fortemente a velocidade de crescimento dos compósitos de PAni-CMC, sendo dependente da natureza da superfície metálica (inerte ou oxidável). Em ambos os casos, o aumento na concentração de monômero em solução com CMC, promove um aumento na velocidade de eletropolimerização, entretanto, altas concentrações de monômero (superiores a 0,2 $\mathrm{mol} \mathrm{L}^{-1}$ ) podem ser desfavoráveis quando o substrato é o aço inoxidável, pois a adsorção de CMC durante a polimerização é reduzida. Além do mais, a velocidade de polimerização também pode ser reduzida devido a uma competição dos sítios ativos na cadeia polimérica. Assim, o uso de concentrações de anilina superiores a $0,2 \mathrm{~mol} \mathrm{~L}^{-1}$ é dependente do substrato.

Altas concentrações de CMC (>0,1\%) não aumentam a velocidade de polimerização, resultando em um retardamento do processo de polimerização. Isto é indicativo de que moléculas de CMC estão sendo adsorvidas em sítios ativos na cadeia de PAni e sendo incluídas dentro da estrutura polimérica.

A eletropolimerização de PAni-CMC sobre platina é de primeira ordem em relação a concentração de anilina, enquanto que, sobre AISI-304 o mesmo não ocorre devido a natureza do substrato e a complexidade do mecanismo de polimerização sobre superfícies oxidáveis.

A presença de um polímero isolante na mistura polimérica influencia o comportamento eletroativo do polímero condutor. O comportamento eletroquímico de PAni e PAni-CMC 
apresentam diferenças, que estão centradas nos valores de densidade de corrente e de potencial de pico, sendo menores para misturas entre os polímeros condutor e não-condutor.

PAni-CMC eletropolimerizada, tanto sobre AISI-304 quanto sobre platina apresenta o mesmo comportamento eletrônico, mantendo as características do espectro da PAni, independente da concentração de CMC. O espectro dos compósitos de PAni-CMC desdopados é similar ao da base esmeraldina, enquanto, dopados ao do sal esmeraldina.

No geral, a condutividade de PAni-CMC é dependente da concentração de CMC. A presença de baixas concentrações de CMC (de 0,1 a 0,3\%) aumenta a condutividade da PAni, favorecendo a inclusão de CMC em sítios da cadeia polimérica que promovem pouca interação, intra ou inter cadeia. Para altas concentrações de CMC (>0,3\%) as interações entre os polímeros (PAni e CMC) são mais intensas e maior interação intra e inter cadeias é promovida. Como consequência das intensas interações a altas concentrações de CMC $(>0,3 \%)$, a estrutura da PAni-CMC, que é globular, torna-se menos porosa e mais uniforme.

$\mathrm{O}$ conteúdo de fósforo $(\mathrm{P})$, proveniente do ácido dopante $\left(\mathrm{H}_{3} \mathrm{PO}_{4}\right)$, analisado e quantificado por EDX mostrou diminuir de 18 a 89\% com o aumento na concentração de CMC, indicando a inclusão de CMC na cadeia de PAni onde se localiza o dopante. Para que o compósito PAni-CMC apresente boas propriedades eletrônica e condutora, $73 \%$ é o limite de redução no conteúdo de $P$, ou seja para a concentração (CMC 0,3\%).

A interação da PAni com a CMC por ligação de hidrogênio é favorecida pela presença dos grupos carboxilícos da CMC e os grupamentos imina da PAni. A formação de ligações de hidrogênio se promove (i) entre os grupos amina da PAni e carbonila presente na CMC (de ácidos carboxílicos, etc.) e, (ii) os nitrogênios imina na PAni e os grupos hidroxila presente na CMC.

Sobre a polimerização química de anilina em presença de CMC, em meio aquoso, devese ter em mente que um aditivo introduzido no meio reacional pode ter um efeito pronunciado sobre a cinética de polimerização. Em presença de $\mathrm{CMC}$, a polimerização por dispersão procede em concentrações maiores que 0,6 \%, comparado ao modo de precipitação, a qual ocorre em concentrações entre 0,1 a $0,6 \%$. A presença de CMC afeta a velocidade de polimerização da PAni devido (i) as partículas de PAni serem cobertas com uma sobrecamada 
isolante de CMC, e (ii) ao eficiente contato das partículas com a CMC (conduzindo o curso da polimerização para o modo de precipitação).

A caracterização das blendas de PAni-CMC por diferentes técnicas permitiu estabelecer uma correlação entre os resultados espectroscópicos (UV-VIS e IV) e a condutividade, bem como as concentrações de CMC. No geral, as blendas de PAni-CMC demonstram forte características espectroscópicas da PAni. A interação de PAni com CMC se promove mediante ligações de hidrogênio, ou na forma de incorporação do CMC na estrutura. A morfologia das blendas de PAni-CMC é globular, independente da concentração de CMC utilizada, e a dispersão de PAni-CMC apresenta partículas globulares.

As blendas de PAni-CMC mostram maior estabilidade térmica do que a PAni e a CMC isoladamente. Além disto,o aumento na concentração de CMC promovem as blendas de PAniCMC um compotamento térmico que tende a se aproximar ao da CMC.

A eletropolimerização de PAni-DBSA ocorre tanto sobre Pt quanto sobre o aço AISI-304 e é fortemente influenciada pelas concentrações de anilina e DBSA. A velocidade de polimerização é influenciada pelas concentrações de anilina e DBSA:

(i) altas concentrações de anilina $\left(>0,015 \mathrm{~mol} \mathrm{~L}^{-1}\right)$ favorecem a formação do complexo PAniDBSA, impossibilitando os monômeros de reagirem com os radicais cátions formados devido a um bloqueio dos sítios ativos pelos complexos de DBSA-PAni e moléculas de DBSA livres; (ii) para baixas concentrações de anilina $\left(<0,015 \mathrm{~mol} \mathrm{~L}^{-1}\right)$ as moléculas de DBSA contribuem para o acoplamento dos monômeros aos radicais cátions formados; (iii) concentrações de DBSA de 0,04 a $0,05 \mathrm{~mol} \mathrm{~L}^{-1}$ aumentam a velocidade de polimerização devido a formação de um complexo entre o DBSA e o cátion anilinium. O DBSA tende a se acumular na interface eletrodo/eletrólito atraindo para si os monômeros, aumentando assim, a concentração local de monômero. (iv) Acima da concentração de $0,05 \mathrm{~mol} \mathrm{~L}^{-1}$ de DBSA, os cátions anilinium estariam interagindo mais fortemente com as micelas, diminuindo o suplemento de monômero e limitando sua difusão para o superfície do eletrodo.

A velocidade de eletropolimerização de PAni-DBSA sobre o aço AISI-304 é mais rápida do que sobre Pt. Isto devido á existência da camada de óxido formada durante a polimerização. Os filmes de PAni-DBSA eletropolimerizados sobre Pt e AISI-304 são eletroativos. Contudo, PAni-DBSA sobre AISI-304 tem uma maior eletroatividade, propriedade que indica ser 
promovida pela estrutura polimérica formada quando presente a camada de óxido (eletrodo oxidável).

Tanto sobre Pt quanto sobre o aço AISI-304, PAni-DBSA, demonstra um comportamento eletrônico similar e característico ao da PAni (esmeraldina base e sal esmeraldina). Estruturalmente, os espectros de infravermelho de PAni-DBSA sobre Pt e sobre AISI-304 demonstram pequenas diferenças indicando haver uma maior quantidade de DBSA incorporado na estrutura do polímero sobre Pt.

A estrutura morfológica de PAni-DBSA é depende do substrato, com a PAni-DBSA sobre Pt demonstra uma estrutura granular, compacta, homogênea e menos porosa, enquanto que sobre AISI-304 ocorre a formação de uma estrutura porosa e homogênea, com aspecto de couve-flor. Neste último caso, o aumento de espessura do filme de PAni-DBSA sobre a camada de óxido pré-existente promove o aspecto couve-flor.

PAni-DBSA eletropolimerizada sobre o aço AISI-304 apresenta condutividade similar em ordem de grandeza a descrita em literatura para PAni-DBSA química. No entanto, a presença de uma camada de óxido no polímero pode conduzir a uma redução no transporte de elétrons na estrutura, reduzindo a condutividade de PAni-DBSA eletropolimerizada, o que pode ser corroborado pelo valor de condutividade que foi inferior aos descritos em literatura para PAniDBSA química.

Filmes de PAni-CMC e PAni-DBSA protegem o aço AISI-304 contra a corrosão em meio de $\mathrm{NaCl} 3 \%$. Ambos os materiais demonstram aplicabilidade como materiais alternativos na proteção contra a corrosão do aço inoxidável. A proteção anódica promovida pelos filmes polimérico promoveu o deslocamento do potencial de corrosão e do potencial de pite para valores mais positivos e, dependendo do filme polimérico, aumento no valor da densidade de corrosão, que pode ter sido ocasionado pelas reações de oxi-redução no sistema e pelo aumento de área do eletrodo, revestido com o filme.

A eficiência dos filmes de PAni-DBSA em proteger o aço AISI-304 é fortemente influenciada pela espessura do filme, sendo o filme de espessura $0,25 \mu \mathrm{m}$ o de melhor eficiência em proteger o AISI-304 em solução de $\mathrm{NaCl}$.

Os filmes de PAni-DBSA e PAni-CMC não desprenderam da superfície durante a imersão em solução de $\mathrm{NaCl}$ e, para PAni-DBSA medidas de potencial de circuito aberto por 30 
dias em solução de $\mathrm{NaCl}$, levaram a observar modificação da superfície metálica promovida pela corrosão por pite.

A composição dos filmes de PAni-CMC é alterada após os ensaios de corrosão, sendo que o conteúdo de fósforo diminui e ocorre um aumento no conteúdo de cloreto. Comparativamente a PAni, PAni-CMC demonstra uma menor variação em sua composição após os ensaios de corrosão.

Tanto, os filmes de PAni-CMC quanto os de PAni-DBSA podem ser aplicados anteriormente a uma sobrecamada de outro revestimento. Esses filmes demonstram potencial para substituir revestimentos atualmente utilizados e podem ser empregados como "primers".

\subsection{Perspectivas de Trabalhos Futuros}

Em vista dos resultados e conclusões deste trabalho, visando esclarecimentos adicionais sobre o tipo de interação entre a PAni e a carboximetilcelulose, será de extremo interesse um estudo sobre as propriedades químicas e físicas de PAni e outro derivado de celulose, tais como, hidroxietilcelulose, quitosana, etc. inclusive com a utilização de outras técnicas.

Além disto, a possibilidade de polimerização de PAni em presença de DBSA por via eletroquímica, permite sugerir a realização de estudos sistemáticos utilizando outros surfactantes, com a consequente investigação das propriedades químicas e físicas desses materiais.

A partir da potenciabilidade de aplicação da PAni podem também ser sugeridos estudos sistemáticos de aplicação dos filmes de PAni-CMC e PAni-DBSA em sensores que, em particular para PAni-DBSA, devido a maior eletroatividade e uma estrutura porosa, apresenta grande potencial de aplicação. Ainda visando a aplicação, são necessários realizar estudos sistemáticos do uso de PAni-CMC e PAni-DBSA, eletropolimerizadas sobre aços, aplicando sobrecamadas de resina epoxi, almejando melhoria nos parâmetros eletroquímicos contra a corrosão metálica, além da investigação em outros meios agressivos, como por exemplo, ácido sulfúrico. 


\section{Referências Bibliográficas}

[1] KANATZIDIS, M. G. Conductive polymers. Chem. Eng. News, v. 3, p. 36-54, 1990.

[2] NALWA, H. S. Handbook of organic condutive molecules and polymers. New York: John Wiley, 1997. 3 v.

[3] HANS-GEORG, E. An introduction to polymer science. Weinheim: VHC, 1997. p. 470

[4] MATTHEWS, F. L.; RAWLINGS, R. D. Composite Materials: engineering and science. London: Chapman \& Hall, 1994. p. 470.

[5] DAUTZENBERG, H. Polyelectrolytes: formation, characterization and application. Munich: Hanser/Gardner Publications, 1994. p. 343.

[6] GILBERT, R. D. Cellulosic Polymers, blends and composites. Munich: Hanser/Gardner Publications, 1994. p. 244.

[7] SKOTHEIM, T. A. Handbook of Conducting Polymers. New York: Marcel Dekker, 1986. $2 \mathrm{v}$.

[8] DE PAOLI, M-A; GAZOTTI, W. A. Electrochemistry, polymers and opto-electronic devices: a combination with a future. J. Braz. Chem. Soc., v. 13, n. 4, p. 410-424, 2002.

[9] EPSTEIN, A. J. Electrically conducting polymers: science and technology. MRS Bull., v. 22, n. 6, p. 16-23, 1997.

[10] MACDIARMID, A. G.; Zheng, W. Electrochemistry of conjugated polymers and electrochemical applications. MRS Bull., v. 22, n. 10, p. 24-30, 1997.

[11] IROH, J. O.; RAJAGOPALAN, R. R. Electrochemical polymerization of aniline on carbon fibers in aqueous toluene sulfonate solution. J. Appl. Polym. Sci., v. 76, p. 1503-1509, 2000.

[12] TRIVED, D. C. Polyanilines. In: NALWA, H. S. Handbook of organic conductive molecules and polymers. New York: John Wiley, 1997. 505 p. 
[13] MATTOSO, L. H. C. Polianilinas: síntese, estrutura e propriedades. Quim. Nova, v. 19, n. 4, p. 388-399, 1996.

[14] MANOHAR, S.K.; MACDIARMID, A. G. Polyaniline: Pernigraniline, an isolable intermediate in the conventional chemical synthesis of emeraldine. Synth. Met., v. 41-43, p. 711-714, 1991.

[15] LI, Y.; YAN, B.; YANG, Y.; CAO, Y.; QUIAN, B. Spectroelectrochemical studies of polyaniline. Synth. Met., v. 25, n. 1, p. 79-88, 1988.

[16] CONKLIN, J. A.; HUANG, S. C.; HUANG, S. M.; WEN, T.; KANAR, R. B. Thermal properties of polyaniline and poly(aniline-co-ethylaniline). Macromolecules, v. 28, n. 19, p. 6522-6527, 1995.

[17] CAO, Y.; SMITH, P.; HEEGER. A. J. Counter-ion induced processability of conducting polyaniline and conducting polyblends of polyaniline in bulk polymers. Synth. Met., v. 48, p. 9197, 1992.

[18] HANS-GEORG, E. An introduction to polymer science. Weinheim: VHC, 1997. p. 470.

[19] MANO, E. B.; MENDES, L. Introdução a polímeros, 2. ed. São Paulo: Edgard Blucher, 1999. p. $7-23$

[20] JIA, W.; TCHOUDAKOV, R.; SEGAL, E.; JOSEPH, R.; NARKIS, M.; SIEGMANN, A. Electrically conductive composites based on epoxy resin with polyaniline-DBSA fillers. Synth. Met., v.132, n. 3, p. 269-278, 2003.

[21] JIA, W.; SEGAL, E.; NARKIS, M.; SIEGMANN, A. Polymerization of anilium-DBSA in the presence of clay particles. Kinetics and formation of core shell structures. Polym. Adv.

Technol., v. 13, n. 1, p. 16-24, 2002.

[22] BISCARO, R. S.; BOTELHO, E. C., TAKAHASHI, M. F. K, FAEZ, R., REZENDE, M. C. Estudo reológico de tintas de poliuretano contendo PAni-DBSA aplicada como materiais absorvedores de microondas. Polímeros: ciência e tecnologia, v. 12, n. 4, p. 318-32, 2002.

[23] CARINHANA JUNIOR, D.; FAEZ, R.; NOGUEIRA, A. F.; DE PAOLI, M.-A. Photoelectrochemical properties of PAni-DBSA/EPDM blends. Synth. Met., v. 121, p. 15691570, 2001.

[24] CHOI, B. Y.; CHUNG, I. J.; CHUN, H. J.; KO, M. J. Electrochemical characteristics of dodecylbenzene sulfonic acid-doped polyaniline in aqueous solutions. Synth. Met., v. 99, p. 253-256, 1999.

[25] HAN, M. G.; CHO, K. S.; OH, S. G.; IM, S. S. Preparation and characterization of polyaniline nanoparticles synthesized from DBSA micellar solution. Synth. Met., v. 126, p. 5360, 2002. 
[26] KIM, B. J.; OH, S. G.; HAN, M. G.; IM, S. S. Preparation of polyaniline nanoparticles in micellar solution as polymerization medium. Langmuir, v. 16, p. 5841-5845, 2000.

[27] ANTONIETTI, M.; BASTEN, R.; LOHMANN, S. Polymerization in microemulsions - A new approach to ultrafine highly functionalized polymer dispersions. Macromol. Chem. Phys., v.196, n. 2, p. 441-466, 1995.

[28] KURAMOTO, N.; TOMITA, A. Aqueous polyaniline suspensions: chemical oxidative polymerization of dodecylbenzene-sulfonic acid aniline salt. Polymer., v. 38, n. 12, p. 30553058, 1997.

[29] HABA, Y.; SEGAL, E.; NARKIS, M.; TITELMAN, G. I., Siegmann, A. Polymerization of aniline in the presence of DBSA in na aqueous dispersion. Synth. Met., v. 106, p. 59-66, 1999.

[30] MOULTON, S. E.; INNIS, P. C.; KANE-MAGUIRE, L. A. P.; NGAMNA, O.; WALLACE, G. G. Polymerisation and characterisation of conducting polyaniline nanoparticle dispersions. Curr. Appl. Phys., v. 4, p. 402-406, 2004.

[31] PRISSANAROON, W.; BRACK, N.; PIGRAM, P. J.; LIESEGANG, J. A surface and electrochemical study of polypyrrole coated on stainless steel and cooper. Curr. Appl. Phys., v. 4, p. 163-166, 2004.

[32] LASKA J.; PRON A.; ZAGORSKA M.; LAPKOWSKI, S.; LEFRANT S. Thermally processable conducting polyaniline. Synth. Met., v. 69, n.1-3, p.113-115, 1995.

[33] PRON, A.; LASKA J.; OSTERHOLM, J. E., SMITH, P. Processable conducting polymers obtained via protonation of polyaniline with phosphoric acid esters. Polymer, v. 34, n. 20, p. 4235-4240, 1993.

[34] ANAND, J.; PALANIAPPAN, S.; SATHYANARAYANA, D. N. Conducting polyaniline blends and composites. Prog. Polym. Sci., v. 23, n. 6, p. 993-1018, 1998.

[35] PAUL, R. K., VIJAYANATHAN, V., PILLAI, C. K. S. Melt/solution processable conducting polyaniline: doping studies with a novel phosphoric acid ester. Synth. Met., v. 104, n. 3, p. 189195, 1999.

[36] CAO, Y., SMITH, P., HEEGER, A. J. Solution-cast films of polyaniline: optical-quality transparent electrodes. US Patent Application WO 22/22911, 20 mar. 1992.

[37] IKKALA, O. T.; LAAKSO, J.; VAKIPARTA, K.; VIRTANEN, E.; RUOHONEN, H.; JARVINEN, H.; TAKA,T.; PASSINIEMI, P.; OSTERHOLM, J. E.; CAO, Y.; ANDREATTA, A.; SMITH, P.; HEEGER A. J. Counter-ion induced processibility of polyaniline: conducting melt processible polymer blends. Synth. Met., v. 69, n.1-3, p.97-100, 1995.

[38] PEI, Q.; BI, X. Electrochemical preparation preparation of electrically conducting polyurethane/polyaniline composite. J. Appl. Polym. Sci., v. 38, n. 10, p. 1819-1828, 1989. 
[39] DOGAN, S.; AKBULUT, U.; TOPPARE, L. Conducting polymers of aniline I.

Electrochemical synthesis of a conducting composite. Synth. Met., v. 53, n. 1, p. 29-35, 1992.

[40] SAWAI, T.; SHINOHARA, H.; IKARIYAMA, Y.; AIZAWA, M. Electrical modulation of the solution $\mathrm{pH}$ near polyaniline and its composite electrodes. J. Electroanal. Chem., v. 283, n. 12, p. 221-230, 1990.

[41] LASKA, J.; PRON, A.; LEFRANT, S. Phosphoric acid diesters protonated polyaniline: preparation, spectroscopic, properties and processability. J. Polym. Sci. Part A: Polym. Chem., v. 33, n. 9, p. 1437-1445, 1995.

[42] GHOSH, P.; SIDDHANTA, S. K.; CHAKRABARTI, A. Characterization of poly(vinyl pyrrolidone) modified polyaniline prepared in stable aqueous medium. Eur. Polym. J., v. 35, p. 699-710, 1999.

[43] SULIMENKO, T.; STEJSKAL, J.; KRIVKA, I.; PROKES, J. Conductivity of colloidal polyaniline dispersions. Eur. Polym. J., v. 37, p. 219-226, 2001.

[44] GHOSH, M.; BARMAN, A.; DE, S.K.; CHATTERJEE, S. Low temperature electrical conductivity of polyaniline-polyvinylalcohol blends. Solid State Commun., v. 103, n. 11, p. 629633, 1997.

[45] MIRMOHSENI, A.; WALLACE, G. G. Preparation and characterization of processable electroactive polyaniline-polyvinyl alcohol composite. Polymer, v. 44, p. 3523-3528, 2003.

[46] CHATTOPADHYAY, D.; MANDAL, B. M. Methyl Cellulose Stabilized Polyaniline Dispersions. Langmuir, v. 12, p. 1585-1588, 1996.

[47] STEJSKAL, J.; SPIRKOVA, M.; RIED, A.; HELMSTEDT, M.; MOKREVA, P.; PROKES, J. Polyaniline dispersions. 8. The control of particle morphology. Polymer, v. 40, p. 2487-2492, 1999.

[48] MIN, G. Conducting polymers their applications in the film industry - polyaniline/polyimide blended films. Synth. Met., v. 102, n. 1-3, p. 1163-1166, 1999.

[49] GAZOTTI JUNIOR., W. A.; FAEZ, R.; DE PAOLI, M-A. Thermal and mechanical behaviour of a conductive elastomeric blend based on soluble polyaniline derivative. Eur. Polym. J., v. 35, n. 1, p. 35-40, 1999.

[50] GAO Z. Q.; BOBACKA, J.; IVASKA, A. Electrochemical study on the polypyrrole-polyaniline bilayer. Synth. Met., v. 55, n. 2-3, p. 1477-1482, 1993.

[51] GILMARA, Oliveira Machado. Preparação e caracterização de CMC e CMC graftizada. 102f. Dissertação (Mestrado em Físico-Química) - Instituto de Química de São Carlos, Universidade de São Paulo, São Carlos, 2000. 
[52] CARASCHI, José Cláudio. Estudo das relações estrutura/propriedades de carboximeticelulose obtida por derivatização de polpa de bagaço de cana-de-áçucar. 188f. Tese (Doutorado em Físico-Química) - Instituto de Química de São Carlos, Universidade de São Paulo, São Carlos, 1997.

[53] NICHOLSON, M. D.; MERRIT, F. M. Cellulose ethers. In: NEVELL, T. P., ZERONIAN, H. S. Cellulose Chemistry and its applications. New York: John Wiley, 1985. cap.15.

[54] JUSTE, K. E.; MAJEWICZ, T. G. Cellulose ethers. In: MARK, H. Encyclopedia of polymer science and engineering. New York: John Wiley, 1985. v. 3, p. 226-269.

[55] MINCHUERRI, A. S; AZANHA, E. S. Plano de Desenvolvimento Técnico. São Paulo: Rener Dupont Tintas Automotivas e Industriais S/A, 1996. p.69 (Apostila: Curso Básico de Tintas I).

[56] FELCHT, U. H. Cellulose Ethers: synthesis, application and analytical aspects. In: KENNEDY, J.F.; PHILLIPS, G.O.; WEDLOCK, D. J.; WILLIAMS, P. A. (Eds.). Cellulose and its Derivatives: chemistry, biochemistry and applications. New York: John Wiley, 1985. p. 273-284

[57] CHAUDHARI, S. N. K.; GOUNDEN, K. C.; SRINIVASAN, G. High Resolution 13C-NMR Spectroscopy of sodium carboxy Methyl Cellulose. J. Polym. Sci. Part A: Polym. Chem., v. 25, n. 1, p. 337-342, 1987.

[58] OTERO T. F.; VAZQUES, M. V. Electrogeneration of a composite polypyrrolecarboxymethycellulose: kinetic study. J. Electroanal. Chem., v. 397, p. 171-176, 1995.

[59] OTERO, T. F.; HERRASTI, P.; OCON, P.; ALVES, C. R. Electrogeneration of polypyrrolecarboxymethycellulose composites: electrochemical, microgravimetric and morphological studies. Electrochim. Acta, v. 43, n. 9, p. 1089-1100, 1998.

[60] HERRASTI, P.; OCON, P. Polypyrrole layers for steel protection. Appl. Surf. Sci., v. 172, p. 276-284, 2001.

[61] BANERJEE, P. Carboxymethycellulose stabilized polyaniline dispersions and conducting copolymer latex composites. Eur. Polym. J., v. 34, n. 5/6, p. 841-847, 1998.

[62] BANERJEE, P. Electrically conductive interpenetrating network composites of polyaniline and carboxymethycellulose. Eur. Polym. J., v. 34, n. 10, p. 1557-1560, 1998.

[63] WRANGLÉN, G. An introducion to corrosion and protection of metals. New York:Chapman and Hall, 1975. p. 288.

[64] GENTIL, V. Corrosão. 3.ed. Rio de Janeiro: LTC, 1996. 372 p.

[65] BRUMBAUGH, D. Spotlight on technology: metal passivation and ennoblement using conductive polymers. Synth. Met., v. 48, p. 91-97, 1999. 
[66] LEIDHEISER JR, H. Fundamentals of corrosion protection in aqueous solutions. In: DAVIS, J. R. (Ed.), ASM Handbook, Corrosion. New York: ASM Internayional, Library of Congress, 1987. v. 13. p. 377-379.

[67] SEDRIKS, A. J. Corrosion of Stainless Steels. 2.ed. New York: John Wiley, 1996. p. 437.

[68] TOWSEND, H. E.; HART, R. G. Composition of chromate passivation films on aluminiumzinc alloy coated sheet steel. J. Electrochem. Soc. v. 131, n. 6, p. 1345-1348, 1984.

[69] FERNANDES, E. G. Coatings and corrosion-even the best fail. Ind. Eng. Chem. Prod. Res. Dev., v. 24, p. 353-357, 1985.

[70] FRANKEL, G. S. Pitting corrosion of metals a review of the critical factors. J. Electrochem. Soc., v. 145, n. 6, p. 2186-2198, 1998.

[71] KORINEK, K. A. Chromate conversion coatings. In: DAVIS, J. R. (Ed.), ASM Handbook, Corrosion. New York: ASM International, Library of Congress, 1987. v. 13, p. 389-398.

[72] BLASIAK, J.; KOWALIK, J. A. Comparison of the in vitro genotoxicity of tri-and hexavalent chromium. Mutat. Ser., v. 469, p. 135-145, 2000.

[73] ENVIRONMENTAL PROTECTION AGENCY. NATIONAL EMISSIONS STANDARDS. National emissions standards for chromium electroplating and chromium anodizing tanks. Cincinati: EPA, 1995. Federal register RIN 2060- AC14J.

[74] COHEN, S. M. Review - replacements for chromium pretreatments on aluminium. Corrosion, v. 51, p. 71-78, 1995.

[75] TWITE, R. L.; BIERWAGEN, G. P. Review of alternative to chromate for corrosion protection aluminium aerospace alloys. Prog. Org. Coat., v. 33, p. 91-100, 1998.

[76] DEBERRY, D. W. Modification of the electrochemical and corrosion behavior of stainless steels with an electroactive coating. J. Electrochem. Soc., v. 132, n. 5, p. 1022-1026, 1985.

[77] AHMAD, N.; MACDIARMID, A. G. Inhibition of corrosion of steels using conducting polymers. Bull. Am. Phys. Soc., v. 32, n. 3, p. 548, 1987.

[78] LU, W.-K.; ELSENBAUMER, R. L.; WESSLING, B. Corrosion protection of mild steel by coatings containg polyaniline. Synth. Met., v. 71, p. 2163-2166, 1995.

[79] AHMAD, N.; MACDIARMID, A. G. Inhibition of corrosion of steels with the exploitation of conducting polymers. Synth. Met., v. 78, p. 103-110, 1996. 
[80] FAHLMAN, M.; JASTY, S.; EPSTEIN, A. J. Corrosion protection of iron/steel by emeraldine base polyaniline: an x-ray photoelectron spectroscopy study. Synth. Met., v. 85, p. 1323-1326, 1997.

[81] SANTOS Junior, J. R.; MATTOSO, L. H. C.; Motheo, A. J. Investigation of corrosion protection of steel by polyaniline films. Electrochim. Acta, v. 43, p. 309-313, 1998.

[82] TALLMAN, D.E.; PAE, Y.; BIERWAGEN, G.P., Conducting polymers and corrosion polyaniline on steel. Corrosion, v. 55, n. 8, p. 779-786, 1999.

[83] KINLEN, P. J.; SILVERMAN, D. C.; JEFFERS, C. R. Corrosion protection using polyaniline coating formulations. Synth. Met., v. 85, n. 1-3, p. 1327-1332, 1997.

[84] WESSLING, B.; POSDORFER, J., Corrosion prevention with na organic metal (polyaniline): corrosion test results. Electrochim. Acta, v. 44, p. 2139-2147, 1999.

[85] WESSLING, B. Polymers to organic metals. Chem. Innovation, p. 35-40, 2001.

[86] SAMUI, A. B.; PATANKAR, A. S.; RANGARAJAN, J.; DEB, P. C. Study of polyaniline containing paint for corrosion prevention. Prog. Org. Coat., v. 47, p. 1-7, 2003.

[87] WESSLING, B. Passivation of metals by coating with polyaniline: corrosion potential shift and morphological changes. Adv. Mater., v. 6, n. 3, p. 226-228, 1994.

[88] SCHAUER, T.; JOOS, A.; DULOG, L.; EISENBACH, C. D. Protection of iron against corrosion with polyaniline primers. Prog. Org. Coat., v. 33, n.1, p. 20-27, 1998.

[89] MCANDREW, T. P. Corrosion prevention with electrically conductive polymers. TRIP, v. 5, n. 1, p. 7-12, 1997.

[90] LU, W.-K.; BASAK, S.; ELSENBAUMER, R. L. Corrosion Inhibition of metals by conductive polymers. In: SKOTHEIM, T. A., ELSENBAUMER, R. L., REYNOLDS. J. R. (Eds.). Handbook of Conducting Polymers, 2. ed. New York: Marcel Dekker, 1998. p. 881-920.

[91] BERRY, B. C.; SHIKH, A. U.; VISWANATHAN, T. Corrosion prevention of cold rolled steel using water dispersible lignosulfonic acid-doped polyaniline. Polym. Prepr., v. 41, n. 2, p. 17391740, 2000.

[92] MORAES, S. R.; HUERTA-VILCA, D.; MOTHEO, A. J. Corrosion protection of stainless steel by polyaniline electrosynthesized from phosphate buffer solutions. Prog. Org. Coat., v. 48, p. 28-33, 2003.

[93] TAN, C. K.; BLACKWOOD, D. J. Corrosion protection by multilayered conducting polymer coatings. Corros. Sci., v. 45, p. 545-557, 2003. 
[94] MOTHEO, A. J.; HUERTA-VILCA, D.; MORAES, S. R. Processo de recobrimento de metais com múltiplas camadas de polianilina eletropolimerizada. BR n. PI0103373-5, 20 jun. 2001.

[95] HUH, J. H.; OH, E. J.; CHO, J. H. Investigation of corrosion protection of iron by polyaniline blend coatings. Synth. Met., v. 137, p. 965-966, 2003.

[96] PUD, A. A.; SHAPOVAL, G. S.; KAMARCHIK, P.; OGURTSOV, N. A.; GROMOVAYA, V. F.; MYRONYUK, I. E.; KONTSUR, Y. Electrochemical behavior of mild steel coated by polyaniline doped with organic sulfonic acids. Synth. Met., v. 107, p. 111-115, 1999.

[97] LIU, L.-M.; LEVON, K. Undoped polyaniline-surfactant complex for corrosion prevention. J. Appl. Polym. Sci., v. 73, p. 2849-2856, 1999.

[98] KRSTAJIC, N. V.; GRGUR, B. N.; JOVANOVIC, S. M.; VOJNOVIC, M. V. Corrosion protection of mild steel by polypyrrole coatings in acid sulfate solutions. Electrochim. Acta, $v$. 42, p. 1685-1691, 1997.

[99] SU, W.; IROH, J. O. Formation of polypyrrole coatings on stainless steel in aqueous benzene sulfonate solution. Electrochim. Acta, v. 17, p. 2685-2694, 1997.

[100] KRALJUC, M.; MANDIC, Z.; DUIC, L. Inhibition of steel corrosion by polyaniline coatings. Corros. Sci., v. 45, p. 181-198, 2003.

[101] MIRMOHSENI, A.; OLADEGARAGOZE A. Anti-corrosive properties of polyaniline coating on iron. Synth. Met., v. 114, p. 105-108, 2000.

[102] SOUZA, S.; SILVA, J. E. P.; TORRESI, S. I. C.; TEMPERIN, M. L. A.; TORRESI, R. M. Polyaniline based acrylic blends for iron corrosion protection. Electrochem. Solid State Lett., v. 4, p. B27-B30, 2001.

[103] NUZIANTE, P.; PISTOIA, G. Factors affecting the growth of thicck polyaniline films by the cyclic voltammetry technique. Electrochim. Acta, v. 34, n. 2, p. 223-228,1989.

[104] PERRY, R. H. Manual de Engenharia Química. 5. ed. Rio de Janeiro: Editora Guanabara, 1980. p. 23-24.

[105] BARD, A. J.; FAULKNER, L. R. Electrochemical Methods: fundamentals and applications. New York: John Wiley, 1980. 718p.

[106] ATKINS, P. W. Physical Chemistry. Oxford: Oxford University Press, 1994. 1031p.

[107] STILWELL, D. E.; PARK, S.M. Electrochemistry of conductive polymers. V. In situ spectroelectrochemical studies of polyaniline films. J. Electrochim. Soc., v. 136, n. 2, p. 427432, 1989. 
[108] MORAES, S. R.; HUERTA-VILCA, D.; MOTHEO, A. J. Characteristics of polyaniline synthetizes in phosphate buffer solution. Eur. Polym. J., v. 40, p. 2033-2041, 2004.

[109] MACDIARMID, A.G.; MANOHAR, S. K.; MASTERS, J. G.; SUN, Y.; WEISS, H.; EPSTEIN, A. Polyaniline: Synthesis and properties of pernigraniline base. Synth. Met., v. 4143, p. 621-626, 1991.

[110] MATTOSO, L.H.C.; MACDIARMID, A. G.; EPSTEIN, A. J. Controlles synthesis of high molecular - wieght polyaniline and (poly-o-methoxyaniline). Synth. Met., v.68, p. 1-11,1994.

[111] MANDIC, Z.; DUIC, L. Polyaniline as an electrocatalytic material. J. Electroanal. Chem., v. 403 , p. $133-141,1996$.

[112] DUIC, L.; GRIGIC, S. The effect of polyaniline morphology on hydroquinone/quinone redox reaction. Electrochim. Acta, v. 46, p. 2795-2803, 2001.

[113] BLYTHE, A. R. Electrical properties of polymers. Cambrigde: Cambrigde University Press, 1979. p.132-139.

[114] VAN DER PAUW, L. J. A method of measuring specific resistivity and hall effect of discs of arbitrary shape. Philips Res. Rep., v. 13, n. 1, p. 1-9, 1958.

[115] HATAKEYAMA, T., QUINN, F. X. Thermal analysis fundamentals and applications to polymer science. New York: John Wiley, 1994. 158p.

[116] SETTLE, F. Handbook of instrumental techniques for analytical chemistry. New York: Simon \& Schuster, 1997. 994p.

[117] CAVALHEIRO, Éder Tadeu Gomes. Estudos de equílibrio, estabilidade e análise térmica de compostos de piperidino e pirrolidino ditiocarbamato. 191f. Tese(Doutorado) Instituto de Química de São Carlos, Universidade de São Paulo, São Carlos, 1995.

[118] CAVALHEIRO, E. T. G., IONASHIRO, M. A influência de fatores experimentais nos resultados de análises termogravimétricas. Quim. Nova, v. 18, n. 3, p. 305-308, 1995.

[119] WENDLANT, W. W. Thermal Analysis. New York: John Wiley, 1986. v.19.

[120] UHLIG, H. H.; REVIE, W. Corrosion and corrosion control: an introduction to corrosion science and engieering. New York: John Wiley, 1985. 487p.

[121] RAMANATHAN, L. V. Corrosão e seu controle. São Paulo: Hemus, 1979. 339 p.

[122] DHAWAN, S.; TRIVEDI, D. C. Electrochemical behaviour of polyaniline in aromatic sulphonic acids. Polym. Int., v. 25, n. 1, p. 55-60, 1991. 
[123] DHAWAN, S.; TRIVEDI, D. C. Synthesis and properties of polyaniline obtained using sulphamic acid. Polym. Int., v. 39, p. 153-159, 1992.

[124] KARAKISLA, M.; SACAK, M.; ERDEM, E.; AKBULUT, U. Synthesis and characterization of malonic acid-doped polyaniline. J. Appl. Electrochem., v. 27, p. 309-316, 1997. [125] WEI, Y.; SUN, Y.; JANG, G. W.; TANG, X. Effects of p-aminodiphenylanine on electrochemical polymerization of aniline. J. Polym. Sci. Part C: Polym. Lett., v. 28, p. 81-87, 1990.

[126] SYED, A. A.; DINESAN, M. K. Polyaniline - A novel polymeric material. Talanta, v. 38, n. 8, p. 815-837, 1991.

[127] DE PAOLI, M.-A.; WALTMAN, R. J.; DIAZ, A. F.; BARGON, J. Conductive Composites from poly(vinyl chloride) and polypyrrole. J. Chem. Soc. Chem. Commun., p. 1015-1016, 1984.

[128] GAZZOTTI JUNIOR., W. A.; CASALBORE-MICELI, G.; MITZAKOFF, S.; GERI, A.; GALLAZZI, M. C.; DE PAOLI, M-A. Conductive polymer blends as electrochromic materials. Electrochim. Acta, v. 44, p. 1965-1971, 1999.

[129] MANO, V.; FELISBERTI, T.; MATENCIO, T.; DE PAOLI, M-A. Thermal, mechanical and electrochemical behaviour of poly (vinyl chloride)/polypyrrole blends (PVC/PPy). Polymer, v. 37, p. 5165, 1996.

[130] DUIC, L. J.; MANDIC, Z.; KOVACICEK, F. The effect of supporting electrolyte on the electrochemical synthesis, morphology and conductivity of polyaniline. J. Polym. Sci. Part A: Polym. Chem., v. 32, p. 105-111,1994

[131] MILAS, M. Polieletrólitos. São Carlos: IFQSC, 1991. 84p.

[132] VINCENT, B.; WATERSON, J. Colloidal dispersions of electrically-conducting, spherical polyaniline particles. J. Chem. Soc. Chem. Commun., p. 683, 1990.

[133] TANG, J. S.; XING, X. B.; WANG, B. C.; WANG, F. Infrared-spectra of soluble polyaniline. Synth. Met., v. 24, n. 3, p. 231-238, 1988.

[134] WAN, M. The influence of polymerization method and temperature on the absorption spectra and morphology of polyaniline. Synth Met., v. 31, p. 51-59, 1989.

[135] XIANG, Q.; XIE, H. Q. Preparation and characterization of alkali soluble polyacrylamidepolyaniline. Eur. Polym. J., v. 32, p. 865-868, 1996.

[136] CHAN, H. S. O.; NG, S. C., SIM, W. S.; SEOW, S. H.; TAN, K. L.; TAN, B. T. G. Synthesis and characterization of conducting poly(o-aminobenzylacohol) and its copolymers with aniline. Macromolecules, v. 26, n. 1, p. 144-150, 1993. 
[137] DAS B.; KAR, S.; CHAKRABORTY, S.; CHAKRABOTY, D.; GANGOPADHYAY, S. Synthesis and characterization of polyacrylamide-polyanilina conductive blends. J. Appl. Polym. Sci., v. 69, p. 841-844, 1998.

[138] RODRIGUES, P. C.; MURARO, M.; GARCIA, C. M.; SOUZA, G. P.; ABBATE, M., SCHREINER, W. H.; GOMES, M. A. B. Polyaniline/lignin blends: thermal analysis and XPS. Europ. Polym. J., v. 37, p. 2217-2223, 2001.

[139] SHAW, D. J. Introdução à química dos colóides e de superfícies. Tradução de J.H. MAAR. São Paulo: Edgar Blucher, 1975. 185p.

[140] TADROS, T. F. Surfactantes. Florida: Academic Press, 1984. 342p.

[141] SHARMA, V. K.; SINGH, J. Condutometric, surface tensionad thermodynamic studies of aqueous sodium dodecylbenzene sulphonate in pyridine and isomeric picoline. Indian $\mathbf{J}$. Chem., v. 35 A, p. 1056-1061, 1996.

[142] BOCKRIS, J. O'M; KHAN, S. U. M. Surface Electrochemistry: a molecular level approach. New York: Plenum Press, 1993. 1014p.

[143] KIM, B.-J.; OH, S.-G.; HAN, M. G.; IM, S.-S. Synthesis and characterization of polyaniline nanoparticles in SDS micellar solution. Synth. Met., v.122, 297-304, 2001.

[144] GAZZOTI JUNIOR, W. A.; DE PAOLI, M.-A. High yield preparation of a soluble polyaniline derivative. Synth. Met., v.80, 263-269,1996.

[145] ALBUQUERQUE, M. S. L.; TORRESI, R. M. Quartz cristal microbalance study of charge compensation process in polyaniline films doped with surfactant anions. Electrochim. Acta, v. 44, n.12, p. 1879-1885, 1999.

[146] KANUNGO, M.; KUMAR, A., Contractor, A.Q. Studies on electropolymerization of aniline in the presence of sodium dodecyl sulfate and its application in sensing urea. J. Electroanal. Chem., v. 528, p. 46-56, 2002.

[147] LU, X.; NG, H. Y.; XU, J.; HE, C. Electrical conductivity of polyaniline-dodecylbenzene sulphonic acid complex: thermal degradation and its mechanism. Synth. Met., v. 128, 167-178, 2002.

[148] LEVON, K.; HO, K. H.; ZHENG, W. Y.; LAAKSO, J.; KARNA, T.; TAKA, T.; OSTERHOLM, J. E. Polymer, v. 36, n. 14, p.2733-2738, 1995.

[149] TALLMAN, D. E.; SPINKS, G.; DOMINIS, A.; WALLACE, G. G. Electroactive conducting polymers for corrosion control. Part 1. General introduction and review of non-ferrous metals. J. Solid State Electrochem., v. 6, p. 73-84, 2002. 